\title{
CARACTERIZAÇÃO DE AMBIENTES INTERNOS DA REGIÃO CENTRAL DE SÃO CARLOS/SP: MATERIAL PARTICULADO E POLUIÇÃO SONORA
}

\section{ELAINE SCHORNOBAY}

Dissertação apresentada à Escola de Engenharia de São Carlos, da Universidade de São Paulo, como parte dos requisitos para obtenção do título de Mestra em Ciências, Programa de Engenharia Hidráulica e Saneamento.

Área de concentração: Hidráulica e Saneamento

ORIENTADOR: Prof. Dr. Wiclef Dymurgo Marra Jr.

\section{[VERSÃO CORRIGIDA]}

São Carlos, SP 
Autorizo a reprodução e divulgação total ou parcial deste trabalho, por qualquer meio convencional ou eletrônico, para fins de estudo e pesquisa, desde que citada a fonte.

Ficha catalográfica preparada pela Seção de Tratamento da Informação do Serviço de Biblioteca - EESC/USP

S374C

Schornobay, Elaine

mum Caracterização de ambientes internos da região central de São Carlos-SP : material particulado e poluição sonora. / Elaine Schornobay ; orientador Wicleff Dymurgo Marra Jr. São Carlos, 2012.

Dissertação (Mestrado - Programa de Pós-Graduação e Área de Concentração em Engenharia Hidráulica e Saneamento)-- Escola de Engenharia de São Carlos da Universidade de São Paulo, 2012.

1. Poluição sonora. 2. Material particulado. 3. Conforto térmico. I. Título. 


\section{FOLHA DE IULGAMENTO}

\section{Candidata: Bacharel ELAINE SCHORNOBAY.}

Título da dissertação: "Caracterização de ambientes internos da regiāo central de Săo Carlos/SP: material particulado e poluiçầo sonora".

Data da defesa: 25/05/2012

\section{Comissão Julgadora:}

Prof. Dr. Wiclef Dymurgo Marra Junior (Orientador)

(Escola de Engenharia de Săo Carlos/EESC)

Profe, Drª . Mônica Lopes Aguiar

(Universidade Federal de São Carlos/UFSCar)

Profe, Dr. Simone Andrea Pozza

(Universidade Estadual de Campinas/UNICAMP)
Resultado:

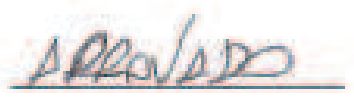

APROVIDO

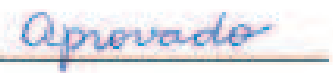

Coordenador do Programa de Pós-Graduaçāo em Engenharia Hidráulica e Saneamento:

Prof, Titular Edson Cezar Wendland

Presidente da Comissão de Pós-Graduaş̃o:

Prof, Associado Paulo Cesar Lima Segantine 



\section{DEDICATÓRIA}

"Aos mais importantes e amados, minha família. Pela liberdade, pela confiança e apoio incondicionais em todas as minhas decisões." 



\section{AGRADECIMENTOS}

À Fundação de Amparo à Pesquisa do Estado de São Paulo, pelo auxílio regular, essencial para o desenvolvimento da presente pesquisa.

À Coordenação de Aperfeiçoamento de Pessoal de Nível Superior, pela concessão da bolsa de mestrado.

Ao Professor Wiclef, pelo apoio, orientação e infra-estrutura disponibilizada para a realização deste trabalho.

À Professora Mônica, pelas considerações, apoio e suporte instrumental para o trabalho.

Aos companheiros de pesquisa e amigos Lênin, Tatiane e Guilherme, pelas discussões e trocas de aprendizado.

Aos funcionários e responsáveis dos locais em que este trabalho foi realizado, sempre atenciosos.

À todos os colegas, Professores e funcionários do PPG-SHS, pela troca de experiências e pelos momentos de lazer.

Aos amigos, Amanara, Bruno, Córdoba, Filipe, Flávia, Luciano, Natália, Raphael e em especial ao Lucas, que pela amizade me trouxe para São Carlos, e ao Narumi, meu grande companheiro em São Carlos, amigo para todas as horas.

As amigos Edicléia, Elizângela, Solange, Lucas Rocha, Mariana, Priscila e Viviane, que mesmo à distância sempre me confortaram nas horas amargas e torceram pelas minhas realizações.

Ao meu namorado Roberto, pela presença em todos os momentos, por toda paciência e compreensão a mim dedicadas.

E especialmente, à minha família querida, minha mãe Tereza, meu pai Eugênio e meu admirado irmão Eliton, por tudo de mais importante que cultivaram na minha educação, os bons exemplos!! 



\section{RESUMO}

Este trabalho teve como objetivo avaliar a qualidade ambiental interna de lojas da região central na cidade de São Carlos/SP. Foram monitorados os seguintes parâmetros: concentração e análise química de $\mathrm{MP}_{10}$ e de $\mathrm{MP}_{2,5}, \mathrm{CO}_{2}$, níveis de ruído, temperatura e umidade relativa do ar. A coleta de dados foi realizada de maneira simultânea em ambientes internos e externos de quatro lojas do centro da cidade por um período de oito horas diárias, das $9 \mathrm{~h}$ às $17 \mathrm{~h}$. Dois pontos estavam localizados de frente para vias de grande circulação de veículos e dois no calçadão da cidade (sem trânsito de veículos). Os valores de concentração, tanto de $\mathrm{MP}_{10}$ como de $\mathrm{MP}_{2,5}$, se apresentaram, na maior parte dos dias de coleta, com os valores internos superiores aos externos. Para o período chuvoso, em que foi realizado o maior número de coletas, os valores de concentração não ultrapassaram os limites estabelecidos pela OMS, de $25 \mu \mathrm{g} / \mathrm{m}^{3}$ para o $\mathrm{MP}_{2,5}$ e de $50 \mu \mathrm{g} / \mathrm{m}^{3}$ para o $\mathrm{MP}_{10}$. Quanto à análise química, foi observado que não há diferenças significativas entre os ambientes interno e externo. Sendo que, em ambos os ambientes, foram encontrados Si, S, Ca, $\mathrm{Fe}, \mathrm{Al}, \mathrm{K}$ e $\mathrm{Cu}$, elementos comumente observados em áreas urbanas. Em relação ao $\mathrm{CO}_{2}$, o seu monitoramento não se mostrou relevante, já que todos os ambientes monitorados realizavam trocas de ar com o ambiente externo de forma natural, dessa forma a concentração não atingiu valores preocupantes. Os níveis de poluição sonora monitorados no ambiente externo foram superiores aos do ambiente interno em todos os dias monitorados. Os pontos de monitoramento que ficavam direcionados para as vias de circulação de veículos apresentaram valores superiores aos encontrados no calçadão da cidade. Em todos os dias monitorados, os valores de ruído dos ambientes interno e externo não apresentaram acordo com o padrão estabelecido pela NBR 10.151/2.000, de 50dB(A) e $60 \mathrm{~dB}(\mathrm{~A})$, respectivamente. Sendo que os valores externos ficaram entre $61 \mathrm{~dB}(\mathrm{~A})$ e $66,8 \mathrm{~dB}(\mathrm{~A})$ e, para o ambiente interno, os valores variaram de 53,9 $\mathrm{dB}(\mathrm{A})$ a 63,6 $\mathrm{dB}(\mathrm{A})$. A temperatura e a umidade relativa do ar apresentaram variações ao longo do dia e, de acordo com a RE/ANVISA nº9/2003 e o índice HI, a maioria dos dias monitorados sugere sensação de desconforto térmico aos ocupantes desses locais.

Palavras- chave: Material particulado, poluição sonora, conforto térmico. 



\section{ABSTRACT}

This study aimed to evaluate the indoor environmental quality of shops in the central region in São Carlos/SP. The following parameters were monitored: the concentration and chemical analysis of $\mathrm{MP}_{10}$ and $\mathrm{MP}_{2,5}, \mathrm{CO}_{2}$, noise levels, temperature and relative humidity. Data collection was performed simultaneously in internal and eternal environments of four stores in the center of town for period of eight hours daily, from 9 am to $5 \mathrm{pm}$. Two points were located in front of large circulation routes for vehicles and two on the sidewalk of the city (no vehicle traffic). The values concentration both $\mathrm{PM}_{10}$ and $\mathrm{PM}_{2,5}$ are presented, in most days of collection, with the internal values higher than the outside. For the rainy season, which was held in the greatest number of samples, the concentration values did not exceed the limits set by OMS of $25 \mu \mathrm{g} / \mathrm{m}^{3}$ for $\mathrm{MP}_{2,5}$ and $50 \mu \mathrm{g} / \mathrm{m}^{3}$ for $\mathrm{MP}_{10}$. In the chemical analyses, it was not observed significant differences between the internal and external environments, since in both environments were found $\mathrm{Si}, \mathrm{S}, \mathrm{Ca}, \mathrm{Fe}, \mathrm{Al}$, $\mathrm{Cu}$ and $\mathrm{K}$, elements commonly seen in urban areas. In relation to the $\mathrm{CO}_{2}$ monitoring was not relevant, since all monitored environments performed ais exchanges with the external environment in a natural way, producing values concentration not concern. The noise levels monitored in the external environment were superior to the internal environment every day. The monitoring points directed to the traffic routes of vehicles had higher values than those found on the sidewalk of the city. On each day the monitored noise vaues of the internal and external environments not presented inside of the standard established by NRB $10.151 / 2000$ of $50 \mathrm{~dB}(\mathrm{~A})$ e $60 \mathrm{~dB}(\mathrm{~A})$, respectively, since external values were between $61 \mathrm{~dB}(\mathrm{~A})$ and $66,8 \mathrm{~dB}(\mathrm{~A})$, and the internal environment values ranged from $53,9 \mathrm{~dB}(\mathrm{~A})$ and $63,6 \mathrm{~dB}(\mathrm{~A})$. The temperature and relative humidity showed variations thoughout the day, and according to RE/ANVISA n 09/2003 and the index HI, most of the days monitored suggests thermal discomfort to the occupants of these places.

Keywords: Particulate matter, noise pollution, thermal comfort. 



\section{LISTA DE FIGURAS}

1 Concentração de $\mathrm{MP}_{10}$ coletados no centro de São Carlos . . . . . . . . . . . . 15

2 Relação entre precipitação e concentração de $\mathrm{MP}_{10}$ normalizados . . . . . . . . . 16

3 Mapa de localização da cidade de São Carlos . . . . . . . . . . . . . . . . . 19

4 Localização dos pontos amostrais . . . . . . . . . . . . . . . 20

5 Disposição do ponto amostral P1 . . . . . . . . . . . . . . . 21

6 Disposição do ponto amostral P2 . . . . . . . . . . . . . . . . 22

7 Disposição do ponto amostral P3 . . . . . . . . . . . . . . . 22

8 Disposição do ponto amostral P4 . . . . . . . . . . . . . . . 23

9 Bomba de sucção da SKC (a ), PEM (b) utilizados para coleta de material particulado e disposição das partes do PEM (c) . . . . . . . . . . . . . . . . 27

10 Monitores Portáteis EVM-7 (a) pDR-1.500 (b) . . . . . . . . . . . . . . . 29

11 Concentração de $\mathrm{CO}_{2}$ interno . . . . . . . . . . . . . . . . . 32

12 Concentração de $\mathrm{CO}_{2}$ externo . . . . . . . . . . . . . . . 33

13 Comportamento diário típico de temperatura e umidade relativa do ar no P1 -

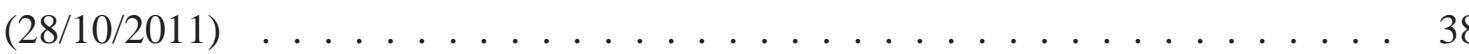

14 Temperaturas médias dos meses de junho, julho e novembro dos últimos 6 anos para a cidade de São Carlos . . . . . . . . . . . . . . . . . . . . 39

15 Índice de calor $-\mathrm{HI} \ldots \ldots \ldots \ldots \ldots$

16 Gráfico do comportamento de um dia típico da poluição sonora no P1 (24/11/2011) 44

17 Valores médios de poluição sonora por ponto de coleta . . . . . . . . . . . . 45

18 Gráfico em boxplot dos níveis de poluição sonora interno para cada dia de coleta 47

19 Gráfico em boxplot dos níveis de poluição sonora externo para cada dia de coleta 48

20 Comportamento do material particulado ao longo de um dia de coleta no P2 $(25 / 11 / 2.011) \ldots \ldots \ldots \ldots \ldots \ldots \ldots$

21 Gráfico de boxplot das coletas de $\mathrm{MP}_{2,5}$ da etapa de coleta preliminar dos dados com o EVM-7 . . . . . . . . . . . . . . . . . . . . . . 53 
22 Gráfico de boxplot da concentração do $\mathrm{MP}_{2,5}$ no ambiente interno coletado com o

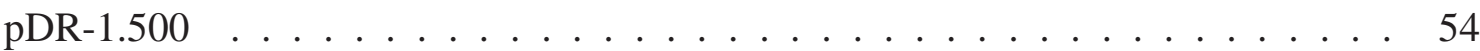

23 Gráfico de boxplot da concentração do $\mathrm{MP}_{2,5}$ no ambiente externo coletado com o

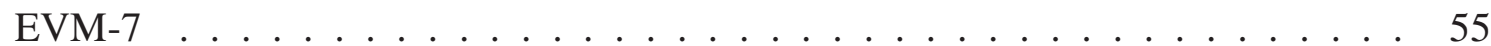

24 Gráfico de boxplot da concentração do $\mathrm{MP}_{10}$ no ambiente interno coletado com o

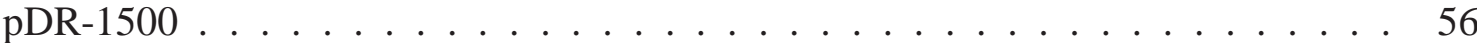

25 Gráfico de boxplot da concentração do $\mathrm{MP}_{10}$ no ambiente externo coletado com o

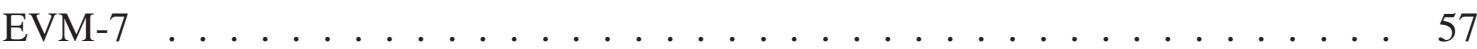

26 Valores de concentração de material particulado obtidos na etapa de coleta preliminar dos dados . . . . . . . . . . . . . . . . . . . . . . . . 58

27 Comparação das concentrações $\mathrm{MP}_{10}$ e $\mathrm{MP}_{2,5}$ no ambiente interno . . . . . . . . . 60

28 Comparação das concentrações $\mathrm{MP}_{10}$ e $\mathrm{MP}_{2,5}$ no ambiente externo . . . . . . . . . 62

29 Análise química das membranas brancas . . . . . . . . . . . . . . . . 63

30 Análise química da etapa de coleta preliminar de dados . . . . . . . . . . . . 64

31 Constituição química do $\mathrm{MP}_{10}$ interno e externo . . . . . . . . . . . . . . . . 66

32 Constituição química do $\mathrm{MP}_{10}$ e $\mathrm{MP}_{2,5}$ externos . . . . . . . . . . . . . . . . 67

33 Análise química da etapa de coleta efetiva de dados $(1) \ldots \ldots 8$

34 Análise química da etapa de coleta efetiva de dados (2) . . . . . . . . . . . . 69

35 Membrana de coleta de $\mathrm{MP}_{10}$ externo $(07 / 06 / 2011) \ldots \ldots$. . . . . . . . 70

36 Membrana de coleta de $\mathrm{MP}_{10}$ externo $(25 / 11 / 2011) \ldots \ldots \ldots$

37 Membrana de coleta de $\mathrm{MP}_{2,5}$ externo $(07 / 06 / 2011) \ldots \ldots \ldots$. . . . . . . 71

38 Membrana de coleta de $\mathrm{MP}_{2,5}$ externo $(01 / 12 / 2011) \ldots \ldots \ldots$. . . . . . . 71

39 Comparação equipamentos de coletas do $\mathrm{MP}_{2,5}$ no ambiente interno . . . . . . . . 72

40 Comparação equipamentos de coletas do $\mathrm{MP}_{2,5}$ no ambiente externo . . . . . . . . 73

41 Comparação equipamentos de coletas do $\mathrm{MP}_{10}$ no ambiente interno $\quad$. . . . . . . . 74

42 Comparação equipamentos de coletas do $\mathrm{MP}_{10}$ no ambiente externo $\quad$. . . . . . . . 74

43 Comparação da temperatura e concentração de $\mathrm{MP}_{10}$ internos . . . . . . . . . . . 77

44 Comparação da umidade relativa e concentração de $\mathrm{MP}_{10}$ internos . . . . . . . . 78 


\section{LISTA DE TABELAS}

1 Características dos locais de amostragens . . . . . . . . . . . . 21

2 Distribuição da coleta de dados da etapa preliminar . . . . . . . . . . . . . . . 24

3 Distribuição da coleta de dados da etapa efetiva . . . . . . . . . . . . . 25

4 Valores de média, desvio padrão e relação interno/externo (I/E) de temperatura e umidade relativa do ar para cada ponto de amostragem na etapa de coleta preliminar dos dados (inverno) . . . . . . . . . . . . . . . . . . . . . . 34

5 Valores de média, desvio padrão e relação interno/externo (I/E) de temperatura e umidade relativa do ar para cada ponto de amostragem na etapa de coleta efetiva dos dados (verão). . . . . . . . . . . . . . . . . . . . . . 35

6 Valores de média, desvio padrão e relação interno/externo (I/E) para temperatura e umidade relativa do ar para cada dia da etapa de coleta preliminar de dados . . . . 35

7 Valores de média, desvio padrão e relação interno/externo (I/E) para temperatura e umidade relativa do ar para cada dia da etapa de coleta efetiva de dados . . . . . . 36

8 Índice de calor $-\mathrm{HI} \ldots \ldots \ldots \ldots$. . . . . . . . . . . . . . 40

9 Valores de média e desvio padrão de poluição sonora por ponto de coleta . . . . . . 45

10 Valores de média e desvio padrão da poluição sonora para cada dia de coleta . . . . 46

11 Médias e desvio padrão do material particulado coletado com os monitores portáteis 52

12 Concentrações de $\mathrm{MP}_{10}$ e $\mathrm{MP}_{2,5}$ de todos os dias de coleta e relação interno/externo $(\mathrm{I} / \mathrm{E}) \ldots \ldots \ldots \ldots \ldots \ldots \ldots$

13 Relação $\mathrm{MP}_{2,5} / \mathrm{MP}_{10} \ldots \ldots \ldots \ldots$. . . . . . . . . . . . . . . 61

14 Valores de precipitação e concentração de $\mathrm{MP}_{10}$ e $\mathrm{MP}_{2,5}$ nos ambientes interno e

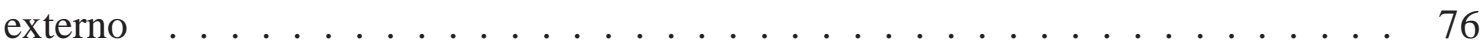

15 Gravimetria da fase de coleta preliminar . . . . . . . . . . . . . . 87

16 Gravimetria da fase de coleta efetiva . . . . . . . . . . . . . . . . . 88

17 Gravimetria da fase de coleta efetiva (continuação) . . . . . . . . . . . . . . 89

18 Temperatura e umidade relativa do ar do dia 28/10/2011 . . . . . . . . . . . 90

19 Níveis de ruído para o dia $24 / 11 / 2011 \ldots \ldots$. . . . . . . . . . . . . 91

20 Níveis de ruído para o dia 24/11/2011 (continuação) . . . . . . . . . . . . . . . . 92 
21 Níveis de ruído para o dia 24/11/2011 (continuação) . . . . . . . . . . . . . . 93

22 Níveis de ruído para o dia 24/11/2011 (continuação) . . . . . . . . . . . . . . . . 94

23 Níveis de ruído para o dia 24/11/2011 (continuação) . . . . . . . . . . . . . . 95

24 Níveis de ruído para o dia 24/11/2011 (continuação) . . . . . . . . . . . . . . . . . 96

25 Níveis de ruído para o dia 24/11/2011 (continuação) . . . . . . . . . . . . . . . . 97

26 Níveis de ruído para o dia 24/11/2011 (continuação) . . . . . . . . . . . . . . . 98

27 Material particulado do dia 25/11/2011 . . . . . . . . . . . . . . 99

28 Material particulado do dia 25/11/2011 (continuação) . . . . . . . . . . . . . . . 100

29 Material particulado do dia 25/11/2011 (continuação) . . . . . . . . . . . . . . 101

30 Material particulado do dia 25/11/2011 (continuação) . . . . . . . . . . . . . 102 


\title{
LISTA DE SÍMBOLOS
}

\author{
$\mathrm{MP}_{10} \quad$ Material particulado com diâmetro aerodinâmico de $10 \mu \mathrm{m}$ \\ $\mathrm{MP}_{2,5} \quad$ Material particulado com diâmetro aerodinâmico de 2,5 $\mu \mathrm{m}$ \\ $\mathrm{MP}_{2,5-10}$ Material particulado com diâmetro aerodinâmico de 2,5 $\mu \mathrm{m}$ à $10 \mu \mathrm{m}$ \\ $\mathrm{CO}_{2} \quad$ Dióxido de Carbono \\ OMS Organização Mundial da Saúde \\ COV Compostos Orgânicos Voláteis \\ ANVISA Agência Nacional de Vigilância Sanitária \\ USEPA United States Environmental Protection Agency \\ CO Monóxido de Carbono \\ $\mathrm{SO}_{2} \quad$ Dióxido de Enxofre \\ $\mathrm{NO}_{x} \quad$ Óxido de Nitrogênio \\ CETESB Companhia de Tecnologia de Saneamento Ambiental \\ CONAMA Conselho Nacional de Meio Ambiente \\ NIOSH National Institute for Occupational Safety and Health \\ dB Decibéis \\ dB(A) Decibéis em nível de ponderação A \\ $\mu \mathrm{g} \quad$ Microgramas \\ $\mu \mathrm{g} / \mathrm{m}^{3} \quad$ Microgramas por metro cúbico \\ ABNT Associação Brasileira de Normas Técnicas \\ UFSCar Universidade Federal de São Carlos \\ IBGE Instituto Brasileiro de Geografia e Estatística \\ PEM Personal Environmental Monitor
}




\section{SUMÁRIO}

LISTA DE FIGURAS

LISTA DE TABELAS iii

LISTA DE SIGLAS v v v

1 Introdução 1

2 Objetivos $\quad 3$

3 Revisão Bibliográfica $\quad 4$

3.1 Qualidade do ar em ambientes internos . . . . . . . . . . . . . 4

3.2 Material Particulado . . . . . . . . . . . . . . . . 7

3.3 Poluição Sonora . . . . . . . . . . . . . . . . . . . . . . . 11

3.4 Histórico de Estudos em São Carlos . . . . . . . . . . . . . . . . . . . . . . . . . 14

4 Materiais e Métodos $\quad 18$

4.1 Local de estudo . . . . . . . . . . . . . . . . . . . . . . . . 18

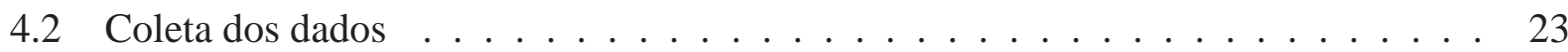

4.3 Material Particulado . . . . . . . . . . . . . . . . . 25

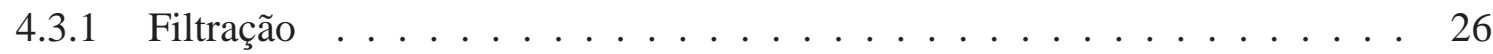

4.3.2 Monitores de material particulado . . . . . . . . . . . . . . . 28

4.4 Análise do dióxido de carbono $\left(\mathrm{CO}_{2}\right) \ldots \ldots \ldots$

4.5 Poluição Sonora . . . . . . . . . . . . . . . . . . . . . 30

4.6 Variáveis climáticas . . . . . . . . . . . . . . . . . . . 30

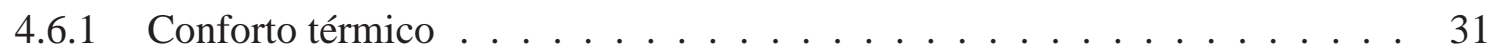

5 Resultados e Discussão $\quad 32$

5.1 Temperatura e umidade relativa do ar . . . . . . . . . . . . 33 
$5.1 .1 \quad$ Índice de Calor $(\mathrm{HI}) \quad \ldots \ldots \ldots \ldots$. . . . . . . . . . . . . 40

5.2 Poluição sonora . . . . . . . . . . . . . . . . . . . . . 41

5.3 Material particulado . . . . . . . . . . . . . . . . 50

5.3.1 Resultado dos Monitores Portáteis . . . . . . . . . . . . . . . . . . 50

5.3.2 Resultados da Gravimetria . . . . . . . . . . . . . . . . . . . . 58

5.3 .3 Análise química . . . . . . . . . . . . . . . . . . . . . 63

5.3.4 Comparação métodos de medição de material particulado . . . . . . . . . . 72

5.4 Váriaveis climáticas . . . . . . . . . . . . . . . . . . . . . . . . . . . 75

6 Conclusões $\quad 79$

$\begin{array}{llr}7 & \text { Sugestões para trabalhos futuros } & \mathbf{8 0}\end{array}$

$\begin{array}{ll}\text { REFERÊNCIAS BIBLIOGRÁFICAS } & 81\end{array}$

$\begin{array}{lll}\text { A APÊNDICE - Dados da gravimetria da fase de coleta preliminar de dados } & 87\end{array}$

B APÊNDICE - Dados da gravimetria da fase de coleta efetiva dos dados 88

C APÊNDICE - Dados de temperatura e umidade relativa do ar do dia 28/10/2011 90

D APÊNDICE - Dados dos níveis de ruído do dia 24/11/2011 91

E APÊNDICE - Dados de concentração de $\mathrm{MP}_{2,5}$ do dia 25/11/2011 99 


\section{Introdução}

O crescimento das aglomerações urbanas nas últimas décadas criou, nesses ambientes, condições adversas à qualidade de vida das populações. Os avanços industriais e o aumento exorbitante da frota veicular são os principais fatores relacionados aos efeitos negativos, e um dos sistemas que mais tem sofrido com essa degradação é o ar.

A deterioração da qualidade do ar causa danos aos materiais, à fauna, à flora, às condições de visibilidade e também agride de muitas maneiras a saúde da população (CETESB, 2011). Há algum tempo se sabe a relação existente entre o aumento dos casos de internações e mortes por complicações cardiorrespiratórias, nos episódios em que ocorre aumento da concentração dos poluentes. Além disso, as partículas e gases são formadas de componentes químicos que podem ser tóxicos à saúde e ter potencial cancerígeno (SALDIVA et al., 1992). Neste contexto, especial atenção se tem dado às partículas finas, menores que $10 \mu \mathrm{m}$ de diâmetro, que por possuírem menores dimensões, atingem o trato respiratório, e as menores que 2,5 $\mu \mathrm{m}$ podem chegar até os alvéolos pulmonares. Como agravante, as partículas inferiores a 2,5 $\mu \mathrm{m}$, diferentemente das partículas maiores que logo se depositam no solo com a ação da gravidade, podem permanecer suspensas por um tempo muito maior e viajar dezenas de quilômetros (MARQUES, 2000).

A quantificação dos poluentes pode ser realizada de duas maneiras, por meio de amostragens diretamente na fonte ou, nos chamados receptores. A quantificação realizada nos receptores é interessante porque se está avaliando não apenas a liberação de substâncias por uma única fonte, mas a soma de todas as fontes após dispersão e reações químicas, tendo-se dessa forma uma idéia melhor da exposição.

Além da poluição do ar, o aumento da frota veicular nas últimas décadas, juntamente com outros fatores, têm provocado sérios problemas devido ao aumento do nível de poluição sonora nos centros urbanos. As pessoas que frequentam esses ambientes diariamente podem sofrer danos que vão desde aumento do stress, perturbação do sono, até danos relacionados à perda da audição, dependendo dos níveis e da quantidade de horas semanais a que são expostas (ZANNIN; DINIZ; BARBOSA, 2002).

Dessa forma, o ambiente criado nos centros urbanos tem se mostrado inadequado em muitas 
situações e pode afetar de várias maneiras os frequentadores desses locais. Sendo assim, os maiores afetados com os malefícios são os trabalhadores, que diariamente frequentam por longas horas esses ambientes e são expostos a vários fatores que afetam sua integridade física e mental. 


\section{Objetivos}

Este trabalho teve como objetivo a caracterização de ambientes internos da região central de São Carlos/SP, principalmente, no tocante à influência do ambiente externo nos internos. Para isto, o levantamento de dados foi realizado de maneira simultânea em ambientes internos e externos de 4 pontos comerciais da região central. Foram monitorados: concentração e composição química do $\mathrm{MP}_{10}$ e do $\mathrm{MP}_{2,5}$, temperatura, umidade relativa do ar, dióxido de carbono $\left(\mathrm{CO}_{2}\right)$ e níveis de ruído. Dos quatro pontos, dois estavam alocados em vias de grande circulação de veículos e dois no calçadão da cidade (sem trânsito de veículos). O levantamento desses dados teve como objetivo verificar:

- A concentração de $\mathrm{MP}_{10}$ e $\mathrm{MP}_{2,5}$;

- A composição química das duas frações de MP;

- Os níveis de poluição sonora;

- Os níveis de temperatura e umidade relativa do ar;

- A comparação entre os ambientes interno e externo para todas as variáveis;

- As diferenças entre os pontos de coleta;

- A comparação com padrões estabelecidos. 


\section{Revisão Bibliográfica}

Nesta seção será apresentada a revisão bibliográfica considerada relevante para o tema desta pesquisa.

\subsection{Qualidade do ar em ambientes internos}

A qualidade do ar em ambientes internos é um fator determinante para a saúde e o bem-estar da população. Nas sociedades modernas, com as pessoas passando a maior parte do seu tempo no interior de ambientes (em casa, no trabalho, na escola e em veículos), a exposição a poluentes presentes no ar, na maioria desses ambientes, causa efeitos adversos à saúde, como doenças respiratórias, alergias e irritação do trato respiratório (BRUCE; PEREZ-PADILLA; ALBALAK, 2000). Várias publicações da Organização Mundial da Saúde (OMS) alertam para o perigo da exposição à poluição do ar e os seus malefícios. Alguns estudos científicos, como Peters et al. (1999), Bernstein et al. (2004), Sundell (2004), Myers e Maynard (2005) e Frew (2005), evidenciam a associação do aparecimento de algumas doenças e o aumento da mortalidade infantil com a exposição ao ar contaminado com determinados poluentes. Além disso, outros estudos revelam que doenças como asma, segundo Richardson, Eick e Jones (2005), e catarata, Pokhrel et al. (2005), estão associadas à má qualidade do ar em ambientes internos.

O controle da qualidade do ar em ambientes internos é frequentemente inadequado e muitas vezes sua importância para à saúde é ignorada, sendo importante o fortalecimento das pesquisas nesse sentido para auxiliar e estimular o planejamento de programas de prevenção dos orgãos de saúde. Os efeitos deletérios da poluição do ar, na saúde das pessoas, são mais evidentes principalmente nas crianças, idosos e naqueles pertencentes a subgrupos mais suscetíveis, particularmente as com asma. Tal suscetibilidade deve ser levada em consideração nas ações de controle da qualidade do ar (BRUCE; PEREZ-PADILLA; ALBALAK, 2000).

A poluição do ar interior é causada por uma combinação de agentes físicos, químicos e biológicos. Pode ser proveniente de fontes externas, como automóveis e indústrias, e de fontes internas, como: mobiliário, cigarro, equipamentos eletrônicos e a própria atividade humana. As queixas podem estar localizadas ou espalhadas por todo o ambiente, podem ter origem biológica, alérgica, química e fisiológica (ELLER, 1998). A qualidade do ar nesses ambientes está relacionada à com- 
binação de vários fatores: entendimento das fontes de emissão, da ventilação dos prédios, das salas e dos processos que afetam o transporte e o destino dos contaminantes (BRICKUS; NETO, 1999). O avanço tecnológico colocou a população em contato com novos materiais, empregados na construção civil e em mobiliário, que podem alterar consideravelmente a qualidade do ar interior. Neste contexto, a avaliação da qualidade do ar (IQA) em ambientes internos torna-se importante.

Outro importante fator na interferência da qualidade do ar dos ambientes internos é a qualidade do ar externo. Assim, a relação entre os níveis de concentração interna e externa (I/E) de um determinado poluente é um parâmetro importante na avaliação da qualidade do ar interior (GODISH, 1991). No Brasil, devido ao tipo de clima, a ventilação dos interiores é na maioria das vezes realizada, deixando-se portas e janelas abertas. Por essa razão, a poluição do ar exterior é considerada como fator determinante na qualidade do ar interior, tanto em residências como em escritórios e casas comerciais, especialmente as situadas próximos a vias urbanas (BRICKUS; NETO, 1999).

Lee et al. (2002) avaliaram a qualidade do ar interior em residências, escritórios, escolas, shoppings centers e restaurantes, avaliando os níveis de $\mathrm{CO}_{2}, \mathrm{MP}_{10}, \mathrm{COV}$ e bactérias. Todos os valores encontrados desses poluentes excederam os níveis aceitos na legislação do país (China), evidenciando deficiências na ventilação dos ambientes, ocupação inadequada, presença de fumantes e uso de materiais na construção e no mobiliário com emissões de poluentes (COV's). Os estudos de Keller-Olaman et al. (2005) demonstram a má qualidade do ar interior de 300 residências da cidade de Hamilton (Canadá) e sua possível influência na qualidade de vida de seus ocupantes.

No Brasil, os estudos relacionados à qualidade do ar interior são escassos e se restringem na maioria das vezes a ambientes climatizados artificialmente. Em alguns ambientes, como bibliotecas, escolas e hospitais, também já foram conduzidos estudos, mas são ainda em número reduzido e restritos a algumas cidades. A regulamentação no país acerca da qualidade do ar interior é ditada principalmente pela RE/ANVISA n ${ }^{\circ}$ 09/2003, que determina o limite de exposição de vários poluentes e por normatizações da Associação Brasileira de Refrigeração, Ar Condicionado, Ventilação e Aquecimento - ABRAVA. No entanto, essas normas são direcionadas para ambientes com climatização artificial.

Na cidade de São Carlos, há alguns estudos voltados ao tema, como por exemplo Ito (2007), que realizou um estudo acerca da qualidade do ar interior de duas bibliotecas da cidade, a biblioteca municipal Amadeu Amaral e a biblioteca da UFSCar. Este trabalho também avaliou duas 
bibliotecas na capital do estado de São Paulo, realizando dessa forma o monitoramento em duas cidades com portes diferentes, uma cidade capital e uma cidade do interior. Em todos os ambientes monitorados a concentração de material particulado foi superior no ambiente interno. Em São Carlos, a biblioteca Amadeu Amaral, localizada no centro da cidade, apresentou concentrações mais elevadas de MP do que a biblioteca da UFSCar. Para os gases, apenas o $\mathrm{CO}_{2}$ esteve presente em concentração detectável pelo aparelho de medição, sendo que apresentava acordo com os limites determinados em todos os ambientes monitorados. Nascimento (2011) também avaliou a qualidade da biblioteca municipal Amadeu Amaral, de São Carlos, verificando que os ocupantes estão expostos à sensação de desconforto térmico, bem como a elevados níveis de poluição sonora e taxa de iluminação insuficiente. Em relação à concentração de bioaerossóis, material particulado, gás carbônico e taxa de ventilação, os valores encontrados estavam em acordo com os padrões estabelecidos. 


\subsection{Material Particulado}

Nas últimas décadas, o avanço industrial e comercial nos centros urbanos levou a um acentuado crescimento da concentração de gases e partículas poluentes, excedendo as concentrações naturalmente encontradas na atmosfera. A emissão, seja por fontes fixas, móveis e ou geradas por meio de reações químicas, tem tornado a atmosfera urbana inadequada à saúde humana. Segundo Saldiva et al. (1992), o material particulado inalável encontrado nessa atmosfera, juntamente com os gases poluentes presentes, são tóxicos à saúde e têm potencial cancerígeno. Além disso, outros estudos mostram que o material particulado tem influência no meio ambiente, como por exemplo Martins, Dias e Gonçalves (2009), que afirmam a existência da interferência dos aerossóis nas propriedades radioativas da atmosfera. Sendo assim, pode ocorrer a alteração das condições climáticas locais porque o material particulado atua como núcleos de condensação. Contini et al. (2012) reafirmam, dizendo que o estudo das emissões do aerosol urbano é importante devido aos efeitos potenciais que têm sobre à saúde e o clima. Principalmente por causa dos grandes impactos à saúde humana, as altas concentrações de MP são de maior interesse em áreas urbanas (LEE; HO; CHOI, 2011).

O material particulado é classificado de acordo com suas propriedades aerodinâmicas como: grossa (diâmetro aerodinâmico entre 10 e 2,5 $\mu \mathrm{m}$ ), finas (menores que 2,5 $\mu \mathrm{m}$ ) e ultrafinas (menores que $0,1 \mu \mathrm{m}$ de diâmetro) (POPE; YOUNG; DOCKERY, 2006). O conhecimento do diâmetro da partícula tem importância pois pode ser usado como um indicador da fonte emissora, e também está associado a deposição da partícula no trato respiratório. As partículas de maiores dimensões são menos prejudiciais à saúde, já que se depositam no solo em poucas horas, em função da ação da gravidade. O mesmo não ocorre com as partículas de menores dimensões, que são pequenas o suficiente para permanecerem em suspensão na atmosfera, movendo-se juntamente com o gás e, na prática, não se depositam no solo, permanecendo na atmosfera por horas ou até dias, podendo viajar por distâncias consideráveis a partir da fonte (MARQUES, 2000).

Durante a década de 1980 e início de 1990, resultados de estudos epidemiológicos nos EUA identificaram o MP menor que $10 \mu \mathrm{m}$ como sendo o diâmetro de partícula relacionado aos danos agudos e crônicos à saúde. Mais recentemente, as crescentes pesquisas mostram que a atenção deve ser focada nas partículas menores que 2,5 $\mu \mathrm{m}$ de diâmetro, sendo estas mais relevantes aos efeitos adversos à saúde do que as partículas menores que 10 $\mu$ m (HARRISON et al., 2011). Em 1997, a USEPA (United States Environmentl Protection Agency), baseada em evidências de que as 
partículas com menores diâmetros aerodinâmicos são mais patogênicas, propôs a inclusão de um novo padrão de qualidade do ar (USEPA, 1997), separando o $\mathrm{MP}_{10}$ em duas frações:

- $\mathrm{MP}_{2,5}$ : partículas com diâmetro aerodinâmico menor que 2,5 $\mu \mathrm{m}$;

- $\mathrm{MP}_{10}$ : partículas com diâmetro aerodinâmico menor que $10 \mu \mathrm{m}$.

As partículas mais finas podem ultrapassar as defesas respiratórias, causando respostas inflamatórias, podem chegar aos alvéolos pulmonares, atingir a corrente sanguínea, causar doenças do coração e do pulmão, diabetes, nascimentos prematuros, baixo peso ao nascer, câncer, morte súbita e alterações cognitivas (OLMO et al., 2011; RAASCHOU-NIELSEN et al., 2001; MODIG et al., 2006; WILHELM; RITZ, 2003; BRAUER et al., 2008; POWER et al., 2011; POPE; YOUNG; DOCKERY, 2006; HOEK et al., 2002; FILHO et al., 2008; CENDON et al., 2006). Se existir revestimento químico da partícula, como com nitratos, sulfatos ou metais, pode ocorrer um dano oxidativo local e/ou dano carcinogênico (BASCOM, 1996). Centros urbanos geralmente reúnem uma grande frota veicular, além de atividades industriais, o que torna a poluição antropogênica significativamente maior do que a natural nestes locais (WATSON; CHOW, 2001).

Em relação às fontes emissoras não naturais, os veículos apresentam participação significativa na emissão de material particulado. São responsáveis por emissões de metais agregados ao material particulado (STERNBECK; SJÖDIN; ANDRÉASSON, 2002), além de gases como $\mathrm{CO}_{2}$, $\mathrm{CO}, \mathrm{SO}_{2}$ e $\mathrm{NO}_{x}$. Contini et al. (2012) concluíram em seu trabalho realizado em Lecce, na Itália, que a concentração de partículas revela a marcação de padrões diários e semanais, correlacionados com a taxa de tráfego. Castanho e Artaxo (2001) identificaram como principais fontes de $\mathrm{MP}_{2,5}$ atmosférico na região metropolitana de São Paulo: veículos, ressuspensão de partículas do solo, combustão e óleo combustível, além de sulfatos e emissões industriais. Em um relatório elaborado pela Companhia Ambiental do Estado de São Paulo (CETESB), foi identificado como maiores fontes de aerossol, em Araraquara/SP, o tráfego de veículos, emissões industriais e componentes típicos de queimadas. No mesmo local, foi observado que o $\mathrm{MP}_{2,5}$ representa $45 \%$ da massa do $\mathrm{MP}_{10}$ (CETESB, 2000). Este dado inspira cuidados com a qualidade do ar em cidades de médio porte do interior paulista, pois praticamente metade do material particulado respirável pertence a fração fina e, portanto a mais patogênica do MP. No mesmo relatório, é constatado que em Campinas/SP as partículas de $\mathrm{MP}_{2,5}$ representam $60 \%$ do $\mathrm{MP}_{10}$, indicando que em locais nos quais as 
fontes veiculares são preponderantes, as partículas finas são responsáveis por grande parte do MP respirável.

Bruno (2005) realizou um trabalho de identificação de fontes de material particulado para a cidade de São Carlos. E verificou que há diferença na origem do MP entre as estações seca e chuvosa. Para o $\mathrm{MP}_{2,5}$, a presença de elementos de origem secundária (carbono e enxofre secundário) é mais relevante, provavelmente gerados a partir de emissão veicular. No $\mathrm{MP}_{10-2,5}$, a emissão veicular direta se apresenta como a maior fonte de contribuição na massa do MP, e no período seco a contribuição das queimadas é bastante significativa.

Shaka e Saliba (2004) compararam as características químicas do $\mathrm{MP}_{10-2,5}$ e $\mathrm{MP}_{2,5}$ de Beirut, no Mediterrâneo Oriental, e mostraram que, o $\mathrm{MP}_{2,5}$ apresenta altas concentrações tanto de íons inorgânicos como de compostos orgânicos. As espécies carbonadas se apresentam na forma de íon carbonado no $\mathrm{MP}_{2,5}$ e carbonato de cálcio no $\mathrm{MP}_{10-2,5}$. Ácidos carboxílicos e alcoóis de longa cadeia são mais presentes no $\mathrm{MP}_{2,5}$ e água é predominantemente detectada no $\mathrm{MP}_{10-2,5}$.

Evidências epidemiológicas produzidas usando diferentes modelos de estudos têm demonstrado que a poluição atmosférica tem efeitos negativos sobre a saúde humana, mesmo se os poluentes estão abaixo do limite permitido pela legislação brasileira no CONAMA 03/1990. Medidas como inspeções veiculares, transportes públicos eficientes, gestão de tráfego, corredores de ônibus, sistemas de ciclovias e pedágios urbanos são todos consistentes como propostas para a criação de um ambiente saudável. O Brasil precisa mudar seus padrões de emissões e adotar políticas voltadas para a conscientização, expansão e melhoria do transporte público. Estudos epidemiológicos precisam ser entendidos e usados como a base para a definição das políticas públicas que têm o objetivo de prover a qualidade de vida da população (OLMO et al., 2011).

A legislação brasileira que regula os níveis de material particulado é a Resolução CONAMA 03/1990, que determina níveis de média $24 \mathrm{~h}$ de $150 \mu \mathrm{g} / \mathrm{m}^{3}$ para o $\mathrm{MP}_{10}$. Para a fração $\mathrm{MP}_{2,5}$, o país não possui padrões estabelecidos. No entanto, a normatização do CONAMA está ultrapassada, de acordo com a OMS seriam adequados níveis máximos de $50 \mu \mathrm{g} / \mathrm{m}^{3}$ para o $\mathrm{MP}_{10}$ e de $25 \mu \mathrm{g} / \mathrm{m}^{3}$ para o $\mathrm{MP}_{2,5}$. A CETESB em 2011 estabeleceu novos padrões de $\mathrm{MP}_{10}$ para o estado de São Paulo e pela primeira vez definiu padrões para o $\mathrm{MP}_{2,5}$. Os valores da média de $24 \mathrm{~h}$ são de $120 \mu \mathrm{g} / \mathrm{m}^{3}$ para o $\mathrm{MP}_{10}$, e de $60 \mu \mathrm{g} / \mathrm{m}^{3}$ para o $\mathrm{MP}_{2,5}$. O objetivo é, ao final de 3 estágios, atingir os mesmos padrões estabelecidos pela OMS. O primeiro estágio terá duração de três anos, para os outros dois a 
determinação do tempo de duração será de acordo com a avaliação do estágio anterior (AFEEVAS, 2012). 


\subsection{Poluição Sonora}

O incremento no número de pessoas e veículos circulando nas ruas, recentemente, levou a inserção de um novo tema de pesquisas ao currículo das universidades: a poluição sonora. O ruído, uma das consequências do desenvolvimento urbano diretamente associado ao avanço da tecnologia, juntamente com a poluição do ar, do solo e da água, constituem um grupo significante de fatores de risco para a saúde humana (BARBOSA; CARDOSO, 2005). Em países com grandes problemas sociais, o estudo da poluição sonora não recebe a devida atenção. No Brasil, as poucas pesquisas relacionadas com o tema concentram-se principalmente nas grandes cidades.

O ruído é definido como um som indesejável e é conhecido como um risco a saúde humana há bastante tempo. No entanto, era considerado apenas em alguns ambientes, como o "chão de fábricas", onde se observava os danos relacionados à perda da audição. Há alguns estudos citando o ruído fora do ambiente fabril, porém são escassos, sendo um exemplo Hay e Kemp (1972), que na década de 1970, apontaram a poluição sonora como sendo um dos fatores da diminuição do rendimento do trabalho em escritórios da Inglaterra e do País de Gales. Questionários aplicados a 729 ocupantes de escritórios, nesses países, identificaram o barulho do ar condicionado, da rua e do próprio escritório (telefone tocando, pessoas conversando e o barulho das máquinas) como os maiores geradores de ruído.

De acordo com a OMS (Organização Mundial da Saúde), ruído pode causar prejuízo à audição, interferir na comunicação, perturbar o sono, causar efeitos cardiovasculares e fisiológicos, reduzir o desempenho intelectual e causar mudanças no comportamento social. Passchier-Vermeer e Passchier (2000) afirmam em seu trabalho que há evidências científicas suficientes de que a exposição ao ruído pode induzir a perda da audição, causar hipertensão e doença cardíaca isquêmica, aborrecimento, distúrbios do sono e redução da concentração. Para outros efeitos, como mudança do sistema imune e malformações congênitas, as evidências são ainda limitadas.

Segundo Willich et al. (2006), o limite de 85 dB por até 8 horas, sugerido pelo NIOSH (National Institute for Occupational Safety and Health) é muito elevado e, níveis entre 60 e 70 dB seriam mais adequados. A necessidade de reavaliação dos limites de exposição ao ruído deve ser realizada, em particular, nos locais de trabalho. Por exemplo, o limite de exposição de 85 $\mathrm{dB}$ nesses ambientes pode não causar danos à audição, se o trabalhador usar protetores auditivos, mas ele estará exposto aos efeitos não-auditivos causados pelo ruído, como aumento dos níveis de 
adrenalina e cortisol no sangue, chamados de hormônios do stress, aumento da pressão arterial, etc. Outros trabalhos evidenciam os malefícios causados pela exposição a níveis elevados de ruído, demonstrando a importância do assunto e a necessidade de uma regulamentação adequada para a preservação da saúde (BELOJEVIC et al., 2008; ERLANDSSON et al., 2008; EVANS et al., 2001; MUZET, 2007; OMOKHODION; EKANEM; UCHENDU, 2008).

Muzet (2007) relata que estamos expostos a diferentes fontes de ruído, que dependem da nossa atividade, localização e hora do dia. O ruído urbano, descartando-se emissões temporárias causadas principalmente por obras civis, shows e eventos artísticos, tem como principal fonte de emissão o tráfego de veículos, representado pelo barulho do motor, da fricção entre o veículo e o ar, entre pneus e superfície da estrada, e pela aceleração. As queixas de ruído aumentam de frequência com o aumento do tamanho das cidades. No Brasil, o avanço da indústria automobilística, depois da década de 1950, levou ao incremento no número de veículos nas cidades, provocando um aumento progressivo dos níveis de poluição sonora e de poluição atmosférica.

Zannin, Diniz e Barbosa (2002) publicaram um estudo realizado na cidade de Curitiba. Observaram que a maior parte do ruído provinha dos veículos, e que 93,3\% dos locais monitorados apresentaram níveis maiores que $65 \mathrm{~dB}(\mathrm{~A})$, considerado o limite pela medicina preventiva. E em 40,3\% dos locais de amostragem, os níveis de ruído eram superiores a $75 \mathrm{~dB}(\mathrm{~A})$, valor considerado extremamente alto. Segundo Omokhodion, Ekanem e Uchendu (2008), em estudo relacionado a vários pontos em uma comunidade da Nigéria, o barulho da rua, comércio e circulação de veículos, está associado a perdas auditivas induzidas pelo ruído. A população dessas áreas analisadas está exposta a altos índices de ruído, com níveis variando de 89-99 dB(A), níveis de ruído além dos aceitos para o limite de exposição ocupacional.

Petian (2008) realizou um estudo na população empregada na área central da cidade de São Paulo, incluindo 10 bairros. Foram analisados apenas estabelecimentos comerciais localizados no térreo das edificações e diretamente abertos para a via pública. A metodologia consistiu em um questionário, com algumas perguntas abertas, e a medição dos níveis de pressão sonora. O estudo identificou que a maioria dos trabalhadores, $57 \%$ dos entrevistados, achava o local de trabalho ruidoso, e para 34\% esse ruído incomodava muito, interferindo nas atividades, principalmente na comunicação e concentração. Quando questionados em o que os incomodava na cidade, o ruído apareceu em terceiro lugar, ficando atrás da violência e poluição do ar. As principais fontes de 
ruído citadas foram da rua, do tráfego e do próprio estabelecimento. Perda auditiva, estresse, irritabilidade, dor de cabeça e alterações no sono foram relacionadas ao ruído urbano. Os níveis de ruído alcançaram valores médios variando de $70,4 \mathrm{~dB}(\mathrm{~A})$ e $88,6 \mathrm{~dB}(\mathrm{~A})$, acima dos $60 \mathrm{~dB}(\mathrm{~A})$ recomendado pelas NBR 10151 (2000) e NBR 10152 (1987) para áreas mistas. 


\subsection{Histórico de Estudos em São Carlos}

O Programa de Pós- Graduação de Engenharia Química da Universidade Federal de São Carlos (UFSCar) possui um grupo de pesquisa na área de Controle Ambiental, que hà vários anos tem estudado o material particulado no município de São Carlos. Durante os primeiros estudos, foram definidos 5 pontos de amostragem para coleta de material particulado. Posteriormente, estes pontos foram reduzidos para apenas um ponto de monitoramento localizado no centro da cidade. O ponto foi considerado de interesse devido à grande densidade de pessoas, grande fluxo de veículos e concentrações médias semelhante aos outros pontos monitorados (CELLI, 1999).

Entre setembro de 1997 e janeiro de 2000, foi constatado que os valores encontrados para o $\mathrm{MP}_{10}$ não ultrapassavam os valores estabelecidos na legislação ambiental brasileira (média anual: $50 \mu \mathrm{g} / \mathrm{m}^{3}$, média diária: $150 \mu \mathrm{g} / \mathrm{m}^{3}$ ), excetuando os meses de julho e agosto, coincidindo com o período da queima de cana de açúcar na região (CELLI, 1999; MARQUES, 2000; MARQUES et al., 2001). Durante o monitoramento, verificou-se que existe uma tendência periódica na concentração do MP, apresentando médias menores no verão, maiores no inverno e médias semelhantes durante as outras estações, sendo que, no inverno a concentração encontrada era 2,5 vezes maior do que no verão (MARQUES et al., 2001). Bruno (2005) analisou as concentrações de material particulado respirável $\left(\mathrm{MP}_{10}\right)$ e suas frações fina $\left(\mathrm{MP}_{2,5-10}\right)$ e super fina $\left(\mathrm{MP}_{2,5}\right)$ com as amostragens realizadas entre 1997 e 2004. O ano foi dividido em duas estações, a seca (abril a outubro) e a chuvosa (novembro a março). A estação chuvosa coincide com e época do verão, nessa época ocorre a lavagem dos poluentes pela chuva e as temperaturas são mais elevadas, propiciando uma maior dispersão dos poluentes, pois as altas temperaturas na superfície favorecem o não aparecimento da inversão térmica. A Figura 26 apresenta as médias mensais de concentração de $\mathrm{MP}_{10}$ no período de setembro de 1997 a junho de 2004. É possível verificar que os valores apresentam concentração maior no inverno e menor no verão. 
Figura 1 - Concentração de $\mathrm{MP}_{10}$ coletados no centro de São Carlos

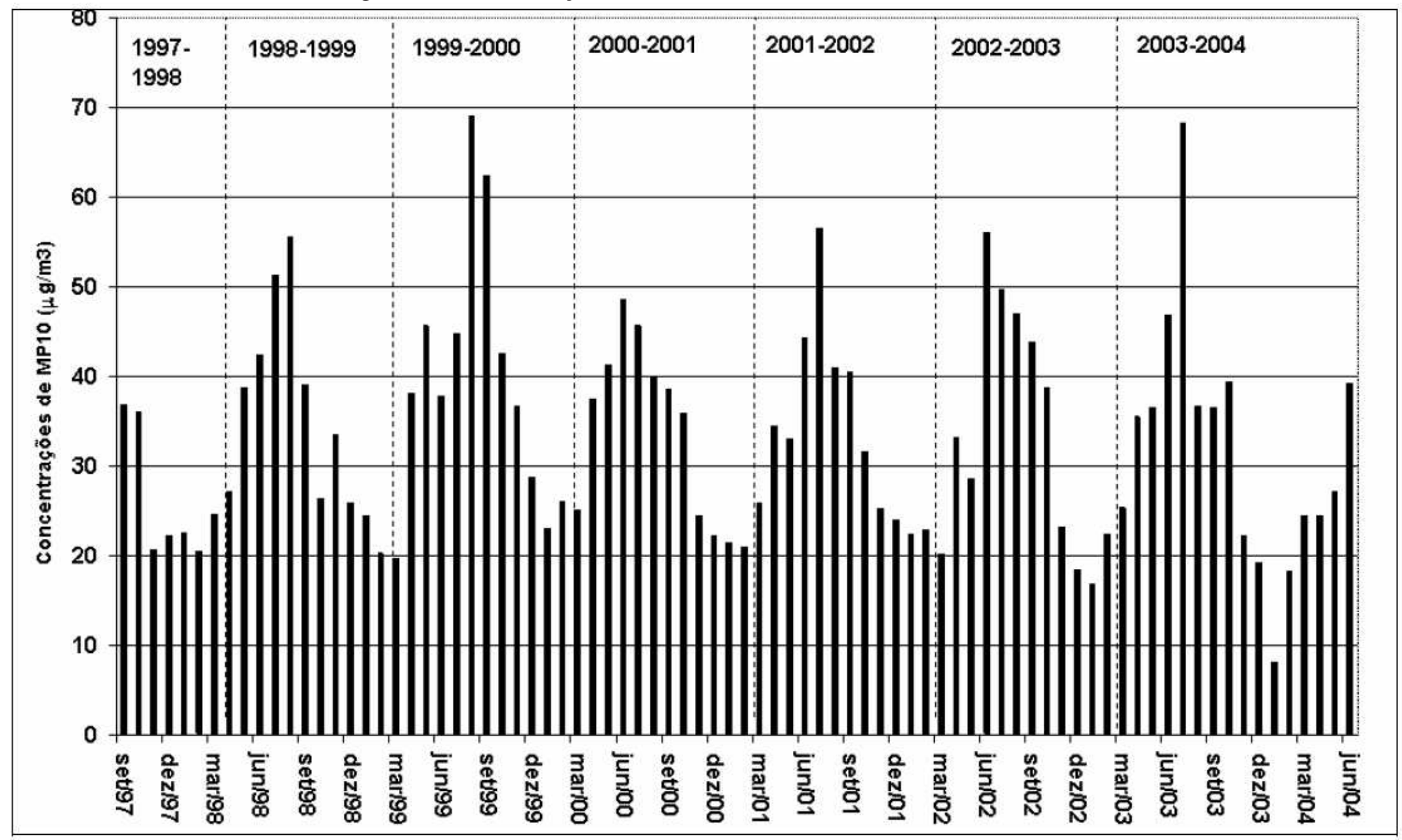

Fonte: (BRUNO, 2005) 
Segundo Bruno (2005), além do clima influenciar diretamente na dispersão do MP, também possui fator determinante no comportamento das atividades antropogênicas, como por exemplo, queimadas. A Figura 2 mostra a precipitação e concentração de $\mathrm{MP}_{10}$ normalizados (cada valor de grandeza foi dividido pelo respectivo valor máximo no período). É possível observar claramente que a concentração de MP é inversamente proporcional à precipitação.

Figura 2 - Relação entre precipitação e concentração de $\mathrm{MP}_{10}$ normalizados

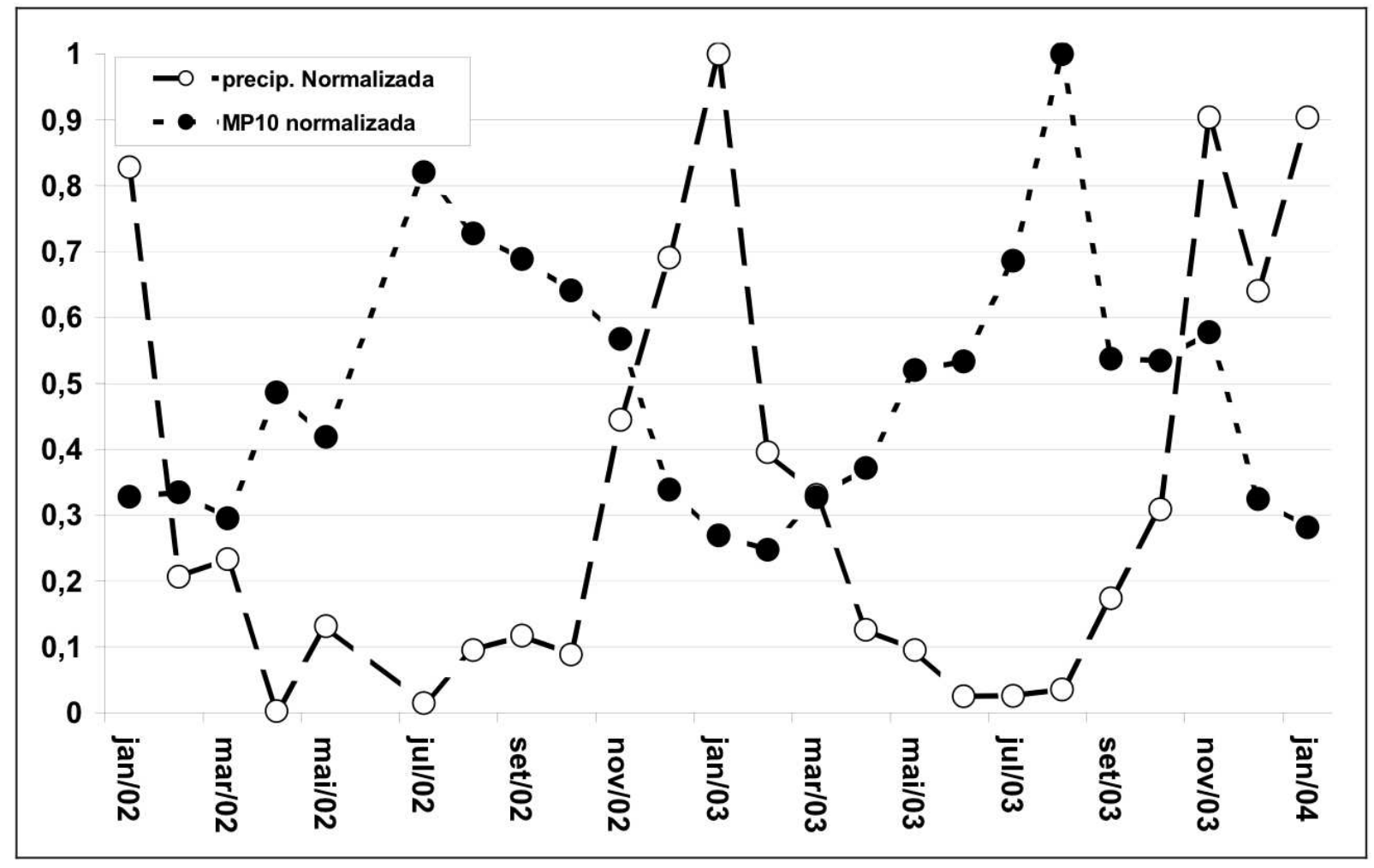

Fonte: (BRUNO, 2005)

Além da influência do clima na variação da concentração do MP, sabe-se que existe um aumento ocasionado devido ao crescimento urbano e rural. Marques (2000) verificou um grande crescimento no $\mathrm{MP}_{10}$ durante o período de 1997 a junho de 2000, embora a média medida não tenha atingido os limites da legislação. $\mathrm{O}$ aumento foi atribuído ao aumento na emissão de $\mathrm{CO}_{2}$, no entanto, não foi verificado a origem da emissão do $\mathrm{CO}_{2}$.

Pozza (2005) realizou um estudo para identificação das fontes de material particulado da cidade de São Carlos, em que foram realizadas análises para determinar fontes consideradas as mais características para a região. Trabalhos anteriores como Marques (2000) e de Pozza et al. (2004), 
indicaram as seguintes fontes: solo, emissão veicular, ressuspensão do solo pela ação veicular e queimadas, confirmados neste trabalho. 


\section{Materiais e Métodos}

\subsection{Local de estudo}

A cidade de São Carlos localiza-se na região central do estado (Latitude: -22,0175 ${ }^{\circ}$ Longitude: -47,89083º; Altitude: $854 \mathrm{~m}$ ) e possui uma população de mais de 220.000 habitantes segundo censo de 2010, com cerca de $95 \%$ vivendo na área urbana (IBGE, 2012). A cidade possui um importante parque industrial, atividades no setor agropecuário, concentrando-se na produção de leite, cana, laranja, frango, carne bovina e milho, e comércio bastante desenvolvido na região central da cidade.

A atividade comerciária na região central de São Carlos oferece produtos e serviços nos diversos ramos, apresentando desde o comércio de ruas (camelôs), pequenas lojas de atividades diversificadas até filiais de grandes redes de magazines do país. Destacam-se entre o comércio varejista de maior porte, as atividades relacionadas a vestuário (roupas e calçados) e as de móveis e eletro-eletrônicos. Possui ainda variedade de pequenos pontos comerciais que oferecem grande diversidade de produtos de moda e decoração, artigos esportivos, prestação de serviços (assistência técnica), pontos de alimentação (restaurantes, lanchonetes, cafés), entre outros.

O local escolhido para a realização deste estudo é a área central da cidade de São Carlos, devido ao intenso fluxo de veículos e pessoas. O local possui também um histórico de estudos realizados acerca da constituição do material particulado da cidade. De acordo com levantamento relaizado pelo Departamento de Trânsito no ano de 2009, o fluxo de veículos é em média de 15.200 veículos por dia na Avenida São Carlos. A Rua José Bonifácio apresenta um fluxo menor que a Avenida São Carlos, sendo que, em média, 5.430 veículos transitam nessa via por dia. Ainda segundo o departamento e trânsito de São Carlos, no período 2009-2012 deve-se estimar um aumento no circulação de veículos de $10 \%$ na Avenida São Carlos e de $15 \%$ na Rua José Bonifácio (NOVAES, 2012 [Comunicação Pessoal]). A Figura 3 apresenta o mapa de localização de Sao Carlos.

Os pontos amostrais foram escolhidos, considerando-se a atividade de comércio desenvolvida e a localização de cada um na região central. Dessa forma, dos quatro pontos selecionados, dois estavam alocados diretamente em frente a vias com grande circulação de veículos (P1 e P4) e os outros dois no calçadão de São Carlos (P2 e P3), onde há somente tráfego de pedestres, havendo 
Figura 3 - Mapa de localização da cidade de São Carlos

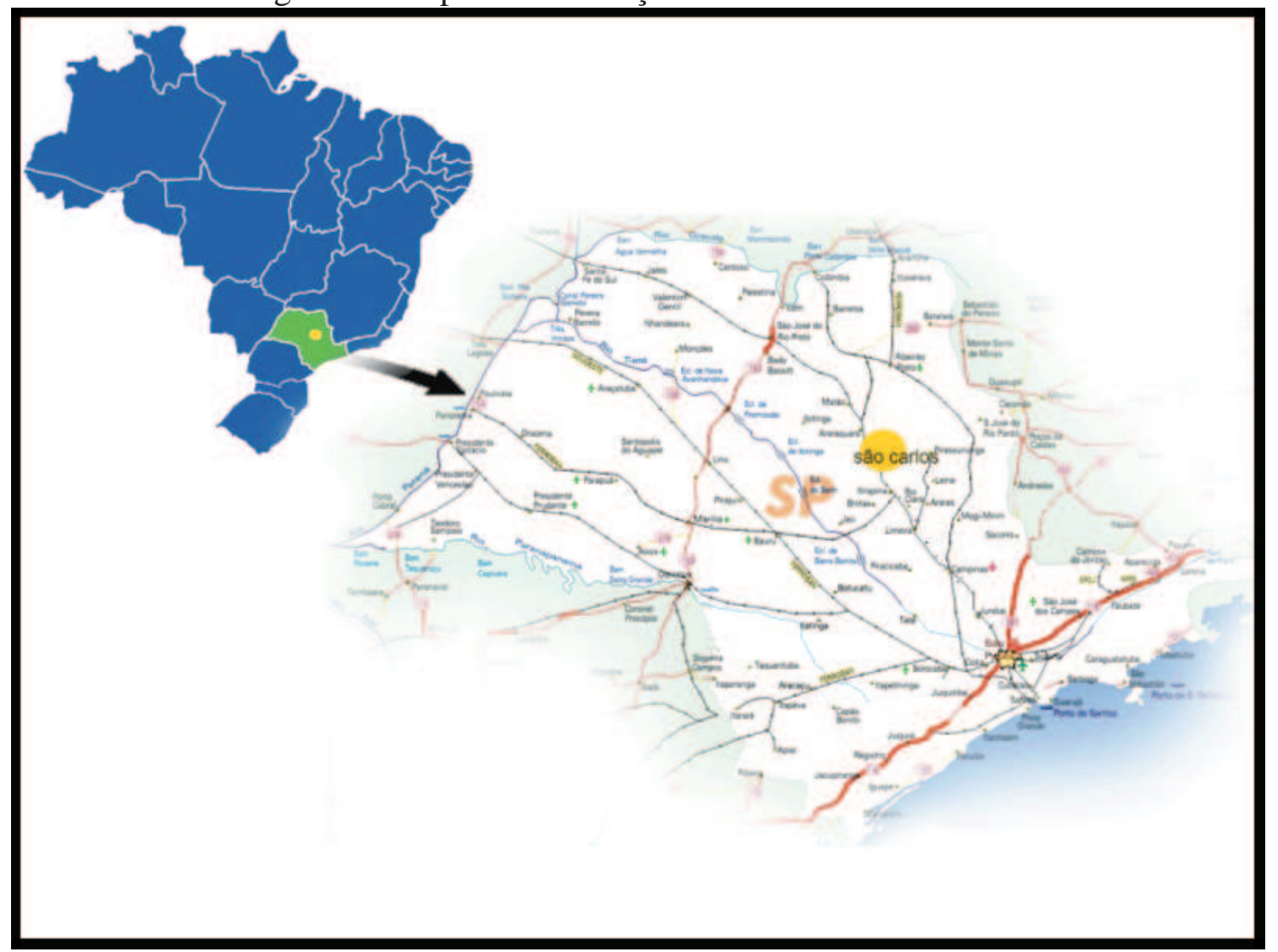

Fonte: LocalizaSãoCarlos (2012)

tráfego de veículos apenas nas ruas transversais. O P1 estava localizado na Avenida São Carlos, rua de maior movimento da cidade, o P4 na esquina das ruas General Osório e José Bonifácio, o P2 no calçadão entre a Avenida São Carlos e a Rua Episcopal e o P3, também no calçadão, entre a Rua Episcopal e a Rua José Bonifácio. A Figura 4 representa os locais de amostragem.

Inicialmente, foi definido que as amostragens seriam realizadas em lojas que tivessem um mesmo objeto de comércio, assim, foram selecionados 4 pontos para amostragem em que era realizado o comércio de confecções de uma maneira geral (roupas, artigos de cama, mesa e banho). A opção pelos que comercializavam tecidos foi devido ao maior aceite da realização do trabalho por esses locais. Apesar de ainda apresentarem uma certa relutância, por não saberem ao certo como o trabalho seria conduzido, todos foram enfáticos em não querer que o nome das lojas fossem divulgados e questionaram se esse tipo de trabalho não traria problemas se apresentasse, por exemplo, condições não adequadas nos ambientes. 
Figura 4 - Localização dos pontos amostrais

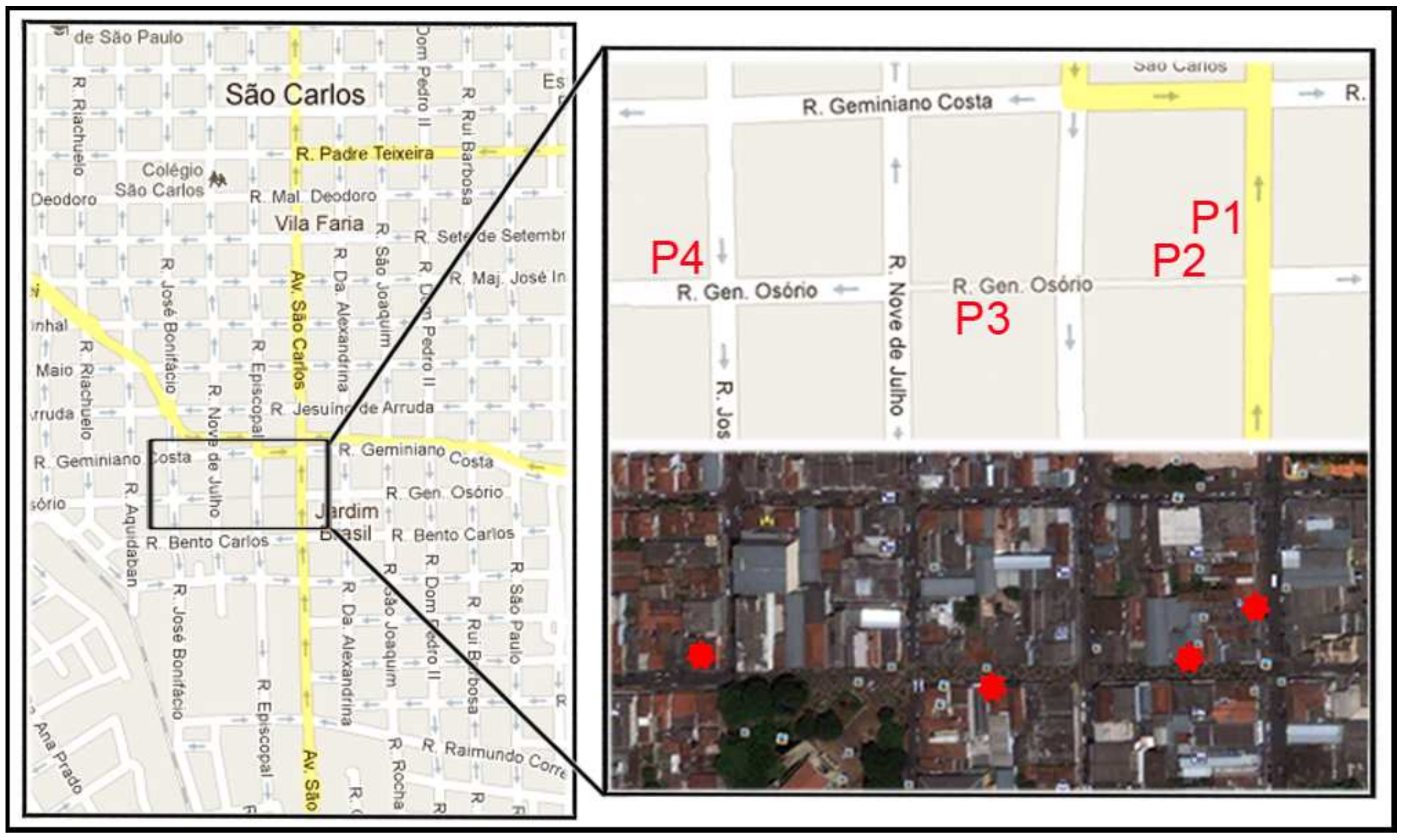

Fonte: GoogleMaps (2012) 
Os pontos comerciais, apesar de apresentarem similaridade quanto ao tipo de produto comercializado, tinham suas singularidades, principalmente em relação à arquitetura das construções, as quais são apresentadas na Tabela 1.

Tabela 1 - Características dos locais de amostragens

\begin{tabular}{cccccc}
\hline Pontos de coleta & Janelas & Ventilação natural & Resfriador de ar & Ventiladores & Som ambiente \\
\hline P1 & & $\mathrm{X}$ & $\mathrm{X}$ & $\mathrm{X}$ \\
P2 & & $\mathrm{X}$ & $\mathrm{X}$ & $\mathrm{X}$ \\
P3 & $\mathrm{X}$ & $\mathrm{X}$ & $\mathrm{X}$ & $\mathrm{X}$ & $\mathrm{X}$ \\
P4 & $\mathrm{X}$ & $\mathrm{X}$ & & $\mathrm{X}$ \\
\hline
\end{tabular}

As Figuras 5, 6, 7 e 8 apresentam a disposição dos pontos amostrais dentro de cada loja, no P1, P2, P3 e P4, respectivamente. Nos 4 pontos amostrais, o ponto de coleta foi definido pelos responsáveis do comércio, para que atrapalhasse o menos possível o andamento normal de cada local. Coincidentemente, nos pontos P1, P2 e P3, o ponto amostral ficou próximo aos caixas das lojas. Isso porque as lojas de roupas costumam ter todos os seus espaços ocupados por araras de roupas e balcões, onde os objetos comercializáveis são alocados. Apenas o P4 ficou próximo a uma vitrine da loja, onde as pessoas apenas visualizavam as peças e não realizavam a manipulação das mesmas, e por consequência disto, este ponto ficou mais próximo à saída do que ao interior da loja.

Figura 5 - Disposição do ponto amostral P1

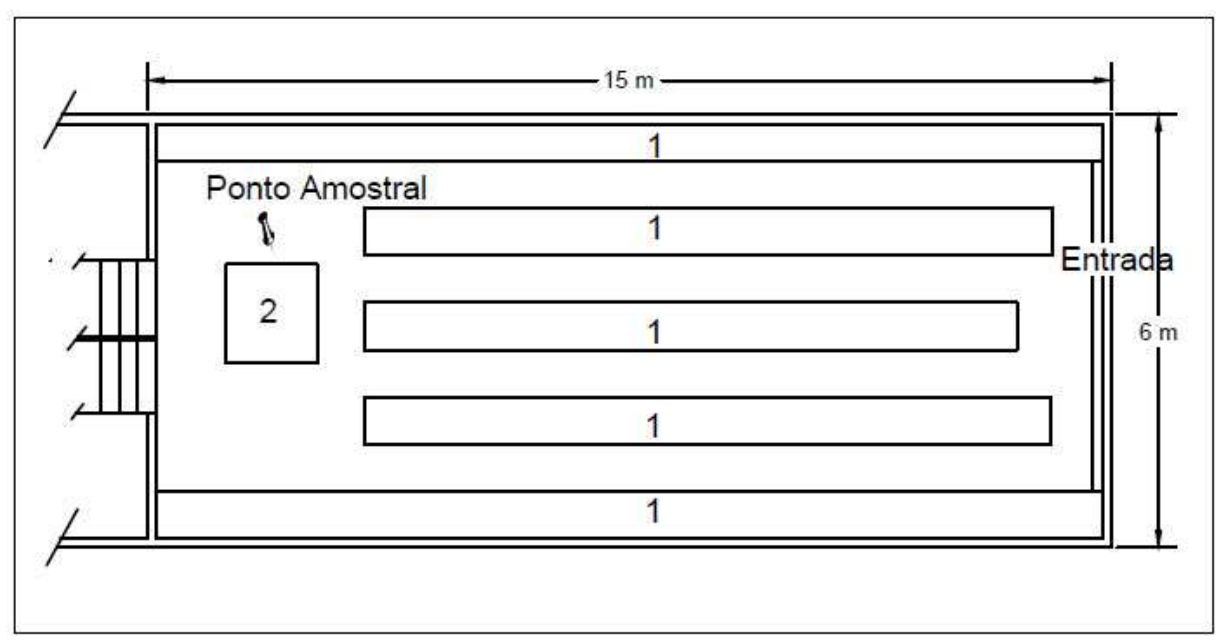

1-Araras de roupa; 2-Caixas. 
Figura 6 - Disposição do ponto amostral P2

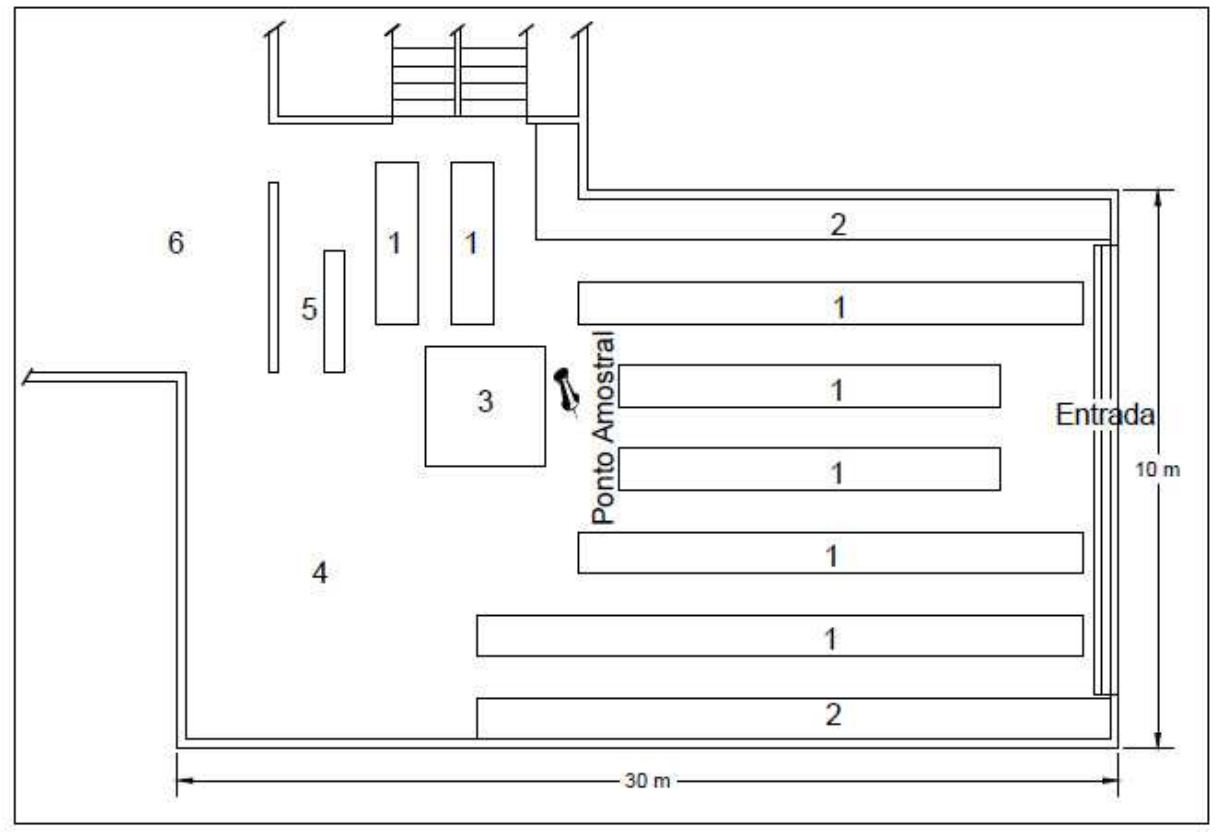

1-Araras de roupas e bancadas de cama, mesa e banho; 2-Araras suspensas; 3-Caixas; 4-Tapetes e cortinas; 5-Crediário; 6-Depósito.

Figura 7 - Disposição do ponto amostral P3

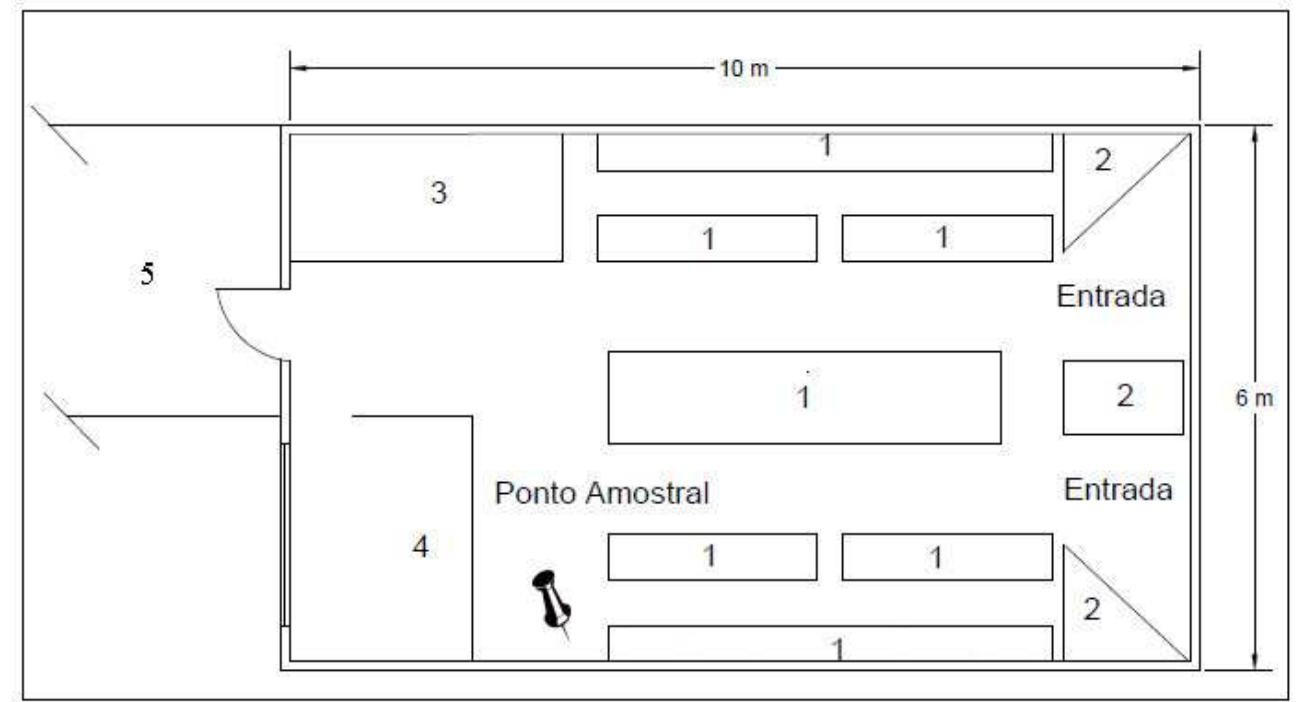

1-Araras de roupas; 2-Vitrines; 3-Provadores; 4-Caixas; 5-Depósito. 
Figura 8 - Disposição do ponto amostral P4

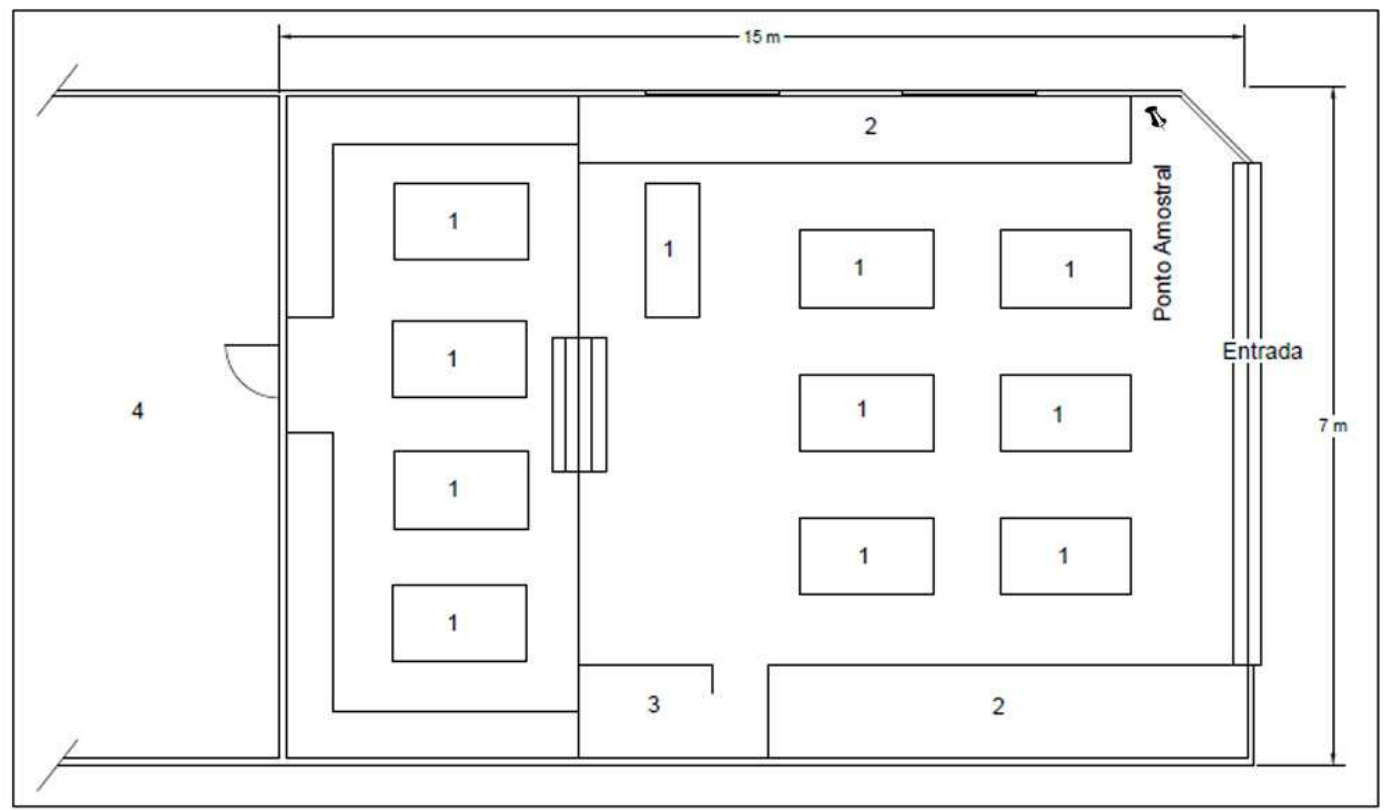

1-Araras de roupa; 2-Vitrines; 3-Caixas; 4-Depósito

\subsection{Coleta dos dados}

A campanha de coleta de dados foi dividida em duas etapas. A primeira, que será aqui chamada de coleta preliminar de dados, foi realizada durante os meses de maio, junho e julho do ano de 2011. Nesta etapa, o monitoramento foi realizado uma vez ao mês em cada local. Dessa forma, cada local foi monitorado três vezes neste período, com exceção do P4 que teve início das coletas no mês de junho, tendo sido monitorado duas vezes. E a segunda etapa, aqui denominada de coleta efetiva dos dados, foi realizada do dia 27 de outubro ao dia $1^{\circ}$ de dezembro de 2011. Como já mencionado, a coleta de dados foi realizada de maneira simultânea nos ambientes interno e externo dos pontos amostrais. No entanto, devido à insuficiência de equipamentos na etapa de coleta preliminar dos dados, não foi possível a coleta simultânea de todas as variáveis. As Tabelas 2 e 3 apresentam de maneira resumida a distribuição da coleta dos dados, na etapa preliminar e efetiva, respectivamente. 
Tabela 2 - Distribuição da coleta de dados da etapa preliminar

\begin{tabular}{|c|c|c|c|c|c|c|c|}
\hline PONTO & DATA & $\mathbf{I} / \mathbf{E}$ & Termohigrômetro & Decibelímetro & EVM & PEM & MultiRAE \\
\hline \multirow{2}{*}{3} & \multirow{2}{*}{$10 / 05 / 2011$} & I & $\mathrm{T}, \mathrm{UR}$ & & & $\mathrm{MP}_{10}$ & \\
\hline & & $\mathrm{E}$ & $\mathrm{T}, \mathrm{UR}$ & & & $\mathrm{MP}_{10}, \mathrm{MP}_{2,5}$ & \\
\hline \multirow{2}{*}{1} & \multirow{2}{*}{$12 / 05 / 2011$} & $\bar{I}$ & T, UR & & & $\mathrm{MP}_{10}$ & \\
\hline & & $\mathrm{E}$ & T, UR & & & $\mathrm{MP}_{10}, \mathrm{MP}_{2,5}$ & \\
\hline \multirow{2}{*}{2} & \multirow{2}{*}{$13 / 05 / 2011$} & I & T, UR & & & $\mathrm{MP}_{10}$ & \\
\hline & & E & $\mathrm{T}, \mathrm{UR}$ & & & $\mathrm{MP}_{10}, \mathrm{MP}_{2,5}$ & \\
\hline \multirow{2}{*}{2} & \multirow{2}{*}{ 07/06/2011 } & $\bar{I}$ & T, UR & & $\mathrm{CO}_{2}, \mathrm{MP}_{2,5}$ & $\mathrm{MP}_{10}$ & \\
\hline & & E & $\mathrm{T}, \mathrm{UR}$ & & & $\mathrm{MP}_{10}, \mathrm{MP}_{2,5}$ & $\mathrm{CO}_{2}$ \\
\hline \multirow{2}{*}{3} & \multirow{2}{*}{ 08/06/2011 } & $\bar{I}$ & T, UR & & $\mathrm{CO}_{2}, \mathrm{MP}_{2,5}$ & $\mathrm{MP}_{10}$ & \\
\hline & & E & T, UR & & & $\mathrm{MP}_{10}, \mathrm{MP}_{2,5}$ & $\mathrm{CO}_{2}$ \\
\hline \multirow{2}{*}{4} & \multirow{2}{*}{$10 / 06 / 2011$} & I & T, UR & & $\mathrm{CO}_{2}, \mathrm{MP}_{2,5}$ & $\mathrm{MP}_{10}$ & \\
\hline & & $\mathrm{E}$ & T, UR & & & $\mathrm{MP}_{10}, \mathrm{MP}_{2,5}$ & $\mathrm{CO}_{2}$ \\
\hline \multirow{2}{*}{1} & \multirow{2}{*}{$14 / 06 / 2011$} & $\bar{I}$ & $\mathrm{~T}, \mathrm{UR}$ & & $\mathrm{CO}_{2}, \mathrm{MP}_{2,5}$ & $\mathrm{MP}_{10}$ & \\
\hline & & E & $\mathrm{T}, \mathrm{UR}$ & & & $\mathrm{MP}_{10}, \mathrm{MP}_{2,5}$ & $\mathrm{CO}_{2}$ \\
\hline \multirow{2}{*}{1} & \multirow{2}{*}{$19 / 07 / 2011$} & $\bar{I}$ & T, UR & ruído & & & $\mathrm{CO}_{2}$ \\
\hline & & $\mathrm{E}$ & T, UR & ruído & $\mathrm{CO}_{2}, \mathrm{MP}_{2,5}$ & & \\
\hline \multirow{2}{*}{3} & \multirow{2}{*}{ 20/07/2011 } & $\mathrm{I}$ & T, UR & ruído & & & $\mathrm{CO}_{2}$ \\
\hline & & $\mathrm{E}$ & $\mathrm{T}, \mathrm{UR}$ & ruído & $\mathrm{CO}_{2}, \mathrm{MP}_{2,5}$ & & \\
\hline \multirow{2}{*}{4} & \multirow{2}{*}{$21 / 07 / 2011$} & $\bar{I}$ & T, UR & ruído & & & $\mathrm{CO}_{2}$ \\
\hline & & $\mathrm{E}$ & T, UR & ruído & $\mathrm{CO}_{2}, \mathrm{MP}_{2,5}$ & & \\
\hline \multirow{2}{*}{2} & \multirow{2}{*}{$25 / 07 / 2011$} & $\mathrm{I}$ & $\mathrm{T}, \mathrm{UR}$ & ruído & & & $\mathrm{CO}_{2}$ \\
\hline & & E & $\mathrm{T}, \mathrm{UR}$ & ruído & $\mathrm{CO}_{2}, \mathrm{MP}_{2,5}$ & & \\
\hline
\end{tabular}

$\mathrm{I}=$ interno; $\mathrm{E}=$ externo; T=temperatura; $\mathrm{UR}=$ =umidade relativa. 
Tabela 3 - Distribuição da coleta de dados da etapa efetiva

\begin{tabular}{|c|c|c|c|c|c|c|c|}
\hline PONTO & DATA & $\mathbf{I} / \mathbf{E}$ & Termohigrômetro & Decibelímetro & EVM & pDR & PEM \\
\hline \multirow{4}{*}{1} & \multirow{2}{*}{$27 / 10 / 2011$} & I & $\mathrm{T}, \mathrm{UR}$ & ruído & & \multirow[t]{2}{*}{$\mathrm{MP}_{10}$} & $\mathrm{MP}_{10}$ \\
\hline & & $\mathrm{E}$ & $\mathrm{T}, \mathrm{UR}$ & ruído & $\mathrm{MP}_{10}$ & & $\mathrm{MP}_{10}$ \\
\hline & \multirow{2}{*}{$28 / 10 / 2011$} & I & $\mathrm{T}, \mathrm{UR}$ & ruído & & \multirow[t]{2}{*}{$\mathrm{MP}_{2,5}$} & $\mathrm{MP}_{2,5}$ \\
\hline & & E & $\mathrm{T}, \mathrm{UR}$ & ruído & $\mathrm{MP}_{2,5}$ & & $\mathrm{MP}_{2,5}$ \\
\hline \multirow{4}{*}{3} & \multirow{2}{*}{$07 / 11 / 2011$} & $\mathrm{I}$ & $\mathrm{T}, \mathrm{UR}$ & & & \multirow[t]{2}{*}{$\mathrm{MP}_{10}$} & $\mathrm{MP}_{10}$ \\
\hline & & $\mathrm{E}$ & $\mathrm{T}, \mathrm{UR}$ & & $\mathrm{MP}_{10}$ & & $\mathrm{MP}_{10}$ \\
\hline & \multirow{2}{*}{$08 / 11 / 2011$} & I & $\mathrm{T}, \mathrm{UR}$ & & & \multirow[t]{2}{*}{$\mathrm{MP}_{2,5}$} & $\mathrm{MP}_{2,5}$ \\
\hline & & E & $\mathrm{T}, \mathrm{UR}$ & & $\mathrm{MP}_{2,5}$ & & $\mathrm{MP}_{2,5}$ \\
\hline \multirow{4}{*}{2} & \multirow{2}{*}{$17 / 11 / 2011$} & $\mathrm{I}$ & T, UR & ruído & & \multirow[t]{2}{*}{$\mathrm{MP}_{10}$} & $\mathrm{MP}_{10}$ \\
\hline & & $\mathrm{E}$ & $\mathrm{T}, \mathrm{UR}$ & ruído & $\mathrm{MP}_{10}$ & & $\mathrm{MP}_{10}$ \\
\hline & \multirow{2}{*}{$18 / 11 / 2011$} & I & $\mathrm{T}, \mathrm{UR}$ & ruído & & \multirow[t]{2}{*}{$\mathrm{MP}_{2,5}$} & $\mathrm{MP}_{2,5}$ \\
\hline & & $\mathrm{E}$ & $\mathrm{T}, \mathrm{UR}$ & ruído & $\mathrm{MP}_{2,5}$ & & $\mathrm{MP}_{2,5}$ \\
\hline \multirow{4}{*}{4} & \multirow{2}{*}{$21 / 11 / 2011$} & $\mathrm{I}$ & $\mathrm{T}, \mathrm{UR}$ & ruído & & \multirow[t]{2}{*}{$\mathrm{MP}_{10}$} & $\mathrm{MP}_{10}$ \\
\hline & & $\mathrm{E}$ & $\mathrm{T}, \mathrm{UR}$ & ruído & $\mathrm{MP}_{10}$ & & $\mathrm{MP}_{10}$ \\
\hline & \multirow{2}{*}{$22 / 11 / 2011$} & I & $\mathrm{T}, \mathrm{UR}$ & ruído & & \multirow[t]{2}{*}{$\mathrm{MP}_{2,5}$} & $\mathrm{MP}_{2,5}$ \\
\hline & & $\mathrm{E}$ & $\mathrm{T}, \mathrm{UR}$ & ruído & $\mathrm{MP}_{2,5}$ & & $\mathrm{MP}_{2,5}$ \\
\hline \multirow{4}{*}{1} & \multirow{2}{*}{$23 / 11 / 2011$} & I & $\mathrm{T}, \mathrm{UR}$ & ruído & & \multirow[t]{2}{*}{$\mathrm{MP}_{10}$} & $\mathrm{MP}_{10}$ \\
\hline & & $\mathrm{E}$ & $\mathrm{T}, \mathrm{UR}$ & ruído & $\mathrm{MP}_{10}$ & & $\mathrm{MP}_{10}, \mathrm{MP}_{2,5}$ \\
\hline & \multirow{2}{*}{$24 / 11 / 2011$} & I & $\mathrm{T}, \mathrm{UR}$ & ruído & & \multirow[t]{2}{*}{$\mathrm{MP}_{2,5}$} & $\mathrm{MP}_{10}, \mathrm{MP}_{2,5}$ \\
\hline & & E & $\mathrm{T}, \mathrm{UR}$ & ruído & $\mathrm{MP}_{2,5}$ & & $\mathrm{MP}_{2,5}$ \\
\hline \multirow{4}{*}{2} & \multirow{2}{*}{$25 / 11 / 2011$} & I & $\mathrm{T}, \mathrm{UR}$ & ruído & & \multirow[t]{2}{*}{$\mathrm{MP}_{10}$} & $\mathrm{MP}_{10}$ \\
\hline & & $\mathrm{E}$ & $\mathrm{T}, \mathrm{UR}$ & ruído & $\mathrm{MP}_{10}$ & & $\mathrm{MP}_{10}, \mathrm{MP}_{2,5}$ \\
\hline & \multirow{2}{*}{$26 / 11 / 2011$} & I & T, UR & & & $\mathrm{MP}_{2,5}$ & $\mathrm{MP}_{10}, \mathrm{MP}_{2,5}$ \\
\hline & & $\mathrm{E}$ & $\mathrm{T}, \mathrm{UR}$ & ruído & $\mathrm{MP}_{2,5}$ & & $\mathrm{MP}_{2,5}$ \\
\hline & $28 / 11 / 2011$ & I & $\mathrm{T}, \mathrm{UR}$ & ruído & & $\mathrm{MP}_{10}$ & $\mathrm{MP}_{10}$ \\
\hline 3 & $28 / 11 / 2011$ & $\mathrm{E}$ & $\mathrm{T}, \mathrm{UR}$ & ruído & $\mathrm{MP}_{10}$ & & $\mathrm{MP}_{10}, \mathrm{MP}_{2,5}$ \\
\hline 3 & $20 / 11 / 2011$ & I & $\mathrm{T}, \mathrm{UR}$ & & & $\mathrm{MP}_{2,5}$ & $\mathrm{MP}_{10}, \mathrm{MP}_{2,5}$ \\
\hline & $29 / 11 / 2011$ & E & $\mathrm{T}, \mathrm{UR}$ & ruído & $\mathrm{MP}_{2,5}$ & & $\mathrm{MP}_{2,5}$ \\
\hline & $30 / 11 / 2011$ & $\bar{I}$ & T, UR & & & $\mathrm{MP}_{10}$ & $\mathrm{MP}_{10}$ \\
\hline 4 & $30 / 11 / 2011$ & E & $\mathrm{T}, \mathrm{UR}$ & ruído & $\mathrm{MP}_{10}$ & & $\mathrm{MP}_{10}, \mathrm{MP}_{2,5}$ \\
\hline 4 & $01 / 11 / 2011$ & I & $\mathrm{T}, \mathrm{UR}$ & ruído & & $\mathrm{MP}_{2,5}$ & $\mathrm{MP}_{10}, \mathrm{MP}_{2,5}$ \\
\hline & $01 / 11 / 2011$ & $\mathrm{E}$ & $\mathrm{T}, \mathrm{UR}$ & ruído & $\mathrm{MP}_{2,5}$ & & $\mathrm{MP}_{2,5}$ \\
\hline
\end{tabular}

I=interno; E=externo; T=temperatura; UR=umidade relativa.

\subsection{Material Particulado}

$\mathrm{O}$ material particulado foi coletado nas frações $\mathrm{MP}_{10}$ e $\mathrm{MP}_{2,5}$. O $\mathrm{MP}_{10}$ é constituído das partículas com diâmetro aerodinâmico inferior a $10 \mu \mathrm{m}$, e o $\mathrm{MP}_{2,5}$ inferior a 2,5 $\mu \mathrm{m}$. A coleta do MP foi realizada de duas maneiras: (1) por meio de filtração, acumulando material em uma membrana, 
de onde se obteve dados de concentração e de caracterização química; e (2) utilizando monitores portáteis de material particulado, que instantaneamente apresentavam os valores de concentração do MP no visor do equipamento, e acumulavam os dados ao longo do dia para serem transferidos em computador.

\subsubsection{Filtração}

A filtração foi realizada utilizando-se o Personal Environmental Monitor - PEM, que é um monitor de uso pessoal, acoplado a uma bomba de sucção que operava à vazão de 10 1/min, ambos são da marca SKC e estão ilustrados na Figura 9. O uso do PEM em um funcionário, que é o comumente realizado, foi substituído pela sua colocação em um suporte de 1,5 m de altura, ficando dessa forma fixo durante todo o tempo amostral. A bomba era acondicionada dentro de uma caixa acústica. O ar contendo o MP era succionado e adentrava pelos orifícios da parte superior do PEM, as partículas com diâmetro superior ao diâmetro de corte eram impactadas no anel [Fig. 9 (c)] que era untado para cada coleta com óleo. Na coleta de MP realizada no mês de maio, este anel foi untado com óleo de baixa viscosidade, que acabou escorrendo e contaminando as membranas, o que interferiu nos resultados. Por conta disso, a partir da coleta do mês de junho, passou-se a utilizar vaselina para untar o anel. As partículas menores que o diâmetro de corte eram então encaminhadas na direção da membrana, onde ficavam retidas.

Durante o período da pré-coleta foram utilizados dois tipos de membrana, uma do tipo PTFE, de $37 \mathrm{~mm}$ de diâmetro e poro de $1 \mu \mathrm{m}$ de diâmetro, no mês de maio, e no mês de junho uma membrana também de PTFE de $37 \mathrm{~mm}$ de diâmetro e poro de $2 \mu \mathrm{m}$ de diâmetro, com anel suporte. No período de coleta efetiva dos dados, foi utilizada uma membrana do tipo PTFE de $37 \mathrm{~mm}$ de diâmetro e poro de $2 \mu \mathrm{m}$ de diâmetro sem anel suporte. Para determinação da concentração do material particulado, foi realizada a pesagem das membranas pré e pós-coleta, em balança com precisão de $1 \mu \mathrm{g}$, e o volume de ar também era conhecido. Como as campanhas de amostragem tinham duração de 8 horas à uma vazão constante de 10 L/min, era obtido o volume de 4.800 L. Como exceção, no dia 21/11/2011, quando a bomba de coleta do ar externo apresentou problema e foi obtido um volume de $3.156 \mathrm{~L}$ apenas, e o dia 26/11/2011, em que a coleta foi realizada em um sábado e teve duração de 7 h e 30 min, com um volume de ar amostrado de 4.500 L.

A pesagem das membranas do período de pré-coleta foi realizada no Laboratório de Polui- 
Figura 9 - Bomba de sucção da SKC (a ), PEM (b) utilizados para coleta de material particulado e disposição das partes do PEM (c)

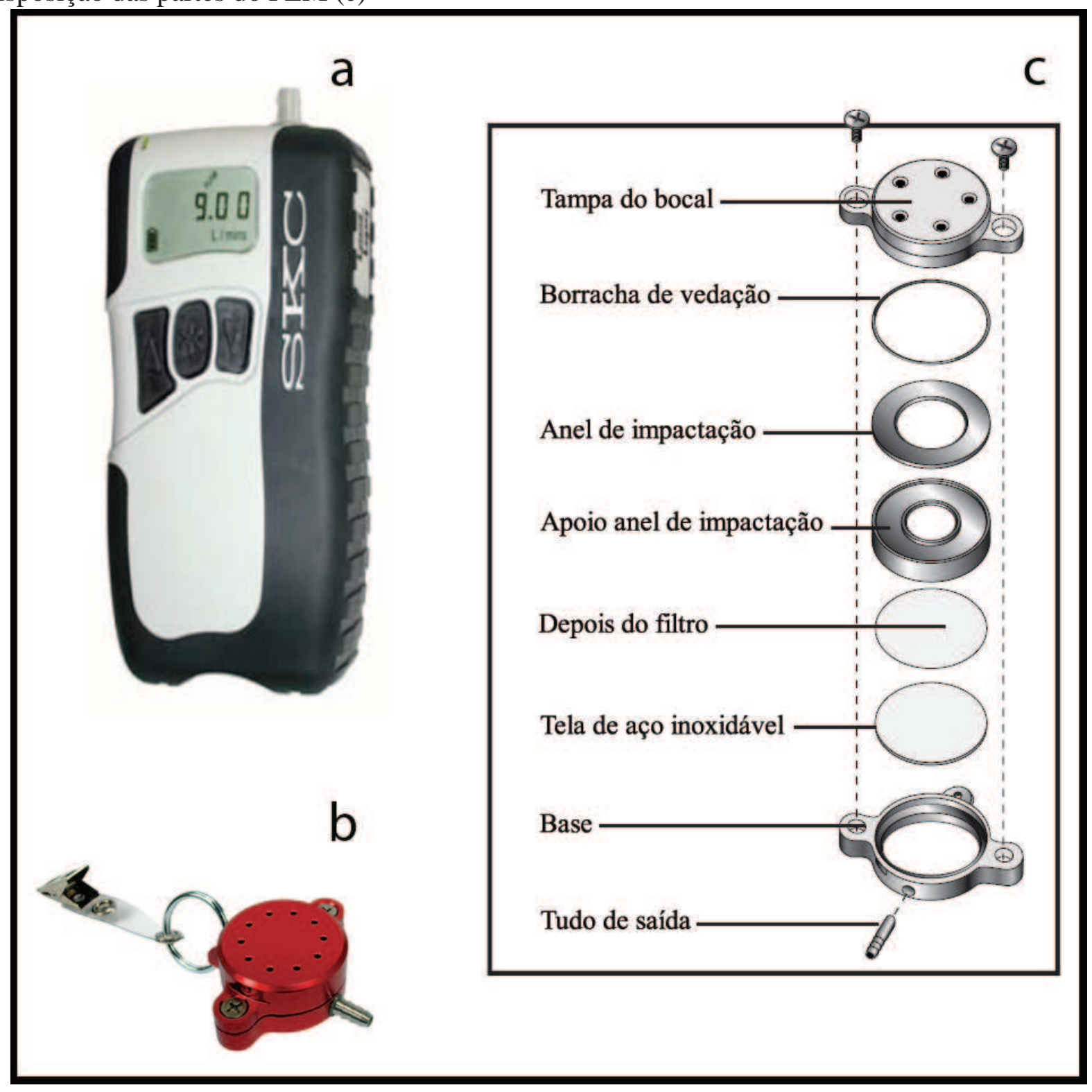

Fonte: SKC (2012)

ção Atmosférica do Instituto de Física da Universidade de São Paulo-SP. No dia anterior a cada pesagem, as membranas eram levadas para ambientação na sala da balança, onde umidade relativa e temperatura eram mantidas constantes. Era necessária também a eliminação da carga eletrostática das membranas, sendo que, no mês de maio, foram utilizadas pastilhas de Polônio, que eram colocadas sobre a caixa contendo as membranas por algum tempo antes da pesagem. Para as pesa- 
gens realizadas com as membranas utilizadas nas coletas do mês de junho, a retirada das cargas foi realizada utilizando-se um eletrodo de remoção de cargas, sendo que a membrana era passada por alguns segundos pelo eletrodo e logo em seguida era realizada a pesagem.

A pesagem das membranas para a coleta efetiva dos dados foi realizada no laboratório de Controle Ambiental I, da Engenharia Química da UFSCar. Na etapa de coleta preliminar, esta balança não foi utilizada porque o laboratório não possuía o equipamento para a retirada da carga eletrostática das membranas. Após aquisição do eletrodo, similar ao utilizado no IFSP, as pesagens passaram a ser realizadas na UFSCar. Como o laboratório não pussuía uma sala única para a balança, as membranas eram acondicionadas em um dessecador pelo menos um dia antes da pesagem. O laboratório em que a balança era mantida também era utilizado por outros pesquisadores e possuía vários outros equipamentos, por causa disso era difícil manter a umidade relativa e a temperatura constantes. Para tentar minimizar interferências, o ar condicionado era ligado uma hora mais ou menos antes de se iniciar a pesagem das membranas e permanecia por todo o tempo de pesagem.

As membranas foram submetidas à análise química por meio de Fluorescência de Raio X, no Laboratório de Caracterização Estrutural (LCE) da Engenharia de Materiais da UFSCar. O equipamento utilizado foi da marca Shimadzu, EDX-720 Energy Dispersive X-Ray Spectrometer, colimador de $10 \mathrm{~mm}$ e na atmosfera ar.

\subsubsection{Monitores de material particulado}

Dois monitores portáteis foram utilizados para a determinação da concentração do material particulado. Ambos são de resposta rápida, ou seja, apresentam em tempo real, na tela do equipamento, os valores da concentração do MP e também armazenam os dados para serem transferidos em um computador. Neste trabalho, os dados foram armazenados de $1 \mathrm{~min}$ em $1 \mathrm{~min}$. A Figura 10 apresenta os monitores, Environmental monitoring instrument (EVM-7) da Quest Technologes, e o personal DataRam (pDR-1500) da Thermo Scientific.

O EVM-7 realiza o monitoramento da concentração de $\mathrm{MP}$ em suas frações $\mathrm{MP}_{10}, \mathrm{MP}_{4}$, $\mathrm{MP}_{2,5}$ e $\mathrm{MP}_{1}$. Uma vez que a fração da partícula a ser coletada é definida, uma bomba interna succiona o ar e ele realiza a medida em tempo real, utilizando espalhamento de luz por um laser

fotômetro para determinar a concentração em massa total (em unidades de $\mathrm{mg} / \mathrm{m}^{3}$ ) de partículas. 
Na etapa de coleta preliminar de dados, o EVM-7 foi utilizado, alternando-se o ambiente interno e externo, já na etapa de coleta efetiva dos dados, ele foi utilizado somente no ambiente externo.

$\mathrm{O}$ pDR-1500 pode coletar partículas nos diâmetros $\mathrm{MP}_{10}, \mathrm{MP}_{4}, \mathrm{MP}_{2,5}, \mathrm{MP}_{1}$, realizando a medição pela detecção por espalhamento de luz. Ele possui dois ciclones, usados separadamente, por onde ocorre a entrada de ar. Variando a vazão, ocorre a diferenciação do diâmetro aerodinâmico das partículas, o que faz com que apenas a fração desejada seja coletada. O pDR-1500 foi utilizado somente no ambiente interno na etapa de coleta efetiva dos dados.

Figura 10 - Monitores Portáteis EVM-7 (a) pDR-1.500 (b)

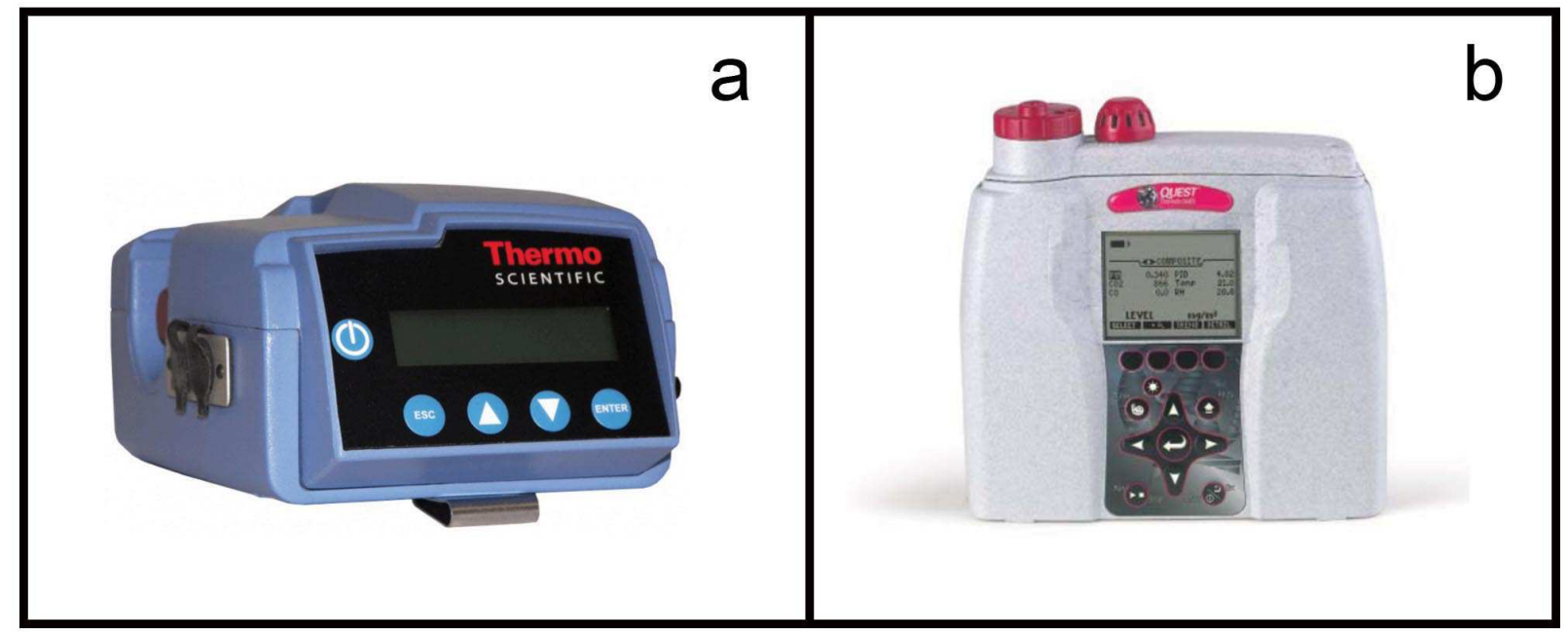

Fonte: Acervo pessoal

\subsection{Análise do dióxido de carbono $\left(\mathrm{CO}_{2}\right)$}

O monitoramento de $\mathrm{CO}_{2}$ foi realizado, utilizando-se um monitor portátil de gases, da marca $R A E$ Systems, modelo MultiRAE IR - PGM54. O equipamento realiza a sucção do ar e a concentração de $\mathrm{CO}_{2}$ é detectada por meio de um sensor infravermelho interno. A concentração era exibida instantaneamente na tela do monitor e os dados armazenados na memória para, posteriormente, serem transferidos para um computador. Neste trabalho os dados foram armazenados a cada 30 segundos. As amostragens foram realizadas, tomando-se por base a ANVISA n09/2003, que determina apenas um ponto de monitoramente em locais que possuem área construída de até $1.000 \mathrm{~m}^{2}$ e que seja realizado por equipamento de leitura direta. 


\subsection{Poluição Sonora}

Para o monitoramento da poluição sonora foram utilizados medidores de nível de pressão sonora, modelo DEC-490 da marca Instrutherm, com escala de medição de 30 a 130 dB. O equipamento armazenava a sequência dos dados, assim um perfil do tempo amostrado pode ser elaborado, sendo que, neste trabalho os dados foram armazenados a cada 30 segundos. A respeito do que diz a NBR10151 de 2000 que norteia a realização das medições, o decibelímetro era mantido, na medida do possível para não atrapalhar as atividades do local, a $1 \mathrm{~m}$ de distância de qualquer superfície. Os dados de ruído foram coletados simultâneamente no ambiente interno e externo dos pontos amostrais, com excessão dos dias 07 e 08/11 em que os decibelímetros estavam sendo utilizados em outra pesquisa, e nos dias 26, 29 e 30/11 em que o decibelímetro do ambiente interno apresentou problemas.

\subsection{Variáveis climáticas}

Os dados de temperatura e de umidade relativa do ar foram coletados utilizando-se termohigrômetros digitais, modelo Hygropalm zero da marca Rotronic. A norma RE/ANVISA nº 9 de 2003 serviu como referência para as medições, qual determina o uso de equipamento de leitura direta, tendo faixa de leitura de $0{ }^{\circ} \mathrm{C}$ à $70^{\circ} \mathrm{C}$ e de $5 \%$ a $95 \%$ para temperatura e umidade relativa do ar, respectivamente. A RE/ANVISA n ${ }^{\circ} 9$ também determina o número mínimo de pontos amostrais de acordo com a área construída, todos os locais de coleta de dados deste trabalho enquadram-se no número mínimo de 1 ponto amostral, por possuírem área construída menor que $1000 \mathrm{~m}^{2}$. A temperatura e a umidade relativa do ar foram coletadas a cada 15 min simultâneamente nos ambientes interno e externo dos pontos amostrais.

Além da temperatura ambiente e da umidade relativa do ar coletados nos locais de amostragem, foram utilizados os dados de precipitação da estação meteorológica da EMBRAPA (Empresa Brasileira de Pesquisa Agropecuária), localizada na Rodovia Washington Luiz, km 234. 


\subsubsection{Conforto térmico}

Para o estudo do conforto térmico, neste trabalho foram utilizados as faixas de valores estabelecidas pela RE/ANVISA no 09/2003. E além disso, foi utilizada uma expressão de Índice de calor (HI), Healt index, da National Oceanic and Atmospheric Administration (NOAA) (ROTHFUSZ; HEADQUARTERS, 1990). Para elaboração deste índice são levados em consideração valores monitorados de temperatura e umidade relativa do ar. Outros parâmetros sao considerados neste cálculo, mas para estes os valores são assumidos, baseados em estudos biometeorológicos, afim de simplificar o modelo, apresentado na equação abaixo.

$$
\begin{gathered}
H I=-42,379+2,04901523(T)+10,14333127(R)-0,22475541(T R)-6,83783 \times 10^{-3}\left(T^{2}\right) \\
\quad-5,481717 \times 10^{(-2)}\left(R^{2}\right)+1,22874 \times 10^{-3}\left(T^{2} R\right)+8,5282 \times 10^{-4}\left(T R^{2}\right)-1,99 \times 10^{-6}\left(T^{2} R^{2}\right)
\end{gathered}
$$

Onde,

$$
\begin{aligned}
& \mathrm{T}=\text { Temperatura }\left({ }^{\circ} \mathrm{F}\right) ; \\
& \mathrm{R}=\text { Umidade relativa }(\%)
\end{aligned}
$$




\section{Resultados e Discussão}

De acordo com o que foi apresentado na metodologia, a coleta de dados foi dividida em duas etapas, a coleta preliminar e a coleta efetiva. Após a etapa de coleta preliminar dos dados, ficou definido que o monitoramento de $\mathrm{CO}_{2}$ não seria mais realizado, pois as áreas de estudo se referem a ambientes abertos, o qual não seria relevante. A seguir, serão apresentados os resultados do monitoramento do $\mathrm{CO}_{2}$, e nas seções seguintes os resultados referentes ao ruído, material particulado e variáveis climáticas.

No Brasil, há duas normas que regem a concentração limite de $\mathrm{CO}_{2}$ em ambientes internos, sendo que ambas são para ambientes internos climatizados artificialmente, não havendo normatização para ambientes não climatizados. A RE/ANVISA nº 09/2.003 da Agência Nacional de Vigilância Sanitária estabelece o limite de concentração de $\mathrm{CO}_{2}$ em 1.000 ppm, e a RN 02 de 2.003 da ABRAVA (Associação Brasileira de Refrigeração, Ventilação, Ar Condiconado e Aquecimento) estabelece uma concentração interna de no máximo 700 ppm maior que a concentração de $\mathrm{CO}_{2}$ externa. As Figuras 11 e 12 apresentam os gráficos de boxplot da concentração de $\mathrm{CO}_{2}$ interna e externa, respectivamente, monitorada durante a etapa de coleta preliminar de dados.

Figura 11 - Concentração de $\mathrm{CO}_{2}$ interno

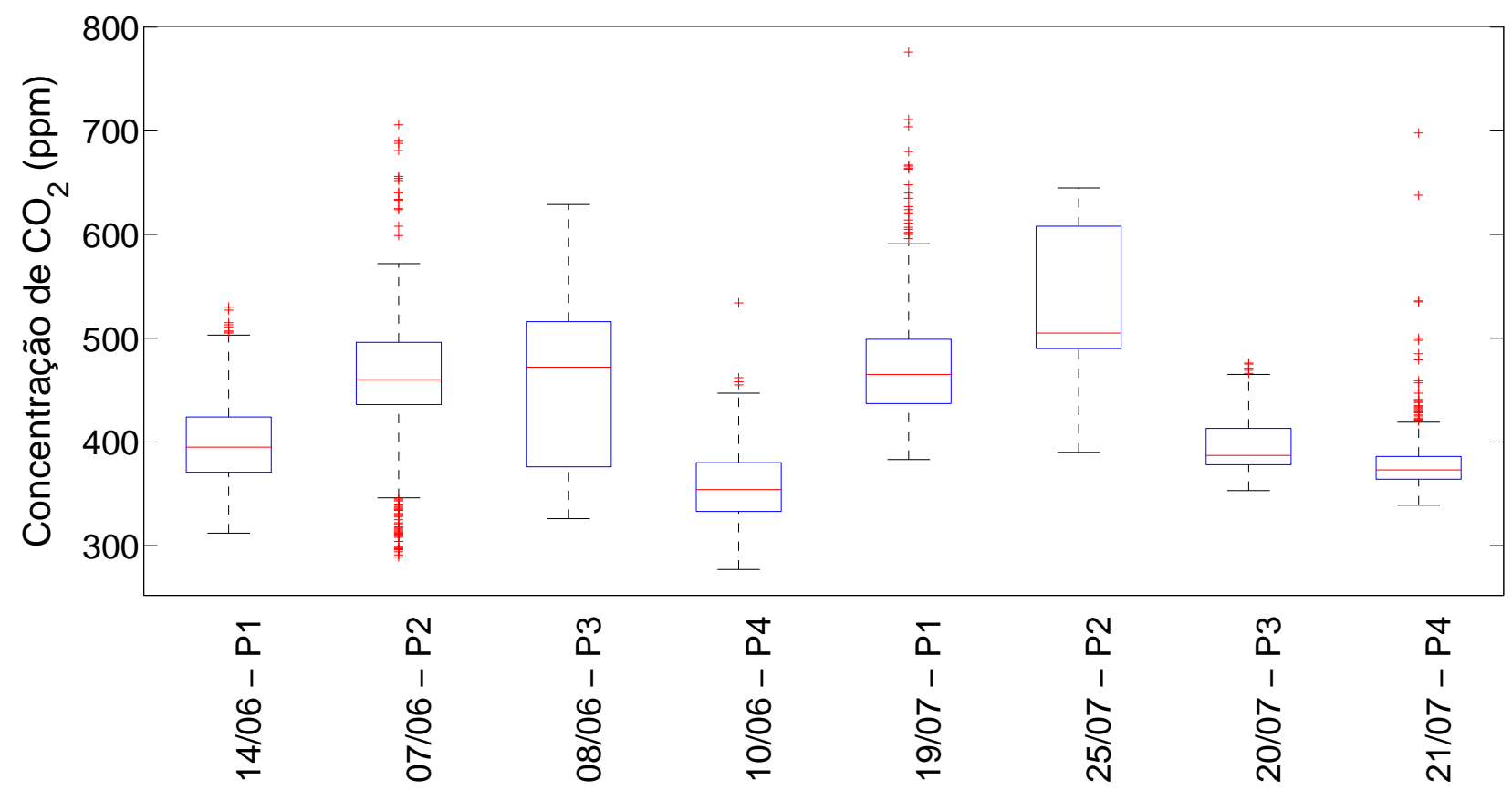


Figura 12 - Concentração de $\mathrm{CO}_{2}$ externo

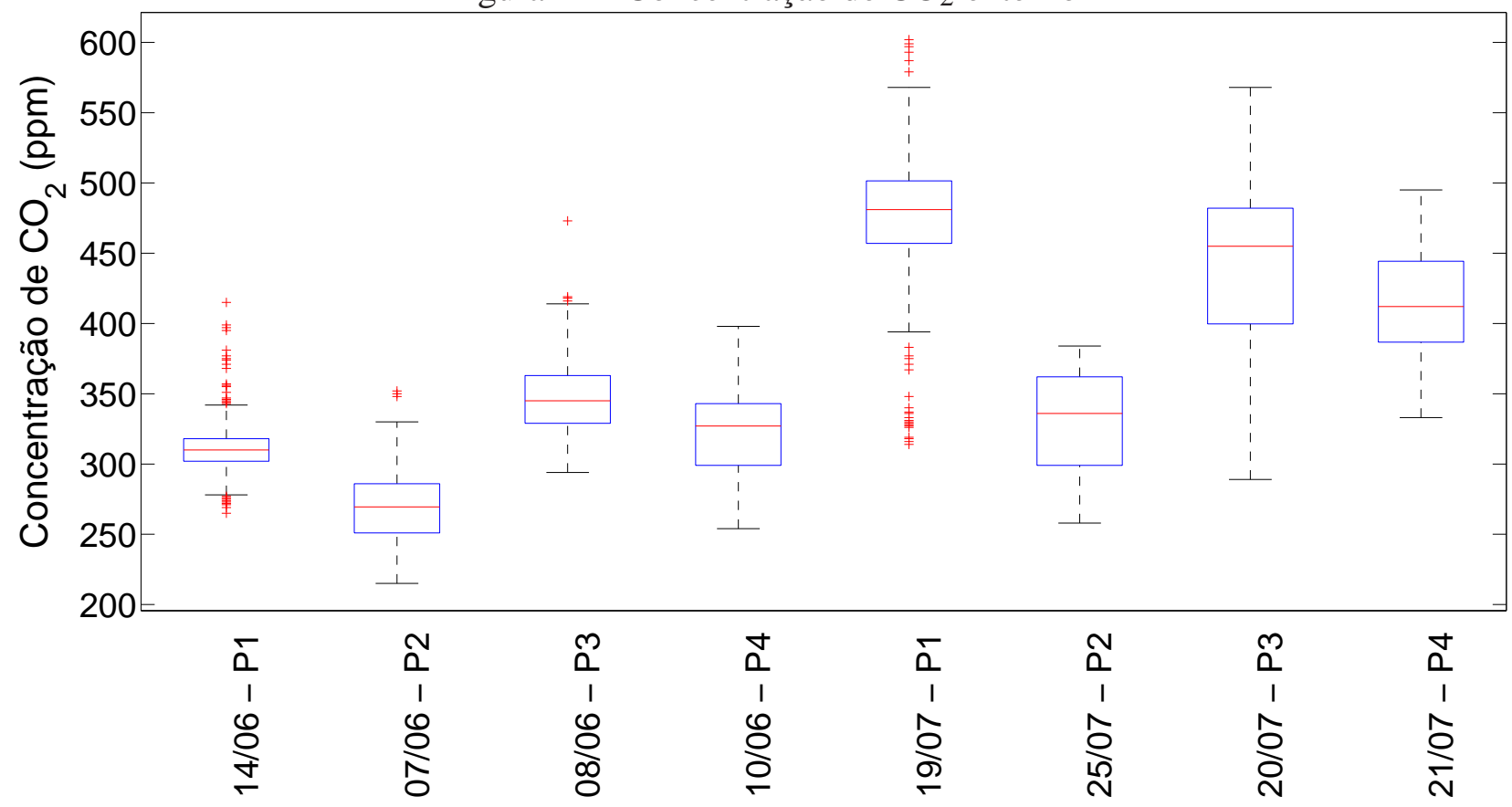

Pode ser observado que os valores da concentração interna de $\mathrm{CO}_{2}$ ficaram abaixo dos 1.000 ppm estabelecidos pela ANVISA n $09 / 2.003$, e que as concentrações internas e externas são muito

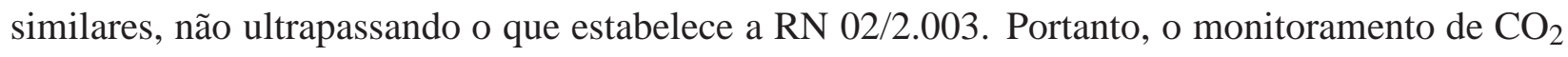
não é interessante no foco deste estudo, por ser realizado em ambientes que as trocas de ar são constantes com o meio externo, principalmente pela manutenção de portas e janelas abertas, fazendo com que os níveis internos de $\mathrm{CO}_{2}$ não atinjam valores que causem danos aos ocupantes. Assim, o estudo do $\mathrm{CO}_{2}$ foi descontinuado na etapa de coleta efetiva dos dados.

\subsection{Temperatura e umidade relativa do ar}

A Resolução RE/ANVISA n ${ }^{\circ}$ 09/2003 estabelece valores adequados de temperatura e umidade relativa do ar para a manutenção do conforto térmico, no entanto, ela é especifica para ambientes climatizados artificialmente. Como não há normatização no Brasil referente à ambientes não climatizados, caso dos ambientes estudados neste trabalho, a norma da ANVISA será utilizada como referência. A norma estabelece valores diferenciados de temperatura e umidade relativa do ar para as estações verão e inverno. Para fins de comparação, neste trabalho a etapa de coleta preliminar de dados, realizada nos meses de maio, junho e julho, será considerada como estação inverno. A etapa 
de coleta efetiva de dados, realizada do final do mês de outubro ao início do mês de dezembro, será considerada como estação verão.

As Tabelas 4 e 5 apresentam os valores de média, desvio padrão e a relação interno/externo (I/E) para temperatura e umidade relativa do ar por ponto de coleta, para a etapa de coleta preliminar e efetiva dos dados, respectivamente. Quando se analisa os valores da relação interno/ externo (I/E), algumas informações interessantes podem ser observadas. Para a temperatura, os valores da relação são maiores no inverno, apenas o P1 apresentou valor menor que 1, significando que as temperaturas internas tendem a ser superiores às externas. No verão todos os valores da relação ficam abaixo de 1, indicando que os valores de temperatura são maiores no ambiente externo. Em relação a umidade relativa do ar, o comportamento se apresenta de maneira diferenciada, sendo que em ambas as estações os valores internos são superiores aos valores externos. No entanto, no inverno a relação I/E fica mais próxima de 1, significando que os valores internos e externos são muito similares. Já no verão, devido ao aumento das temperaturas, a umidade relativa apresenta uma amplitude maior, fazendo com que a relação I/E seja de até 1.23 (P1), devido ao fato da umidade relativa externa apresentar valores significativamente menores que a interna.

Tabela 4 - Valores de média, desvio padrão e relação interno/externo (I/E) de temperatura e umidade relativa do ar para cada ponto de amostragem na etapa de coleta preliminar dos dados (inverno)

\begin{tabular}{|c|c|c|c|c|c|c|c|c|c|c|}
\hline \multirow{3}{*}{ Pontos } & \multicolumn{4}{|c|}{ Temperatura $\left({ }^{\circ} \mathrm{C}\right)$} & \multirow{3}{*}{ Relação I/E } & \multicolumn{4}{|c|}{ Umidade relativa (\%) } & \multirow{3}{*}{ Relação I/E } \\
\hline & \multicolumn{2}{|c|}{ Média } & \multicolumn{2}{|c|}{ Desvio padrão } & & \multicolumn{2}{|c|}{ Média } & \multicolumn{2}{|c|}{ Desvio padrão } & \\
\hline & I & $\mathbf{E}$ & I & $\mathbf{E}$ & & I & $\mathbf{E}$ & I & $\mathbf{E}$ & \\
\hline $\mathrm{P} 1$ & 25,0 & 25,7 & 2,73 & 3,66 & 0,97 & 46,5 & 43,3 & 6,26 & 8,29 & 1,07 \\
\hline $\mathrm{P} 2$ & 24,2 & 24,2 & 2,04 & 2,27 & 1,00 & 53,5 & 52,8 & 5,53 & 6,24 & 1,01 \\
\hline P3 & 24,6 & 23,6 & 2,23 & 4,50 & 1,04 & 50,0 & 49,2 & 6,88 & 10,00 & 1,02 \\
\hline P4 & 22,6 & 22,4 & 3,65 & 3,98 & 1,01 & 53,6 & 53,8 & 14,45 & 15,36 & 1,00 \\
\hline
\end{tabular}

A Tabela 6 apresenta os valores de média, desvio padrão e da relação interno/externo (I/E) para a temperatura e a umidade relativa do ar para cada dia de coleta, realizadas a durante a estação inverno. A RE/ANVISA n ${ }^{\circ} 09 / 2003$ estabelece a faixa de valores de temperatura de $20^{\circ} \mathrm{C}$ a $22^{\circ} \mathrm{C}$ no inverno para manutenção do conforto térmico. Em um único dia (10/06) o valor médio ficou abaixo do estabelecido $\left(19.3^{\circ} \mathrm{C}\right)$, e apenas dois dias apresentaram média dentro do padrão 08/06 e 14/06, $\operatorname{com} 22^{\circ} \mathrm{C}$ e $21,7^{\circ} \mathrm{C}$, respectivamente. No restante dos dias amostrados, todos os valores médios ficaram acima do que estabelece a RE/ANVISA $n^{\circ} 09$, variando de $22,9^{\circ} \mathrm{C}$ à $27,3^{\circ} \mathrm{C}$. Dessa forma, em apenas $27,3 \%$ dos dias amostrados os valores médios foram adequados ao conforto térmico 
Tabela 5 - Valores de média, desvio padrão e relação interno/externo (I/E) de temperatura e umidade relativa do ar para cada ponto de amostragem na etapa de coleta efetiva dos dados (verão).

\begin{tabular}{|c|c|c|c|c|c|c|c|c|c|c|}
\hline \multirow{3}{*}{ Pontos } & \multicolumn{4}{|c|}{ Temperatura $\left({ }^{\circ} \mathrm{C}\right)$} & \multirow{3}{*}{ Relação I/E } & \multicolumn{4}{|c|}{ Umidade relativa (\%) } & \multirow{3}{*}{ Relação I/E } \\
\hline & \multicolumn{2}{|c|}{ Média } & \multicolumn{2}{|c|}{ Desvio padrão } & & \multicolumn{2}{|c|}{ Média } & \multicolumn{2}{|c|}{ Desvio padrão } & \\
\hline & I & $\mathbf{E}$ & I & $\overline{\mathbf{E}}$ & & I & $\mathbf{E}$ & I & $\mathbf{E}$ & \\
\hline $\mathrm{P} 1$ & 28,3 & 30,8 & 1,90 & 2,32 & 0,92 & 45,4 & 36,8 & 8,65 & 7,26 & 1,23 \\
\hline P2 & 27,7 & 29,2 & 3,23 & 4,01 & 0,95 & 43,2 & 39,2 & 9,34 & 10,05 & 1,10 \\
\hline P3 & 26,4 & 28,3 & 1,18 & 2,16 & 0,93 & 52,6 & 47,5 & 6,32 & 9,01 & 1,11 \\
\hline P4 & 27,9 & 28,8 & 1,56 & 2,85 & 0,97 & 56,6 & 54,2 & 9,33 & 12,95 & 1.04 \\
\hline
\end{tabular}

humano.

A umidade relativa do ar, também direcionada pela RE/ANVISA $n^{\circ} 09$, é considerada adequada quando seus valores no inverno ficam dentro da faixa de $35 \%$ à $65 \%$. Considerando os valores de inverno apresentados na Tabela 6, houve uma excessão (10/06) que apresentou um valor superior ao estabelecido $(66,2 \%)$, sendo que em todos os outros dias a média dos valores ficou em acordo com os padrões estabelecidos para o conforto térmico humano. Assim, em 90,9\% dos dias amostrados os valores permaneceram dentro do padrão estabelecido.

Tabela 6 - Valores de média, desvio padrão e relação interno/externo (I/E) para temperatura e umidade relativa do ar para cada dia da etapa de coleta preliminar de dados

\begin{tabular}{|c|c|c|c|c|c|c|c|c|c|c|c|}
\hline \multirow{3}{*}{ Pontos } & \multirow{3}{*}{ Data } & \multicolumn{4}{|c|}{ Temperatura $\left({ }^{\circ} \mathrm{C}\right)$} & \multirow{3}{*}{ Relação I/E } & \multicolumn{4}{|c|}{ Umidade relativa (\%) } & \multirow{3}{*}{ Relação I/E } \\
\hline & & \multicolumn{2}{|c|}{ Média } & \multicolumn{2}{|c|}{ Desvio padrão } & & \multicolumn{2}{|c|}{ Média } & \multicolumn{2}{|c|}{ Desvio padrão } & \\
\hline & & I & $\mathbf{E}$ & I & $\mathbf{E}$ & & $\mathbf{I}$ & $\mathbf{E}$ & $\mathbf{I}$ & $\mathbf{E}$ & \\
\hline \multirow[t]{3}{*}{$\mathrm{P} 1$} & $12 / 5$ & 27,3 & 27,7 & 1,02 & 1,24 & 0,99 & 50,3 & 47,1 & 4,01 & 4,23 & 1,07 \\
\hline & $14 / 6$ & 21,7 & 21,1 & 1,46 & 1,63 & 1,03 & 46,6 & 46,8 & 7,98 & 9,52 & 1,00 \\
\hline & $19 / 7$ & 26,0 & 28,2 & 1,49 & 2,11 & 0,92 & 43,0 & 36,3 & 3,63 & 4,73 & 1,18 \\
\hline \multirow[t]{3}{*}{$\mathrm{P} 2$} & $13 / 5$ & 24,7 & 24,8 & 1,63 & 1,75 & 0,99 & 57,0 & 56,5 & 4,68 & 5,36 & 1,01 \\
\hline & $7 / 6$ & 25,2 & 25,4 & 1,62 & 1,88 & 0,99 & 52,0 & 49,8 & 5,48 & 6,42 & 1,04 \\
\hline & $25 / 7$ & 22,9 & 22,3 & 2,07 & 1,92 & 1,02 & 51,7 & 52,2 & 4,85 & 5,02 & 0,99 \\
\hline \multirow[t]{3}{*}{ P3 } & $10 / 5$ & 26,0 & 25,8 & 1,30 & 1,46 & 1,01 & 55,4 & 53,7 & 3,88 & 5,39 & 1,03 \\
\hline & $8 / 6$ & 22,0 & 18,1 & 1,63 & 2,68 & 1,22 & 42,6 & 49,0 & 5,98 & 14,04 & 0,87 \\
\hline & $20 / 7$ & 25,7 & 27,0 & 0,86 & 1,78 & 0,95 & 52,3 & 45,0 & 1,45 & 6,20 & 1,16 \\
\hline \multirow[t]{2}{*}{$\mathrm{P} 4$} & $10 / 6$ & 19,3 & 18,9 & 1,23 & 1,67 & 1,02 & 66,2 & 66,4 & 7,10 & 8,95 & 1,00 \\
\hline & $21 / 7$ & 26,0 & 25,9 & 1,47 & 1,89 & 1,00 & 41,0 & 41,2 & 6,83 & 8,52 & 0,99 \\
\hline
\end{tabular}

Para a estação verão a Tabela 7 apresenta os valores de média, desvio padrão e da relação interno/externo (I/E) para a temperatura e a umidade relativa do ar, para cada dia de coleta. Nesta 
estação a RE/ANVISA n ${ }^{\circ}$ 09/2003 estabelece a faixa de valores entre $23^{\circ} \mathrm{C}$ e $26^{\circ} \mathrm{C}$, podendo operar com um máximo de $27^{\circ} \mathrm{C}$. Não foram obtidos valores abaixo do indicado e apenas três dias ficaram dentro do padrão estabelecido $(07 / 11,17 / 11$ e $18 / 11) \operatorname{com} 26^{\circ} \mathrm{C}, 25,1^{\circ} \mathrm{C}$ e $25,3^{\circ} \mathrm{C}$, respectivamente. Quatro valores fcaram na faixa de $26^{\circ} \mathrm{C}$ à $27^{\circ} \mathrm{C}$, e o restante ficou acima do limite estabelecido de $27^{\circ} \mathrm{C}$. Portanto, apenas $43,7 \%$ dos dias amostrados apresentaram valores adequados ao conforto humano.

A faixa de umidade relativa do ar considerada adequada para o verão é de $45 \%$ à $65 \%$, segundo RE/ANVISA nº 09/2003. Houve um único dia na etapa de coleta efetiva de dados que apresentou valor superior ao estabelecido, 69\% (22/11) e houveram dois dias em que a umidade relativa do ar ficou abaixo do recomendado, com 37,5\% e 32,1\% (24/11 e 25/11). Portanto, no restante dos $81,2 \%$ dos dias amostrados os valores médios permaneceram dentro do que é admitido para o conforto humano (Tabela 7).

Tabela 7 - Valores de média, desvio padrão e relação interno/externo (I/E) para temperatura e umidade relativa do ar para cada dia da etapa de coleta efetiva de dados

\begin{tabular}{|c|c|c|c|c|c|c|c|c|c|c|c|}
\hline \multirow{3}{*}{ Pontos } & \multirow{3}{*}{ Data } & \multicolumn{4}{|c|}{ Temperatura $\left({ }^{\circ} \mathrm{C}\right)$} & \multirow{3}{*}{ Relação I/E } & \multicolumn{4}{|c|}{ Umidade relativa(\%) } & \multirow{3}{*}{ Relação I/E } \\
\hline & & \multicolumn{2}{|c|}{ Média } & \multicolumn{2}{|c|}{ Desvia padrão } & & \multicolumn{2}{|c|}{ Média } & \multicolumn{2}{|c|}{ Desvio padrão } & \\
\hline & & I & $\mathbf{E}$ & I & $\mathbf{E}$ & & I & $\mathbf{E}$ & I & $\mathbf{E}$ & \\
\hline \multirow{4}{*}{$\mathrm{P} 1$} & $27 / 10$ & 27,7 & 31,2 & 1,78 & 1,32 & 0,89 & 53,07 & 41,8 & 10,20 & 7,58 & 1,27 \\
\hline & $28 / 10$ & 29,6 & 33,0 & 1,71 & 1,65 & 0,90 & 45,2 & 35,6 & 3,70 & 3,32 & 1,27 \\
\hline & $23 / 11$ & 27,3 & 28,9 & 1,67 & 2,26 & 0,95 & 45,8 & 38,3 & 6,36 & 8,17 & 1,20 \\
\hline & $24 / 11$ & 28,5 & 30,2 & 1,69 & 1,78 & 0,94 & 37,5 & 31,5 & 4,78 & 4,63 & 1,19 \\
\hline \multirow{4}{*}{$\mathrm{P} 2$} & $17 / 11$ & 25,1 & 25,7 & 2,54 & 2,95 & 0,98 & 50,3 & 47,7 & 7,48 & 8,75 & 1,05 \\
\hline & $18 / 11$ & 25,3 & 26,3 & 2,11 & 2,24 & 0,96 & 45,3 & 42,1 & 6,29 & 7,51 & 1,08 \\
\hline & $25 / 11$ & 29,9 & 32,2 & 1,63 & 1,87 & 0,93 & 32,1 & 27,3 & 2,56 & 3,04 & 1,18 \\
\hline & $26 / 11$ & 30,6 & 32,9 & 1,71 & 1,94 & 0,93 & 45,4 & 39,8 & 8,20 & 6,07 & 1,14 \\
\hline \multirow{4}{*}{ P3 } & $7 / 11$ & 26,0 & 27,0 & 0,78 & 1,39 & 0,96 & 52,5 & 47,3 & 2,67 & 4,70 & 1,11 \\
\hline & $8 / 11$ & 26,2 & 28,9 & 1,32 & 2,44 & 0,91 & 48,2 & 41,1 & 7,03 & 9,97 & 1,18 \\
\hline & $28 / 11$ & 26,3 & 28,1 & 1,04 & 1,95 & 0,94 & 55,8 & 52,4 & 6,93 & 9,90 & 1,07 \\
\hline & $29 / 11$ & 26,9 & 29,2 & 1,31 & 2,10 & 0,92 & 53,7 & 49,4 & 5,22 & 6,47 & 1,09 \\
\hline \multirow{4}{*}{ P4 } & $21 / 11$ & 28,0 & 30,0 & 1,87 & 3,14 & 0,93 & 49,5 & 43,8 & 8,95 & 10,80 & 1,13 \\
\hline & $22 / 11$ & 26,4 & 26,2 & 0,70 & 1,42 & 1,01 & 69,0 & 69,5 & 4,19 & 7,28 & 0,99 \\
\hline & $30 / 11$ & 28,5 & 29,7 & 1,10 & 2,18 & 0,96 & 53,4 & 50,6 & 4,86 & 8,22 & 1,05 \\
\hline & $1 / 12$ & 28,8 & 29,4 & 1,05 & 2,66 & 0,98 & 54,5 & 52,8 & 3,20 & 9,01 & 1,03 \\
\hline
\end{tabular}

Para os resultados apresentados dos níveis de umidade relativa do ar, a maior parte dos dias amostrados encontra-se em acordo com o que estabelece a RE/ANVISA nº9/2003, sendo em 
90,9\% dos casos do inverno e em $81,2 \%$ do verão. Para a temperatura, apenas $27,3 \%$ dos casos no inverno e 43,7\% no verão estão em acordo com a ANVISA. Observando os valores da relação I/E de temperatura, percebe-se que a variação entre os ambientes é pequena, estando a maior parte dos valores da relação próximo à 1, representando alta influência do ambiente externo no interno. Isto expressa um aspecto de desconforto térmico para os ocupantes dos locais amostrados, uma vez que toda a mudança ocorrida no ambiente externo será também sentida no ambiente interno (Tabela 6 e 7).

Ao longo do dia de trabalho as pessoas são expostas à variação das condições do ambiente. Dessa forma, apesar da média diária poder apresentar valores adequados, a mudança ao longo do dia pode expor os ocupantes desses locais à condições não adequadas. A Figura 13 apresenta o gráfico com o comportamento diário típico dos níveis de temperatura e umidade relativa do ar, do dia 28/10/2011 no P1. De acordo com o gráfico temperatura e umidade relativa do ar são inversamente proporcionais, sendo que esse foi o comportamento encontrado para a maioria dos dias amostrados em que não houve ocorrência de precipitação. A variação no ambiente externo é superior à variação no ambiente interno tanto para a umidade relativa do ar como para a temperatura.

Como já mencionado, a RE/ANVISA nº 09/2003 é uma norma criada para ambientes climatizados, o estabelecimento de seus padrões leva em consideração vários aspectos, como por exemplo, o gasto de energia. Caso contrário, se pensássemos apenas no conforto térmico humano, poderiam ser estabelecidos valores ideais de temperatura e umidade relativa do ar iguais durante todo o ano. Nos ambientes estudados neste trabalho, a maior parte dos dias em que a temperatura estava em acordo com os padrões estavam contidos na estação verão. No entanto, os valores não adequados do inverno não foram decorrência de temperaturas muito baixas nesta estação. Pelo contrário, um único valor $\left(19,3^{\circ} \mathrm{C}\right)$ foi menor que o estabelecido pela ANVISA, todos os outros não estavam em acordo por apresentarem valores maiores que o padrão. Isto ocorre porque o inverno em São Carlos não é muito rigoroso, não apresenta temperaturas muito baixas como no sul do país, por exemplo. 
Figura 13 - Comportamento diário típico de temperatura e umidade relativa do ar no P1 - (28/10/2011)

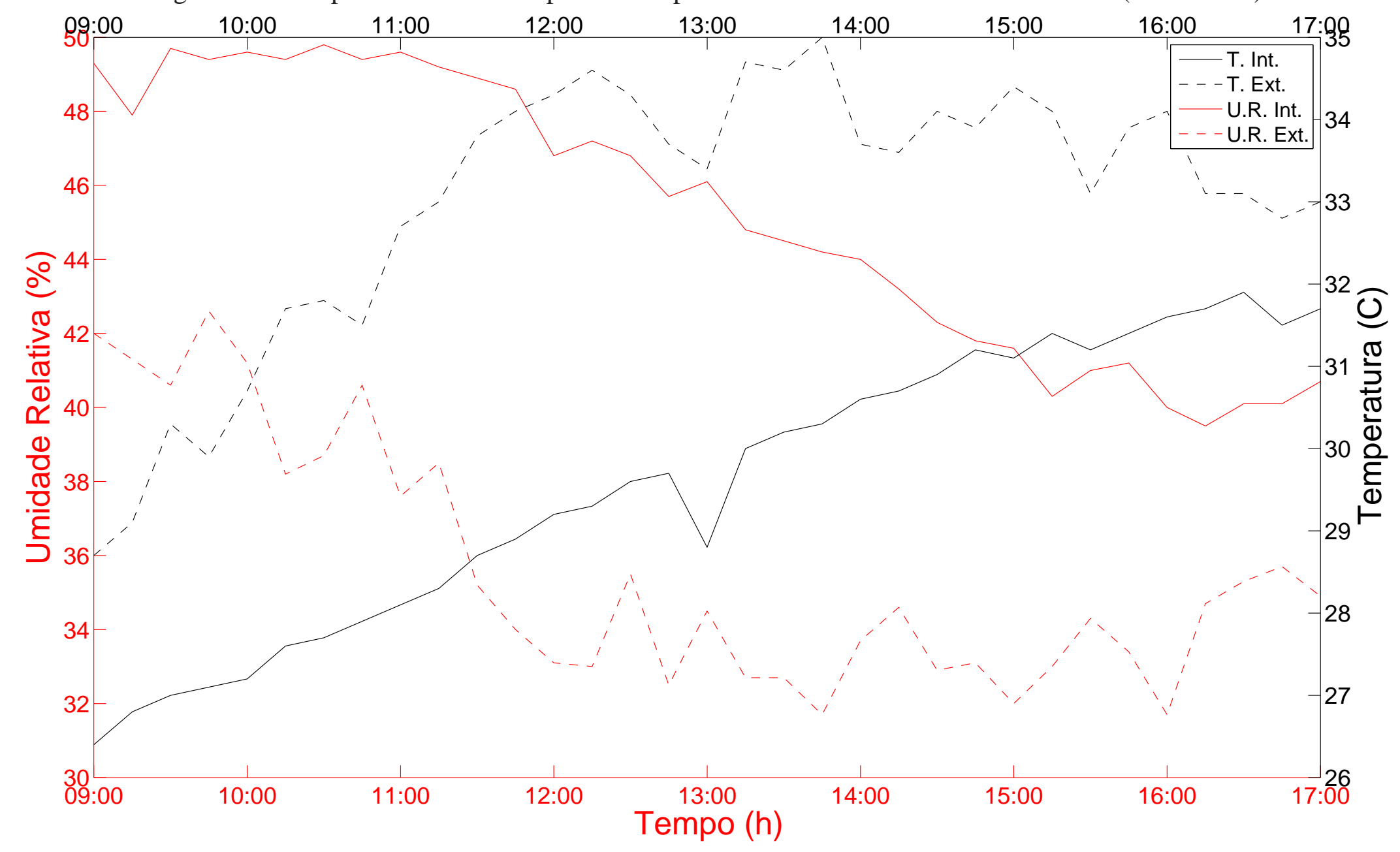


A Figura 14 apresenta um gráfico com os valores médios dos meses junho, julho e novembro (nos quais as coletas para este trabalho foram mais significativas) para os últimos 6 anos, os dados foram obtidos da Estação Meteorológica da EMBRAPRA Pecuária Sudeste (EMBRAPA, 2012).

Figura 14 - Temperaturas médias dos meses de junho, julho e novembro dos últimos 6 anos para a cidade de São Carlos

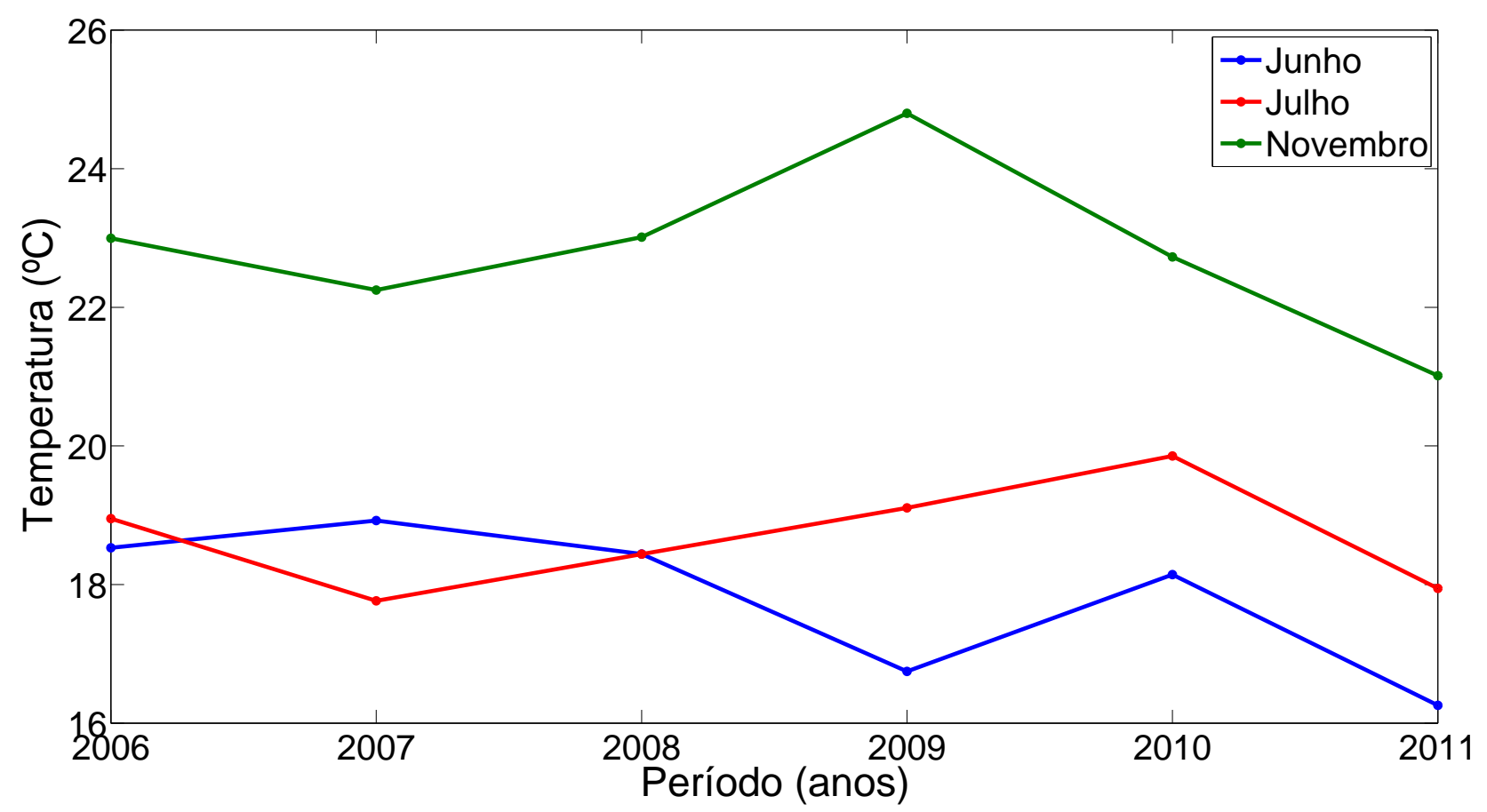

Fonte: (EMBRAPA, 2012)

Nenhuma média mensal ficou abaixo $\operatorname{dos} 15^{\circ} \mathrm{C}$, sendo que a maior parte dos valores da estação fria estão na faixa de $18^{\circ} \mathrm{C}$ à $20^{\circ} \mathrm{C}$, no entanto, esses números são de médias compostas com valores noturnos, diferentemente das médias deste trabalho que são apenas do período diurno. Se considerarmos o valor mínimo do inverno e o valor máximo do verão da RE/ANVISA n09/2003 como uma faixa adequada, com excessão do dia 10/06 em que foi obtido $19,3^{\circ} \mathrm{C}$, todos os outros dias ficariam dentro dessa faixa de valores, sendo assim, os valores apresentados para a estação inverno não caracterizam desconforto térmico aos ocupantes dos ambientes amostrados. 


\subsection{1 Índice de Calor (HI)}

Como descrito na metodologia o índice de calor ou HI é uma maneira simplificada de definir a sensação de conforto térmico em um ambiente. Para elaboração do índice, é necessário realizar apenas o monitoramento da temperatura e da umidade relativa do ar, já que para os outros parâmetros utilizados na avaliação do conforto térmico são assumidos valores. A Tabela 8 apresenta os valores do HI (Heat Index) e os valores utilizados para elaboração do índice.

Tabela 8 - Índice de calor - HI

\begin{tabular}{ccccc}
\hline Ponto de coleta & Data & Temperatura $\left({ }^{(} \mathbf{F}\right)$ & Umidade relativa (\%) & HI \\
\hline \multirow{3}{*}{ P1 } & $12 / 05$ & 81,2 & 50,3 & 81,9 \\
& $14 / 06$ & 71,1 & 46,6 & 77,0 \\
& $19 / 07$ & 78,8 & 43,0 & 79,4 \\
\hline \multirow{3}{*}{ P2 } & $13 / 05$ & 76,4 & 57,0 & 78,3 \\
& $7 / 06$ & 77,4 & 52,0 & 78,9 \\
& $25 / 07$ & 73,1 & 51,7 & 77,0 \\
\hline \multirow{3}{*}{ P3 } & $10 / 05$ & 78,8 & 55,4 & 80,2 \\
& $8 / 06$ & 71,7 & 42,6 & 77,0 \\
& $20 / 07$ & 78,3 & 52,3 & 79,5 \\
\hline \multirow{2}{*}{ P4 } & $10 / 06$ & 66,7 & 66,2 & 75,1 \\
& $21 / 07$ & 78,8 & 41,0 & 79,2 \\
\hline \multirow{4}{*}{ P1 } & $27 / 10$ & 81,8 & 53,07 & 83,0 \\
& $28 / 10$ & 85,2 & 45,2 & 85,6 \\
& $23 / 11$ & 81,2 & 45,8 & 81,5 \\
& $24 / 11$ & 83,2 & 37,5 & 82,2 \\
\hline \multirow{4}{*}{ P2 } & $25 / 11$ & 85,9 & 32,1 & 83,9 \\
& $26 / 11$ & 87,1 & 45,4 & 88,1 \\
& $17 / 11$ & 77,2 & 50,3 & 78,7 \\
& $18 / 11$ & 77,6 & 45,3 & 78,8 \\
\hline \multirow{3}{*}{ P3 } & $07 / 11$ & 78,8 & 52,5 & 80,0 \\
& $08 / 11$ & 79,2 & 48,2 & 80,0 \\
& $28 / 11$ & 79,4 & 55,8 & 80,7 \\
& $29 / 11$ & 80,5 & 53,7 & 81,7 \\
\hline \multirow{3}{*}{ P4 } & $30 / 11$ & 83,4 & 53,4 & 85,0 \\
& $01 / 12$ & 83,8 & 54,5 & 85,9 \\
& $21 / 11$ & 82,4 & 49,5 & 83,1 \\
& $22 / 11$ & 79,5 & 69,0 & 82,0 \\
\hline
\end{tabular}

A Figura 15 apresenta os valores encontrados do índice, como também a linha que representa o limite da sensação de conforto térmico. É possível observar que grande parte dos valores se en- 
contra acima do limite determinado, em 59,3\% dos casos, significando que na maior parte dos dias monitorados, os trabalhadores ficaram expostos à sensação de desconforto térmico. Comparando a número de dias monitorados que apresentam acordo com o HI e o número de dias que apresentam acordo com a RE/ANVISA n ${ }^{\circ}$ 09/2.003, observa-se que o índice mantém um maior número dos dias monitorados dentro dos limites estabelecidos para a manutenção do conforto térmico. Esta diferenciação entre as duas formas de determinação pode ser devido à ANVISA estabelecer uma comparação separada entre umidade relativa do ar e temperatura, já o valor do índice é uma junção dos dois fatores.

\subsection{Poluição sonora}

Os níveis de poluição sonora foram coletados de maneira simultânea nos ambientes interno e externo. A Figura 16 apresenta um gráfico do comportamento típico ao longo de um dia de coleta (24/11/2011). Neste dia, a medição foi realizada no P1, sendo a média do ambiente externo de $66,3 \mathrm{~dB}(\mathrm{~A})$ e do ambiente interno de 58,3 dB(A). A variação que ocorreu no ambiente externo apresentou maior amplitude e atingiu picos mais elevados de ruído. As linhas contínuas do gráfico representam o limite da NBR 10151/2000, que determina o nível máximo de 60 dB(A) para o ambiente externo e de $50 \mathrm{~dB}(\mathrm{~A})$ para o ambiente interno, em áreas mistas com vocação comercial e administrativa. Como pode ser observado no gráfico, ao longo do dia em ambos os ambientes toda a variação que ocorreu foi acima dos limites estabelecidos pela NBR 10151/2000. 
Figura 15 - Índice de calor - HI

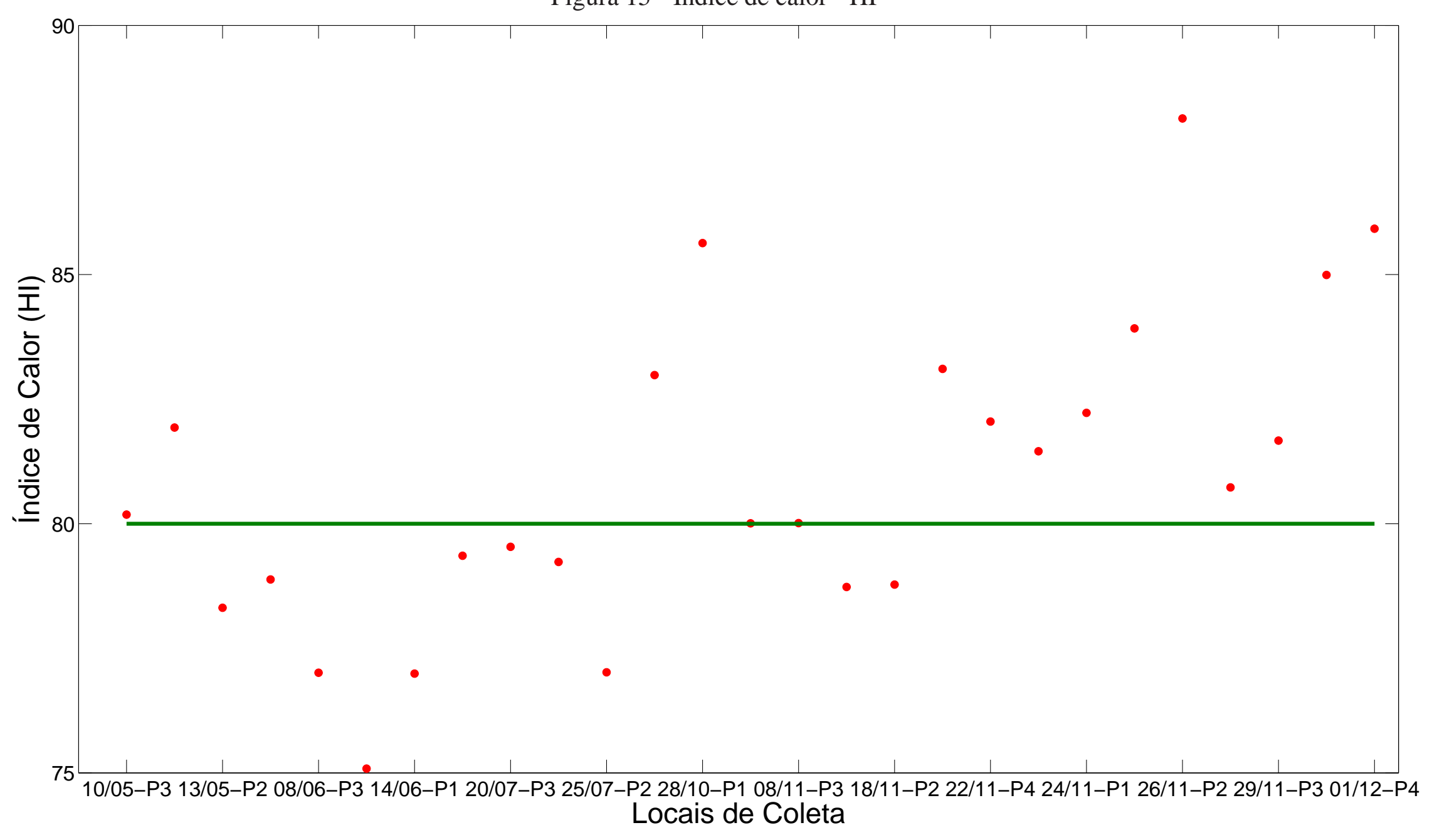


A Figura 17 apresenta os níveis médios de ruído nos ambientes interno e externo para cada ponto de coleta. É possível visualizar que nos 4 pontos os níveis médios de poluição sonora se apresentaram superiores no ambiente externo, isto é atribuído às movimentações regulares de um centro de cidade, circulação de veículos, carros de som, grande volume de pessoas circulando nas calçadas e sistemas de som das lojas. No P1 foi encontrado o valor médio de poluição sonora externo mais elevado, este ponto amostral estava localizado na via de maior movimento da cidade, com grande tráfego de veículos, incluindo todos os ônibus de transporte urbano coletivo que circulam no sentido Sul- Norte de São Carlos. Para o poluição sonora interna, o P4 apresentou o maior valor, isto ocorreu por causa da localização do ponto amostral no interior do ambiente. O P4 era situado mais próximo à saída do que ao interior da loja, por isso também apresenta a menor variação entre os valores médios de poluição sonora interno e externo. Os outros 3 pontos internos eram próximos aos locais de pagamento das lojas, ou seja, aos caixas. Dessa forma esses pontos ficavam mais no interior das lojas, sofrendo uma influência externa menor que o P4. A Tabela 9 apresenta os valores médios com o desvio padrão e a relação interno/externo (I/E)para cada ponto. 
Figura 16 - Gráfico do comportamento de um dia típico da poluição sonora no P1 (24/11/2011)

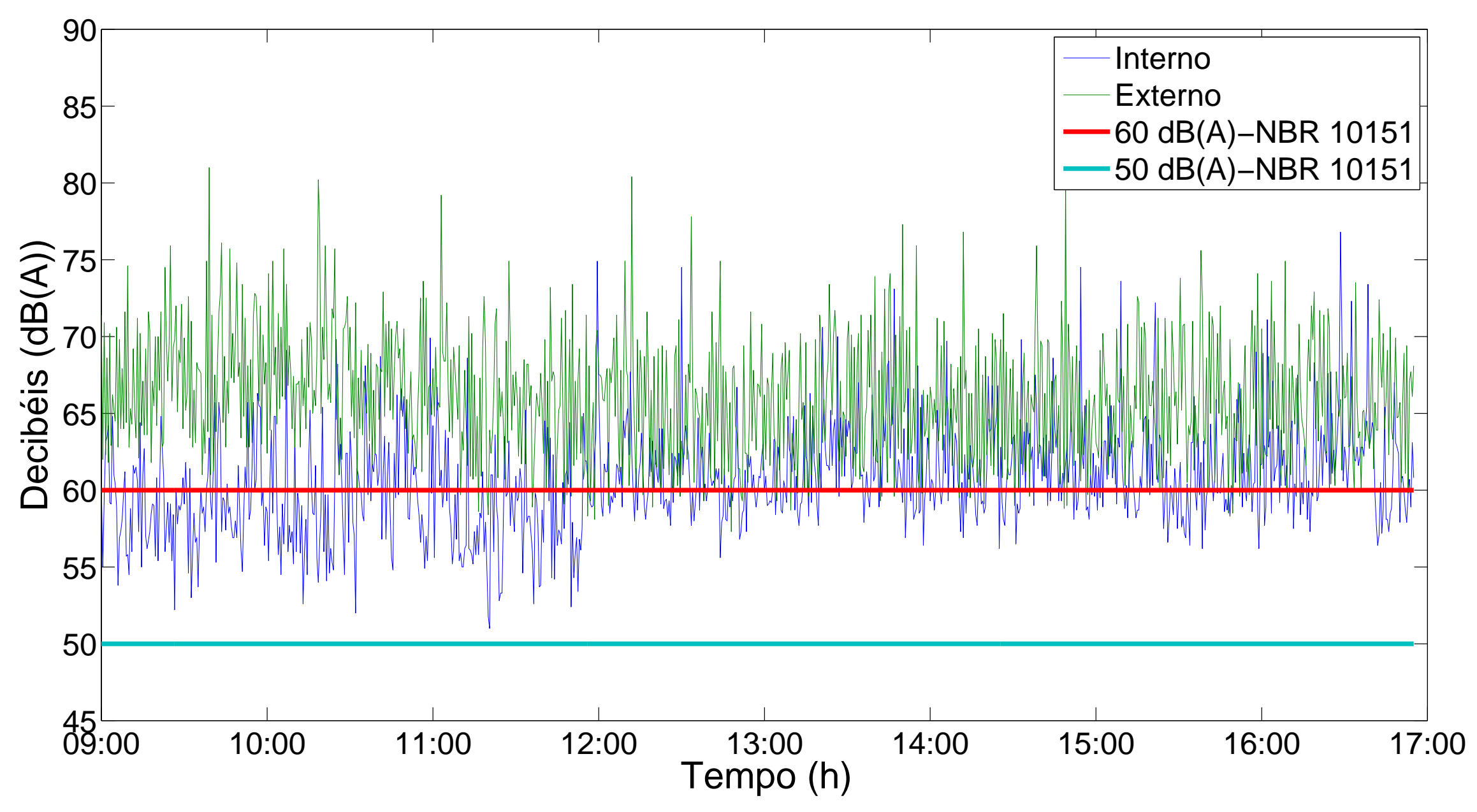


Figura 17 - Valores médios de poluição sonora por ponto de coleta

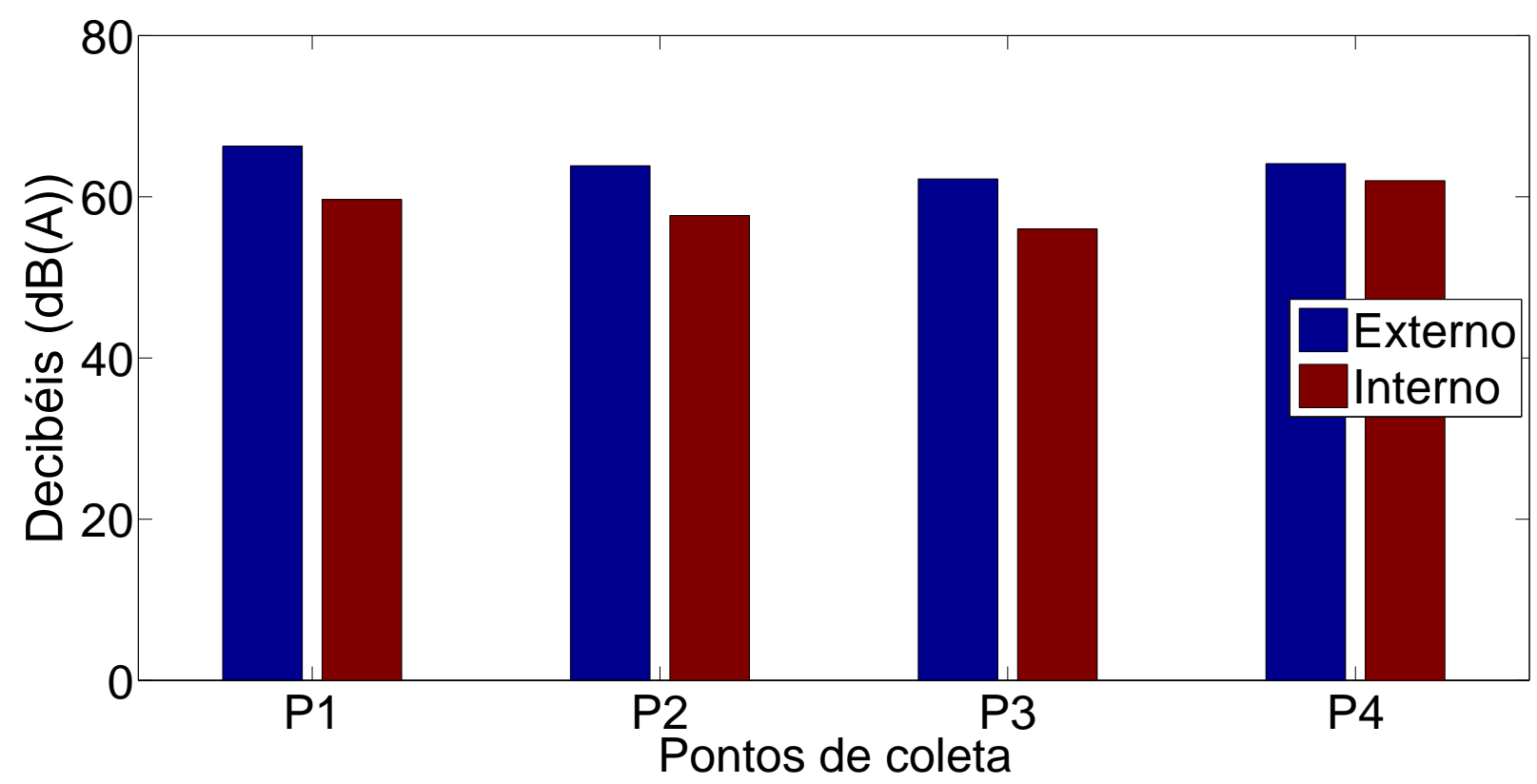

Tabela 9 - Valores de média e desvio padrão de poluição sonora por ponto de coleta

\begin{tabular}{|c|c|c|c|c|c|}
\hline \multirow{2}{*}{ Pontos de coleta } & \multicolumn{2}{|c|}{ Média $(\mathrm{dB}(\mathrm{A}))$} & \multicolumn{2}{|c|}{ Desvio Padrão } & \multirow[b]{2}{*}{ Índice I/E } \\
\hline & I & $\mathrm{E}$ & I & $\mathrm{E}$ & \\
\hline $\mathrm{P} 1$ & 58,8 & 66,2 & 4,29 & 4,60 & 0,89 \\
\hline P2 & 57,3 & 63,6 & 3,65 & 4,31 & 0,90 \\
\hline P3 & 55,0 & 62,9 & 5,05 & 3,13 & 0,87 \\
\hline P4 & 61,3 & 64,0 & 4,11 & 5,27 & 0,96 \\
\hline
\end{tabular}

$\mathrm{I}=$ Interno; E=Externo

A Tabela 5.2 apresenta os valores de média, desvio padrão e o índice I/E para todos os dias de coleta. Em nenhum dos dias amostrados os valores internos e externos de poluição sonora apresentaram acordo com a NBR 10151/2000. Para o ambiente externi o menor valor médio encontrado foi de $61 \mathrm{~dB}(\mathrm{~A})$ no P2 (17/11/2011) e o maior valor médio de 66,8 no P1 (28/10/2011), sendo que o limite da NBR é de $60 \mathrm{~dB}(\mathrm{~A})$. Para o ambiente interno, o menor valor médio foi de 53,9 dB(A) no P3 (20/07/2011), e a maior média de 63,6 dB(A) no P4 (01/12/2011), sendo o limite de $50 \mathrm{~dB}(\mathrm{~A})$. A relação $\mathrm{I} / \mathrm{E}$ variou de 0,83 à 0,99 , portanto em nenhum dia a média diária interna superou a externa. O P4 apresentou os valores da relação mais próximos a 1, indicando que neste ponto houveram as menores diferenças entre os níveis de poluição sonora interno e externo. Como já mencionado anteriormente, isto ocorre devido à localização do ponto amostral interno, que sofre uma influência 
grande da poluição sonora externa. O P1 apresentou os valores mais baixos da relação I/E, indicando que, neste ponto estão presentes as maiores diferenças entre os níveis de poluição sonora interno e externo. Neste caso, isto ocorre porque os valores externos deste ponto também são os mais elevados dos 4 pontos de coleta.

Tabela 10 - Valores de média e desvio padrão da poluição sonora para cada dia de coleta

\begin{tabular}{ccccccc}
\hline \multirow{2}{*}{ Ponto de coleta } & \multirow{2}{*}{ Data da coleta } & \multicolumn{4}{c}{ Média $(\mathrm{dB}(\mathrm{A}))$} & \multicolumn{3}{c}{ Desvio Padrão } & \multirow{2}{*}{ Índice I/E } \\
\cline { 2 - 5 } & & $\mathrm{I}$ & $\mathrm{E}$ & $\mathrm{I}$ & $\mathrm{E}$ & \\
\hline \multirow{3}{*}{ P1 } & $19 / 07$ & 54,7 & 65,8 & 4,86 & 5,31 & 0,83 \\
& $27 / 10$ & 58,3 & 66,3 & 3,88 & 4,85 & 0,88 \\
& $28 / 10$ & 59,8 & 66,8 & 2,95 & 4,22 & 0,89 \\
& $23 / 11$ & 59,8 & 65,8 & 3,62 & 4,48 & 0,91 \\
& $24 / 11$ & 60,7 & 66,1 & 3,41 & 4,02 & 0,92 \\
\hline \multirow{3}{*}{ P2 } & $25 / 07$ & 56,3 & 61,3 & 3,59 & 3,50 & 0,92 \\
& $17 / 11$ & 56,3 & 61,0 & 3,51 & 3,57 & 0,92 \\
& $18 / 11$ & 56,9 & 63,4 & 3,39 & 4,17 & 0,90 \\
& $25 / 11$ & 59,8 & 65,0 & 2,78 & 3,59 & 0,92 \\
P3 & $26 / 11$ & - & 66,0 & - & 4,23 & - \\
\hline \multirow{3}{*}{ P4 } & $20 / 07$ & 53,9 & 64,4 & 5,58 & 2,88 & 0,84 \\
& $28 / 11$ & - & 62,7 & - & 3,10 & - \\
& $29 / 11$ & 56,0 & 61,7 & 4,30 & 2,79 & 0,91 \\
\hline & $21 / 07$ & 59,0 & 62,8 & 4,65 & 6,07 & 0,94 \\
& $21 / 11$ & 59,7 & 63,6 & 3,83 & 5,20 & 0,94 \\
& $22 / 11$ & 62,7 & 63,4 & 2,93 & 5,23 & 0,99 \\
& $30 / 11$ & - & 64,0 & - & 5,30 & - \\
& $01 / 12$ & 63,6 & 65,4 & 2,99 & 4,76 & 0,97 \\
\hline
\end{tabular}

Como mostrado, o maior valor médio encontrado para o ambiente externo foi de $66,8 \mathrm{~dB}(\mathrm{~A})$ e para o interno de 63,6 dB(A). No entanto, ao longo do dia de medição ocorrerram valores muito mais elevados, chegando proximo à $85 \mathrm{~dB}(\mathrm{~A})$ no ambiente interno e a $90 \mathrm{~dB}(\mathrm{~A})$ no ambiente externo. Esses valores que podem ser chamados de outliers, foram devido principalmente à passagem de veículos mais barulhentos, buzinas, carros com volume de som alto, etc. As Figuras 18 e 19 apresentam os gráficos de boxplot dos níveis de poluição sonora interno e externo, respectivamente. $\mathrm{O}$ gráfico de boxplot apresenta uma sensibilidade em capturar e apresentar os valores de outliers, e os valores de mediana são representados pela linha no centro da caixa. No caso deste trabalho, os valores de outliers devem ser considerados, já que não são valores errôneos e sim picos de ruído. 


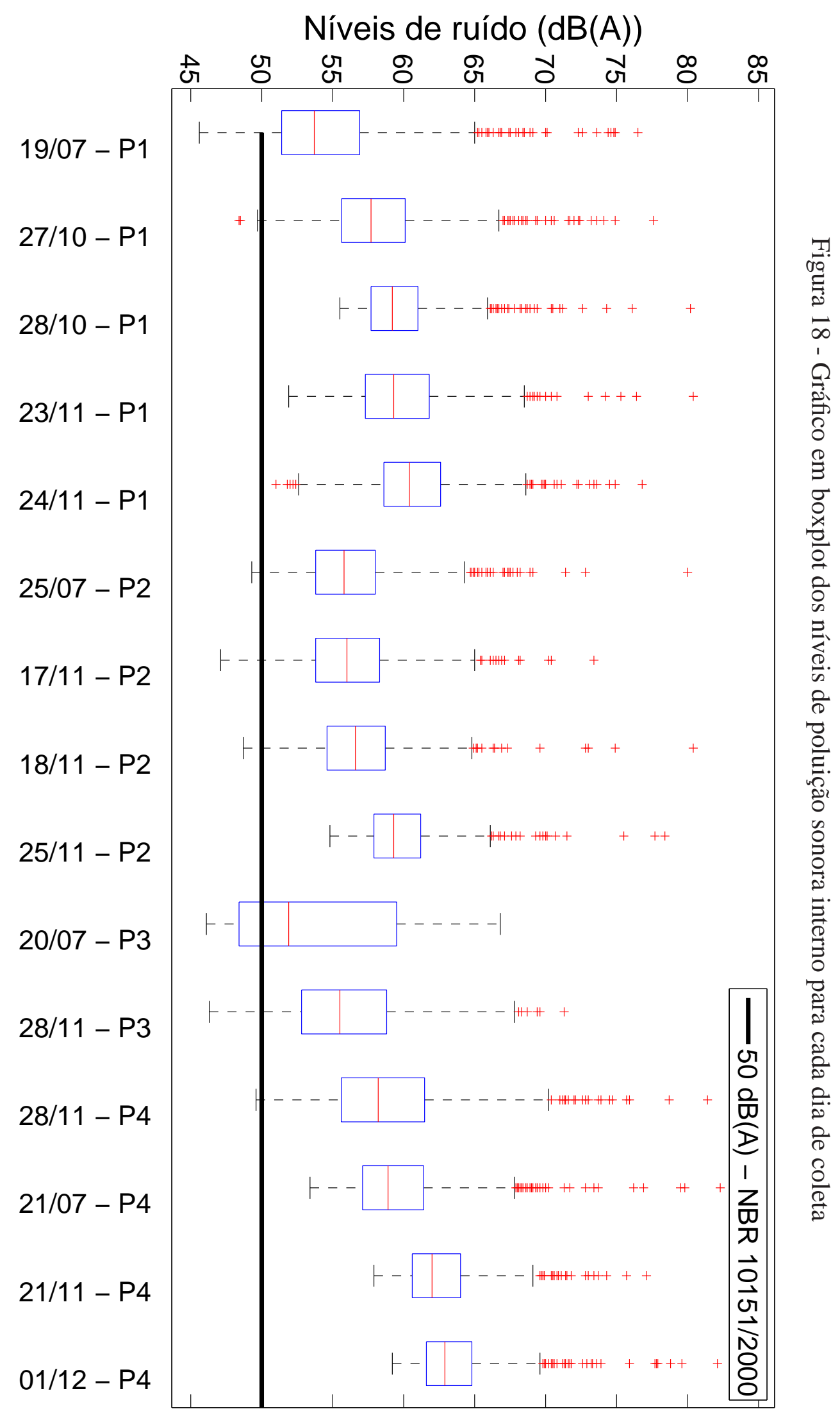




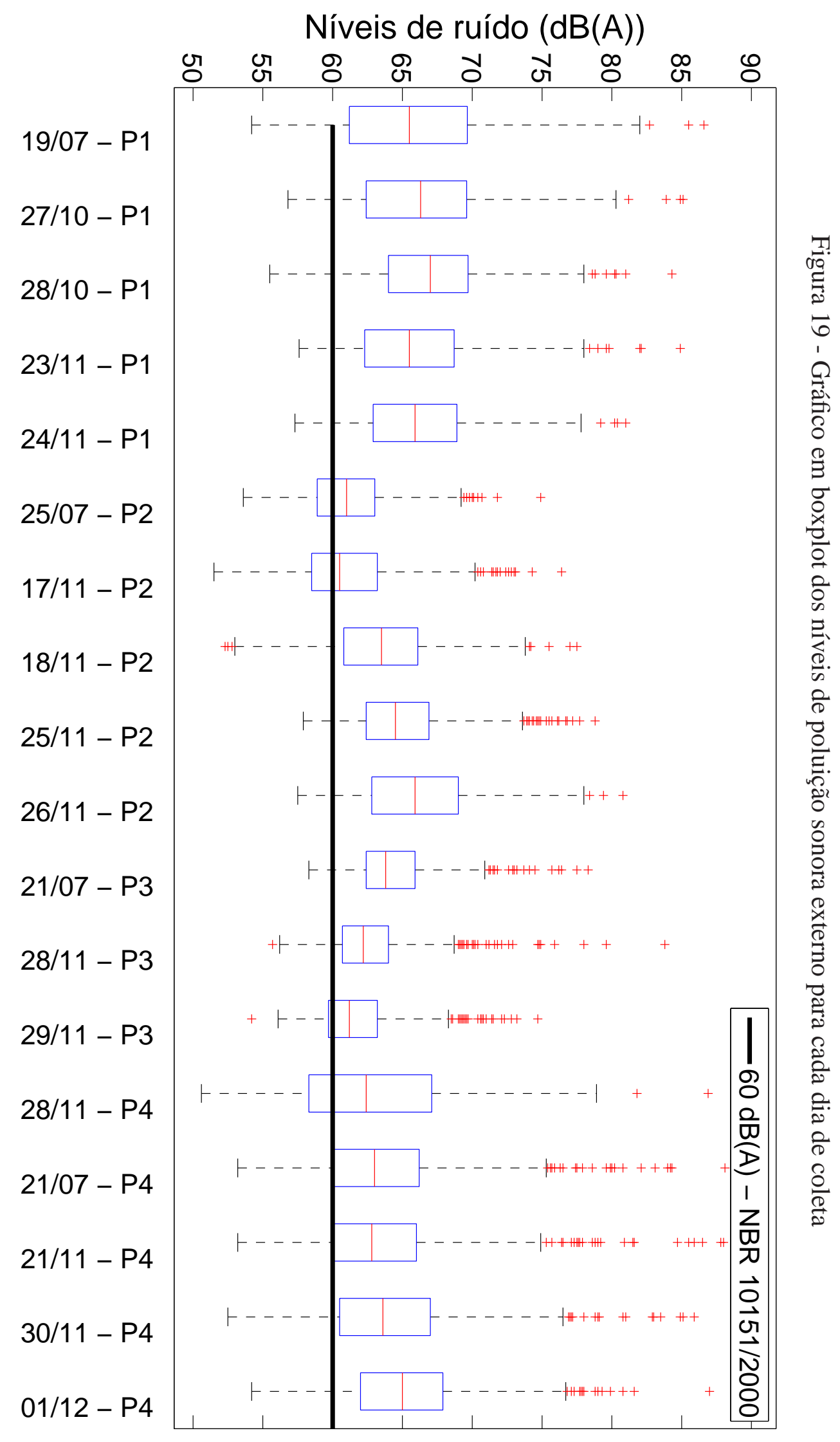


A Lei municipal n ${ }^{\circ}$ 14.415/08 norteia alguns parâmetros acerca da poluição sonora na cidade de São Carlos. Estabelece, por exemplo, a proibição de alto-falantes expostos no exterior dos estabelecimentos comerciais e exige que os carros de som trabalhem com alvará de funcionamento. Em relação aos limites máximos dos níveis sonoros, a Lei n ${ }^{\circ}$ 14.415/08 aborda em seu texto que utiliza os mesmos parâmetros da NBR 10151. No entanto, ela faz uso de uma versão antiga da norma, a NBR 10.151/1987, que é menos rigorosa que a versão de 2000. Para a área de estudo deste trabalho o limite municipal é de $70 \mathrm{~dB}(\mathrm{~A})$, portanto, em nenhum dos dias amostrados a média ultrapassou este valor. Optou-se pela utilização da NBR 10.151/2000 para fins de comparação dos valores obtidos neste trabalho, visto que seus parâmetros são mais atuais. Apesar de o município possuir uma lei que estabelece limites para a poluição sonora, ainda não pratica penalizações para os casos que não atendem os padrões. Há especulações entre os comerciantes que este é um assunto em ínicio de discussões. Por conta disso, enquanto as amostragens eram realizadas no centro da cidade, as pessoas aproximavam para perguntar o que era e qual o objetivo da pesquisa. Além disso, muitas questionavam se era da prefeitura, e muitas outras (as que costumam frequentar o centro de São Carlos diariamente) indagavam sobre o aspecto de que nos dias em que as amostragens estavam sendo realizadas, os comerciantes diminuiam o volume ou desligavam seus sistemas de som. Por isso, é possível que os níveis de ruído de São Carlos apresentem valores maiores dos que os encontrados neste trabalho. 


\subsection{Material particulado}

A coleta de dados de material particulado foi realizada por meio da utilização dos monitores portáteis e por meio da filtração. Com os monitores foi possível apresentar o comportamento do material particulado ao longo do dia de amostragem. Da filtração se obteve os resultados de concentração pela gravimetria e foi realizada a análise química dos componentes presentes na amostra.

\subsubsection{Resultado dos Monitores Portáteis}

A coleta de material particulado com os monitores portáteis foi realizada utilizando-se dois diferentes monitores, o EVM-7 e o pDR-1500. O EVM-7 foi utilizado para monitoramento interno e externo de $\mathrm{MP}_{2,5}$, na etapa de coleta preliminar de dados, e para monitamento de $\mathrm{MP}_{10}$ e $\mathrm{MP}_{2,5}$ externos na etapa de coleta efetiva de dados. O pDR-1.500 foi utilizado para monitoramento de $\mathrm{MP}_{10}$ e $\mathrm{MP}_{2,5}$ no ambiente interno, apenas na etapa de coleta efetiva dos dados. A Figura 20 apresenta o gráfico do comportamento de um dia do material particulado interno e externo do dia 25/11/2.011 no P2. Por conta do uso de dois equipamentos diferentes, o gráfico apresenta o comportamento da concentração do material particulado sem levar em consideração os valores de concentração obtidos. Com esse objetivo, o gráfico foi construído com os valores obtidos de concentração de cada ambiente divididos pelo maior valor de concentração daquele dia.

A Tabela 11 apresenta os valores médios, o desvio padrão e a relação interno/externo (I/E) para cada dia de coleta. Observando a Tabela 11, percebe-se claramente que há dias em que os valores encontrados não são coerentes, especialmente os valores do ambiente externo, coletados com o EVM-7, que apresentou valores de desvio padrão muito altos. Os valores da relação I/E também não são satisfatórios, pois os valores da relação apresentados não condizem com o tipo de ambiente monitorado. A Figura 21 apresenta o gráfico de boxplot das coleta de $\mathrm{MP}_{2,5}$ realizadas durante a etapa de coleta preliminar de dados. 
Figura 20 - Comportamento do material particulado ao longo de um dia de coleta no P2 - (25/11/2.011)

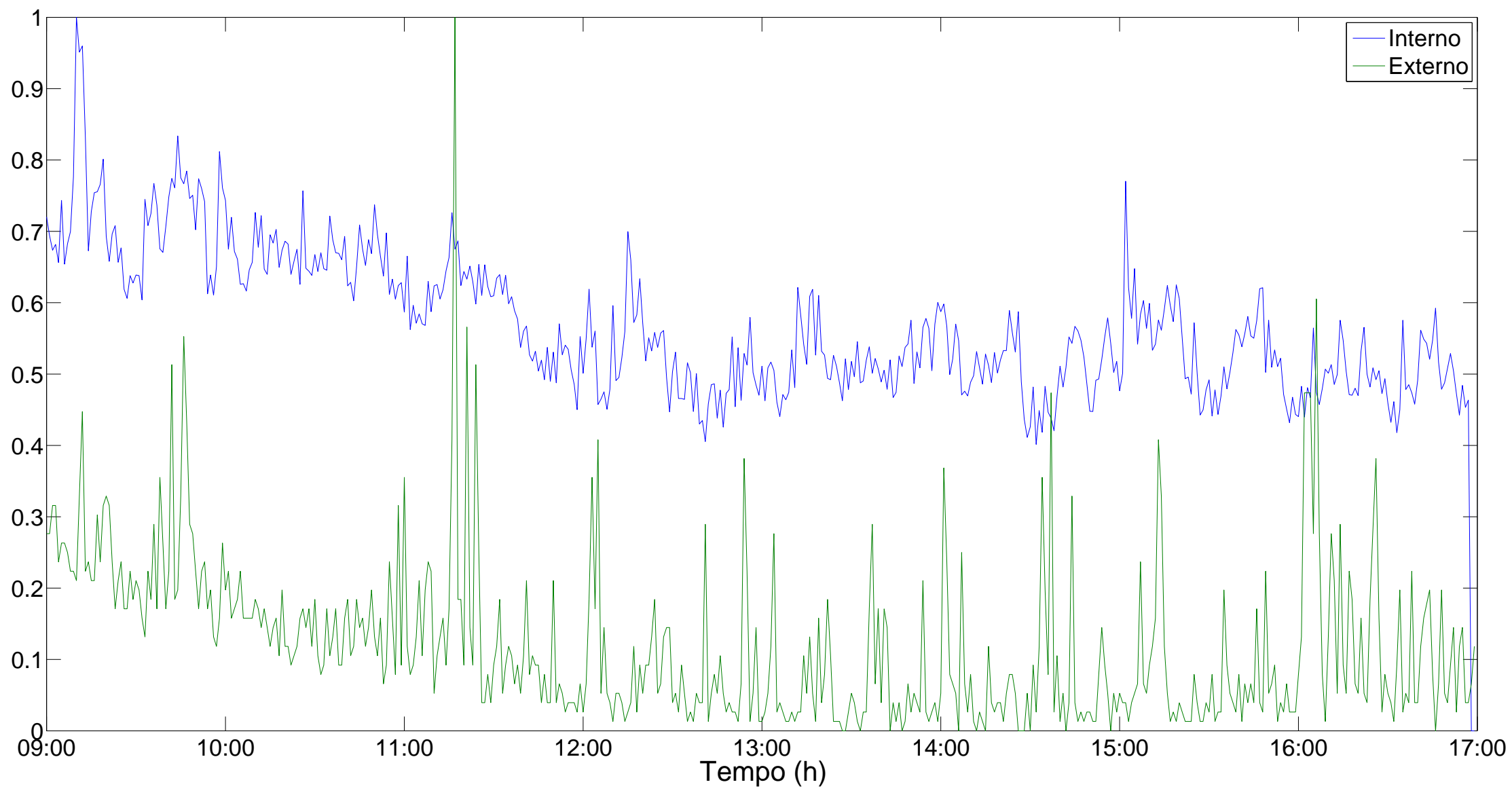


Tabela 11 - Médias e desvio padrão do material particulado coletado com os monitores portáteis

\begin{tabular}{|c|c|c|c|c|c|c|c|}
\hline \multirow{2}{*}{ Ponto de coleta } & \multirow{2}{*}{ Data } & \multirow{2}{*}{ Fração } & \multicolumn{2}{|c|}{ Média $\left(\mu \mathrm{g} / \mathrm{m}^{3}\right)$} & \multicolumn{2}{|c|}{ Desvio padrão } & \multirow{2}{*}{ Relação I/E } \\
\hline & & & Interno & Externo & Interno & Externo & \\
\hline \multirow{6}{*}{$\mathrm{P} 1$} & $14 / 06$ & $\mathrm{MP}_{2,5}$ & 44,1 & - & 12,7 & - & - \\
\hline & $19 / 07$ & $\mathrm{MP}_{2,5}$ & - & 3,5 & - & 3,3 & - \\
\hline & $27 / 10$ & $\mathrm{MP}_{10}$ & 12,9 & 23,4 & 3,8 & 10,8 & 0,55 \\
\hline & $28 / 10$ & $\mathrm{MP}_{2,5}$ & 14,1 & 13,1 & 2,9 & 4,0 & 1,08 \\
\hline & $23 / 11$ & $\mathrm{MP}_{10}$ & 8,3 & 5,6 & 2,3 & 9,4 & 1,48 \\
\hline & $24 / 11$ & $\mathrm{MP}_{2,5}$ & 5,9 & 3,1 & 3,8 & 6,5 & 1,92 \\
\hline \multirow{6}{*}{$\mathrm{P} 2$} & $07 / 06$ & MP & 17,1 & - & 5,4 & - & - \\
\hline & $25 / 07$ & $\mathrm{MP}_{2,5}$ & - & 5,7 & - & 6,3 & - \\
\hline & $17 / 11$ & $\mathrm{MP}_{10}$ & 11,6 & 15,4 & 2,8 & 13,2 & 0,75 \\
\hline & $18 / 11$ & $\mathrm{MP}_{2,5}$ & 9,4 & 9,2 & 2,0 & 5,8 & 1,02 \\
\hline & $25 / 11$ & $\mathrm{MP}_{10}$ & 12,7 & 9,9 & 2,2 & 12,1 & 1,28 \\
\hline & $26 / 11$ & $\mathrm{MP}_{2,5}$ & 7,6 & 3,2 & 2,0 & 9,9 & 2,40 \\
\hline \multirow{6}{*}{ P3 } & $8 / 6$ & MP & 3,0 & - & 2,2 & - & - \\
\hline & $20 / 07$ & $\mathrm{MP}_{2,5}$ & - & 12,0 & - & 4,9 & - \\
\hline & $07 / 11$ & $\mathrm{MP}_{10}$ & 18,4 & 24,8 & 3,0 & 8,2 & 0,74 \\
\hline & $08 / 11$ & $\mathrm{MP}_{2,5}$ & 15,8 & 13,1 & 3,4 & 5,9 & 1,20 \\
\hline & $28 / 11$ & $\mathrm{MP}_{10}$ & 5,3 & 13,1 & 3,6 & 4,0 & 0,40 \\
\hline & $29 / 11$ & $\mathrm{MP}_{2,5}$ & 11,7 & 0,9 & 3,4 & 1,2 & 12,54 \\
\hline \multirow{6}{*}{ P4 } & $10 / 6$ & MP & 11,1 & - & 8,3 & - & - \\
\hline & $21 / 07$ & $\mathrm{MP}_{2,5}$ & - & 9,0 & - & 6,6 & - \\
\hline & $21 / 11$ & $\mathrm{MP}_{10}$ & 11,4 & 10,4 & 2,3 & 8,0 & 1,10 \\
\hline & $22 / 11$ & $\mathrm{MP}_{2,5}$ & 14,5 & 14,0 & 5,3 & 11,8 & 1,04 \\
\hline & $30 / 11$ & $\mathrm{MP}_{10}$ & 5,4 & 6,6 & 1,7 & 7,3 & 0,82 \\
\hline & $01 / 12$ & $\mathrm{MP}_{2,5}$ & 8,6 & 6,9 & 3,0 & 10,0 & 1,25 \\
\hline
\end{tabular}

As Figuras 22 e 23 apresentam os gráficos de boxplot da concentração de $\mathrm{MP}_{2,5}$ interno e externo, respectivamente, e as Figuras 24 e 25 apresentam os gráficos de boxplot da concentração interna e externa de $\mathrm{MP}_{10}$, respectivamente, da etapa de coleta efetiva de dados. Esse tipo de gráfico apresenta de maneira mais clara a distribuição dos valores coletados. Os dados coletados com o EVM-7 apresentam uma maior variação do que os valores do pDR-1.500, atingindo valores de até $200 \mu \mathrm{g} / \mathrm{m}^{3}$. 
Figura 21 - Gráfico de boxplot das coletas de $\mathrm{MP}_{2,5}$ da etapa de coleta preliminar dos dados com o EVM-7

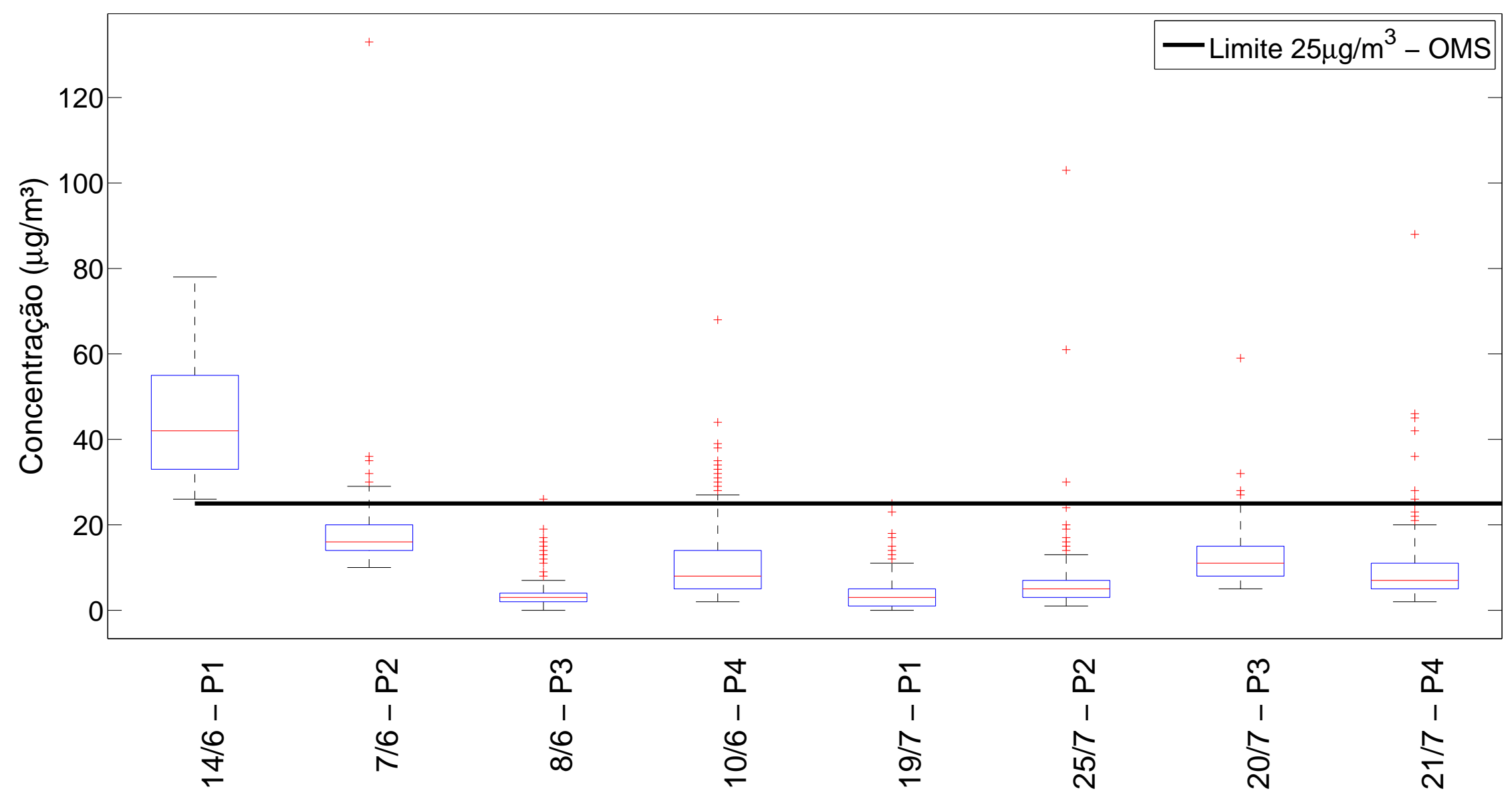


Figura 22 - Gráfico de boxplot da concentração do $\mathrm{MP}_{2,5}$ no ambiente interno coletado com o pDR-1.500

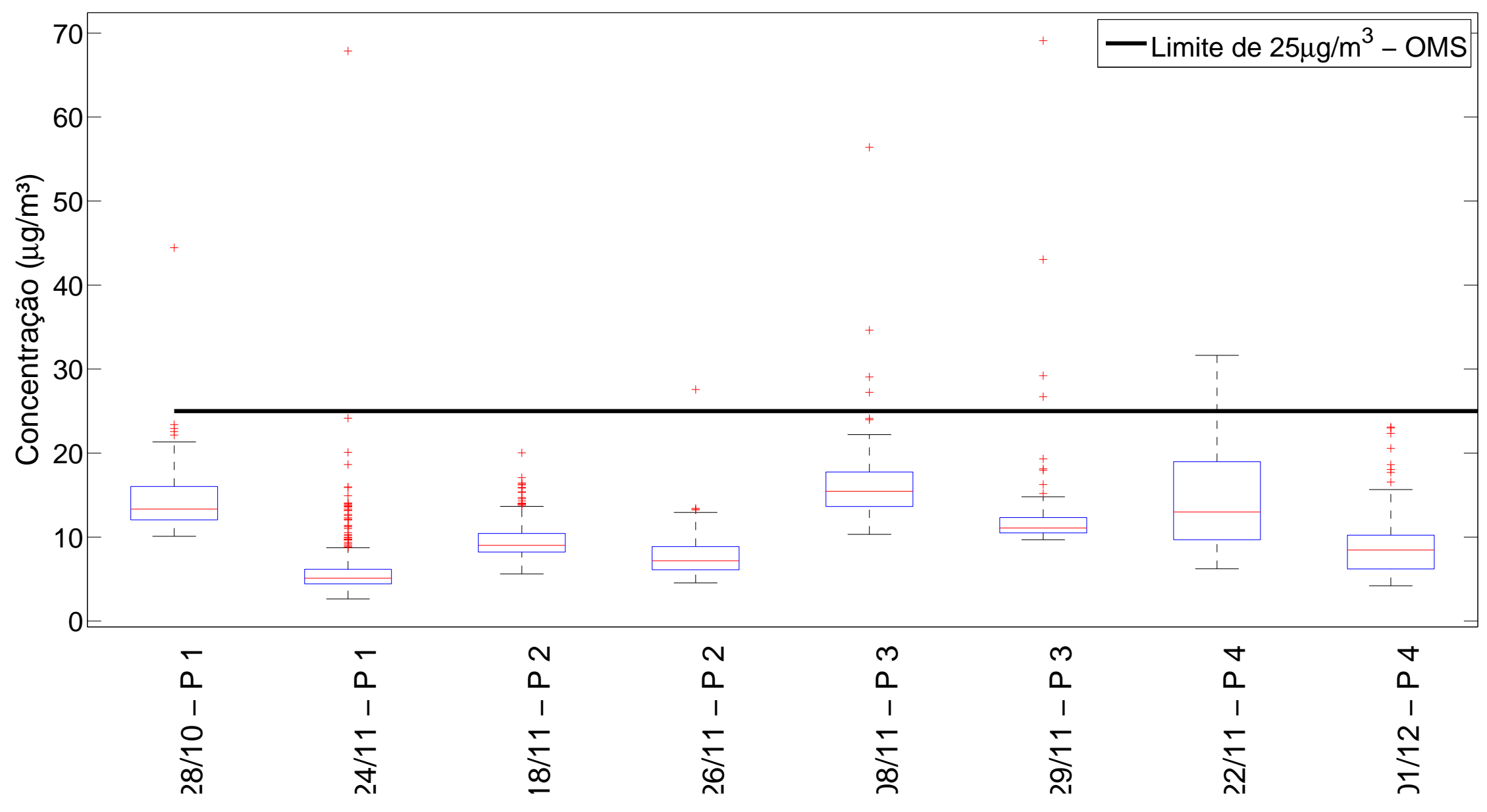


Figura 23 - Gráfico de boxplot da concentração do $\mathrm{MP}_{2,5}$ no ambiente externo coletado com o EVM-7

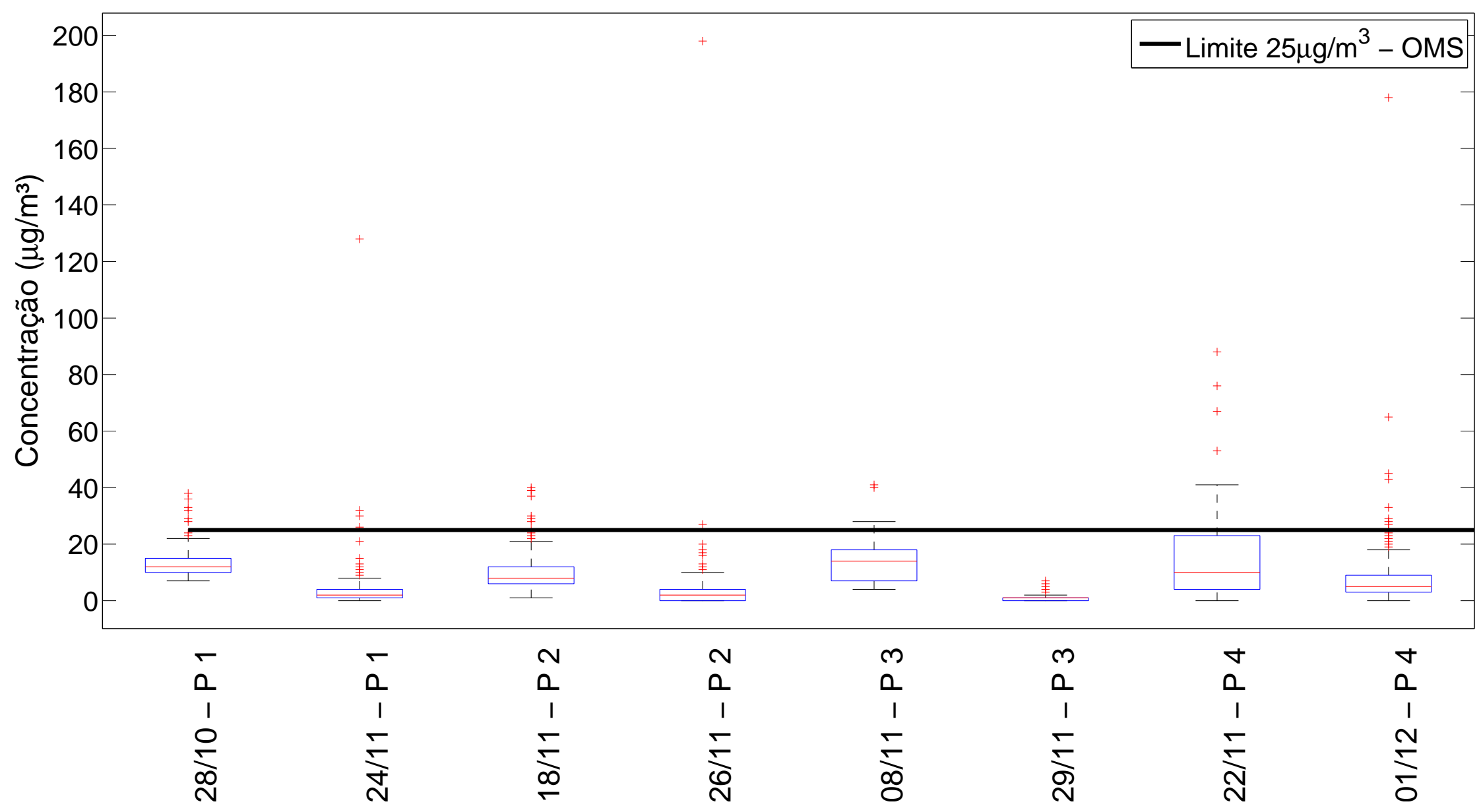


Figura 24 - Gráfico de boxplot da concentração do $\mathrm{MP}_{10}$ no ambiente interno coletado com o pDR-1500

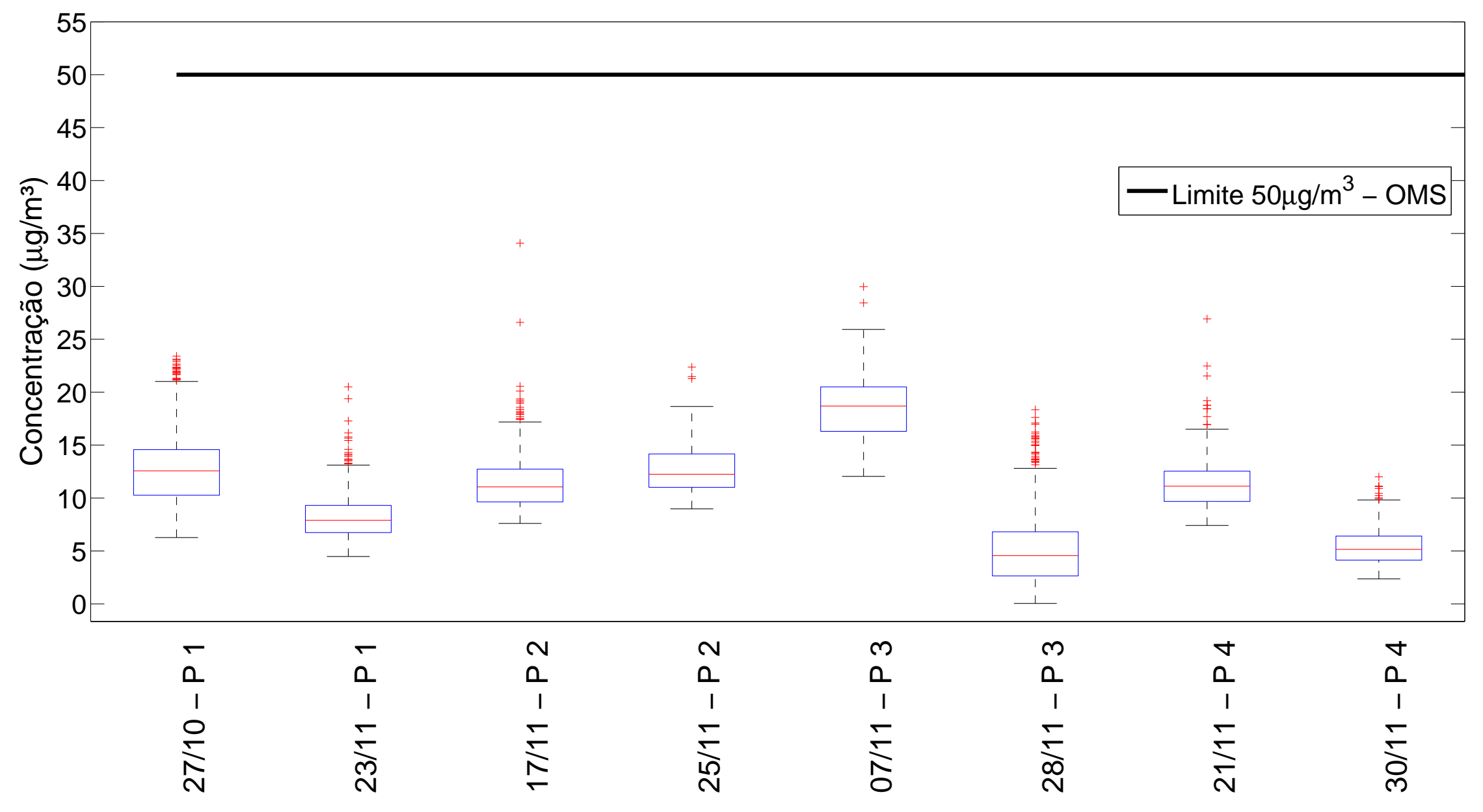


Figura 25 - Gráfico de boxplot da concentração do $\mathrm{MP}_{10}$ no ambiente externo coletado com o EVM-7

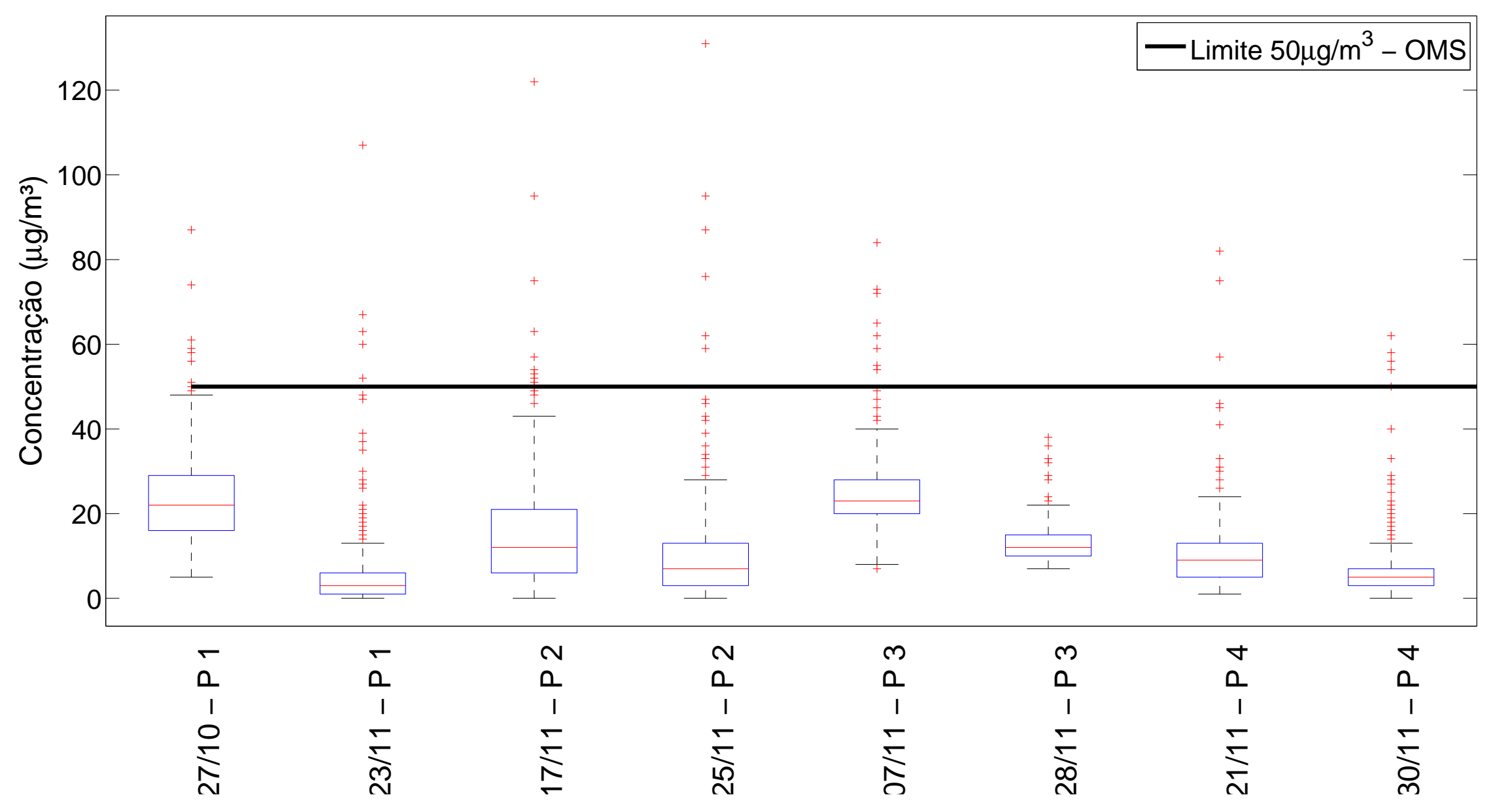




\subsubsection{Resultados da Gravimetria}

Como apresentado na metodologia, durante a coleta do mês de maio foi utilizado um óleo de baixa viscosidade para untar o anel do PEM. As membranas foram contaminadas com esse óleo que acabou escorrendo e o valor de concentração do material particulado foi bastante superior ao esperado, como mostra o gráfico da Figura 26, que apresenta os valores de concentração obtidos na etapa de coleta preliminar dos dados. Por conta disso, os resultados de gravimetria do mês de maio não foram incorporados à discussão dos resultados deste trabalho, sendo consideradas apenas as coletas realizadas a partir do mês de junho.

Figura 26 - Valores de concentração de material particulado obtidos na etapa de coleta preliminar dos dados

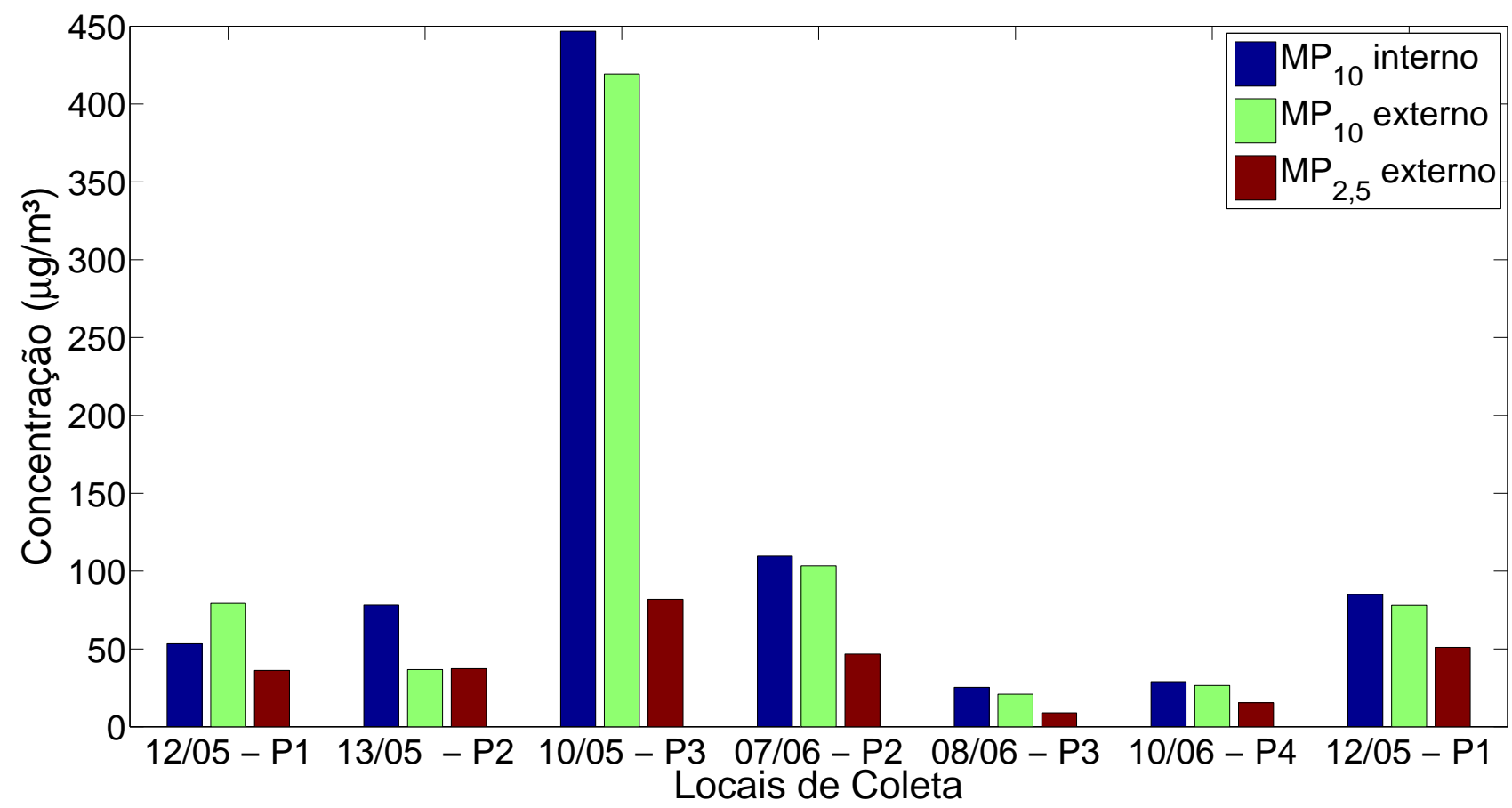

Trabalhos anteriores relacionados ao material particulado de São Carlos mostraram que os valores de concentração apresentam variação sazonal, sendo maiores durante os meses de maio a outubro (estação seca) e menores durante os meses de novembro a abril (estação chuvosa) (CELLI et al., 2003; MARQUES et al., 2001). A variação entre esses períodos é determinada, principalmente, pela precipitação, que funciona como lavador para as partículas da atmosfera. A Tabela 12 apresenta os valores de concentração e a relação interno/externo (I/E) do $\mathrm{MP}_{10}$ e do $\mathrm{MP}_{2,5}$. Apesar 
de o número de amostragens no período seco ser limitado, a média desse período superou a média da estação chuvosa. Comparando os valores de concentração com os padrões sugeridos pela Organização Mundial da Saúde - OMS, de $50 \mu \mathrm{g} / \mathrm{m}^{3}$ para o $\mathrm{MP}_{10}$ e $25 \mu \mathrm{g} / \mathrm{m}^{3}$ para o $\mathrm{MP}_{2,5}$, apenas na estação seca os padrões não foram atendidos, no entanto, com valores ultrapassando 100\% do limite estabelecido.

Tabela 12 - Concentrações de $\mathrm{MP}_{10}$ e $\mathrm{MP}_{2,5}$ de todos os dias de coleta e relação interno/externo $(\mathrm{I} / \mathrm{E})$

\begin{tabular}{|c|c|c|c|c|c|c|c|}
\hline \multirow{2}{*}{ Ponto de coleta } & \multirow{2}{*}{ Data } & \multicolumn{2}{|c|}{$\mathbf{M P} \mathbf{P}_{10}\left(\mu \mathbf{g} / \mathbf{m}^{3}\right)$} & \multirow{2}{*}{ Índice $\mathbf{I} / \mathbf{E}$} & \multicolumn{2}{|c|}{$\mathbf{M P} \mathbf{P}_{2,5}\left(\mu \mathbf{g} / \mathbf{m}^{3}\right)$} & \multirow{2}{*}{ Índice I/E } \\
\hline & & I & $\mathbf{E}$ & & I & $\mathbf{E}$ & \\
\hline 1 & $14 / 6 / 2011$ & 85 & 78 & 1,06 & - & 51 & - \\
\hline 2 & 7/6/2011 & 108 & 102 & 1,26 & - & 45 & - \\
\hline 3 & 8/6/2011 & 24 & 19 & 1,08 & - & 7 & - \\
\hline 4 & $10 / 6 / 2011$ & 27 & 25 & 1,09 & - & 14 & - \\
\hline \multirow{2}{*}{3} & $7 / 11 / 2011$ & 40 & 32 & 1,25 & - & - & - \\
\hline & $8 / 11 / 2011$ & - & - & - & 19 & 17 & 1,12 \\
\hline \multirow{2}{*}{2} & $17 / 11 / 2011$ & 23 & 22 & 1,05 & - & - & - \\
\hline & $18 / 11 / 2011$ & - & - & - & 21 & 17 & 1,24 \\
\hline \multirow{2}{*}{4} & $21 / 11 / 2011$ & 27 & 34 & 0,79 & - & - & - \\
\hline & $22 / 11 / 2011$ & - & - & - & 19 & 17 & 1,12 \\
\hline \multirow{2}{*}{1} & $23 / 11 / 2011$ & 27 & 25 & 1,08 & - & 13 & - \\
\hline & $24 / 11 / 2011$ & 24 & - & - & 14 & 12 & 1,17 \\
\hline \multirow{2}{*}{2} & $25 / 11 / 2011$ & 24 & 27 & 0,89 & - & 17 & - \\
\hline & $26 / 11 / 2011$ & 26 & - & - & 14 & 15 & 0,93 \\
\hline \multirow{2}{*}{3} & $28 / 11 / 2011$ & 21 & 13 & 1,62 & - & 8 & - \\
\hline & $29 / 11 / 2011$ & 24 & - & - & 11 & 9 & 1,22 \\
\hline \multirow{2}{*}{4} & $30 / 11 / 2011$ & 22 & 24 & 0,92 & - & 12 & - \\
\hline & $1 / 12 / 2011$ & 30 & - & - & 17 & 18 & 0,94 \\
\hline
\end{tabular}

${ }^{1} \mathrm{I}=$ Interno; $\mathrm{E}=$ Externo

Para a relação interno/externo (I/E) pode ser observado, tanto para o $\mathrm{MP}_{10}$ como para o $\mathrm{MP}_{2,5}$ que, na maioria dos dias amostrados, a concentração interna foi superior à concentração externa. Mais precisamente em $71 \%$ das coletas de $\mathrm{MP}_{2,5}$ e em $72 \%$ das coletas de $\mathrm{MP}_{10}$. Em três pontos de monitoramento, P1, P2 e P3, o local de coleta no ambiente interno era localizado próximo aos caixas das lojas e, como o comércio praticado era de artigos de confecção, a ressuspenssão de partículas pela manipulação dos objetos de tecido teve contribuição nos níveis de MP interno. Já no $\mathrm{P} 4$, o local de monitoramento interno estava localizado mais próximo à saída do que ao interior da loja. 
Os valores da relação I/E em torno de 1 (12, tanto para o $\mathrm{MP}_{2,5}$ como para o $\mathrm{MP}_{10}$, indicam que, as diferenças entre as concentrações do MP, nos ambientes interno e externo, não são significativas. Nenhum dos ambientes amostrados neste trabalho possui climatização artificial, sendo que a ventilação e as trocas de ar são naturais e constantes devido à manutenção de portas e janelas abertas, justificando os valores da relação I/E.

Um dos resultados mais interessante obtido neste trabalho, foi a verificação da elevação dos níveis médios da concentração do $\mathrm{MP}_{2,5}$ em mais de $20 \%$ nos últimos dez anos. Estudos anteriores, no ambiente externo de São Carlos, encontraram a relação $\mathrm{MP}_{2,5} / \mathrm{MP}_{10}$ variando de $30 \%$ a $80 \%$ na estação seca, e sendo cerca de $31 \%$ na estação chuvosa, para os anos de 2.001 e 2.002 . A Tabela 13 apresenta os valores da relação $\mathrm{MP}_{2,5} / \mathrm{MP}_{10}$ encontrados para o ano de 2.011, o valor médio para a estação chuvosa foi de $56 \%$. E, os valores médios da concentração de $\mathrm{MP}_{10}$ e $\mathrm{MP}_{2,5}$ eram de $23,4 \mu \mathrm{g} / \mathrm{m}^{3}$ e $8,6 \mu \mathrm{g} / \mathrm{m}^{3}$, respectivamente, dez anos atrás, na estação chuvosa (BRUNO et al., 2004). Em 2.011 os resultados obtidos apresentaram concentração média de $25,3 \mu \mathrm{g} / \mathrm{m}^{3}$ para o $\mathrm{MP}_{10}$ e de $14,1 \mu \mathrm{g} / \mathrm{m}^{3}$ para o $\mathrm{MP}_{2,5}$ (Tabela 12). É evidente o aumento nos níveis de $\mathrm{MP}_{2,5}$, ocasionando, dessa forma, o aumento dos valores da relação $\mathrm{MP}_{2,5} / \mathrm{MP}_{10}$.

Figura 27 - Comparação das concentrações $\mathrm{MP}_{10}$ e $\mathrm{MP}_{2,5}$ no ambiente interno

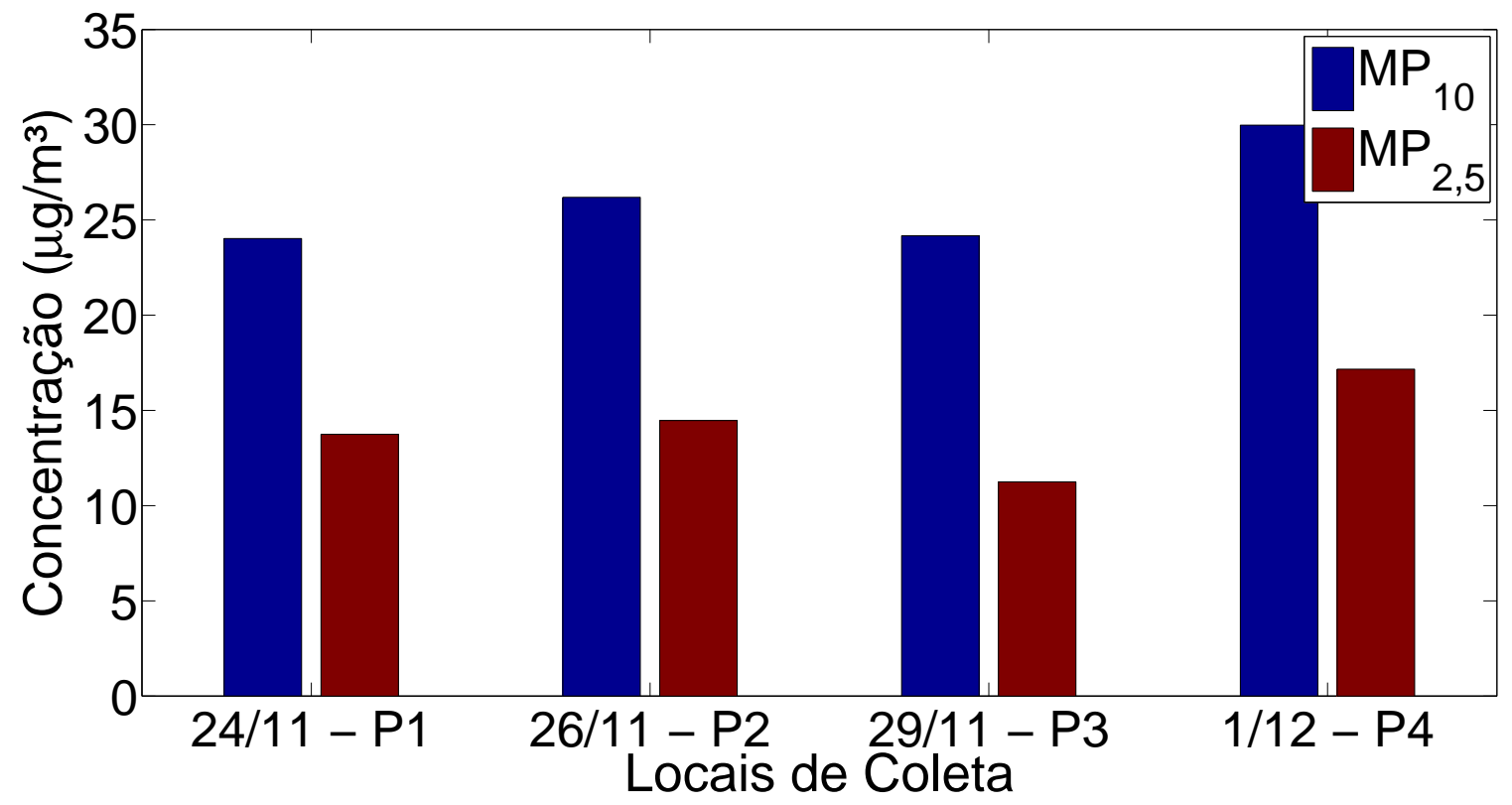

A relação $\mathrm{MP}_{2,5} / \mathrm{MP}_{10}$ também apresenta similaridade entre os ambientes interno e externo, como já mencionado, devido às trocas de ar frequentes entre esses ambientes. As Figuras 27 e 28 


\begin{tabular}{ccc}
\multicolumn{3}{c}{ Tabela 13 - Relação $\mathrm{MP}_{2,5} / \mathrm{MP}_{10}$} \\
\hline Pontos de coleta & Externo & Interno \\
\hline 1 & 0,66 & - \\
2 & 0,44 & - \\
3 & 0,38 & - \\
4 & 0,55 & - \\
1 & 0,54 & 0,57 \\
2 & 0,63 & 0,55 \\
3 & 0,58 & 0,47 \\
4 & 0,50 & 0,57 \\
\hline
\end{tabular}

apresentam as concentrações de $\mathrm{MP}_{10}$ e $\mathrm{MP}_{2,5}$ para o ambiente interno e externo, respectivamente, é possível observar que a massa do $\mathrm{MP}_{10}$ é composta em média por mais de $50 \%$ de massa $\mathrm{MP}_{2,5}$. 
Figura 28 - Comparação das concentrações $\mathrm{MP}_{10}$ e $\mathrm{MP}_{2,5}$ no ambiente externo

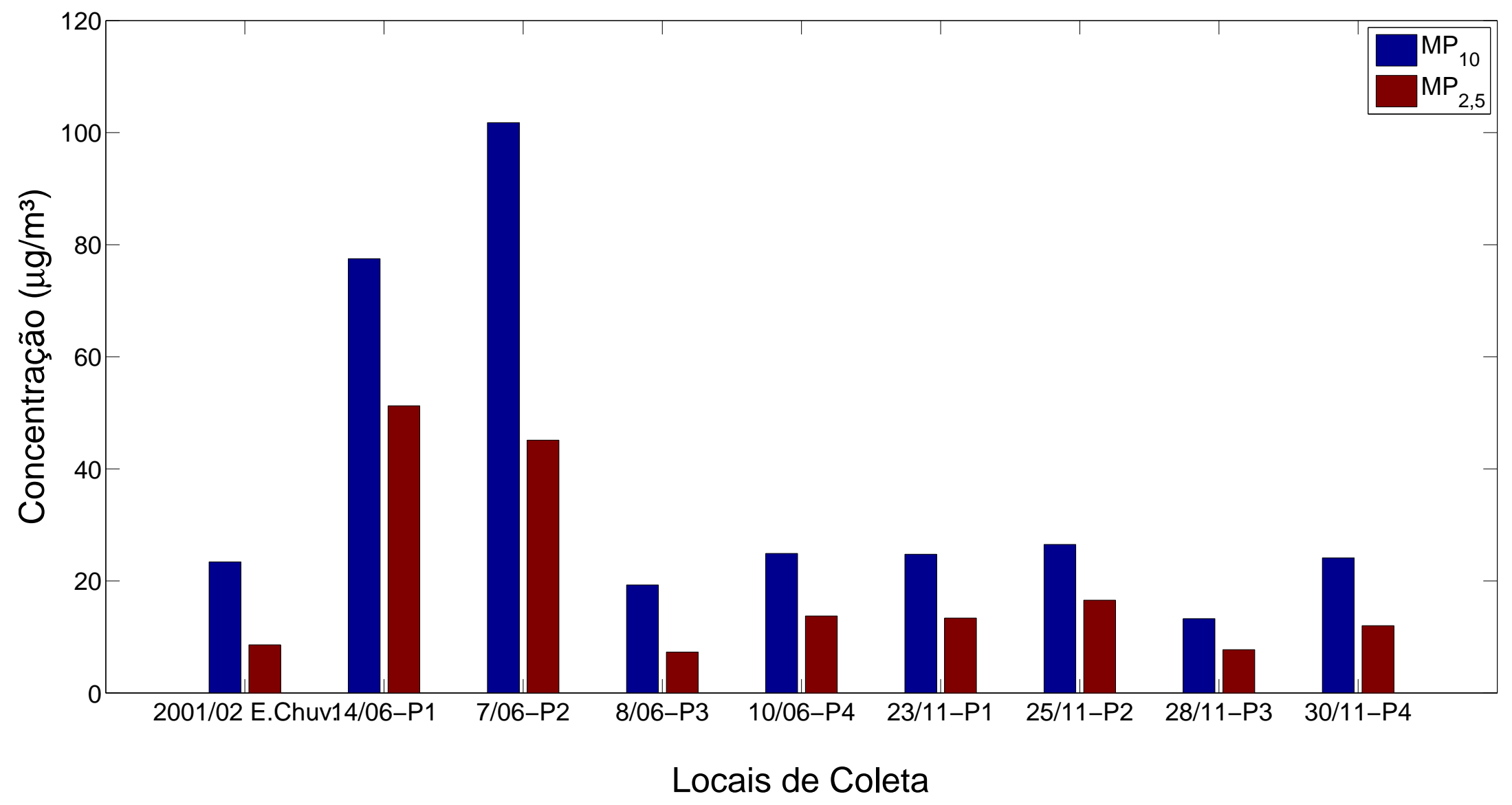




\subsubsection{Análise química}

A análise química das membranas foi realizada por meio de Fluorescência de Raio-X. Como mencionado na metodologia, foram utilizadas duas membranas diferentes, uma na etapa de coleta preliminar de dados e outra na etapa de coleta efetiva dos dados. A Figura 29 apresenta os elementos encontrados na análise química realizada com as duas membranas brancas (sem uso), da etapa de coleta efetiva e preliminar de dados, respectivamente.

Figura 29 - Análise química das membranas brancas

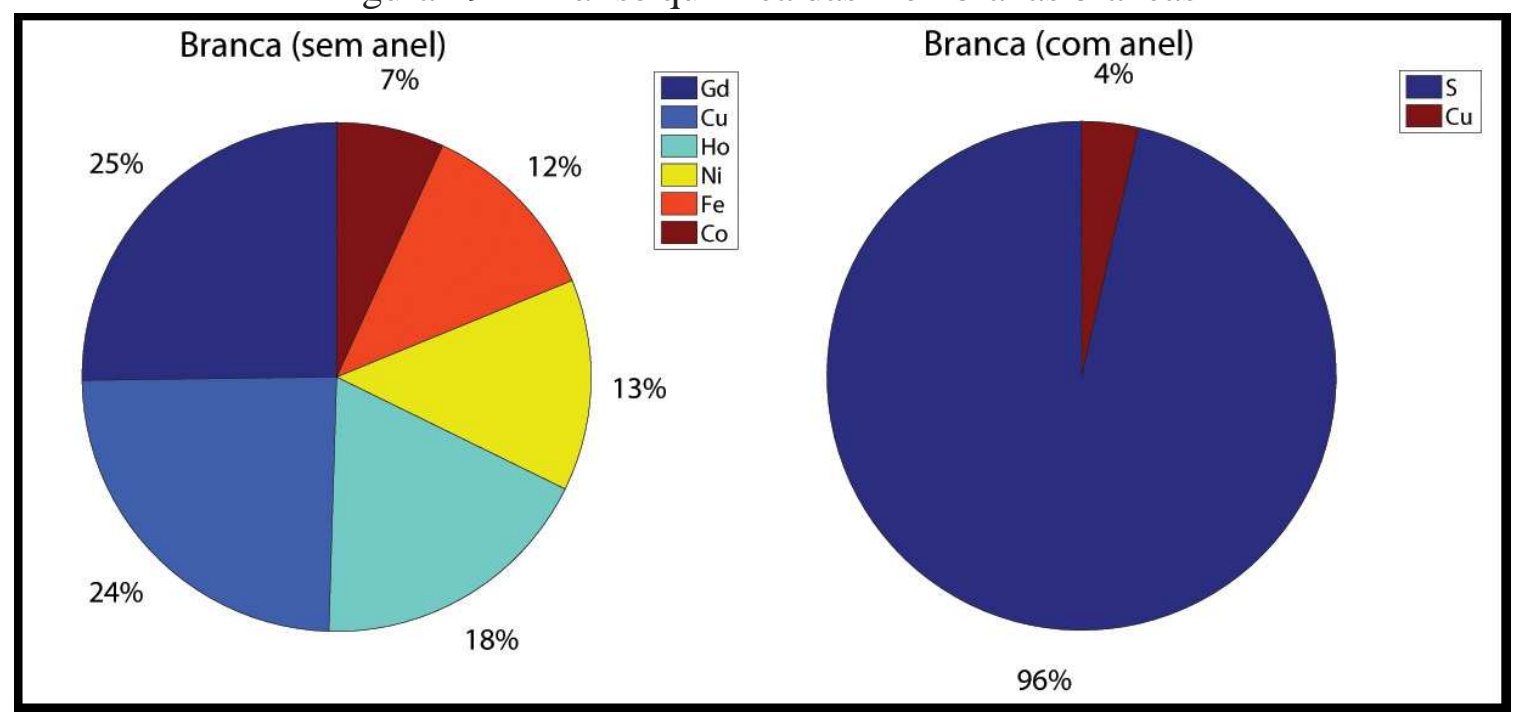

A Figura 30 apresenta os gráficos com as porcentagens dos elementos encontrados durante a etapa de coleta preliminar de dados, utilizando o primeiro tipo de membrana. As análises químicas realizadas, nesta etapa, apresentaram resultados satisfatórios, sendo que, os elementos encontrados estão em acordo com a literatura para a área de estudo e, também, apresentam acordo com estudos anteriores realizados sobre a constituição química do material particulado de São Carlos (POZZA, 2005; BRUNO et al., 2004). Há algumas pontos interessantes que podem ser observados, como o aparecimento do Alumínio, apenas no $\mathrm{MP}_{10}$ do $\mathrm{P} 2$, e o $\mathrm{MP}_{2,5}$ externo do P3 apresentando apenas Enxofre, Ferro e Cobre. No entanto, para melhor entendimento desses acontecimentos, seriam necessárias a realização de um número maior de amostragens com este tipo de membrana, o que não foi possível neste estudo. 
Figura 30 - Análise química da etapa de coleta preliminar de dados

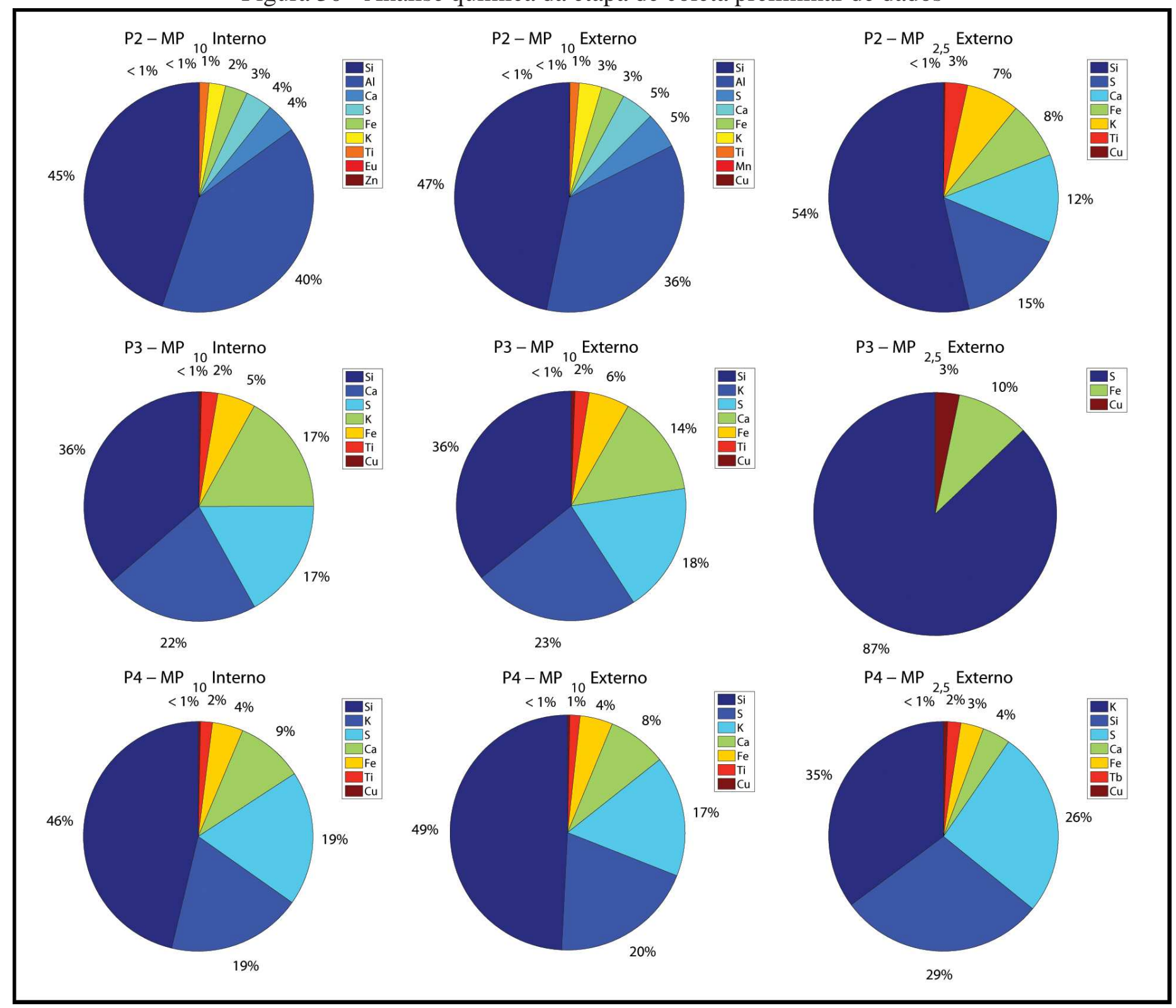


A Figura 31 apresenta a comparação da constituição química do $\mathrm{MP}_{10}$ interno e externo coletados simultaneamente na etapa preliminar, e mostra que, as concentrações entre os ambientes são muito semelhantes. Os elementos encontrados na análise química são característicos de fontes externas, principalmente emissão veicular e ressuspensão. Essas fontes foram identificadas por estudos anteriores que avaliaram as principais fontes de contribuição para o material particulado de São Carlos (POZZA, 2005; BRUNO et al., 2004). O aparecimento do elemento potássio é explicado pelo fato das coletas terem sido realizadas no mês de junho, portanto no período seco, mais propício para as queimadas, sendo esta a maior fonte de contribuição deste elemento. A Figura 32 apresenta a comparação dos resultados da análise química do MP10 e MP2,5 externos. Seriam necessárias um maior número de amostragens, a fim de entender o não aparecimento de elementos como Si, Ca, K e Ti, na fração $\mathrm{MP}_{2,5}$ do P3. Para os outros pontos amostrais, a análise apresentou concordância com estudos anteriores (POZZA, 2005; BRUNO et al., 2004).

Para a etapa efetiva de dados, em que foram utililizadas membranas diferentes das da etapa de coleta preliminar, os resultados da análise química não foram satisfatórios. As Figuras 33 e 34 apresentam os gráficos com os resultados obtidos para cada amostra. Nesta etapa, foram encontrados elementos atípicos para o tipo de área de estudo, como Hólmio, Gadolínio, Háfnio, Túlio, Érbio, Térbio, Disprósio, Lutécio e Ródio, sendo que, destes elementos apenas o Gadolínio e o Hólmio apareceram na análise da membrana branca. E, em apenas algumas amostras, foram encontrados os elementos esperados como Silício, Enxofre, Ferro e Alumínio, por exemplo.

Enquanto que a massa das membranas utilizadas na fase de coleta preliminar de dados não ultrapassava $100 \mu \mathrm{g}$, a massa da membrana utilizada na fase de coleta efetiva de dados era em torno de $200 \mu \mathrm{g}$. Portanto, um fator para as análises químicas desta etapa não apresentarem resultados satisfatórios pode ser o fato do tempo de coleta, de oito horas diárias, não ter sido suficiente para acumular a quantidade de massa necessária. As Figuras 35 a 38 apresentam fotos das membranas utilizadas para coleta de material particulado, $\mathrm{MP}_{10}$ e $\mathrm{MP}_{2,5}$, das etapas de coleta preliminar e efetiva, que foram analisadas em microscópio Olympus BX50 e as imagens capturadas pelo software DP2-BSW (Olympus). É possivel observar, nas imagens abaixo, que a membrana utilizada na etapa de coleta efetiva dos dados se apresenta muito mais densa, devido a maior quantidade de massa de membrana, que a utilizada na etapa de coleta preliminar. Os círculos em vermelho apresentam o acúmulo de material particulado em algumas regiões da membrana, o que é mais visível na coleta do $\mathrm{MP}_{10}$ do que na coleta do $\mathrm{MP}_{2,5}$. 
Figura 31 - Constituição química do $\mathrm{MP}_{10}$ interno e externo

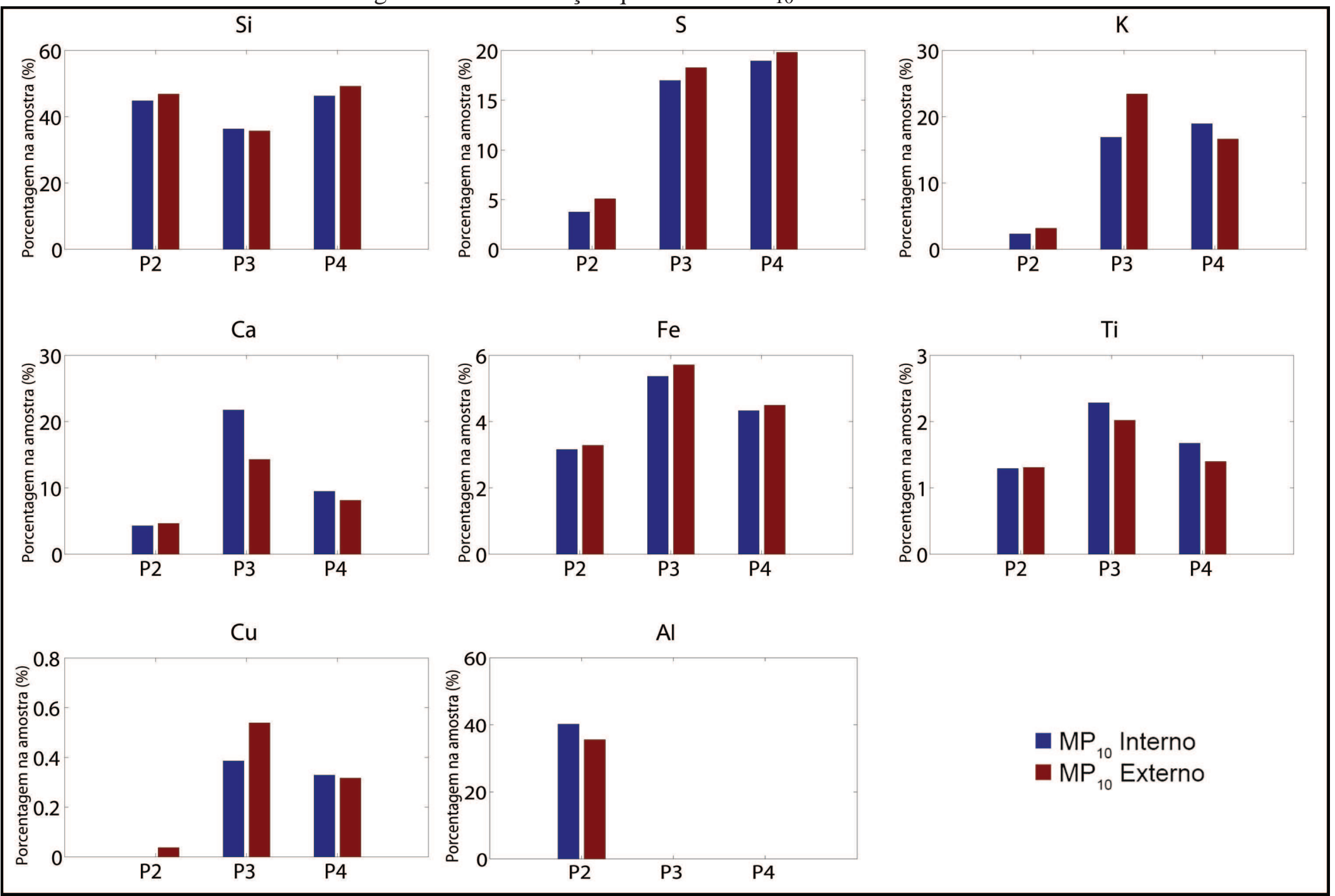


Figura 32 - Constituição química do $\mathrm{MP}_{10}$ e $\mathrm{MP}_{2.5}$ externos

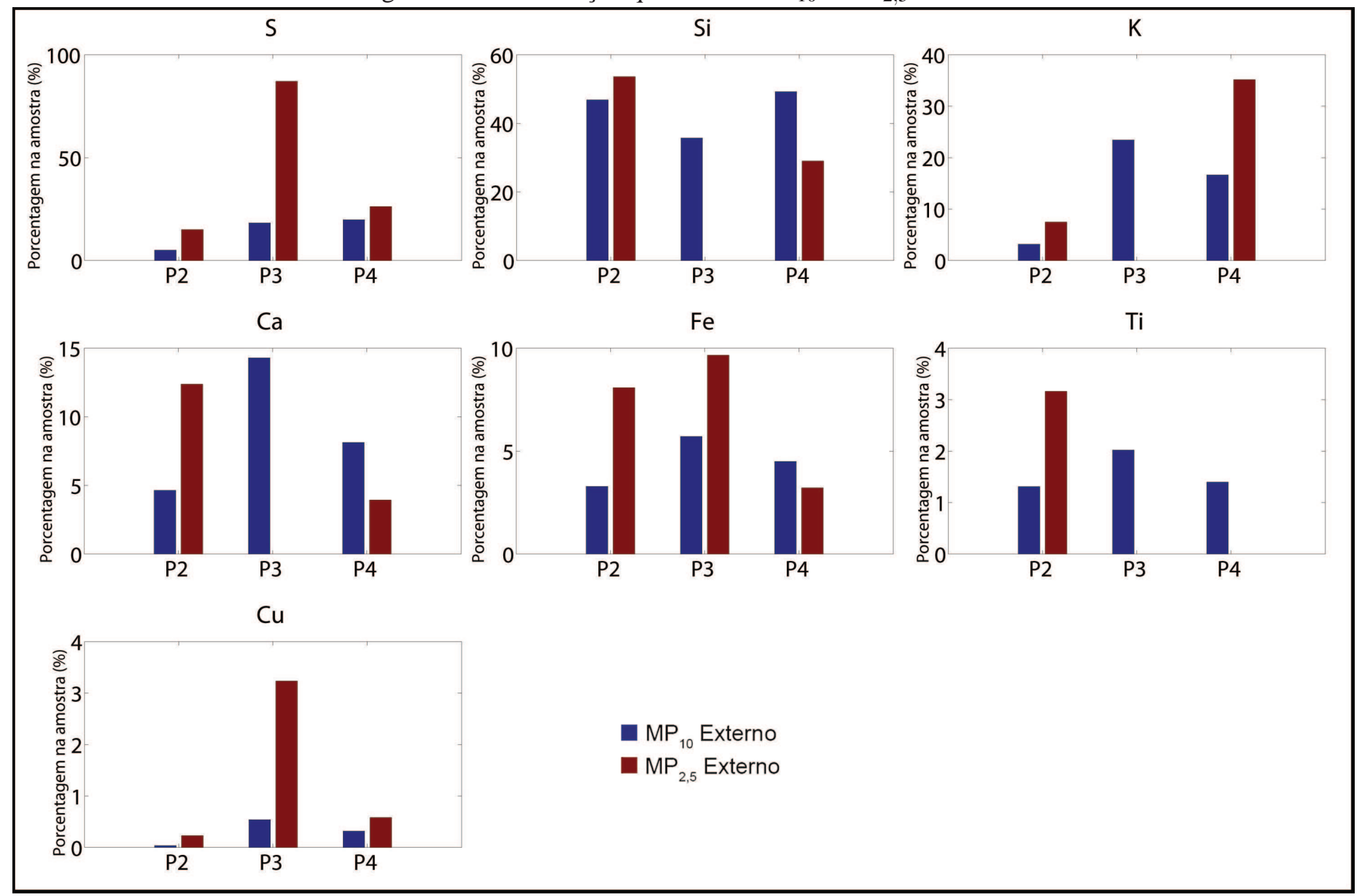


Figura 33 - Análise química da etapa de coleta efetiva de dados (1)

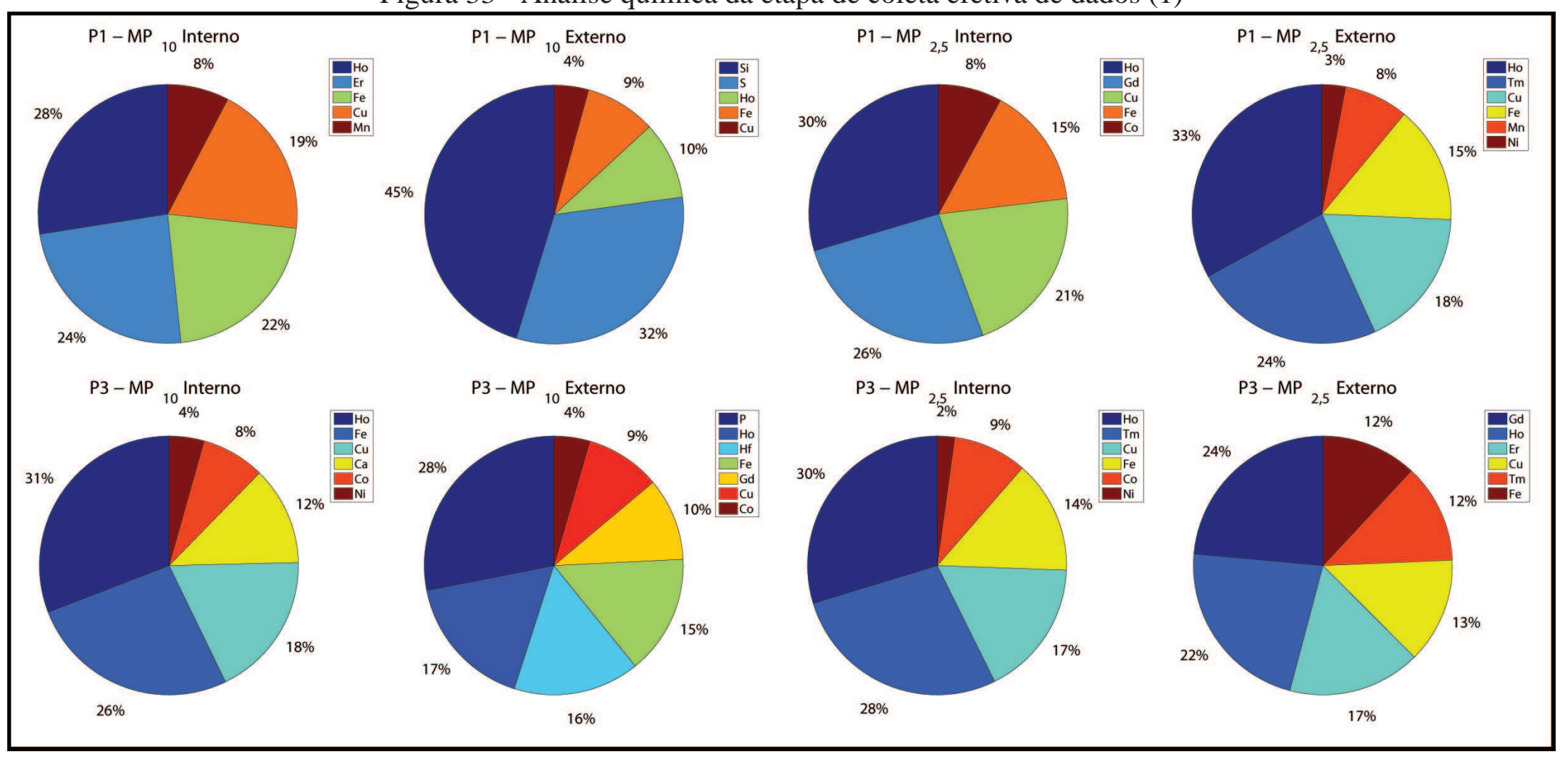


Figura 34 - Análise química da etapa de coleta efetiva de dados (2)

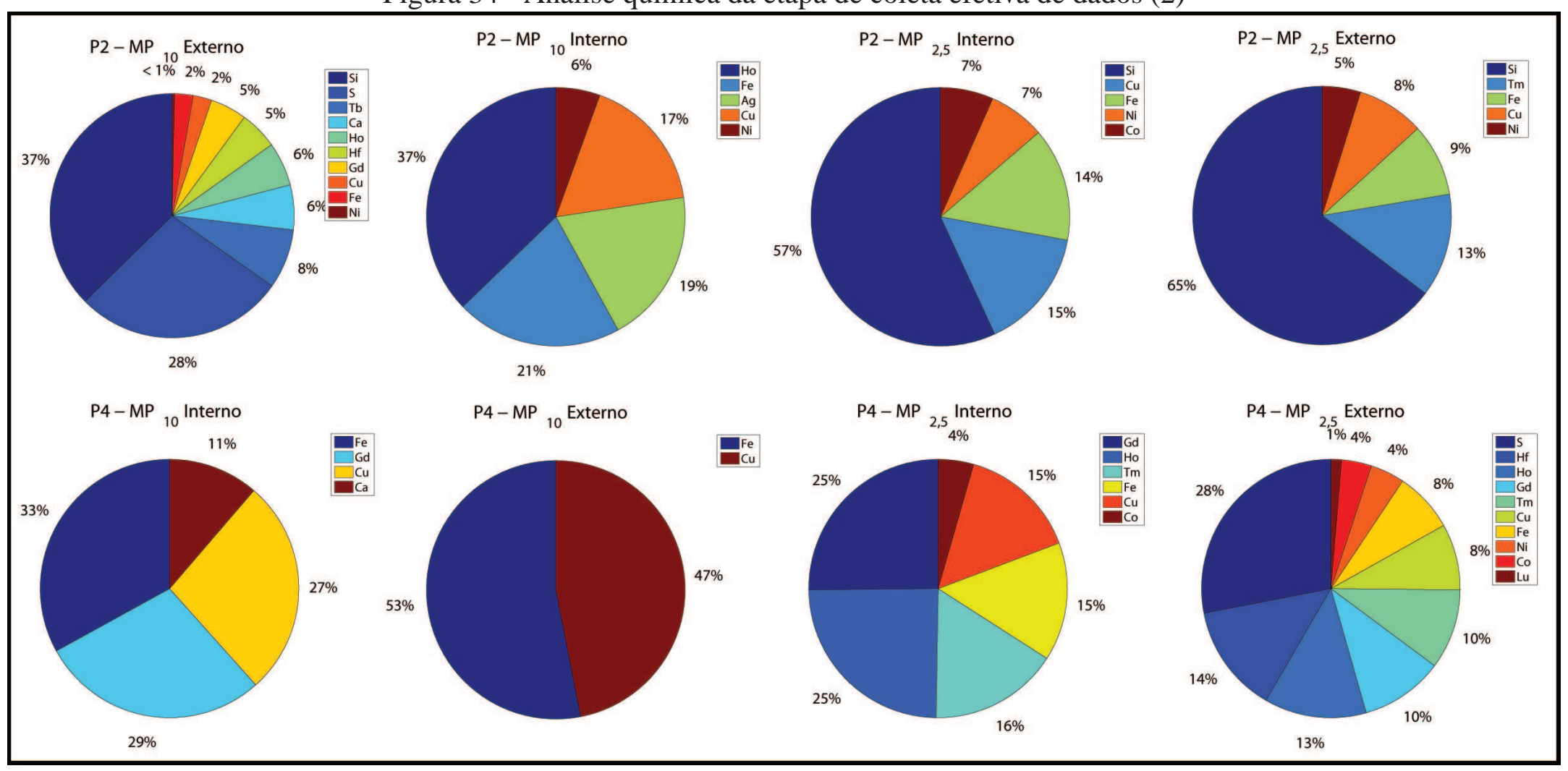


Figura 35 - Membrana de coleta de $\mathrm{MP}_{10}$ externo (07/06/2011)

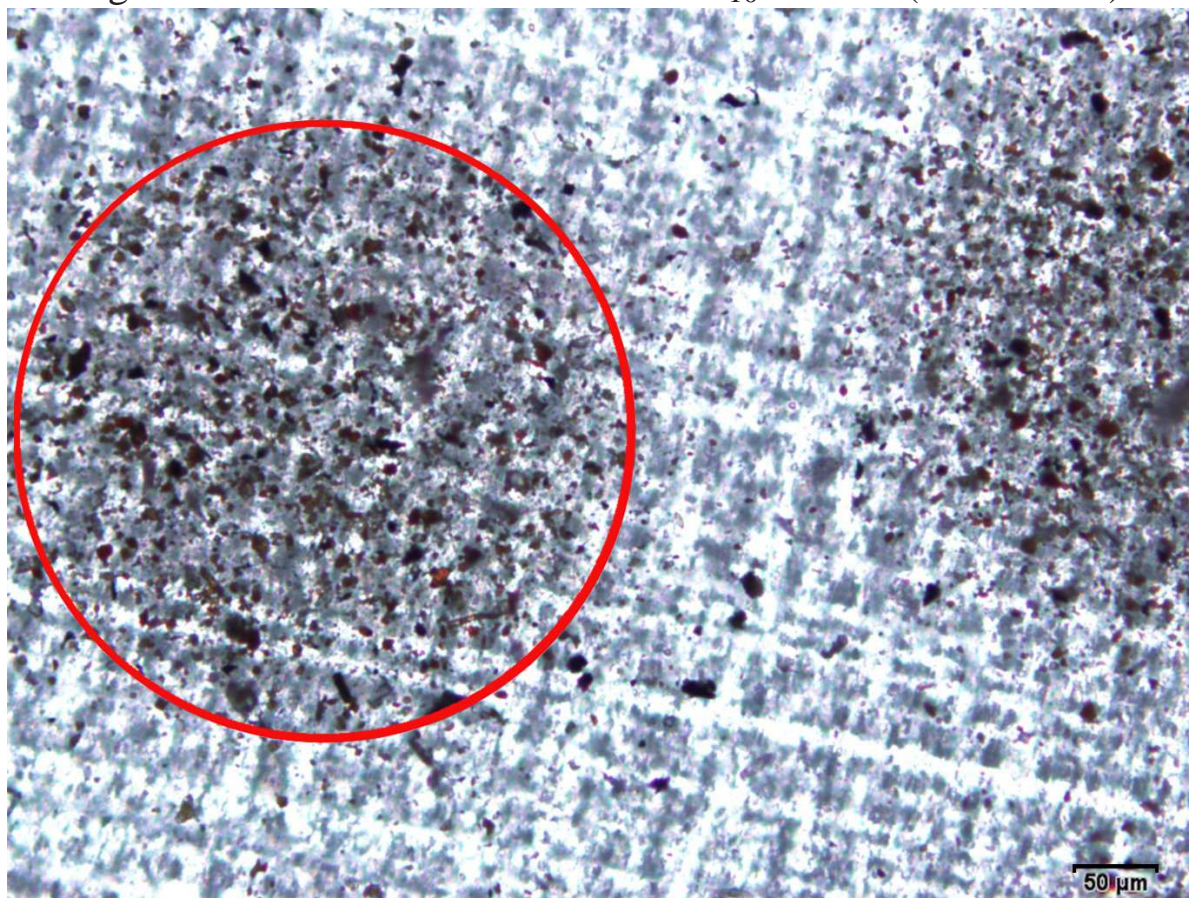

Figura 36 - Membrana de coleta de MP 10 externo (25/11/2011)

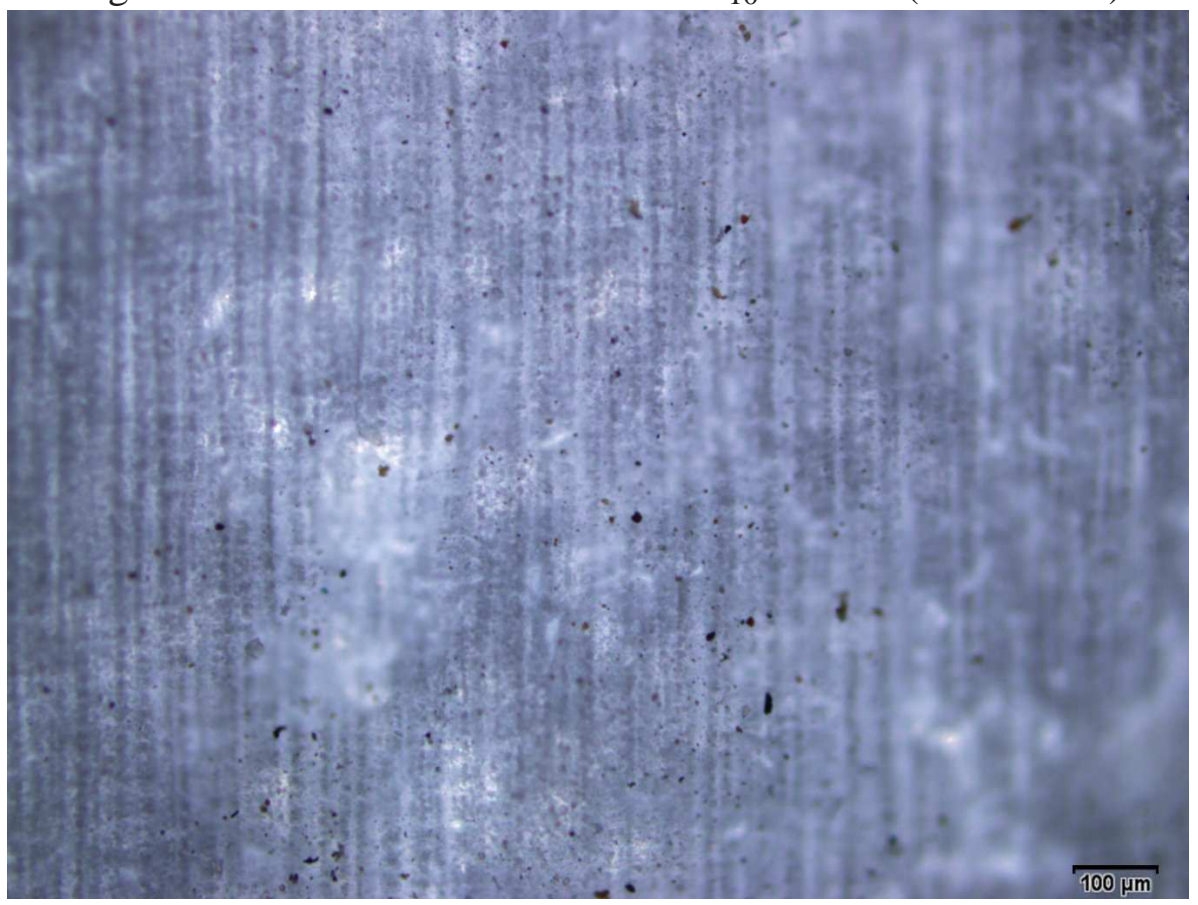


Figura 37 - Membrana de coleta de $\mathrm{MP}_{2,5}$ externo (07/06/2011)

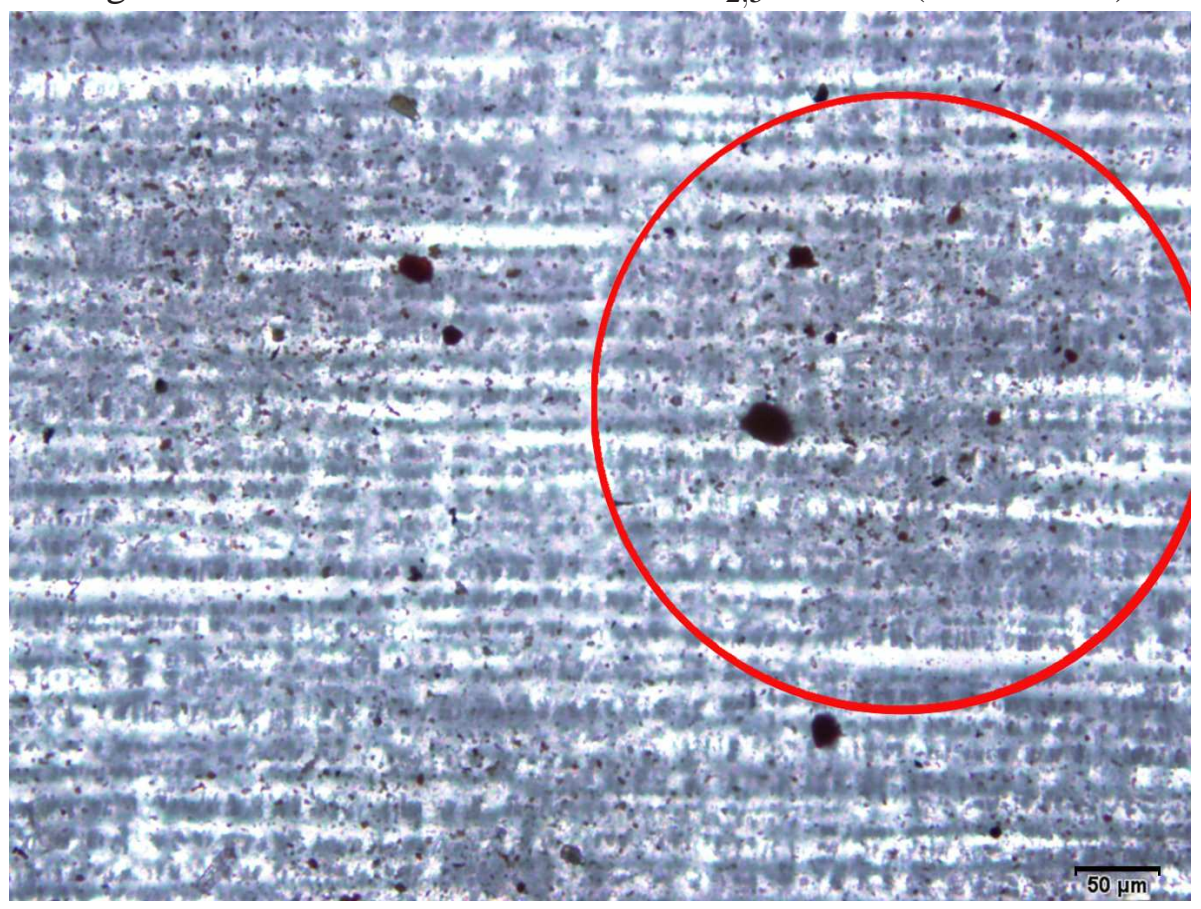

Figura 38 - Membrana de coleta de $\mathrm{MP}_{2,5}$ externo (01/12/2011)

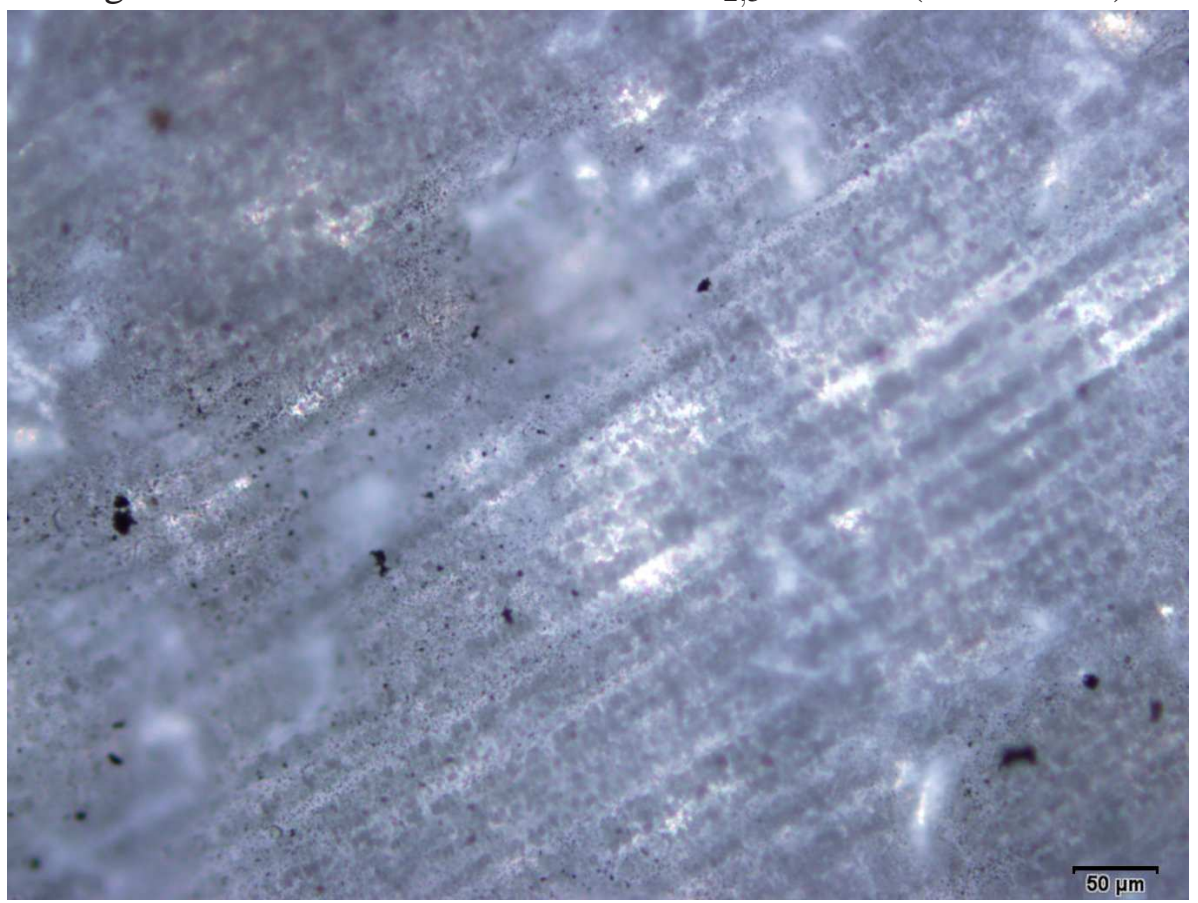




\subsubsection{Comparação métodos de medição de material particulado}

As Figuras 39 a 42 apresentam os gráficos das comparações realizadas entre as duas formas de monitoramento de material particulado, a gravimetria e os monitores portáteis. Os gráficos apresentados são para os dias em que as coletas foram realizadas simultaneamente com as duas formas de medição. Para o ambiente interno, foi utilizado o pDR-1500, e para o ambiente externo o EVM7, ambos para coleta de $\mathrm{MP}_{2,5}$ e $\mathrm{MP}_{10}$.

Figura 39 - Comparação equipamentos de coletas do $\mathrm{MP}_{2,5}$ no ambiente interno

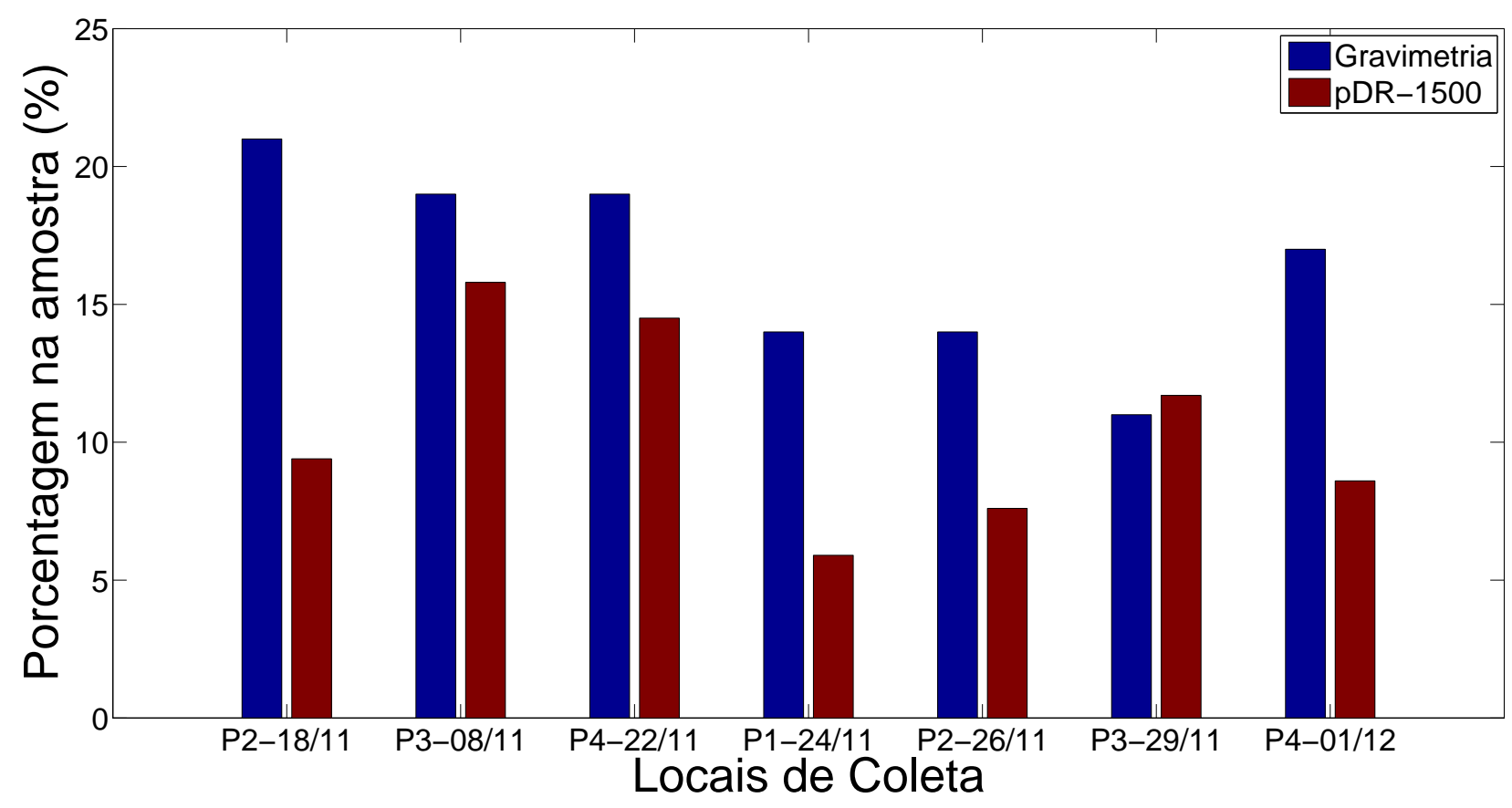


Figura 40 - Comparação equipamentos de coletas do $\mathrm{MP}_{2,5}$ no ambiente externo

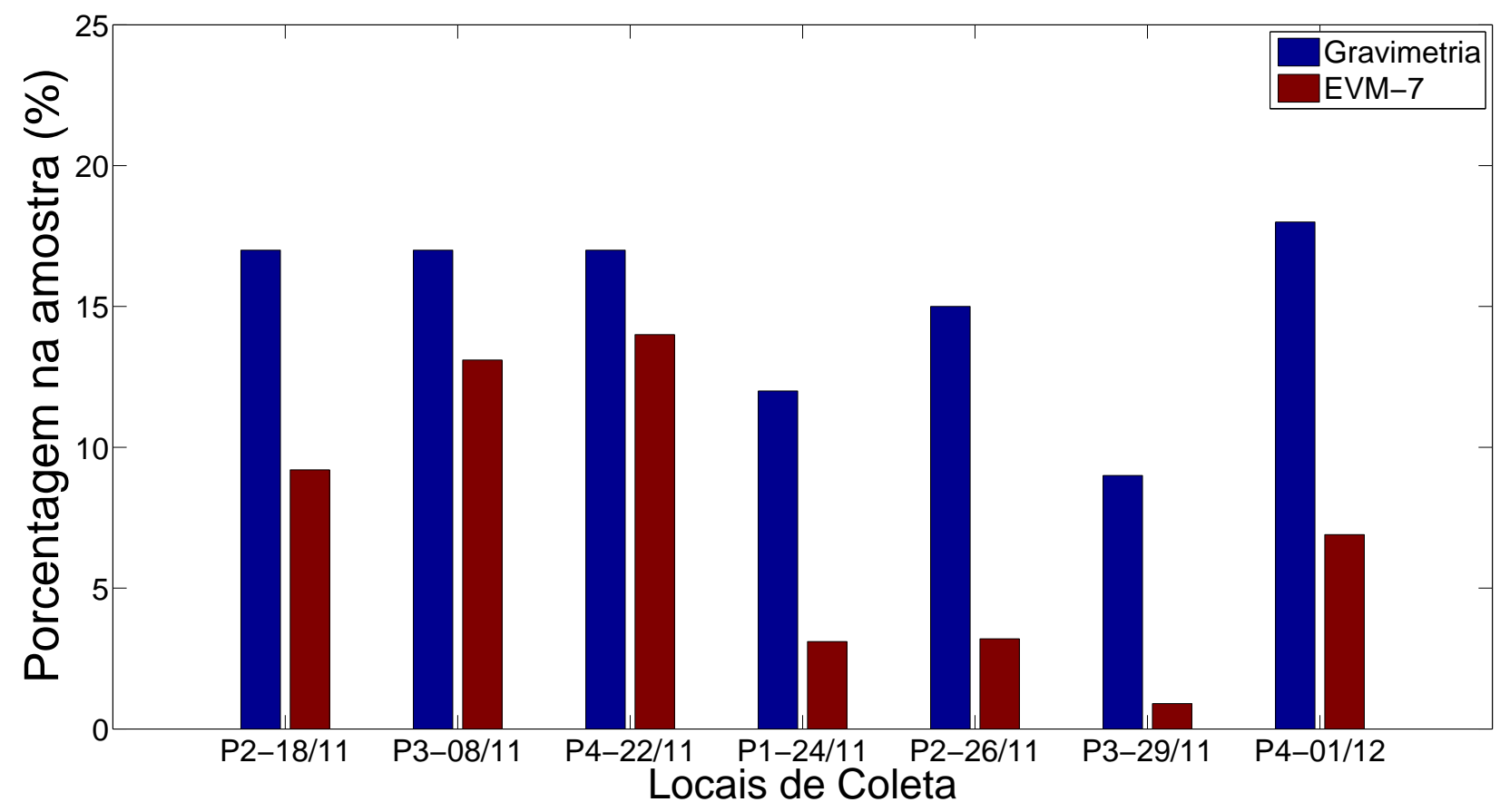

Houve apenas duas amostragens em que os monitores portáteis apresentaram valores de concentração superiores à gravimetria: na coleta de $\mathrm{MP}_{2,5}$ no ambiente interno do $\mathrm{P} 3$ no dia 29/11, e na coleta de $\mathrm{MP}_{10}$ do ambiente externo do P3 no dia 28/11. Coincidentemente foram em dias próximos, no entanto, não há a formação de nenhum padrão de diferenciação entre as coletas realizadas com os monitores e a gravimetria. Nos outros dias, todas os valores apresentados pelos monitores portáteis foram inferiores aos da gravimetria. O EVM-7 apresentou as maiores discrepâncias, com um valor de $\mathrm{MP}_{2,5}$ no $\mathrm{P} 3$ dia $29 / 11$, de apenas $0.9 \mu \mathrm{g} / \mathrm{m}^{3}$, enquanto a gravimetria apresentou $9 \mu \mathrm{g} / \mathrm{m}^{3}$. 
Figura 41 - Comparação equipamentos de coletas do $\mathrm{MP}_{10}$ no ambiente interno

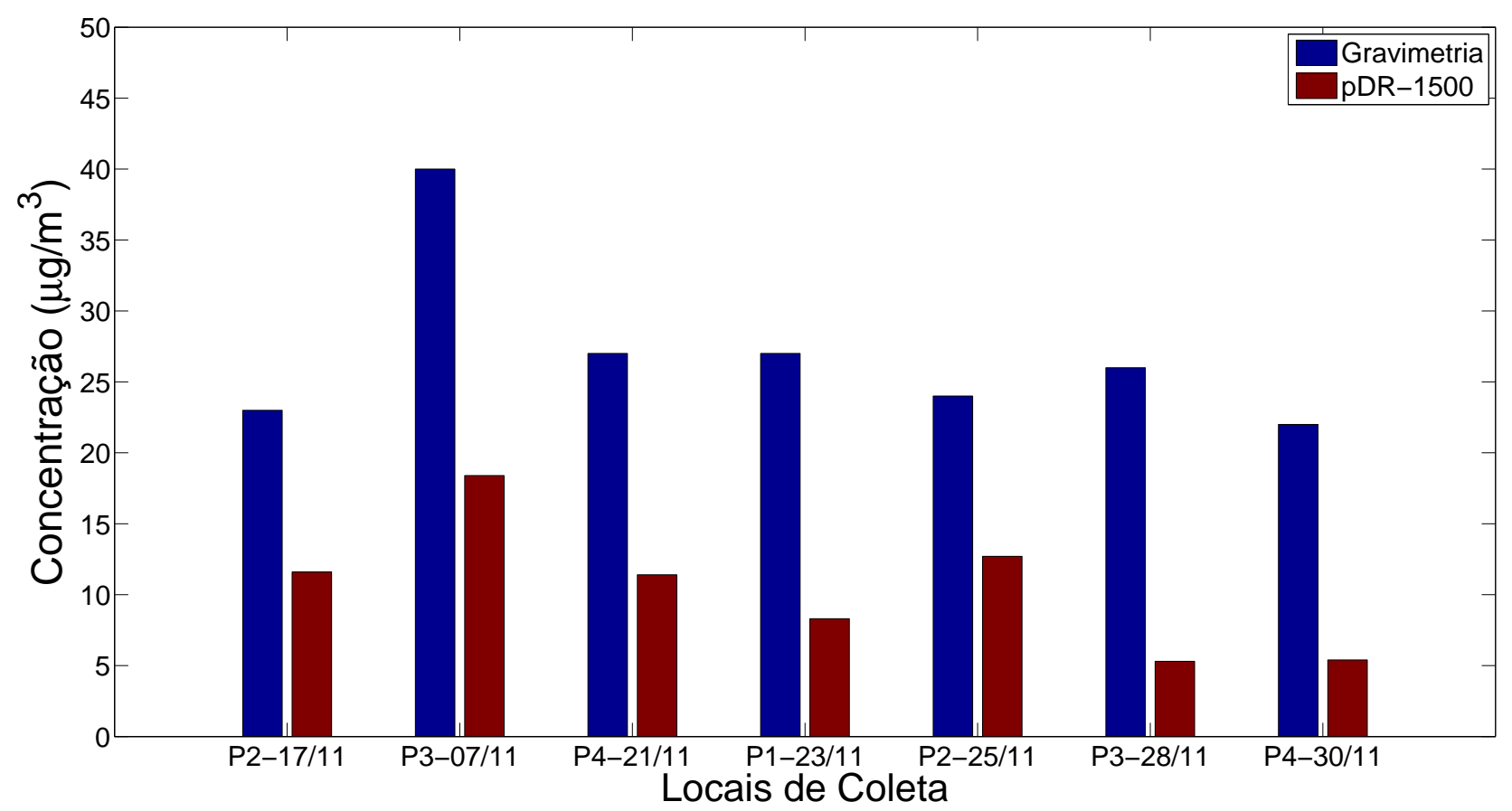

Figura 42 - Comparação equipamentos de coletas do $\mathrm{MP}_{10}$ no ambiente externo

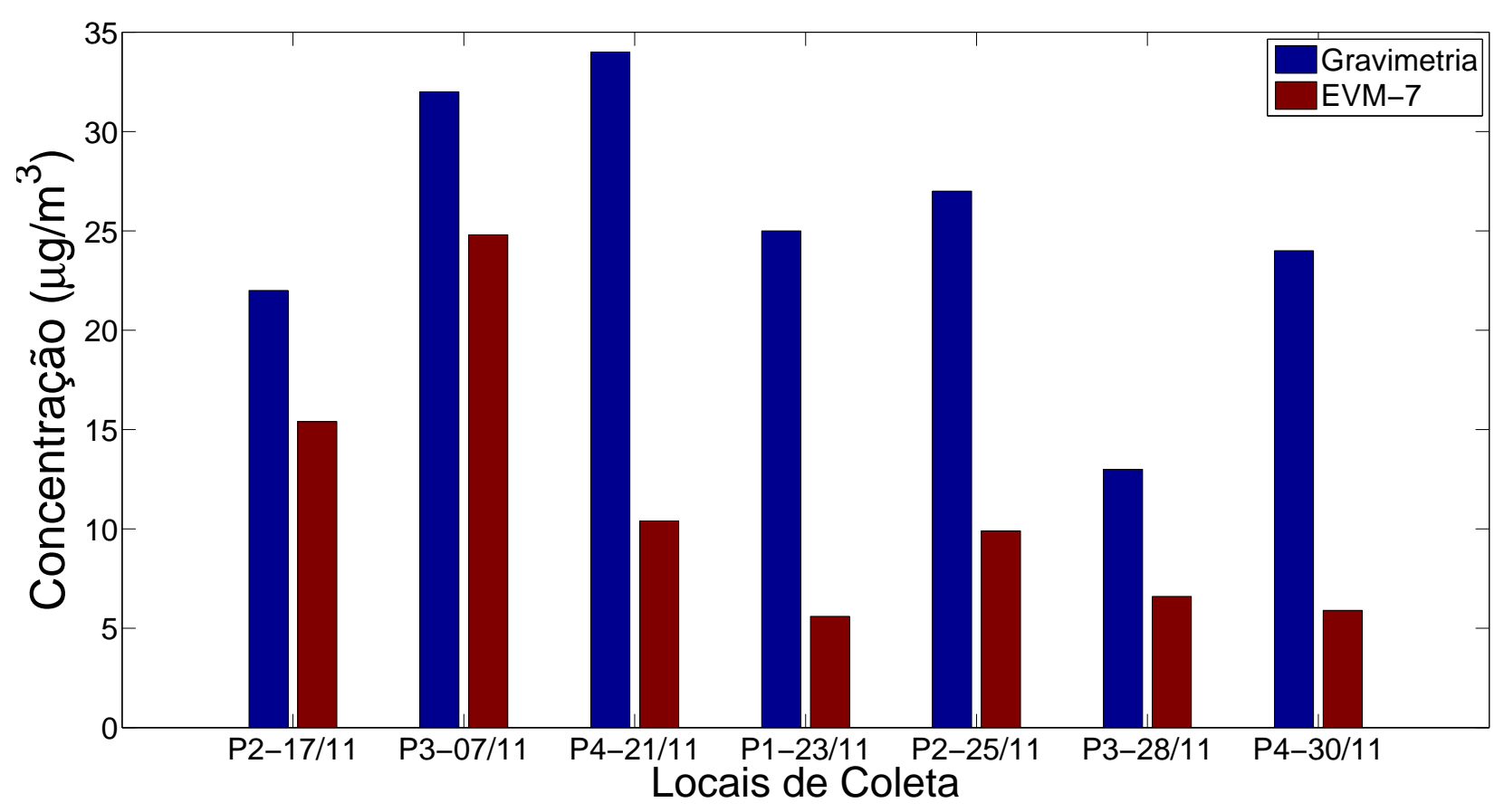




\subsection{Váriaveis climáticas}

Um dos fenômenos que regula a concentração de poluentes atmosféricos e, consequentemente, a concentração de material particulado, é a ocorrência ou não de precipitação. A chuva atua na atmosfera como um lavador de gases, carregando consigo as partículas e gases dispersos. Na cidade de São Carlos, de acordo com vários trabalhos anteriores, esta situação é bem definida, na estação seca a concentração dos níveis de material particulado é superior as concetrações encontradas na época em que há ocorrência de chuva.

Apesar de o número de coletas realizadas na estação seca ter sido restrita, é possivel observar que as concentrações, neste período, apresentam valores superiores aos da estação chuvosa. A Tabela 14 apresenta os valores de precipitação e das concentrações de MP nas frações coletadas. Nos dias que antecederam a coleta do dia 7/6/2.011 não houve precipitação, sendo que neste dia ocorreu um evento atípico, uma ventania, ocasionando grande ressuspensão. Por isso, os valores altos de concentração encontrados neste dia, de 108, 102 e $45 \mu \mathrm{g} / \mathrm{m}^{3}$ para $\mathrm{MP}_{10}$ interno, $\mathrm{MP}_{10}$ e $\mathrm{MP}_{2,5}$ externo, respectivamente. Devido à ocorrência de precipitação, nos dias subsequentes, os valores de concentração obtidos foram menores. Já na coleta do dia 14/6/2.011, depois de quatro dias sem chuva ou com valores ínfimos, a concentração apresentou resultados mais elevados de 85,78 e $51 \mu \mathrm{g} / \mathrm{m}^{3}$ para o $\mathrm{MP}_{10}$ interno e para o $\mathrm{MP}_{10}$ e $\mathrm{MP}_{2,5}$ externo, respectivamente. Mas este ponto estava localizado na Avenida São Carlos, sendo o ponto de coleta que ficava na via de maior trânsito de veículos, podendo este também ser um fator da elevação dos valores de concentração de MP.

Para as coletas realizadas no mês de novembro e dezembro, as concentrações apresentaram valores inferiores aos encontrados na estação seca. A variação ocorrida entre os dias de coleta foi pequena, com exceção dos dias 7/11/2.011 e 1/12/2.011, em que as concentrações foram de 40 e $30 \mu \mathrm{g} / \mathrm{m}^{3}$, respectivamente (Tabela 14 ).

Não era um dos objetivos deste trabalho comparar as duas estações, sendo priorizado o estudo da relação interno/externo das concentrações de MP. Como já mencionado anteriormente, os valores de concentração internos, apesar de na maioria dos casos apresentarem valores um pouco superiores ao ambiente externo, acompanham a variação do ambiente externo, nos dias em que houve precipitação, fazendo com que a concentração do ambiente externo apresentasse valores mais baixos, sendo que essa variação era também seguida no ambiente interno. 
Tabela 14 - Valores de precipitação e concentração de $\mathrm{MP}_{10}$ e $\mathrm{MP}_{2,5}$ nos ambientes interno e externo

\begin{tabular}{|c|c|c|c|c|c|c|}
\hline \multirow{2}{*}{ Data } & \multirow{2}{*}{ Ponto de coleta } & \multirow{2}{*}{ Precipitação $(\mathrm{mm})$} & \multicolumn{2}{|c|}{$\mathbf{M P} 10$} & \multicolumn{2}{|c|}{$\mathbf{M P} \mathbf{P}_{2,5}$} \\
\hline & & & Interno & externo & Interno & Externo \\
\hline $5 / 6 / 11$ & - & 0 & - & - & - & - \\
\hline $6 / 6 / 11$ & - & 0 & - & - & - & - \\
\hline $7 / 6 / 11$ & $\mathrm{P} 2$ & 20,4 & 108 & 102 & - & 45 \\
\hline $8 / 6 / 11$ & P3 & 0 & 24 & 19 & - & 7 \\
\hline $9 / 6 / 11$ & - & 23,4 & - & - & - & - \\
\hline $10 / 6 / 11$ & P4 & 0,2 & 27 & 25 & - & 14 \\
\hline $11 / 6 / 11$ & - & 0,4 & - & - & - & - \\
\hline $12 / 6 / 11$ & - & 0 & - & - & - & - \\
\hline $13 / 6 / 11$ & - & 0,2 & - & - & - & - \\
\hline 14/6/11 & $\mathrm{P} 1$ & 0 & 85 & 78 & - & 51 \\
\hline $6 / 11 / 11$ & - & 0 & - & - & - & - \\
\hline 7/11/11 & D3 & 1,6 & 40 & 32 & - & - \\
\hline $8 / 11 / 11$ & P3 & 0,2 & - & - & 19 & 17 \\
\hline $14 / 11 / 11$ & - & 38,6 & - & - & - & - \\
\hline $15 / 11 / 11$ & - & 53 & - & - & - & - \\
\hline $16 / 11 / 11$ & - & 0 & - & - & - & - \\
\hline $17 / 11 / 11$ & P2 & 0 & 23 & 22 & - & - \\
\hline $18 / 11 / 11$ & $\mathrm{P} 2$ & 0 & - & - & 21 & 17 \\
\hline $19 / 11 / 11$ & - & 0 & - & - & - & - \\
\hline $20 / 11 / 11$ & - & 0 & - & - & - & - \\
\hline $21 / 11 / 11$ & D4 & 0 & 27 & 34 & - & - \\
\hline $22 / 11 / 11$ & P4 & 15,4 & - & - & 19 & 17 \\
\hline $23 / 11 / 11$ & P1 & 0,2 & 27 & 25 & - & 13 \\
\hline $24 / 11 / 11$ & P1 & 0 & 24 & - & 14 & 12 \\
\hline $25 / 11 / 11$ & P2 & 0 & 24 & 27 & - & 17 \\
\hline $26 / 11 / 11$ & $\mathrm{P} 2$ & 26,2 & 26 & - & 14 & 15 \\
\hline $27 / 11 / 11$ & - & 3,4 & - & - & - & \\
\hline $28 / 11 / 11$ & P3 & 0 & 21 & 13 & - & 8 \\
\hline $29 / 11 / 11$ & P3 & 1,2 & 24 & - & 11 & 9 \\
\hline $30 / 11 / 11$ & $\mathrm{P} 4$ & 6,6 & 22 & 24 & - & 12 \\
\hline $1 / 12 / 11$ & $\mathrm{P} 4$ & 0 & 30 & - & 17 & 18 \\
\hline
\end{tabular}

As Figuras 43 e 44 apresentam os gráficos do comportamento entre temperatura e umidade relativa do ar e as concentrações de $\mathrm{MP}_{10}$ para o ambiente interno, apenas para as coletas da estação chuvosa. A concentração de MP seguiu uma têndencia em acompanhar a umidade relativa, já que está está bastante relacionada com a precipitação. 
Figura 43 - Comparação da temperatura e concentração de $\mathrm{MP}_{10}$ internos

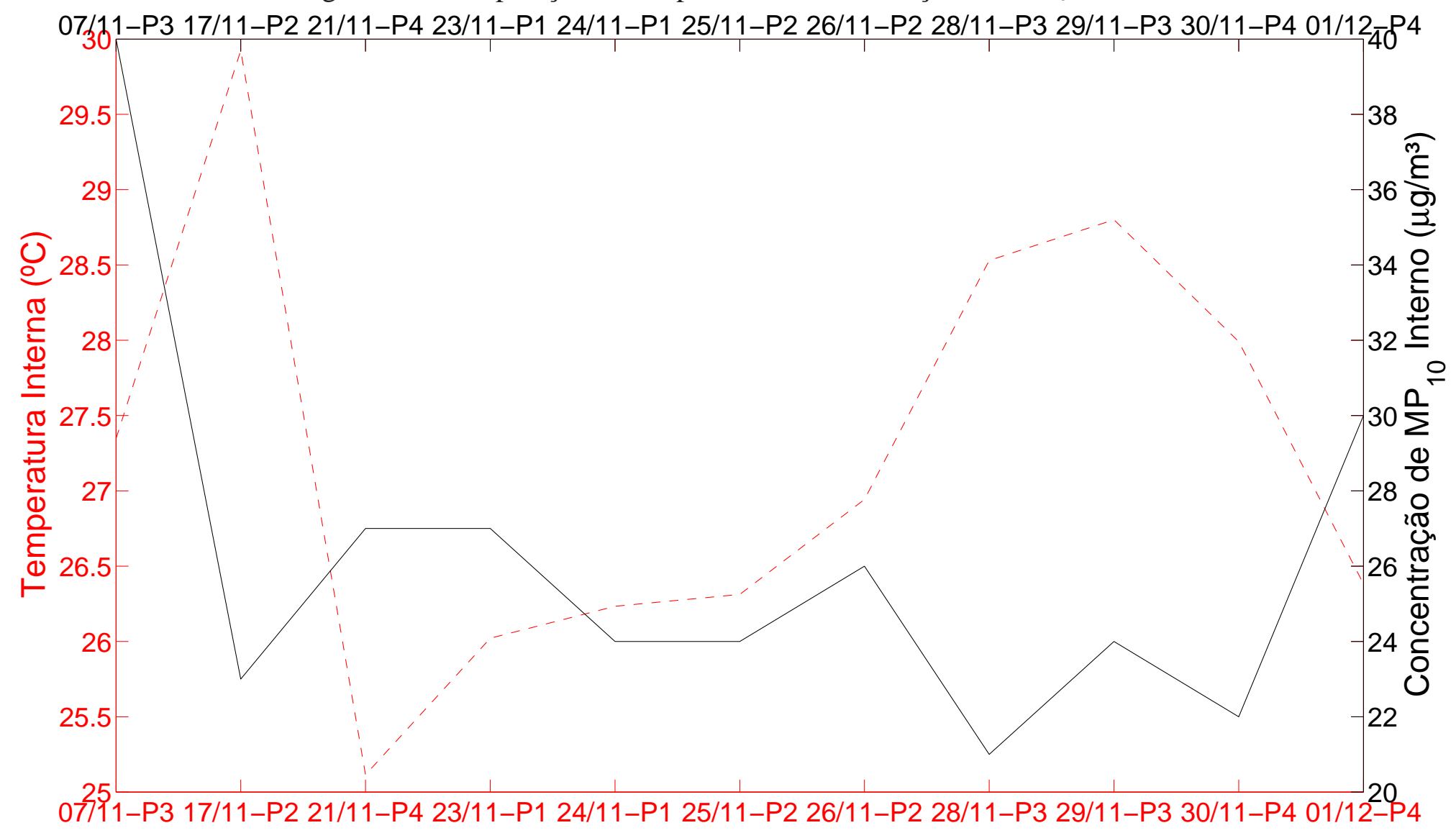


Figura 44 - Comparação da umidade relativa e concentração de $\mathrm{MP}_{10}$ internos

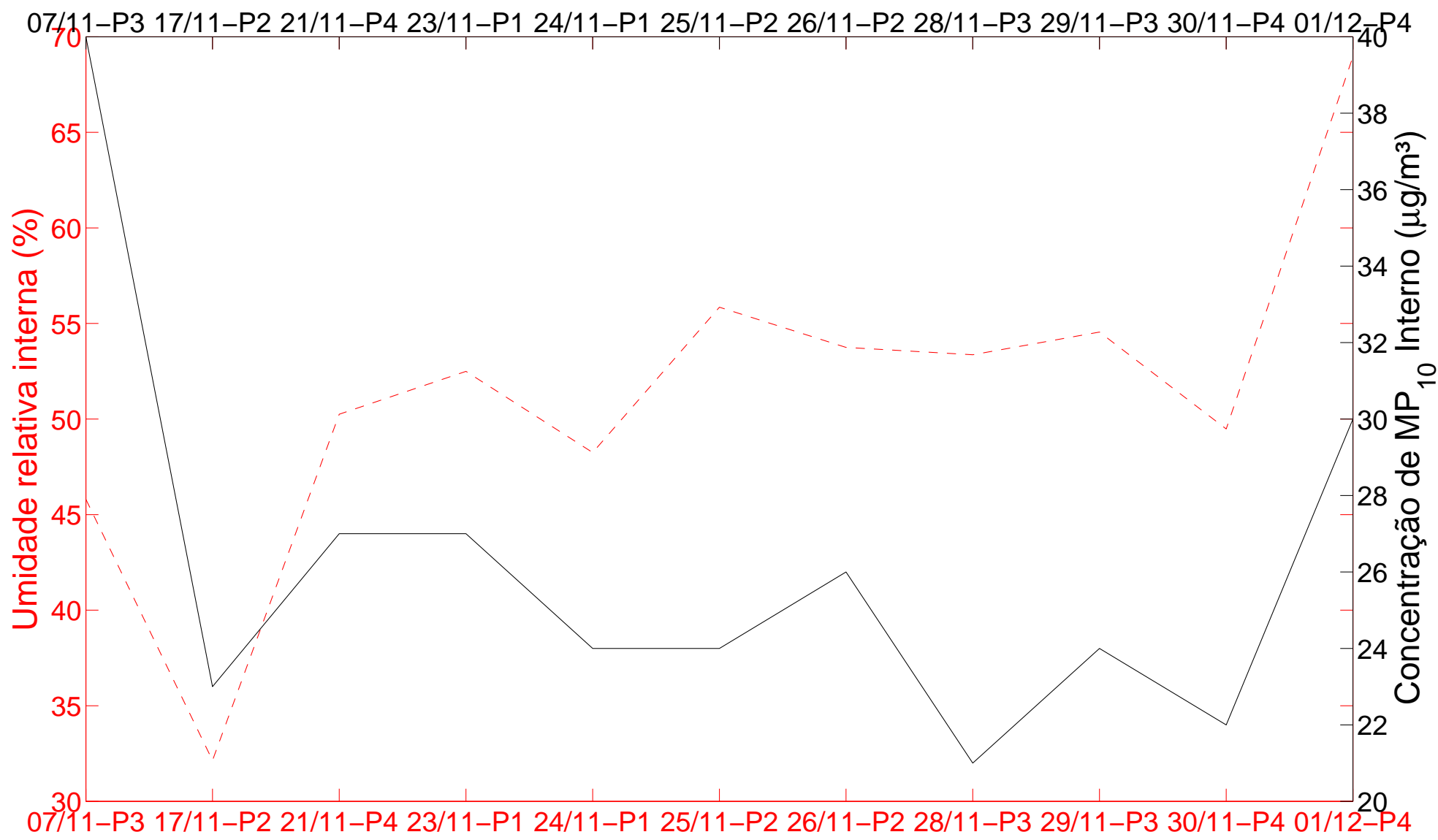




\section{Conclusões}

Conclui-se pelo presente trabalho que:

- Com os valores de concentração e a análise química do material particulado deste trabalho, foi possível observar que os ambientes internos monitorados seguem as variações sofridas pelo ambiente externo. Apesar das concentrações serem muito próximas entre os ambientes, o ambiente interno apresentou valores superiores aos do ambiente externo, na maior parte dos dias monitorados. Com relação aos padrões estabelecidos, foi observado que, na estação chuvosa, os valores encontrados não ultrapassaram os limites estabelecidos pela OMS, no entanto, o aumento das concentrações do $\mathrm{MP}_{2,5}$, nos últimos dez anos, inspira cuidados, principalmente porque não é acompanhado pela elevação do $\mathrm{MP}_{10} \mathrm{e}$, sim, vêm se apresentando como uma fração cada vez mais significativa do $\mathrm{MP}_{10}$. Também não foram observados diferenças significativas entre os pontos de monitoramento, sendo que, os valores encontrados são semelhantes nas duas vias de grande circulação de veículos e no calçadão da cidade.

- Em relação ao ruído, os valores encontrados, no calçadão, foram inferiores aos encontrados nos ambientes que ficavam de frente para as vias de circulação de veículos, indicando que os veículos representam uma fonte relevante para aumento dos níveis de poluição sonora do centro de São Carlos. Os níveis encontrados de ruído para os ambientes internos e externos em nenhum dia atenderam ao padrão estabalecido pela NBR 10.151/2000.

- Para os níveis de conforto térmico apresentados neste trabalho, foi verificado que os ocupantes desses ambientes estiveram, na maior parte dos dias monitorados, expostos à sensação relativa de desconforto térmico, o que foi observado comparando-se os valores encontrados de temperatura e umidade relativa do ar com o índice de calor (HI) e a ANVISA nº 09/2003.

- A membrana utilizada para coleta de material particulado não é adequada para a realização da análise química pela técnica do XRF. 


\section{Sugestões para trabalhos futuros}

A partir dos resultados obtidos por esta pesquisa, consideram-se os seguintes pontos pertinentes para trabalhos futuros:

- Inicialmente, a necessidade da realização da análise química do material particulado de maneira contínua, especialmente do $\mathrm{MP}_{2,5}$, que mostrou relevante crescimento nos últimos anos e a identificação das fontes de poluição.

- A realização de estudo similar a este em diferentes tipos de comércio, objetivanto verificar, por exemplo, a interferência dos diferentes objetos de comércio na qualidade do ar dos ambientes internos.

- O monitoramento de ambientes climatizados artificialmente e a sua comparação com os de ventilação natural.

- A aplicação de questionários, para entendimento da percepção da população em relação à qualidade ambiental dos ambientes internos e da região central.

- Realizar caracterização das membranas e, adequação da metodologia para que a análise química possa ser realizada de maneira efetiva, como a substituição do uso do PEM por outros métodos de filtração. 


\section{Referências}

ABNT. ASSOCIAÇÃO BRASILEIRA DE NORMAS TÉCNICAS - NBR 10151. Avaliação do Ruído em Áreas Habitadas Visando o Conforto da Comunidade, 2000.

AFEEVAS. Conselho estadual do meio ambiente. In: . Padrões de Qualidade do Ar Aprovados em 25/05/2011 pelo CONSEMA (Conselho Estadual do Meio Ambiente) para o Estado de São Paulo. CONSEMA, 2012. Disponível em: <http://www.afeevas.org.br $=>$.

ANVISA. AGÊNCIA NACIONAL DE VIGILÂNIA SANITÁRIA. RE/ANVISA $n^{\circ}$ 09: Avaliação da qualidade do ar interior, 2003.

BARBOSA, A.; CARDOSO, M. Hearing loss among workers exposed to road traffic noise in the city of São Paulo in Brazil. Auris Nasus Larynx, Elsevier, v. 32, n. 1, p. 17-21, 2005.

BASCOM, R. Health effects of outdoor air pollution. American Journal of Respiratory and Critical Care Medicine, v. 153, n. 1, p. 3-50, 1996.

BELOJEVIC, G. et al. Urban road-traffic noise and blood pressure and heart rate in preschool children. Environment international, Elsevier, v. 34, n. 2, p. 226-231, 2008.

BERNSTEIN, J. et al. Health effects of air pollution. Journal of Allergy and Clinical Immunology, Elsevier, v. 114, n. 5, p. 1116-1123, 2004.

BRAUER, M. et al. A cohort study of traffic-related air pollution impacts on birth outcomes. Environmental Health Perspectives, National Institute of Environmental Health Science, v. 116, n. 5 , p. 680, 2008.

BRICKUS, L.; NETO, F. A. A qualidade do ar de interiores e a química. Química Nova, SciELO Brasil, v. 22, n. 1, p. 56-74, 1999.

BRUCE, N.; PEREZ-PADILLA, R.; ALBALAK, R. Indoor air pollution in developing countries: a major environmental and public health challenge. Bulletin of the World Health Organization, v. 78, n. 9, p. 1078-1092, 2000.

BRUNO, L. R. Material particulado atmosférico na cidade de São Carlos-SP: quantificação e identificação de fontes. Tese (Doutorado) — Universidade Federal de São Carlos, 2005. 
BRUNO, R. et al. Atmospheric particulate matter in the city of São Carlos/SP, Brazil. International Journal of Environment and Pollution, Inderscience, v. 22, n. 4, p. 476-489, 2004.

CASTANHO, A.; ARTAXO, P. Wintertime and summertime são paulo aerosol source apportionment study. Atmospheric Environment, Elsevier, v. 35, n. 29, p. 4889-4902, 2001.

CELLI, C. et al. Concentração de material particulado suspenso na atmosfera em São Carlos-SP. Engenharia Sanitária e Ambiental, v. 8, n. 1/2, p. 6-12, 2003.

CELLI, C. E. Monitoramento do material particulado respirável suspenso na atmosfera no centro da cidade de São Carlos - SP. Dissertação (Mestrado) — Universidade Federal de São Carlos, 1999.

CENDON, S. et al. Air pollution effects on myocardial infarction. Revista de Saúde Pública, SciELO Public Health, v. 40, n. 3, p. 414-419, 2006.

CETESB. Comparação entre os períodos de safra e entressafra de cana de açucar. [S.1.], 2000.

CETESB. Relatório de qualidade do ar no estado de São Paulo. [S.1.], 2011.

CONTINI, D. et al. Analysis of particles and carbon dioxide concentrations and fluxes in an urban area: correlation with traffic rate and local micrometeorology. Atmospheric Environment, Elsevier, v. 46, p. 25-35, 2012.

ELLER, P. Niosh manual of analytical methods. Department of Health and Human Services, 1998.

EMBRAPA. Dados meteorológicos. In: __ Pecuária Sudeste. Empresa Brasileira de Pesquisa Agropecuária, 2012. Disponível em: <http://www.cppse.embrapa.br/dadosmeteorologicos >. Acesso em: 23 mar. 2012.

ERLANDSSON, S. et al. Cultural and social perspectives on attitudes, noise, and risk behavior in children and young adults. In: THIEME MEDICAL PUBLISHERS INC. Seminars in hearing. [S.1.], 2008. v. 29, n. 1, p. 29.

EVANS, G. et al. Community noise exposure and stress in children. The Journal of the Acoustical Society of America, v. 109, p. 1023, 2001. 
FILHO, M. P. et al. Effect of air pollution on diabetes and cardiovascular diseases in São Paulo, Brazil. Brazilian Journal of Medical and Biological Research, SciELO Brasil, v. 41, n. 6, p. 526-532, 2008.

FREW, A. Advances in environmental and occupational diseases 2004. Journal of allergy and clinical immunology, Elsevier, v. 115, n. 6, p. 1197-1202, 2005.

GODISH, T. Air quality. Lewis Publishers, Chelsea, MI, 1991.

GOOGLEMAPS. Google maps. In: __ Cidade de São Carlos. Google, 2012. Disponível em: $<$ http://maps.google.com.br/ = >.

HARRISON, R. et al. Processes affecting concentrations of fine particulate matter $\left(\mathrm{PM}_{2.5}\right)$ in the UK atmosphere. Atmospheric Environment, Elsevier, v. 46, p. 115-124, 2011.

HAY, B.; KEMP, M. Measurements of noise in air conditioned, landscaped offices. Journal of Sound and Vibration, Elsevier, v. 23, n. 3, p. 363-373, 1972.

HOEK, G. et al. Association between mortality and indicators of traffic-related air pollution in the netherlands: a cohort study. The lancet, Elsevier, v. 360, n. 9341, p. 1203-1209, 2002.

IBGE. Ibge: São carlos/sp. In: ___ IBGE Cidades@. Instituto Brasieliro de Geografia e Estatística, 2012. Disponível em: <http://www.ibge.gov.br/cidadesat/link.php?uf=sp >. Acesso em: 26 jan. 2012.

ITO, L. X. Monitoramento da qualidade ao ar de ambientes internos - Bibliotecas. Tese (Doutorado) — Universidade Federal de São Carlos, 2007.

KELLER-OLAMAN, S. et al. Individual and neighborhood characteristics associated with environmental exposure. Environment and behavior, Sage Publications, v. 37, n. 4, p. 441, 2005.

LEE, S. et al. Inter-comparison of air pollutant concentrations in different indoor environments in hong kong. Atmospheric Environment, Elsevier, v. 36, n. 12, p. 1929-1940, 2002.

LEE, S.; HO, C.; CHOI, Y. High-pm10 concentration episodes in seoul, korea: Background sources and related meteorological conditions. Atmospheric Environment, Elsevier, v. 45, p. 72407247, 2011. 
LOCALIZASãOCARLOS. Mapa de são carlos. In: Localiza São Carlos. Universidade de São Paulo, 2012. Disponível em: <http://www.saocarlos.usp.br/calouros/sobre-a-cidade.php $=>$.

MARQUES, K. et al. Assessment of atmospheric particulate matter in São Carlos-SP, Brazil. Environmental Management and Health, MCB UP Ltd, v. 12, n. 1, p. 17-25, 2001.

MARQUES, K. A. Caracterização do material particulado suspenso na atmosfera da cidade de São Carlos. Dissertação (Mestrado) — Universidade Federal de São Carlos, 2000.

MARTINS, J.; DIAS, M.; GONÇALVES, F. Impact of biomass burning aerosols on precipitation in the Amazon: A modeling case study. J. Geophys. Res, v. 114, p. D02207, 2009.

MODIG, L. et al. Vehicle exhaust exposure in an incident case-control study of adult asthma. European Respiratory Journal, Eur Respiratory Soc, v. 28, n. 1, p. 75, 2006.

MUZET, A. Environmental noise, sleep and health. Sleep medicine reviews, Elsevier, v. 11, n. 2, p. 135-142, 2007.

MYERS, I.; MAYNARD, R. Polluted air-outdoors and indoors. Occupational medicine, Soc Occupational Med, v. 55, n. 6, p. 432, 2005.

NASCIMENTO, G. C. do. Avaiação da qualidade do ar em ambientes internos: Biblioteca pública. Dissertação (Mestrado) — Universidade de São Paulo, 2011.

OLMO, N. et al. A review of low-level air pollution and adverse effects on human health: implications for epidemiological studies and public policy. Clinics, SciELO Brasil, v. 66, n. 4, p. 681-690, 2011.

OMOKHODION, F.; EKANEM, S.; UCHENDU, O. Noise levels and hearing impairment in an urban community in ibadan, southwest nigeria. Journal of Public Health, Springer, v. 16, n. 6, p. 399-402, 2008.

OMS. ORGANIZAÇÃO MUNDIAL DA SAUDE. Air quality guidelines: global update 2005: particulate matter, ozone, nitrogen dioxide and sulfur dioxide, 2006. 
PASSCHIER-VERMEER, W.; PASSCHIER, W. Noise exposure and public health. Environmental Health Perspectives, National Institute of Environmental Health Science, v. 108, n. Suppl 1, p. 123, 2000.

PETERS, J. et al. A study of twelve southern california communities with differing levels and types of air pollution. i. prevalence of respiratory morbidity. American journal of respiratory and critical care medicine, Am Thoracic Soc, v. 159, n. 3, p. 760, 1999.

PETIAN, A. Incomôdo em relação ao ruído urbano entre os trabalhadores de estabelecimentos comerciais no município de São Paulo. Tese (Doutorado) — Faculdade de Medicina da Universidade de São Paulo, 2008.

POKHREL, A. et al. Case-control study of indoor cooking smoke exposure and cataract in Nepal and India. International journal of epidemiology, IEA, v. 34, n. 3, p. 702, 2005.

POPE, C.; YOUNG, B.; DOCKERY, D. Health effects of fine particulate air pollution: lines that connect. Journal of the Air \& Waste Management Association, Air \& Waste Management Association, One Gateway Center, Third Floor, 420 Fort Duquesne Blvd, Pittsburgh, PA, 15222, USA,, v. 56, n. 6, p. 709-742, 2006.

POWER, M. et al. Traffic-related air pollution and cognitive function in a cohort of older men. Environmental health perspectives, National Institute of Environmental Health Science, v. 119, n. 5 , p. $682,2011$.

POZZA, S. A. Identificação das fontes de poluição atmosférica na cidade de São Carlos - SP. Dissertação (Mestrado) - Universidade Federal de São Carlos, 2005.

POZZA, S. A. et al. Identificação de possíveis fontes de poluição atmosférica na cidade de São Carlos. In: Anais do 9Simpósio Internacional da Qualidade Ambiental. Porto Alegre: [s.n.], 2004.

RAASCHOU-NIELSEN, O. et al. Air pollution from traffic at the residence of children with cancer. American journal of epidemiology, Oxford Univ Press, v. 153, n. 5, p. 433, 2001.

RICHARDSON, G.; EICK, S.; JONES, R. How is the indoor environment related to asthma?: literature review. Journal of advanced nursing, Wiley Online Library, v. 52, n. 3, p. 328-339, 2005. 
ROTHFUSZ, L.; HEADQUARTERS, N. The heat index equation (or, more than you ever wanted to know about heat index). Fort Worth, Texas: National Oceanic and Atmospheric Administration, National Weather Service, Office of Meteorology, p. 90-23, 1990.

SALDIVA, P. et al. Respiratory alterations due to urban air pollution: an experimental study in rats. Environmental Research, Elsevier, v. 57, n. 1, p. 19-33, 1992.

SHAKA, H.; SALIBA, N. Concentration measurements and chemical composition of $\mathrm{PM}_{10-2.5}$ and $\mathrm{PM}_{2.5}$ at a coastal site in Beirut Lebanon. Atmospheric Environment, Elsevier, v. 38, n. 4, p. 523-531, 2004.

SKC. Skc. In: __ _ SKC. World Leader in Sampling Technologies, 2012. Disponível em: $<$ http://www.skcinc.com $=>$.

STERNBECK, J.; SJÖDIN, A.; ANDRÉASSON, K. Metal emissions from road traffic and the influence of resuspension-results from two tunnel studies. Atmospheric Environment, Elsevier, v. 36, n. 30, p. 4735-4744, 2002.

SUNDELL, J. On the history of indoor air quality and health. Indoor air, Wiley Online Library, v. 14, p. 51-58, 2004.

USEPA. PM 2.5 NAAQS Implementation. [S.1.], 1997.

WATSON, J.; CHOW, J. Source characterization of major emission sources in the Imperial and Mexicali valleys along the US/Mexico border. The science of the total environment, Elsevier, v. 276, n. 1-3, p. 33-47, 2001.

WILHELM, M.; RITZ, B. Residential proximity to traffic and adverse birth outcomes in Los Angeles county, California, 1994-1996. Environmental Health Perspectives, National Institute of Environmental Health Science, v. 111, n. 2, p. 207, 2003.

WILLICH, S. et al. Noise burden and the risk of myocardial infarction. European heart journal, Eur Soc Cardiology, v. 27, n. 3, p. 276, 2006.

ZANNIN, P.; DINIZ, F.; BARBOSA, W. Environmental noise pollution in the city of Curitiba, Brazil. Applied Acoustics, Elsevier, v. 63, n. 4, p. 351-358, 2002. 


\section{A APÊNDICE - Dados da gravimetria da fase de coleta preliminar de dados}

Tabela 15 - Gravimetria da fase de coleta preliminar

\begin{tabular}{|c|c|c|c|c|c|c|c|c|c|c|c|c|}
\hline $\mathbf{M} \mathbf{P}_{10} / \mathbf{M P}_{2,5}$ & & Data da coleta & P1 (mg) & P2 (mg) & Média (mg) & P1(mg) & P2(mg) & Média (mg) & $\Delta$ Média $(\mu \mathrm{g})$ & Volume $(\mathrm{L})$ & Correção $\Delta$ Média & Concentração $\left(\mu \mathrm{g} / \mathbf{m}^{3}\right)$ \\
\hline $\mathrm{MP}_{10}$ & I & $10 / 5 / 2011$ & 40,598 & 40,595 & 40,5965 & 42,696 & 42,69 & 42,693 & 2096,5 & 4701 & 2096,503 & 446 \\
\hline $\mathrm{MP}_{10}$ & $\mathrm{E}$ & $10 / 5 / 2011$ & 38,893 & 38,891 & 38,892 & 40,861 & 40,861 & 40,861 & 1969,0 & 4705 & 1969,003 & 418 \\
\hline $\mathrm{MP}_{2,5}$ & $\mathrm{E}$ & $10 / 5 / 2011$ & 38,457 & 38,455 & 38,456 & 38,822 & 38,824 & 38,823 & 367,0 & 4527 & 367,003 & 81 \\
\hline $\mathrm{MP}_{10}$ & I & $12 / 5 / 2011$ & 39,796 & 39,787 & 39,7915 & 40,04 & 40,04 & 40,04 & 248,5 & 4732 & 248,503 & 53 \\
\hline $\mathrm{MP}_{10}$ & $\mathrm{E}$ & $12 / 5 / 2011$ & 40,086 & 40,086 & 40,086 & 40,455 & 40,458 & 40,4565 & 370,5 & 4725 & 370,503 & 78 \\
\hline $\mathrm{MP}_{2,5}$ & $\mathrm{E}$ & $12 / 5 / 2011$ & 37,162 & 37,164 & 37,163 & 37,33 & 37,331 & 37,3305 & 167,5 & 4731 & 167,503 & 35 \\
\hline $\mathrm{MP}_{10}$ & I & $13 / 5 / 2011$ & 41,058 & 41,063 & 41,0605 & 41,421 & 41,422 & 41,4215 & 361,0 & 4665 & 361,003 & 77 \\
\hline $\mathrm{MP}_{10}$ & $\mathrm{E}$ & $13 / 5 / 2011$ & 40,208 & 40,204 & 40,206 & 40,374 & 40,374 & 40,374 & 168,0 & 4677 & 168,003 & 36 \\
\hline $\mathrm{MP}_{2,5}$ & $\mathrm{E}$ & $13 / 5 / 2011$ & 40,045 & 40,044 & 40,0445 & 40,215 & 40,216 & 40,2155 & 171,0 & 4677 & 171,003 & 37 \\
\hline $\mathrm{MP}_{2,5}$ & E & $7 / 6 / 2011$ & 97,001 & 97,003 & 97,002 & 97,222 & 97,215 & 97,2185 & 216,5 & 4800 & 216,5 & 45 \\
\hline $\mathrm{MP}_{10}$ & I & 7/6/2011 & 88,871 & 88,873 & 88,872 & 89,378 & 89,403 & 89,3905 & 518,5 & 4800 & 518,5 & 108 \\
\hline $\mathrm{MP}_{10}$ & $\mathrm{E}$ & $7 / 6 / 2011$ & 90,173 & 90,17 & 90,1715 & 90,658 & 90,662 & 90,66 & 488,5 & 4800 & 488,5 & 102 \\
\hline $\mathrm{MP}_{10}$ & I & $8 / 6 / 2011$ & 90,998 & 90,997 & 90,9975 & 91,111 & 91,111 & 91,111 & 113,5 & 4800 & 113,5 & 24 \\
\hline $\mathrm{MP}_{10}$ & E & $8 / 6 / 2011$ & 96,171 & 96,171 & 96,171 & 96,264 & 96,263 & 96,2635 & 92,5 & 4800 & 92,5 & 19 \\
\hline $\mathrm{MP}_{2,5}$ & $\mathrm{E}$ & 8/6/2011 & 94,797 & 94,801 & 94,799 & 94,834 & 94,834 & 94,834 & 35,0 & 4800 & 35,0 & 7 \\
\hline $\mathrm{MP}_{10}$ & I & $10 / 6 / 2011$ & 92,956 & 92,955 & 92,9555 & 93,09 & 93,083 & 93,0865 & 131,0 & 4800 & 131,0 & 27 \\
\hline $\mathrm{MP}_{10}$ & $\mathrm{E}$ & $10 / 6 / 2011$ & 90,912 & 90,913 & 90,9125 & 91,033 & 91,031 & 91,032 & 119,5 & 4800 & 119,5 & 25 \\
\hline $\mathrm{MP}_{2,5}$ & $\mathrm{E}$ & $10 / 6 / 2011$ & 91,584 & 91,584 & 91,584 & 91,652 & 91,648 & 91,65 & 66,0 & 4800 & 66,0 & 14 \\
\hline
\end{tabular}




\section{B APÊNDICE - Dados da gravimetria da fase de coleta efetiva dos dados}

Tabela 16 - Gravimetria da fase de coleta efetiva

\begin{tabular}{|c|c|c|c|c|c|c|c|c|c|c|c|c|}
\hline $\mathbf{M P} \mathbf{P}_{10} / \mathbf{M P}_{2,5}$ & $\mathbf{I} / \mathbf{E}$ & Data coleta & P1 (mg) & $\mathbf{P 2}(\mathbf{m g})$ & Média (mg) & P1(mg) & P2(mg) & Média (mg) & $\Delta$ Média $(\mu \mathrm{g})$ & Volume $(\mathrm{L})$ & Correção $\Delta$ Média & Concentração $\left(\mu \mathrm{g} / \mathbf{m}^{3}\right)$ \\
\hline BRANCA & & & 184,2066 & 184,201 & 184,2038 & 184,2092 & 184,2075 & 184,20835 & 4,55 & & & \\
\hline BRANCA & & & 191,4415 & 191,4424 & 191,44195 & 191,444 & 191,4449 & 191,44445 & 2,5 & & & \\
\hline BRANCA & & & 195,5046 & 195,5043 & 195,50445 & 195,5081 & 195,5085 & 195,5083 & 3,85 & & & \\
\hline BRANCA & & & 176,081 & 176,083 & 176,082 & 176,0838 & 176,0843 & 176,08405 & 2,05 & & & \\
\hline $\mathrm{MP}_{10}$ & I & 7/11/2011 & 227,853 & 227,8535 & 227,85325 & 228,0491 & 228,0486 & 228,04885 & 195,6 & 4800 & 192,3625 & 40 \\
\hline $\mathrm{MP}_{10}$ & E & 7/11/2011 & 221,2644 & 221,2637 & 221,26405 & 221,4209 & 221,4238 & 221,42235 & 158,3 & 4800 & 155,0625 & 32 \\
\hline $\mathrm{MP}_{2,5}$ & I & 8/11/2011 & 222,777 & 222,777 & 222,777 & 222,8728 & 222,8748 & 222,8738 & 96,8 & 4800 & 93,5625 & 19 \\
\hline $\mathrm{MP}_{2,5}$ & E & 8/11/2011 & 221,8452 & 221,8451 & 221,84515 & 221,9304 & 221,931 & 221,9307 & 85,55 & 4800 & 82,3125 & 17 \\
\hline $\mathrm{MP}_{10}$ & I & 17/11/2011 & 177,8427 & 177,8429 & 177,8428 & 177,9565 & 177,9576 & 177,95705 & 114,25 & 4800 & 111,0125 & 23 \\
\hline $\mathrm{MP}_{10}$ & E & $17 / 11 / 2011$ & 189,44 & 189,4425 & 189,44125 & 189,5472 & 189,5484 & 189,5478 & 106,55 & 4800 & 103,3125 & 22 \\
\hline $\mathrm{MP}_{2,5}$ & I & 18/11/2011 & 179,5054 & 179,506 & 179,5057 & 179,6078 & 179,6085 & 179,60815 & 102,45 & 4800 & 99,2125 & 21 \\
\hline $\mathrm{MP}_{2,5}$ & E & $18 / 11 / 2011$ & 193,0866 & 193,0861 & 193,08635 & 193,1695 & 193,1714 & 193,17045 & 84,1 & 4800 & 80,8625 & 17 \\
\hline $\mathrm{MP}_{10}$ & I & $21 / 11 / 2011$ & 213,045 & 213,0455 & 213,04525 & 213,1767 & 213,1802 & 213,17845 & 133,2 & 4800 & 129,9625 & 27 \\
\hline $\mathrm{MP}_{10}$ & E & $21 / 11 / 2011$ & 207,196 & 207,1957 & 207,19585 & 207,3056 & 207,3082 & 207,3069 & 111,05 & 3156 & 107,8125 & 34 \\
\hline $\mathrm{MP}_{2,5}$ & I & 22/11/2011 & 185,7739 & 185,7746 & 185,77425 & 185,8687 & 185,8692 & 185,86895 & 94,7 & 4800 & 91,4625 & 19 \\
\hline $\mathrm{MP}_{2,5}$ & E & $22 / 11 / 2011$ & 214,754 & 214,7542 & 214,7541 & 214,8383 & 214,8385 & 214,8384 & 84,3 & 4800 & 81,0625 & 17 \\
\hline $\mathrm{MP}_{10}$ & I & 23/11/2011 & 186,7424 & 186,7431 & 186,74275 & 186,8761 & 186,8746 & 186,87535 & 132,6 & 4800 & 129,3625 & 27 \\
\hline $\mathrm{MP}_{10}$ & E & 23/11/2011 & 197,4601 & 197,4605 & 197,4603 & 197,584 & 197,5807 & 197,58235 & 122,05 & 4800 & 118,8125 & 25 \\
\hline $\mathrm{MP}_{2,5}$ & E & 23/11/2011 & 214,1059 & 214,1049 & 214,1054 & 214,1736 & 214,1721 & 214,17285 & 67,45 & 4800 & 64,2125 & 13 \\
\hline $\mathrm{MP}_{10}$ & I & 24/11/2011 & 189,0988 & 189,0954 & 189,0971 & 189,2151 & 189,2162 & 189,21565 & 118,55 & 4800 & 115,3125 & 24 \\
\hline $\mathrm{MP}_{2,5}$ & I & 24/11/2011 & 175,9045 & 175,9078 & 175,90615 & 175,9739 & 175,9768 & 175,97535 & 69,2 & 4800 & 65,9625 & 14 \\
\hline $\mathrm{MP}_{2,5}$ & E & $24 / 11 / 2011$ & 181,0507 & 181,0527 & 181,0517 & 181,1129 & 181,1132 & 181,11305 & 61,35 & 4800 & 58,1125 & 12 \\
\hline
\end{tabular}


Tabela 17 - Gravimetria da fase de coleta efetiva (continuação)

\begin{tabular}{|c|c|c|c|c|c|c|c|c|c|c|c|c|}
\hline $\mathbf{M P} \mathbf{P}_{10} / \mathbf{M P}_{2,5}$ & $\mathbf{I} / \mathbf{E}$ & Data coleta & P1 (mg) & P2 (mg) & Média (mg) & P1(mg) & P2(mg) & Média (mg) & $\Delta$ Média $(\mu \mathrm{g})$ & Volume $(\mathrm{L})$ & Correção $\Delta$ Média & Concentração $\left(\mu \mathrm{g} / \mathbf{m}^{3}\right)$ \\
\hline $\mathrm{MP}_{10}$ & $\mathrm{I}$ & $25 / 11 / 2011$ & 197,7973 & 197,7937 & 197,7955 & 197,9134 & 197,9118 & 197,9126 & 117,1 & 4800 & 113,8625 & 24 \\
\hline $\mathrm{MP}_{10}$ & $\mathrm{E}$ & $25 / 11 / 2011$ & 186,1049 & 186,1064 & 186,10565 & 186,2363 & 186,2359 & 186,2361 & 130,45 & 4800 & 127,2125 & 27 \\
\hline $\mathrm{MP}_{2,5}$ & $\mathrm{E}$ & $25 / 11 / 2011$ & 183,4632 & 183,4641 & 183,46365 & 183,5467 & 183,5461 & 183,5464 & 82,75 & 4800 & 79,5125 & 17 \\
\hline $\mathrm{MP}_{10}$ & I & $26 / 11 / 2011$ & 173,9561 & 173,957 & 173,95655 & 174,0793 & 174,076 & 174,07765 & 121,1 & 4500 & 117,8625 & 26 \\
\hline $\mathrm{MP}_{2,5}$ & I & $26 / 11 / 2011$ & 190,1857 & 190,1853 & 190,1855 & 190,2526 & 190,2551 & 190,25385 & 68,35 & 4500 & 65,1125 & 14 \\
\hline $\mathrm{MP}_{2,5}$ & $\mathrm{E}$ & $26 / 11 / 2011$ & 187,2435 & 187,2499 & 187,2467 & 187,3176 & 187,3145 & 187,31605 & 69,35 & 4500 & 66,1125 & 15 \\
\hline BRANCA & & & 187.2895 & 187,2894 & 187,28945 & 187,2973 & 187,2972 & 187,29725 & 7,8 & & & \\
\hline BRANCA & & & 193,8269 & 193,8279 & 193,8274 & 193,8281 & 193,8283 & 193,8282 & 0,8 & & & \\
\hline BRANCA & & & 191,4906 & 191,4905 & 191,49055 & 191,4898 & 191,49 & 191,4899 & $-0,65$ & & & \\
\hline $\mathrm{MP}_{10}$ & I & $28 / 11 / 2011$ & 206,9603 & 206,9552 & 206,95775 & 207,0623 & 207,063 & 207,06265 & 104,9 & 4800 & 102,25 & 21 \\
\hline $\mathrm{MP}_{10}$ & $\mathrm{E}$ & $28 / 11 / 2011$ & 179,3191 & 179,3195 & 179,3193 & 179,3863 & 179,385 & 179,38565 & 66,35 & 4800 & 63,7 & 13 \\
\hline $\mathrm{MP}_{2,5}$ & $\mathrm{E}$ & $28 / 11 / 2011$ & 191,5829 & 191,5833 & 191,5831 & 191,6228 & 191,623 & 191,6229 & 39,8 & 4800 & 37,15 & 8 \\
\hline $\mathrm{MP}_{10}$ & I & $29 / 11 / 2011$ & 197,7369 & 197,7358 & 197,73635 & 197,8561 & 197,8539 & 197,855 & 118,65 & 4800 & 116 & 24 \\
\hline $\mathrm{MP}_{2,5}$ & I & $29 / 11 / 2011$ & 176,7088 & 176,7057 & 176,70725 & 176,7639 & 176,7639 & 176,7639 & 56,65 & 4800 & 54 & 11 \\
\hline $\mathrm{MP}_{2,5}$ & $\mathrm{E}$ & $29 / 11 / 2011$ & 183,4147 & 183,4149 & 183,4148 & 183,4596 & 183,4607 & 183,46015 & 45,35 & 4800 & 42,7 & 9 \\
\hline $\mathrm{MP}_{10}$ & I & $30 / 11 / 2011$ & 183,5043 & 183,5047 & 183,5045 & 183,6139 & 183,6103 & 183,6121 & 107,6 & 4800 & 104,95 & 22 \\
\hline $\mathrm{MP}_{10}$ & E & $30 / 11 / 2011$ & 183,3982 & 183,4001 & 183,39915 & 183,518 & 183,517 & 183,5175 & 118,35 & 4800 & 115,7 & 24 \\
\hline $\mathrm{MP}_{2,5}$ & $\mathrm{E}$ & $30 / 11 / 2011$ & 184,7004 & 184,7008 & 184,7006 & 184,7615 & 184,7604 & 184,76095 & 60,35 & 4800 & 57,7 & 12 \\
\hline $\mathrm{MP}_{10}$ & I & $1 / 12 / 2011$ & 180,5896 & 180,5877 & 180,58865 & 180,7357 & 180,7347 & 180,7352 & 146,55 & 4800 & 143,9 & 30 \\
\hline $\mathrm{MP}_{2,5}$ & I & $1 / 12 / 2011$ & 198,5636 & 198,5639 & 198,56375 & 198,6472 & 198,6504 & 198,6488 & 85,05 & 4800 & 82,4 & 17 \\
\hline $\mathrm{MP}_{2,5}$ & $\mathrm{E}$ & $1 / 12 / 2011$ & 171,6588 & 171,6599 & 171,65935 & 171,7486 & 171,7495 & 171,74905 & 89,7 & 4800 & 87,05 & 18 \\
\hline
\end{tabular}




\section{APÊNDICE - Dados de temperatura e umidade relativa do ar do dia 28/10/2011}

Tabela 18 - Temperatura e umidade relativa do ar do dia 28/10/2011

\begin{tabular}{ccccc}
\hline \multirow{2}{*}{ Hora } & \multicolumn{2}{c}{ Temperatura $\left({ }^{\mathbf{0}} \mathbf{C}\right)$} & \multicolumn{2}{c}{ Umidade relativa $(\%)$} \\
\cline { 2 - 5 } & Interno & Externo & Interno & Externo \\
\hline $09: 00$ & 26,4 & 28,7 & 49,3 & 42 \\
$09: 15$ & 26,8 & 29,1 & 47,9 & 41,3 \\
$09: 30$ & 27 & 30,3 & 49,7 & 40,6 \\
$09: 45$ & 27,1 & 29,9 & 49,4 & 42,6 \\
$10: 00$ & 27,2 & 30,7 & 49,6 & 41,2 \\
$10: 15$ & 27,6 & 31,7 & 49,4 & 38,2 \\
$10: 30$ & 27,7 & 31,8 & 49,8 & 38,7 \\
$10: 45$ & 27,9 & 31,5 & 49,4 & 40,6 \\
$11: 00$ & 28,1 & 32,7 & 49,6 & 37,6 \\
$11: 15$ & 28,3 & 33 & 49,2 & 38,5 \\
$11: 30$ & 28,7 & 33,8 & 48,9 & 35,2 \\
$11: 45$ & 28,9 & 34,1 & 48,6 & 34 \\
$12: 00$ & 29,2 & 34,3 & 46,8 & 33,1 \\
$12: 15$ & 29,3 & 34,6 & 47,2 & 33 \\
$12: 30$ & 29,6 & 34,3 & 46,8 & 35,5 \\
$12: 45$ & 29,7 & 33,7 & 45,7 & 32,5 \\
$13: 00$ & 28,8 & 33,4 & 46,1 & 34,5 \\
$13: 15$ & 30 & 34,7 & 44,8 & 32,7 \\
$13: 30$ & 30,2 & 34,6 & 44,5 & 32,7 \\
$13: 45$ & 30,3 & 35 & 44,2 & 31,7 \\
$14: 00$ & 30,6 & 33,7 & 44 & 33,7 \\
$14: 15$ & 30,7 & 33,6 & 43,2 & 34,6 \\
$14: 30$ & 30,9 & 34,1 & 42,3 & 32,9 \\
$14: 45$ & 31,2 & 33,9 & 41,8 & 33,1 \\
$15: 00$ & 31,1 & 34,4 & 41,6 & 32 \\
$15: 15$ & 31,4 & 34,1 & 40,3 & 33 \\
$15: 30$ & 31,2 & 33,1 & 41 & 34,3 \\
$15: 45$ & 31,4 & 33,9 & 41,2 & 33,4 \\
$16: 00$ & 31,6 & 34,1 & 40 & 31,7 \\
$16: 15$ & 31,7 & 33,1 & 39,5 & 34,7 \\
$16: 30$ & 31,9 & 33,1 & 40,1 & 35,3 \\
$16: 45$ & 31,5 & 32,8 & 40,1 & 35,7 \\
$17: 00$ & 31,7 & 33 & 40,7 & 34,9 \\
\hline & & & & \\
\hline
\end{tabular}




\section{APÊNDICE - Dados dos níveis de ruído do dia 24/11/2011}

Tabela 19 - Níveis de ruído para o dia 24/11/2011

\begin{tabular}{|c|c|c|c|c|c|c|c|c|}
\hline \multirow{2}{*}{ Hora } & \multicolumn{2}{|c|}{ Ruído dB(A) } & \multirow{2}{*}{ Hora } & \multicolumn{2}{|c|}{ Ruído dB(A) } & \multirow{2}{*}{ Hora } & \multicolumn{2}{|c|}{ Ruído dB(A) } \\
\hline & Interno & Externo & & Interno & Externo & & Interno & Externo \\
\hline 09:00:00 & 60.3 & 71.4 & 09:18:00 & 58.5 & 61.8 & $09: 36: 00$ & 60.1 & 67.6 \\
\hline 09:00:30 & 55 & 62 & 09:18:30 & 59.1 & 67.1 & 09:36:30 & 58.5 & 61 \\
\hline 09:01:00 & 59.5 & 70.9 & 09:19:00 & 59 & 65.5 & 09:37:00 & 58.9 & 64.6 \\
\hline 09:01:30 & 63.2 & 62.3 & $09: 19: 30$ & 55.7 & 70 & $09: 37: 30$ & 57.3 & 62.4 \\
\hline 09:02:00 & 63.4 & 68.6 & 09:20:00 & 60.8 & 64.2 & 09:38:00 & 60.1 & 74.9 \\
\hline 09:02:30 & 64.2 & 61.8 & 09:20:30 & 55.4 & 70 & 09:38:30 & 60.8 & 63.8 \\
\hline 09:03:00 & 59.2 & 70.2 & 09:21:00 & 59.6 & 66.5 & 09:39:00 & 63.4 & 81 \\
\hline 09:03:30 & 59.1 & 62.9 & $09: 21: 30$ & 64.8 & 71.6 & 09:39:30 & 59.3 & 61 \\
\hline 09:04:00 & 64.8 & 66.2 & 09:22:00 & 62.8 & 62.8 & 09:40:00 & 58.1 & 71.4 \\
\hline 09:04:30 & 61 & 65.2 & $09: 22: 30$ & 60.9 & 63.1 & 09:40:30 & 61.6 & 61.2 \\
\hline 09:05:00 & 60.4 & 64.5 & 09:23:00 & 56 & 74.5 & 09:41:00 & 65.7 & 67.5 \\
\hline 09:05:30 & 58.9 & 70.6 & $09: 23: 30$ & 57.4 & 69.8 & 09:41:30 & 55.3 & 63.8 \\
\hline 09:06:00 & 53.8 & 62.8 & 09:24:00 & 59.2 & 67.1 & 09:42:00 & 62.4 & 68.2 \\
\hline 09:06:30 & 56.9 & 69.8 & $09: 24: 30$ & 56.6 & 69.6 & $09: 42: 30$ & 65.7 & 71.5 \\
\hline 09:07:00 & 57.3 & 64 & 09:25:00 & 59.1 & 75.9 & 09:43:00 & 64.4 & 72.8 \\
\hline 09:07:30 & 58.1 & 67.9 & $09: 25: 30$ & 55.4 & 65.8 & 09:43:30 & 57.3 & 76.1 \\
\hline 09:08:00 & 59.8 & 64 & 09:26:00 & 58.4 & 69.3 & 09:44:00 & 59.5 & 64.4 \\
\hline 09:08:30 & 61.2 & 71.6 & 09:26:30 & 52.2 & 69.8 & 09:44:30 & 59.3 & 68.7 \\
\hline 09:09:00 & 55.7 & 64.4 & 09:27:00 & 60.1 & 72 & 09:45:00 & 57.4 & 62.8 \\
\hline 09:09:30 & 55.8 & 74.6 & $09: 27: 30$ & 57.8 & 65.1 & $09: 45: 30$ & 60.4 & 67.1 \\
\hline 09:10:00 & 54.5 & 62.8 & 09:28:00 & 59 & 69.1 & 09:46:00 & 58.5 & 65 \\
\hline 09:10:30 & 58.8 & 65.3 & $09: 28: 30$ & 58.7 & 68.3 & 09:46:30 & 58.9 & 75.7 \\
\hline 09:11:00 & 56 & 64.3 & 09:29:00 & 59.2 & 72.1 & 09:47:00 & 57.7 & 67.3 \\
\hline 09:11:30 & 61.6 & 69.2 & 09:29:30 & 60.8 & 64 & $09: 47: 30$ & 56.9 & 70.2 \\
\hline 09:12:00 & 61.1 & 65.2 & 09:30:00 & 59.1 & 69.9 & 09:48:00 & 56.9 & 67 \\
\hline 09:12:30 & 61.5 & 63.4 & 09:30:30 & 61.8 & 65.2 & 09:48:30 & 58 & 69.8 \\
\hline 09:13:00 & 60.6 & 71.2 & 09:31:00 & 59.1 & 66.3 & 09:49:00 & 56.9 & 74.8 \\
\hline 09:13:30 & 57.3 & 62.1 & 09:31:30 & 54.6 & 72.6 & 09:49:30 & 61.6 & 67.4 \\
\hline 09:14:00 & 64.4 & 70.2 & 09:32:00 & 61.4 & 63.4 & 09:50:00 & 58.9 & 68.3 \\
\hline 09:14:30 & 55 & 64.2 & 09:32:30 & 53 & 71 & 09:50:30 & 56.2 & 63.4 \\
\hline 09:15:00 & 61 & 67.1 & 09:33:00 & 56.1 & 62.8 & 09:51:00 & 54.7 & 73.4 \\
\hline 09:15:30 & 62.7 & 63.6 & 09:33:30 & 58.5 & 66.5 & 09:51:30 & 58.3 & 64.8 \\
\hline 09:16:00 & 57 & 69.2 & 09:34:00 & 56.6 & 63.1 & 09:52:00 & 61.5 & 71.2 \\
\hline 09:16:30 & 56.2 & 63.6 & 09:34:30 & 56.9 & 68.3 & 09:52:30 & 59.9 & 62.8 \\
\hline 09:17:00 & 56.7 & 71.6 & 09:35:00 & 53.7 & 67.9 & 09:53:00 & 65.7 & 68.1 \\
\hline 09:17:30 & 57.3 & 70.4 & 09:35:30 & 57.6 & 67.8 & 09:53:30 & 58.1 & 62.8 \\
\hline
\end{tabular}


Tabela 20 - Níveis de ruído para o dia 24/11/2011 (continuação)

\begin{tabular}{|c|c|c|c|c|c|c|c|c|}
\hline \multirow{2}{*}{ Hora } & \multicolumn{2}{|c|}{ Ruído dB(A) } & \multirow{2}{*}{ Hora } & \multicolumn{2}{|c|}{ Ruído dB(A) } & \multirow{2}{*}{ Hora } & \multicolumn{2}{|c|}{ Ruído dB(A) } \\
\hline & Interno & Externo & & Interno & Externo & & Interno & Externo \\
\hline 09:54:00 & 58.7 & 68.5 & $10: 15: 30$ & 65.2 & 70.9 & $10: 37: 00$ & 63 & 63.2 \\
\hline 09:54:30 & 61.5 & 63.1 & 10:16:00 & 60.3 & 69.8 & $10: 37: 30$ & 59.3 & 68.9 \\
\hline 09:55:00 & 65.7 & 71.3 & $10: 16: 30$ & 58.5 & 65 & $10: 38: 00$ & 61.7 & 61.6 \\
\hline 09:55:30 & 60.1 & 72.8 & 10:17:00 & 58.4 & 66.5 & $10: 38: 30$ & 61.2 & 66.5 \\
\hline 09:56:00 & 60.7 & 72.6 & $10: 17: 30$ & 61.6 & 65.5 & 10:39:00 & 62.4 & 62.4 \\
\hline 09:56:30 & 66.3 & 70.1 & 10:18:00 & 55.6 & 68.7 & $10: 39: 30$ & 62.3 & 68.2 \\
\hline 09:57:00 & 65.5 & 65.8 & $10: 18: 30$ & 54 & 80.2 & $10: 40: 00$ & 60.3 & 68 \\
\hline 09:57:30 & 65.4 & 72 & 10:19:00 & 56.7 & 77.2 & $10: 40: 30$ & 61.2 & 64.6 \\
\hline 09:58:00 & 59 & 63 & $10: 19: 30$ & 58.7 & 65 & $10: 41: 00$ & 68.7 & 67.9 \\
\hline 09:58:30 & 60.1 & 70.1 & $10: 20: 00$ & 65.4 & 70.6 & $10: 41: 30$ & 56.8 & 67.7 \\
\hline 09:59:00 & 56.4 & 66.9 & $10: 20: 30$ & 56 & 68.5 & $10: 42: 00$ & 61.2 & 72.9 \\
\hline 09:59:30 & 58.9 & 68.3 & 10:21:00 & 59.7 & 75.9 & $10: 42: 30$ & 63.5 & 64.8 \\
\hline 10:00:00 & 58.6 & 62.4 & $10: 21: 30$ & 54.1 & 70.6 & $10: 43: 00$ & 56.8 & 70.8 \\
\hline 10:00:30 & 55.4 & 74.1 & $10: 22: 00$ & 59.7 & 65.9 & $10: 43: 30$ & 60.9 & 66.7 \\
\hline 10:01:00 & 60.7 & 63.9 & $10: 22: 30$ & 54.6 & 66.9 & $10: 44: 00$ & 63.1 & 71 \\
\hline 10:01:30 & 63.9 & 67.6 & $10: 23: 00$ & 56.2 & 65.7 & $10: 44: 30$ & 58.7 & 65.2 \\
\hline $10: 02: 00$ & 58.5 & 74.9 & $10: 23: 30$ & 55.3 & 71.8 & $10: 45: 00$ & 55.6 & 70.5 \\
\hline $10: 02: 30$ & 64.8 & 67.5 & $10: 24: 00$ & 54.8 & 71.2 & $10: 45: 30$ & 54.8 & 64.6 \\
\hline 10:03:00 & 64.8 & 69.3 & $10: 24: 30$ & 61 & 75.7 & $10: 46: 00$ & 62.4 & 67.7 \\
\hline 10:03:30 & 59.1 & 64.3 & $10: 25: 00$ & 69.8 & 64.6 & $10: 46: 30$ & 59.5 & 70 \\
\hline 10:04:00 & 55.8 & 71.5 & $10: 25: 30$ & 63.2 & 68.2 & $10: 47: 00$ & 66.2 & 71 \\
\hline $10: 04: 30$ & 57.6 & 65.3 & 10:26:00 & 61 & 61 & $10: 47: 30$ & 59.7 & 68.6 \\
\hline $10: 05: 00$ & 54.5 & 70.6 & $10: 26: 30$ & 63 & 64.7 & $10: 48: 00$ & 65 & 69.2 \\
\hline $10: 05: 30$ & 59.1 & 66.1 & $10: 27: 00$ & 60.4 & 62 & $10: 48: 30$ & 66.6 & 65.2 \\
\hline 10:06:00 & 56.5 & 75.7 & $10: 27: 30$ & 57.1 & 70.5 & 10:49:00 & 64.8 & 67.5 \\
\hline $10: 06: 30$ & 59.6 & 65.9 & 10:28:00 & 54.5 & 70.6 & $10: 49: 30$ & 66.1 & 70.5 \\
\hline 10:07:00 & 69.1 & 73.4 & $10: 28: 30$ & 62.4 & 71 & 10:50:00 & 60.1 & 64 \\
\hline $10: 07: 30$ & 56 & 66.8 & $10: 29: 00$ & 62.4 & 72.6 & $10: 50: 30$ & 65.5 & 65.9 \\
\hline 10:08:00 & 57.7 & 69.4 & $10: 29: 30$ & 56.6 & 67.8 & $10: 51: 00$ & 58.2 & 62.4 \\
\hline 10:08:30 & 56.6 & 67.8 & 10:30:00 & 63.8 & 70.6 & $10: 51: 30$ & 58.1 & 65.3 \\
\hline 10:09:00 & 57.3 & 64 & $10: 30: 30$ & 62 & 64.8 & $10: 52: 00$ & 60.8 & 67.7 \\
\hline 10:09:30 & 55.2 & 67.4 & 10:31:00 & 57.9 & 67.8 & $10: 52: 30$ & 63.4 & 63.3 \\
\hline 10:10:00 & 64 & 62.8 & $10: 31: 30$ & 57.1 & 63.4 & $10: 53: 00$ & 61 & 63.6 \\
\hline $10: 10: 30$ & 56 & 66.9 & $10: 32: 00$ & 52 & 72.2 & $10: 53: 30$ & 61.5 & 63 \\
\hline $10: 11: 00$ & 59.8 & 66.9 & $10: 32: 30$ & 61.4 & 60 & $10: 54: 00$ & 60.6 & 61.4 \\
\hline $10: 11: 30$ & 59.1 & 67.1 & $10: 33: 00$ & 61 & 67.3 & $10: 54: 30$ & 59.3 & 65.2 \\
\hline $10: 12: 00$ & 55.9 & 62.8 & $10: 33: 30$ & 60.1 & 64 & $10: 55: 00$ & 58.3 & 67.9 \\
\hline $10: 12: 30$ & 59 & 69.8 & $10: 34: 00$ & 59.8 & 69.1 & $10: 55: 30$ & 56.6 & 72.5 \\
\hline 10:13:00 & 52.6 & 65.5 & $10: 34: 30$ & 58.4 & 63.6 & $10: 56: 00$ & 58.4 & 61.2 \\
\hline $10: 13: 30$ & 56 & 67.3 & 10:35:00 & 58 & 67.1 & $10: 56: 30$ & 57.3 & 73.6 \\
\hline $10: 14: 00$ & 58.1 & 64 & $10: 35: 30$ & 68.1 & 66.3 & $10: 57: 00$ & 54.9 & 65.5 \\
\hline $10: 14: 30$ & 54.5 & 70.6 & 10:36:00 & 64.2 & 65 & $10: 57: 30$ & 57 & 72.5 \\
\hline $10: 15: 00$ & 61.6 & 66.7 & $10: 36: 30$ & 59.7 & 69.5 & 10:58:00 & 55.4 & 63.6 \\
\hline
\end{tabular}


Tabela 21 - Níveis de ruído para o dia 24/11/2011 (continuação)

\begin{tabular}{|c|c|c|c|c|c|c|c|c|}
\hline \multirow{2}{*}{ Hora } & \multicolumn{2}{|c|}{ Ruído dB(A) } & \multirow{2}{*}{ Hora } & \multicolumn{2}{|c|}{ Ruído dB(A) } & \multirow{2}{*}{ Hora } & \multicolumn{2}{|c|}{ Ruído dB(A) } \\
\hline & Interno & Externo & & Interno & Externo & & Interno & Externo \\
\hline $10: 58: 30$ & 58.2 & 66.7 & 11:20:00 & 51.8 & 58.4 & $11: 41: 30$ & 64.1 & 67.1 \\
\hline 10:59:00 & 69.9 & 66.9 & $11: 20: 30$ & 51 & 63.9 & $11: 42: 00$ & 59.3 & 60.4 \\
\hline $10: 59: 30$ & 59.8 & 64.9 & $11: 21: 00$ & 61 & 62.4 & $11: 42: 30$ & 63.4 & 73.2 \\
\hline 11:00:00 & 64.2 & 67.9 & $11: 21: 30$ & 61 & 63.5 & $11: 43: 00$ & 54.3 & 67.1 \\
\hline 11:00:30 & 55.6 & 64.8 & $11: 22: 00$ & 56 & 66.3 & $11: 43: 30$ & 62.3 & 67.7 \\
\hline 11:01:00 & 62.6 & 69.3 & $11: 22: 30$ & 63.6 & 70.8 & $11: 44: 00$ & 54.2 & 67.4 \\
\hline 11:01:30 & 66.7 & 65.2 & $11: 23: 00$ & 59 & 71.8 & $11: 44: 30$ & 60 & 59.9 \\
\hline 11:02:00 & 64 & 65.7 & $11: 23: 30$ & 58 & 60.8 & $11: 45: 00$ & 56.4 & 62.8 \\
\hline $11: 02: 30$ & 60.3 & 65.4 & $11: 24: 00$ & 52.8 & 67.3 & $11: 45: 30$ & 57.4 & 65.2 \\
\hline 11:03:00 & 61.3 & 79.2 & $11: 24: 30$ & 53.3 & 64.8 & $11: 46: 00$ & 57.2 & 65.5 \\
\hline 11:03:30 & 58.9 & 69 & $11: 25: 00$ & 53.3 & 66.4 & $11: 46: 30$ & 56.5 & 71.2 \\
\hline 11:04:00 & 60.2 & 68.4 & $11: 25: 30$ & 58.4 & 64.2 & $11: 47: 00$ & 60.5 & 65.5 \\
\hline 11:04:30 & 63.9 & 68.4 & $11: 26: 00$ & 63.5 & 60.7 & $11: 47: 30$ & 57.5 & 59.1 \\
\hline 11:05:00 & 59.3 & 72.2 & $11: 26: 30$ & 59.6 & 69.7 & $11: 48: 00$ & 61 & 71.7 \\
\hline $11: 05: 30$ & 63.4 & 66.5 & 11:27:00 & 59.8 & 63.1 & $11: 48: 30$ & 61.3 & 59.7 \\
\hline 11:06:00 & 58.8 & 63.8 & $11: 27: 30$ & 63.2 & 74.9 & 11:49:00 & 60.4 & 64.6 \\
\hline 11:06:30 & 57.7 & 68.5 & $11: 28: 00$ & 57.7 & 69.5 & $11: 49: 30$ & 64.4 & 69.8 \\
\hline 11:07:00 & 55.2 & 63.4 & $11: 28: 30$ & 60.1 & 63.9 & 11:50:00 & 52.4 & 59.6 \\
\hline $11: 07: 30$ & 56.1 & 69.3 & $11: 29: 00$ & 58.5 & 67.5 & $11: 50: 30$ & 57.9 & 73.4 \\
\hline 11:08:00 & 59.7 & 67.8 & $11: 29: 30$ & 57.3 & 65.5 & $11: 51: 00$ & 54.3 & 61.6 \\
\hline 11:08:30 & 56.8 & 66.3 & 11:30:00 & 60.9 & 67.7 & $11: 51: 30$ & 55.9 & 67.1 \\
\hline 11:09:00 & 61.7 & 64.6 & 11:30:30 & 59.3 & 65.9 & $11: 52: 00$ & 56.9 & 62 \\
\hline 11:09:30 & 55.4 & 69.4 & $11: 31: 00$ & 59.5 & 62.2 & $11: 52: 30$ & 53.4 & 67.1 \\
\hline 11:10:00 & 55.9 & 59.7 & $11: 31: 30$ & 61.4 & 66.7 & $11: 53: 00$ & 56.8 & 69.2 \\
\hline $11: 10: 30$ & 55 & 63.8 & $11: 32: 00$ & 60.5 & 61.7 & $11: 53: 30$ & 56.1 & 62.4 \\
\hline 11:11:00 & 55 & 62.6 & $11: 32: 30$ & 54.6 & 65 & $11: 54: 00$ & 57.5 & 64.8 \\
\hline $11: 11: 30$ & 56.2 & 67.8 & $11: 33: 00$ & 58.1 & 68.5 & $11: 54: 30$ & 65 & 60.7 \\
\hline $11: 12: 00$ & 56.4 & 64.5 & $11: 33: 30$ & 65.2 & 61.7 & $11: 55: 00$ & 61.9 & 61.5 \\
\hline $11: 12: 30$ & 68.6 & 61.6 & $11: 34: 00$ & 57.9 & 68.2 & $11: 55: 30$ & 61.9 & 71.4 \\
\hline 11:13:00 & 56.2 & 71.3 & $11: 34: 30$ & 58.3 & 68.2 & 11:56:00 & 60.9 & 58.3 \\
\hline $11: 13: 30$ & 56.1 & 60.9 & $11: 35: 00$ & 58.3 & 65.5 & $11: 56: 30$ & 59.7 & 68.1 \\
\hline $11: 14: 00$ & 55.8 & 70.2 & $11: 35: 30$ & 57.1 & 66.8 & $11: 57: 00$ & 59.1 & 59.3 \\
\hline $11: 14: 30$ & 55.2 & 60.7 & 11:36:00 & 56 & 58.9 & $11: 57: 30$ & 58.9 & 63.2 \\
\hline 11:15:00 & 57.3 & 67.5 & $11: 36: 30$ & 52.6 & 61.2 & 11:58:00 & 59 & 65.7 \\
\hline $11: 15: 30$ & 55.8 & 60.9 & 11:37:00 & 59.8 & 64 & $11: 58: 30$ & 62.4 & 58.1 \\
\hline $11: 16: 00$ & 57.7 & 64.8 & $11: 37: 30$ & 59.4 & 66.3 & 11:59:00 & 63.6 & 69.4 \\
\hline $11: 16: 30$ & 55.8 & 58.6 & 11:38:00 & 57.7 & 65.5 & $11: 59: 30$ & 74.9 & 70.4 \\
\hline $11: 17: 00$ & 58.5 & 67.3 & 11:38:30 & 53.7 & 64.8 & 12:00:00 & 66.5 & 67.5 \\
\hline $11: 17: 30$ & 58.2 & 60.9 & 11:39:00 & 53.8 & 67.6 & $12: 00: 30$ & 62.8 & 67.5 \\
\hline 11:18:00 & 61.2 & 69.2 & 11:39:30 & 58.7 & 65.5 & 12:01:00 & 59 & 67.3 \\
\hline 11:18:30 & 56 & 72.6 & 11:40:00 & 56.6 & 62.4 & $12: 01: 30$ & 58.3 & 65.9 \\
\hline 11:19:00 & 57.9 & 69.4 & 11:40:30 & 64.5 & 69.8 & $12: 02: 00$ & 61.7 & 65.8 \\
\hline $11: 19: 30$ & 55.1 & 60.3 & 11:41:00 & 61.6 & 60.1 & $12: 02: 30$ & 61.2 & 67 \\
\hline
\end{tabular}


Tabela 22 - Níveis de ruído para o dia 24/11/2011 (continuação)

\begin{tabular}{|c|c|c|c|c|c|c|c|c|}
\hline \multirow{2}{*}{ Hora } & \multicolumn{2}{|c|}{ Ruído dB(A) } & \multirow{2}{*}{ Hora } & \multicolumn{2}{|c|}{ Ruído dB(A) } & \multirow{2}{*}{ Hora } & \multicolumn{2}{|c|}{ Ruído dB(A) } \\
\hline & Interno & Externo & & Interno & Externo & & Interno & Externo \\
\hline 12:03:00 & 61.2 & 67.9 & $12: 24: 30$ & 59.4 & 69.1 & $12: 46: 00$ & 58.1 & 67.7 \\
\hline $12: 03: 30$ & 63.1 & 59 & $12: 25: 00$ & 58.3 & 63.9 & $12: 46: 30$ & 58 & 64.4 \\
\hline 12:04:00 & 58.5 & 67.9 & $12: 25: 30$ & 59.3 & 61 & $12: 47: 00$ & 60.3 & 61.2 \\
\hline $12: 04: 30$ & 59.6 & 67 & $12: 26: 00$ & 57.7 & 65.3 & $12: 47: 30$ & 58.9 & 65.7 \\
\hline $12: 05: 00$ & 59.2 & 68.2 & $12: 26: 30$ & 62.4 & 60.3 & $12: 48: 00$ & 60.1 & 57.3 \\
\hline $12: 05: 30$ & 59.9 & 69.9 & $12: 27: 00$ & 59.2 & 59.8 & $12: 48: 30$ & 59.3 & 67.9 \\
\hline 12:06:00 & 59.5 & 64.8 & $12: 27: 30$ & 62.2 & 68.7 & $12: 49: 00$ & 60.7 & 68.1 \\
\hline 12:06:30 & 61.7 & 71.4 & $12: 28: 00$ & 61.9 & 69.4 & $12: 49: 30$ & 60.9 & 64.2 \\
\hline $12: 07: 00$ & 61.4 & 64.5 & $12: 28: 30$ & 60.9 & 60.3 & $12: 50: 00$ & 66.7 & 63.7 \\
\hline $12: 07: 30$ & 60.4 & 61.2 & $12: 29: 00$ & 62.4 & 71.1 & $12: 50: 30$ & 62 & 61.4 \\
\hline 12:08:00 & 61.5 & 67.8 & $12: 29: 30$ & 59.6 & 59.6 & $12: 51: 00$ & 56.8 & 61.4 \\
\hline $12: 08: 30$ & 58.9 & 60.3 & 12:30:00 & 74.5 & 63.2 & $12: 51: 30$ & 57.3 & 59.7 \\
\hline 12:09:00 & 64.5 & 67 & $12: 30: 30$ & 61 & 62 & $12: 52: 00$ & 58.5 & 59.3 \\
\hline $12: 09: 30$ & 63.4 & 74.9 & $12: 31: 00$ & 63.2 & 62.4 & $12: 52: 30$ & 58.7 & 69.4 \\
\hline 12:10:00 & 64.7 & 67.8 & $12: 31: 30$ & 64.2 & 67.5 & $12: 53: 00$ & 61.3 & 62.4 \\
\hline $12: 10: 30$ & 65.3 & 67.4 & $12: 32: 00$ & 62.9 & 62 & $12: 53: 30$ & 57.3 & 62.4 \\
\hline 12:11:00 & 62.3 & 60.3 & $12: 32: 30$ & 62.3 & 68.2 & $12: 54: 00$ & 62.3 & 60.5 \\
\hline $12: 11: 30$ & 67.7 & 63.5 & $12: 33: 00$ & 60.1 & 67 & $12: 54: 30$ & 61.5 & 64.5 \\
\hline $12: 12: 00$ & 62.4 & 80.4 & $12: 33: 30$ & 57.7 & 77.8 & $12: 55: 00$ & 62.2 & 71.6 \\
\hline $12: 12: 30$ & 59.8 & 67.1 & $12: 34: 00$ & 59.9 & 67.3 & $12: 55: 30$ & 60 & 63.2 \\
\hline $12: 13: 00$ & 58 & 63.7 & $12: 34: 30$ & 58 & 60.5 & $12: 56: 00$ & 61 & 67.8 \\
\hline $12: 13: 30$ & 61.4 & 60 & $12: 35: 00$ & 59.3 & 66.6 & $12: 56: 30$ & 59.7 & 65 \\
\hline $12: 14: 00$ & 58.7 & 69.8 & $12: 35: 30$ & 60.4 & 66.2 & $12: 57: 00$ & 58.9 & 62.6 \\
\hline $12: 14: 30$ & 61 & 63.8 & $12: 36: 00$ & 64.7 & 65.1 & $12: 57: 30$ & 59.7 & 66.9 \\
\hline $12: 15: 00$ & 61.8 & 69.1 & $12: 36: 30$ & 58.7 & 64.8 & $12: 58: 00$ & 60.9 & 66.8 \\
\hline $12: 15: 30$ & 63.7 & 67.6 & $12: 37: 00$ & 61.9 & 62 & $12: 58: 30$ & 60.8 & 66.1 \\
\hline $12: 16: 00$ & 61.3 & 59.7 & $12: 37: 30$ & 62.8 & 66.7 & $12: 59: 00$ & 62.2 & 70.8 \\
\hline $12: 16: 30$ & 59 & 68.7 & $12: 38: 00$ & 59.3 & 59.3 & $12: 59: 30$ & 63 & 61.3 \\
\hline $12: 17: 00$ & 58.1 & 64.8 & $12: 38: 30$ & 60.4 & 63.2 & 13:00:00 & 59.9 & 66.2 \\
\hline $12: 17: 30$ & 59.2 & 71.6 & $12: 39: 00$ & 59.3 & 66.3 & 13:00:30 & 60.9 & 62 \\
\hline $12: 18: 00$ & 60.1 & 67.1 & $12: 39: 30$ & 60.1 & 64.2 & 13:01:00 & 59 & 67.3 \\
\hline $12: 18: 30$ & 63.4 & 60.9 & 12:40:00 & 63.7 & 69 & $13: 01: 30$ & 59.1 & 66.8 \\
\hline $12: 19: 00$ & 61.2 & 66.5 & 12:40:30 & 60.9 & 60.8 & 13:02:00 & 59.3 & 61.6 \\
\hline $12: 19: 30$ & 63.2 & 58.9 & $12: 41: 00$ & 60.3 & 71.6 & $13: 02: 30$ & 59.2 & 66.3 \\
\hline $12: 20: 00$ & 60.1 & 68.7 & $12: 41: 30$ & 60.6 & 67.1 & 13:03:00 & 60.1 & 68.9 \\
\hline $12: 20: 30$ & 62.6 & 61.8 & $12: 42: 00$ & 60.3 & 59.9 & $13: 03: 30$ & 63.3 & 63.6 \\
\hline $12: 21: 00$ & 61.2 & 61.5 & $12: 42: 30$ & 61.4 & 69.6 & 13:04:00 & 58.4 & 63.1 \\
\hline $12: 21: 30$ & 60.5 & 69.2 & $12: 43: 00$ & 60.7 & 63.2 & 13:04:30 & 60.8 & 59.3 \\
\hline $12: 22: 00$ & 64 & 60.9 & $12: 43: 30$ & 61.4 & 69.1 & 13:05:00 & 62.8 & 66.9 \\
\hline $12: 22: 30$ & 59.1 & 60.1 & $12: 44: 00$ & 55.6 & 74.9 & $13: 05: 30$ & 61.8 & 61.3 \\
\hline $12: 23: 00$ & 64 & 69.4 & $12: 44: 30$ & 57.9 & 60.4 & 13:06:00 & 58.7 & 67.9 \\
\hline $12: 23: 30$ & 58.8 & 61.4 & $12: 45: 00$ & 58.3 & 68.1 & 13:06:30 & 58.5 & 68.9 \\
\hline $12: 24: 00$ & 59.3 & 64.4 & $12: 45: 30$ & 61.4 & 61 & 13:07:00 & 60.6 & 62.1 \\
\hline
\end{tabular}


Tabela 23 - Níveis de ruído para o dia 24/11/2011 (continuação)

\begin{tabular}{|c|c|c|c|c|c|c|c|c|}
\hline \multirow{2}{*}{ Hora } & \multicolumn{2}{|c|}{ Ruído dB(A) } & \multirow{2}{*}{ Hora } & \multicolumn{2}{|c|}{ Ruído dB(A) } & \multirow{2}{*}{ Hora } & \multicolumn{2}{|c|}{ Ruído dB(A) } \\
\hline & Interno & Externo & & Interno & Externo & & Interno & Externo \\
\hline $13: 07: 30$ & 60.1 & 69.6 & $13: 29: 00$ & 60.9 & 64.8 & $13: 50: 30$ & 64 & 65.1 \\
\hline 13:08:00 & 59.2 & 65.9 & $13: 29: 30$ & 64.6 & 62.2 & $13: 51: 00$ & 56.9 & 65.8 \\
\hline $13: 08: 30$ & 64.8 & 67.5 & 13:30:00 & 63.5 & 69.8 & $13: 51: 30$ & 59.3 & 70.4 \\
\hline 13:09:00 & 62.7 & 69.1 & $13: 30: 30$ & 64.5 & 71 & $13: 52: 00$ & 66.6 & 62 \\
\hline $13: 09: 30$ & 62.3 & 58.7 & $13: 31: 00$ & 63.8 & 63.1 & $13: 52: 30$ & 60.3 & 70.6 \\
\hline $13: 10: 00$ & 61.2 & 63.7 & $13: 31: 30$ & 60.1 & 70.1 & $13: 53: 00$ & 59.3 & 62.4 \\
\hline $13: 10: 30$ & 64.8 & 62.3 & $13: 32: 00$ & 60.5 & 61.4 & $13: 53: 30$ & 62.2 & 63.4 \\
\hline 13:11:00 & 58.7 & 61.3 & $13: 32: 30$ & 62.8 & 69.3 & $13: 54: 00$ & 58.1 & 66.6 \\
\hline $13: 11: 30$ & 60.9 & 64.6 & $13: 33: 00$ & 62.4 & 60.9 & $13: 54: 30$ & 58.5 & 62.4 \\
\hline $13: 12: 00$ & 58.5 & 59.8 & $13: 33: 30$ & 62.4 & 67.9 & $13: 55: 00$ & 58.8 & 75.9 \\
\hline $13: 12: 30$ & 57.7 & 65.9 & $13: 34: 00$ & 67 & 70.2 & $13: 55: 30$ & 68.1 & 61.2 \\
\hline $13: 13: 00$ & 59.1 & 70.2 & $13: 34: 30$ & 61.7 & 60.7 & $13: 56: 00$ & 58.5 & 60.1 \\
\hline $13: 13: 30$ & 59.2 & 64.6 & 13:35:00 & 60.9 & 71.4 & $13: 56: 30$ & 58.7 & 65.4 \\
\hline $13: 14: 00$ & 60.7 & 65.7 & $13: 35: 30$ & 61 & 61.6 & $13: 57: 00$ & 66.2 & 59.8 \\
\hline $13: 14: 30$ & 65.5 & 60.1 & 13:36:00 & 57.9 & 61.2 & $13: 57: 30$ & 56.4 & 66.5 \\
\hline $13: 15: 00$ & 62.2 & 69.6 & $13: 36: 30$ & 59.7 & 64.8 & $13: 58: 00$ & 59.3 & 63.5 \\
\hline $13: 15: 30$ & 61.8 & 60.1 & 13:37:00 & 61.2 & 65.4 & $13: 58: 30$ & 60.6 & 64 \\
\hline $13: 16: 00$ & 58.3 & 59.6 & $13: 37: 30$ & 59.6 & 70.4 & $13: 59: 00$ & 63.4 & 66.2 \\
\hline $13: 16: 30$ & 66.3 & 65.8 & $13: 38: 00$ & 58.9 & 66.7 & $13: 59: 30$ & 62.4 & 62 \\
\hline $13: 17: 00$ & 59.2 & 61 & $13: 38: 30$ & 60.3 & 71.4 & 14:00:00 & 59.3 & 66.7 \\
\hline $13: 17: 30$ & 64.8 & 65.5 & $13: 39: 00$ & 66.2 & 66.1 & 14:00:30 & 60.7 & 65.9 \\
\hline $13: 18: 00$ & 61.8 & 62.4 & $13: 39: 30$ & 60.6 & 62.2 & 14:01:00 & 60.4 & 64 \\
\hline $13: 18: 30$ & 61.1 & 69.8 & $13: 40: 00$ & 60.9 & 73.9 & $14: 01: 30$ & 58.7 & 65.9 \\
\hline $13: 19: 00$ & 59.1 & 62.4 & $13: 40: 30$ & 63.3 & 61.9 & $14: 02: 00$ & 59.9 & 64.4 \\
\hline $13: 19: 30$ & 57.7 & 60 & $13: 41: 00$ & 62.4 & 61.8 & $14: 02: 30$ & 65.2 & 71.2 \\
\hline $13: 20: 00$ & 62.4 & 71.4 & $13: 41: 30$ & 58.9 & 67.8 & 14:03:00 & 62.4 & 63.2 \\
\hline $13: 20: 30$ & 60.1 & 69.6 & $13: 42: 00$ & 62.2 & 59.3 & $14: 03: 30$ & 60.1 & 64.8 \\
\hline $13: 21: 00$ & 70.6 & 63.1 & $13: 42: 30$ & 59.6 & 69 & 14:04:00 & 59.1 & 69.4 \\
\hline $13: 21: 30$ & 64.9 & 65.9 & $13: 43: 00$ & 64.8 & 62.8 & $14: 04: 30$ & 60.1 & 62.6 \\
\hline $13: 22: 00$ & 62.8 & 63.2 & $13: 43: 30$ & 63.2 & 73.1 & $14: 05: 00$ & 63.6 & 71 \\
\hline $13: 22: 30$ & 61.6 & 67 & $13: 44: 00$ & 65.2 & 63.4 & $14: 05: 30$ & 61.1 & 64.2 \\
\hline $13: 23: 00$ & 61.6 & 68.3 & $13: 44: 30$ & 68.1 & 60.5 & 14:06:00 & 69.7 & 66.1 \\
\hline $13: 23: 30$ & 61.3 & 73.4 & $13: 45: 00$ & 68.4 & 72.8 & 14:06:30 & 59.3 & 65.2 \\
\hline $13: 24: 00$ & 65.2 & 68.3 & $13: 45: 30$ & 62.1 & 74.1 & $14: 07: 00$ & 62.7 & 62.4 \\
\hline $13: 24: 30$ & 61.6 & 64.9 & 13:46:00 & 65.2 & 64.2 & $14: 07: 30$ & 65.3 & 68.2 \\
\hline $13: 25: 00$ & 63.9 & 70 & $13: 46: 30$ & 64.3 & 66.7 & $14: 08: 00$ & 63.6 & 61.6 \\
\hline $13: 25: 30$ & 64.6 & 71.7 & 13:47:00 & 73.1 & 59.6 & 14:08:30 & 60 & 66.6 \\
\hline $13: 26: 00$ & 60 & 69.6 & $13: 47: 30$ & 60.9 & 70.1 & 14:09:00 & 63.7 & 65.2 \\
\hline $13: 26: 30$ & 70 & 63.4 & 13:48:00 & 59.9 & 65.7 & 14:09:30 & 63.2 & 64.4 \\
\hline $13: 27: 00$ & 59.6 & 61.9 & 13:48:30 & 62 & 62.7 & 14:10:00 & 60.7 & 68 \\
\hline $13: 27: 30$ & 64.7 & 67.1 & 13:49:00 & 61.4 & 71.3 & $14: 10: 30$ & 59.6 & 59.5 \\
\hline $13: 28: 00$ & 62.8 & 60.9 & $13: 49: 30$ & 60.5 & 62.4 & $14: 11: 00$ & 57.3 & 68.7 \\
\hline $13: 28: 30$ & 64.5 & 65.1 & 13:50:00 & 59.2 & 77.3 & $14: 11: 30$ & 60.5 & 61.1 \\
\hline
\end{tabular}


Tabela 24 - Níveis de ruído para o dia 24/11/2011 (continuação)

\begin{tabular}{|c|c|c|c|c|c|c|c|c|}
\hline \multirow{2}{*}{ Hora } & \multicolumn{2}{|c|}{ Ruído dB(A) } & \multirow{2}{*}{ Hora } & \multicolumn{2}{|c|}{ Ruído dB(A) } & \multirow{2}{*}{ Hora } & \multicolumn{2}{|c|}{ Ruído dB(A) } \\
\hline & Interno & Externo & & Interno & Externo & & Interno & Externo \\
\hline $14: 12: 00$ & 56.9 & 76.8 & $14: 33: 30$ & 61 & 66.7 & $14: 55: 00$ & 62.4 & 65.1 \\
\hline $14: 12: 30$ & 62.3 & 66.6 & $14: 34: 00$ & 63.8 & 68.9 & $14: 55: 30$ & 61.4 & 62.3 \\
\hline 14:13:00 & 58.5 & 67.8 & $14: 34: 30$ & 59.9 & 61.2 & $14: 56: 00$ & 65.5 & 63.5 \\
\hline 14:13:30 & 61.6 & 59.6 & 14:35:00 & 64.4 & 65.7 & $14: 56: 30$ & 58.7 & 65.9 \\
\hline $14: 14: 00$ & 60.7 & 66.3 & $14: 35: 30$ & 63 & 67.1 & $14: 57: 00$ & 58.9 & 59.7 \\
\hline $14: 14: 30$ & 62.9 & 59.5 & 14:36:00 & 63.7 & 59.6 & $14: 57: 30$ & 58.1 & 66.5 \\
\hline $14: 15: 00$ & 62 & 66.3 & $14: 36: 30$ & 62 & 66.2 & $14: 58: 00$ & 61 & 61 \\
\hline $14: 15: 30$ & 61.3 & 61.5 & $14: 37: 00$ & 62.8 & 65.5 & $14: 58: 30$ & 59.7 & 64 \\
\hline $14: 16: 00$ & 60.1 & 62.4 & $14: 37: 30$ & 59 & 65.1 & 14:59:00 & 62.4 & 65.4 \\
\hline $14: 16: 30$ & 58.4 & 69.4 & 14:38:00 & 67.5 & 70.6 & $14: 59: 30$ & 59.6 & 66.2 \\
\hline $14: 17: 00$ & 57.7 & 60.5 & $14: 38: 30$ & 65.4 & 75.9 & 15:00:00 & 61.6 & 63.1 \\
\hline $14: 17: 30$ & 60.9 & 70.5 & $14: 39: 00$ & 61.4 & 68.7 & $15: 00: 30$ & 58.7 & 62.7 \\
\hline $14: 18: 00$ & 62 & 60.3 & $14: 39: 30$ & 63 & 62.4 & 15:01:00 & 61.5 & 62.1 \\
\hline $14: 18: 30$ & 59.1 & 61.5 & $14: 40: 00$ & 62.8 & 69.7 & $15: 01: 30$ & 59.5 & 69.1 \\
\hline 14:19:00 & 59.3 & 67.5 & $14: 40: 30$ & 60.6 & 69.4 & $15: 02: 00$ & 63.2 & 62.8 \\
\hline $14: 19: 30$ & 58.5 & 59.1 & $14: 41: 00$ & 63.4 & 60.9 & $15: 02: 30$ & 58.9 & 70.2 \\
\hline $14: 20: 00$ & 58.9 & 68.7 & $14: 41: 30$ & 60.9 & 66.3 & $15: 03: 00$ & 63.2 & 68.1 \\
\hline $14: 20: 30$ & 61.5 & 62.3 & $14: 42: 00$ & 63.6 & 60.8 & $15: 03: 30$ & 63.2 & 65.5 \\
\hline 14:21:00 & 67.4 & 64.6 & $14: 42: 30$ & 59 & 69.8 & $15: 04: 00$ & 60.7 & 66.9 \\
\hline $14: 21: 30$ & 63.8 & 64.6 & $14: 43: 00$ & 63.2 & 69.6 & $15: 04: 30$ & 64.8 & 61 \\
\hline $14: 22: 00$ & 64 & 61.6 & $14: 43: 30$ & 59.3 & 62.4 & $15: 05: 00$ & 62.2 & 66.2 \\
\hline $14: 22: 30$ & 66.8 & 70.2 & $14: 44: 00$ & 62.4 & 67.1 & $15: 05: 30$ & 65.5 & 62.4 \\
\hline $14: 23: 00$ & 61.5 & 61 & $14: 44: 30$ & 68.6 & 62.4 & $15: 06: 00$ & 60.8 & 63.7 \\
\hline $14: 23: 30$ & 64 & 69.8 & $14: 45: 00$ & 64.5 & 67.1 & $15: 06: 30$ & 62.3 & 65.5 \\
\hline $14: 24: 00$ & 64.8 & 68.3 & $14: 45: 30$ & 62.8 & 67.5 & $15: 07: 00$ & 63.6 & 60.4 \\
\hline $14: 24: 30$ & 66.8 & 60.9 & $14: 46: 00$ & 63.9 & 62.8 & $15: 07: 30$ & 59.1 & 70.5 \\
\hline $14: 25: 00$ & 56.2 & 66.7 & $14: 46: 30$ & 59.3 & 65.5 & 15:08:00 & 63.4 & 65.9 \\
\hline $14: 25: 30$ & 62.8 & 69.8 & $14: 47: 00$ & 61.6 & 60.4 & $15: 08: 30$ & 62.8 & 65.7 \\
\hline $14: 26: 00$ & 59.2 & 60.8 & $14: 47: 30$ & 59.3 & 72.3 & 15:09:00 & 73.6 & 67.9 \\
\hline $14: 26: 30$ & 58.1 & 71.5 & $14: 48: 00$ & 61.1 & 68.5 & $15: 09: 30$ & 61.6 & 63.8 \\
\hline $14: 27: 00$ & 57.7 & 62 & $14: 48: 30$ & 60.4 & 58.8 & $15: 10: 00$ & 60.1 & 67.4 \\
\hline $14: 27: 30$ & 60.1 & 69 & $14: 49: 00$ & 61.8 & 80.4 & $15: 10: 30$ & 58.8 & 60.3 \\
\hline $14: 28: 00$ & 61.5 & 60.7 & $14: 49: 30$ & 62.8 & 59 & $15: 11: 00$ & 60.3 & 64 \\
\hline $14: 28: 30$ & 61 & 65 & $14: 50: 00$ & 60.5 & 70.8 & $15: 11: 30$ & 58.2 & 70.8 \\
\hline 14:29:00 & 61 & 67.9 & $14: 50: 30$ & 62.3 & 68.2 & $15: 12: 00$ & 61.6 & 60.1 \\
\hline $14: 29: 30$ & 62 & 63 & $14: 51: 00$ & 65.1 & 63.8 & $15: 12: 30$ & 62.4 & 65.5 \\
\hline 14:30:00 & 63.4 & 68.5 & $14: 51: 30$ & 62.2 & 68.7 & $15: 13: 00$ & 63.2 & 63.8 \\
\hline $14: 30: 30$ & 63.6 & 59 & $14: 52: 00$ & 58.1 & 61.6 & $15: 13: 30$ & 60.4 & 62.8 \\
\hline $14: 31: 00$ & 56.5 & 62.3 & $14: 52: 30$ & 61.9 & 66.6 & $15: 14: 00$ & 59.3 & 66.8 \\
\hline $14: 31: 30$ & 59.1 & 66.4 & $14: 53: 00$ & 58.7 & 69.4 & $15: 14: 30$ & 58.2 & 65.3 \\
\hline $14: 32: 00$ & 58.5 & 59.9 & $14: 53: 30$ & 59.3 & 62.4 & $15: 15: 00$ & 58.7 & 72.6 \\
\hline $14: 32: 30$ & 58.8 & 64.6 & $14: 54: 00$ & 61 & 68.4 & $15: 15: 30$ & 58.7 & 72.2 \\
\hline $14: 33: 00$ & 69.8 & 61.7 & $14: 54: 30$ & 74.5 & 60.6 & $15: 16: 00$ & 60.9 & 64.6 \\
\hline
\end{tabular}


Tabela 25 - Níveis de ruído para o dia 24/11/2011 (continuação)

\begin{tabular}{|c|c|c|c|c|c|c|c|c|}
\hline \multirow{2}{*}{ Hora } & \multicolumn{2}{|c|}{ Ruído dB(A) } & \multirow{2}{*}{ Hora } & \multicolumn{2}{|c|}{ Ruído dB(A) } & \multirow{2}{*}{ Hora } & \multicolumn{2}{|c|}{ Ruído dB(A) } \\
\hline & Interno & Externo & & Interno & Externo & & Interno & Externo \\
\hline $15: 16: 30$ & 60.1 & 70.6 & $15: 38: 00$ & 61.8 & 75.6 & $15: 59: 30$ & 61.6 & 60.3 \\
\hline $15: 17: 00$ & 62.7 & 63.8 & $15: 38: 30$ & 56.2 & 72.5 & 16:00:00 & 61.7 & 70.5 \\
\hline $15: 17: 30$ & 64.6 & 70.9 & $15: 39: 00$ & 63.2 & 63.6 & $16: 00: 30$ & 68.9 & 61.4 \\
\hline $15: 18: 00$ & 64.8 & 69.8 & $15: 39: 30$ & 57.4 & 63 & 16:01:00 & 57.7 & 62.9 \\
\hline $15: 18: 30$ & 59.9 & 60.6 & $15: 40: 00$ & 59.6 & 68.6 & $16: 01: 30$ & 58.9 & 62.3 \\
\hline $15: 19: 00$ & 64.6 & 67.5 & $15: 40: 30$ & 60.1 & 60 & $16: 02: 00$ & 71.1 & 62.2 \\
\hline $15: 19: 30$ & 59.7 & 65.5 & $15: 41: 00$ & 59.9 & 71.6 & $16: 02: 30$ & 62.8 & 68.7 \\
\hline $15: 20: 00$ & 63 & 65.5 & $15: 41: 30$ & 64.3 & 65 & 16:03:00 & 63.8 & 64.6 \\
\hline $15: 20: 30$ & 60.3 & 67.1 & $15: 42: 00$ & 61 & 71.3 & $16: 03: 30$ & 58.5 & 73.6 \\
\hline $15: 21: 00$ & 67.9 & 65.3 & $15: 42: 30$ & 59.3 & 70.7 & 16:04:00 & 67.1 & 64 \\
\hline $15: 21: 30$ & 72.2 & 63.9 & $15: 43: 00$ & 60.8 & 60.5 & $16: 04: 30$ & 60.6 & 71 \\
\hline $15: 22: 00$ & 61.1 & 60.7 & $15: 43: 30$ & 65.9 & 65.5 & $16: 05: 00$ & 61.4 & 66.8 \\
\hline $15: 22: 30$ & 60.5 & 71.2 & $15: 44: 00$ & 59.8 & 70.2 & $16: 05: 30$ & 61.6 & 64 \\
\hline $15: 23: 00$ & 63.6 & 60 & $15: 44: 30$ & 60.1 & 65 & $16: 06: 00$ & 64.2 & 68.3 \\
\hline $15: 23: 30$ & 63.2 & 60.1 & $15: 45: 00$ & 59.8 & 72 & 16:06:30 & 59.2 & 61.9 \\
\hline $15: 24: 00$ & 61.4 & 67.9 & $15: 45: 30$ & 61.2 & 63.6 & 16:07:00 & 63.9 & 60.3 \\
\hline $15: 24: 30$ & 57.5 & 60.8 & $15: 46: 00$ & 62.4 & 66.1 & $16: 07: 30$ & 61.6 & 68.2 \\
\hline $15: 25: 00$ & 59.6 & 71.2 & $15: 46: 30$ & 58.6 & 67.1 & 16:08:00 & 62.6 & 63.7 \\
\hline $15: 25: 30$ & 61.9 & 67.1 & $15: 47: 00$ & 59.4 & 64 & $16: 08: 30$ & 60.3 & 74.9 \\
\hline $15: 26: 00$ & 56.6 & 62.4 & $15: 47: 30$ & 58.7 & 64.8 & 16:09:00 & 61.6 & 60.1 \\
\hline $15: 26: 30$ & 58.1 & 66.1 & $15: 48: 00$ & 59.8 & 58.5 & $16: 09: 30$ & 58.5 & 62.4 \\
\hline $15: 27: 00$ & 60.3 & 61.6 & $15: 48: 30$ & 58.3 & 69.8 & $16: 10: 00$ & 60 & 67.9 \\
\hline $15: 27: 30$ & 59.7 & 71 & $15: 49: 00$ & 60.3 & 65.2 & $16: 10: 30$ & 63.7 & 61 \\
\hline $15: 28: 00$ & 58.4 & 68.7 & $15: 49: 30$ & 59.1 & 58.5 & $16: 11: 00$ & 64.5 & 68.1 \\
\hline $15: 28: 30$ & 61.4 & 65.5 & $15: 50: 00$ & 63.4 & 65 & $16: 11: 30$ & 57.5 & 66.5 \\
\hline $15: 29: 00$ & 60.3 & 66.4 & $15: 50: 30$ & 60.5 & 63.3 & $16: 12: 00$ & 60.4 & 64.3 \\
\hline $15: 29: 30$ & 57.5 & 63 & $15: 51: 00$ & 65.9 & 63.2 & $16: 12: 30$ & 59.6 & 67.3 \\
\hline $15: 30: 00$ & 60 & 67.3 & $15: 51: 30$ & 64.4 & 67 & $16: 13: 00$ & 67.5 & 63 \\
\hline $15: 30: 30$ & 61.8 & 73.8 & $15: 52: 00$ & 66.9 & 59.6 & $16: 13: 30$ & 63.6 & 70.8 \\
\hline $15: 31: 00$ & 57.6 & 65.2 & $15: 52: 30$ & 63 & 66.6 & $16: 14: 00$ & 58.4 & 66.7 \\
\hline $15: 31: 30$ & 58.3 & 70.7 & $15: 53: 00$ & 58.9 & 61.1 & $16: 14: 30$ & 60.5 & 64.6 \\
\hline $15: 32: 00$ & 57.2 & 70.8 & $15: 53: 30$ & 62.4 & 66.7 & $16: 15: 00$ & 59.1 & 64 \\
\hline $15: 32: 30$ & 56.9 & 65.7 & $15: 54: 00$ & 60.1 & 69.4 & $16: 15: 30$ & 62.8 & 63.2 \\
\hline $15: 33: 00$ & 60.4 & 60.5 & $15: 54: 30$ & 59.3 & 61.2 & $16: 16: 00$ & 61.9 & 61.6 \\
\hline $15: 33: 30$ & 58.5 & 64.2 & $15: 55: 00$ & 61.6 & 62.7 & $16: 16: 30$ & 58.1 & 67.6 \\
\hline $15: 34: 00$ & 56.4 & 63.6 & $15: 55: 30$ & 63.6 & 59.7 & $16: 17: 00$ & 60.6 & 69.8 \\
\hline $15: 34: 30$ & 63.1 & 64.6 & $15: 56: 00$ & 61.8 & 68.4 & $16: 17: 30$ & 57.3 & 67.1 \\
\hline $15: 35: 00$ & 63.1 & 71 & $15: 56: 30$ & 58.6 & 71.7 & $16: 18: 00$ & 59.9 & 72 \\
\hline $15: 35: 30$ & 66.1 & 61.3 & $15: 57: 00$ & 60.4 & 65.3 & $16: 18: 30$ & 59.6 & 69.8 \\
\hline $15: 36: 00$ & 59.8 & 65.5 & $15: 57: 30$ & 60.5 & 70.7 & $16: 19: 00$ & 68.3 & 72.9 \\
\hline $15: 36: 30$ & 58.7 & 62.8 & $15: 58: 00$ & 69 & 62.9 & $16: 19: 30$ & 65.7 & 64 \\
\hline $15: 37: 00$ & 63.7 & 64 & $15: 58: 30$ & 58.8 & 74.1 & $16: 20: 00$ & 59.3 & 67.1 \\
\hline $15: 37: 30$ & 59.7 & 67.3 & $15: 59: 00$ & 56.2 & 65.5 & $16: 20: 30$ & 59.6 & 63.2 \\
\hline
\end{tabular}


Tabela 26 - Níveis de ruído para o dia 24/11/2011 (continuação)

\begin{tabular}{|c|c|c|c|c|c|}
\hline \multirow{2}{*}{ Hora } & \multicolumn{2}{|c|}{ Ruído dB(A) } & \multirow{2}{*}{ Hora } & \multicolumn{2}{|c|}{ Ruído dB(A) } \\
\hline & Interno & Externo & & Interno & Externo \\
\hline $16: 21: 00$ & 62 & 71.7 & $16: 42: 30$ & 57.1 & 72.4 \\
\hline $16: 21: 30$ & 64.2 & 66.8 & $16: 43: 00$ & 60.5 & 68.3 \\
\hline $16: 22: 00$ & 60.3 & 64.8 & $16: 43: 30$ & 57.2 & 66.7 \\
\hline $16: 22: 30$ & 63.6 & 71.4 & $16: 44: 00$ & 58.8 & 70.2 \\
\hline $16: 23: 00$ & 62.6 & 62.6 & $16: 44: 30$ & 65.4 & 64 \\
\hline $16: 23: 30$ & 61.8 & 62.4 & $16: 45: 00$ & 58.1 & 66 \\
\hline $16: 24: 00$ & 67.6 & 71.8 & $16: 45: 30$ & 58.1 & 69.1 \\
\hline $16: 24: 30$ & 59.9 & 70.6 & $16: 46: 00$ & 57.3 & 62.3 \\
\hline $16: 25: 00$ & 67.7 & 60.4 & $16: 46: 30$ & 58.5 & 70.6 \\
\hline $16: 25: 30$ & 61.1 & 65 & $16: 47: 00$ & 58.8 & 64 \\
\hline $16: 26: 00$ & 62.6 & 62.2 & $16: 47: 30$ & 61.2 & 63.3 \\
\hline $16: 26: 30$ & 60.9 & 60.3 & $16: 48: 00$ & 67 & 66.3 \\
\hline $16: 27: 00$ & 62.3 & 67.7 & $16: 48: 30$ & 63.1 & 69.9 \\
\hline $16: 27: 30$ & 64 & 66.1 & $16: 49: 00$ & 62.8 & 64.7 \\
\hline $16: 28: 00$ & 65.9 & 64.8 & $16: 49: 30$ & 62.4 & 64.8 \\
\hline $16: 28: 30$ & 76.8 & 65.9 & $16: 50: 00$ & 57.9 & 65.7 \\
\hline $16: 29: 00$ & 70.8 & 61.3 & $16: 50: 30$ & 60.7 & 60.5 \\
\hline $16: 29: 30$ & 60.6 & 68.1 & $16: 51: 00$ & 60.9 & 65.7 \\
\hline $16: 30: 00$ & 62.8 & 66 & $16: 51: 30$ & 59.9 & 68.9 \\
\hline $16: 30: 30$ & 62 & 66.1 & $16: 52: 00$ & 58.7 & 61.1 \\
\hline $16: 31: 00$ & 59.9 & 68.9 & $16: 52: 30$ & 57.9 & 69.4 \\
\hline $16: 31: 30$ & 61.7 & 62.8 & $16: 53: 00$ & 59.9 & 59.8 \\
\hline $16: 32: 00$ & 64.9 & 62.9 & $16: 53: 30$ & 60.7 & 67.1 \\
\hline $16: 32: 30$ & 72.3 & 67.4 & $16: 54: 00$ & 58.9 & 67.7 \\
\hline $16: 33: 00$ & 63.3 & 62 & $16: 54: 30$ & 63.1 & 66.1 \\
\hline $16: 33: 30$ & 62 & 59.9 & $16: 55: 00$ & 60.8 & 68.1 \\
\hline $16: 34: 00$ & 61.9 & 73.5 & & & \\
\hline $16: 34: 30$ & 62.8 & 65.8 & & & \\
\hline $16: 35: 00$ & 61.6 & 63.4 & & & \\
\hline $16: 35: 30$ & 62.1 & 63.8 & & & \\
\hline $16: 36: 00$ & 62.8 & 60 & & & \\
\hline $16: 36: 30$ & 62.8 & 65.1 & & & \\
\hline $16: 37: 00$ & 62.2 & 65.2 & & & \\
\hline $16: 37: 30$ & 64 & 63.2 & & & \\
\hline $16: 38: 00$ & 65.5 & 64.5 & & & \\
\hline $16: 38: 30$ & 73.4 & 63.6 & & & \\
\hline $16: 39: 00$ & 62.8 & 62.7 & & & \\
\hline $16: 39: 30$ & 63.5 & 65.9 & & & \\
\hline $16: 40: 00$ & 64.4 & 69.9 & & & \\
\hline $16: 40: 30$ & 64 & 61.4 & & & \\
\hline $16: 41: 00$ & 59.7 & 65.7 & & & \\
\hline $16: 41: 30$ & 57.7 & 63.9 & & & \\
\hline $16: 42: 00$ & 56.4 & 63.9 & & & \\
\hline
\end{tabular}




\section{E APÊNDICE - Dados de concentração de $M P_{2,5}$ do dia 25/11/2011}

Tabela 27 - Material particulado do dia 25/11/2011

\begin{tabular}{|c|c|c|c|c|c|c|c|c|}
\hline \multirow{2}{*}{ Hora } & \multicolumn{2}{|l|}{ MP } & \multirow{2}{*}{ Hora } & \multicolumn{2}{|l|}{ MP } & \multirow{2}{*}{ Hora } & \multicolumn{2}{|l|}{ MP } \\
\hline & Interno & Externo & & Interno & Externo & & Interno & Externo \\
\hline 09:00:00 & 16.11 & 21 & $09: 36: 00$ & 17.16 & 22 & $10: 12: 00$ & 16.15 & 11 \\
\hline 09:01:00 & 15.52 & 21 & 09:37:00 & 16.48 & 13 & 10:13:00 & 14.48 & 13 \\
\hline 09:02:00 & 15.07 & 24 & 09:38:00 & 15.11 & 27 & $10: 14: 00$ & 14.31 & 11 \\
\hline 09:03:00 & 15.25 & 24 & 09:39:00 & 15 & 20 & 10:15:00 & 15.55 & 9 \\
\hline 09:04:00 & 14.68 & 18 & 09:40:00 & 15.81 & 13 & 10:16:00 & 15.29 & 11 \\
\hline 09:05:00 & 16.63 & 20 & 09:41:00 & 16.74 & 17 & 10:17:00 & 15.72 & 12 \\
\hline 09:06:00 & 14.63 & 20 & 09:42:00 & 17.32 & 39 & 10:18:00 & 14.53 & 8 \\
\hline 09:07:00 & 15.27 & 19 & 09:43:00 & 17.02 & 14 & 10:19:00 & 15.07 & 15 \\
\hline 09:08:00 & 15.65 & 17 & 09:44:00 & 18.65 & 15 & 10:20:00 & 15.35 & 9 \\
\hline 09:09:00 & 17.37 & 17 & 09:45:00 & 17.34 & 25 & 10:21:00 & 15.26 & 9 \\
\hline 09:10:00 & 22.37 & 16 & 09:46:00 & 17.15 & 42 & 10:22:00 & 14.31 & 7 \\
\hline 09:11:00 & 21.28 & 25 & 09:47:00 & 17.55 & 33 & 10:23:00 & 14.72 & 8 \\
\hline 09:12:00 & 21.47 & 34 & 09:48:00 & 16.69 & 22 & $10: 24: 00$ & 15.1 & 9 \\
\hline 09:13:00 & 18.59 & 17 & 09:49:00 & 16.79 & 21 & $10: 25: 00$ & 14 & 12 \\
\hline 09:14:00 & 15.05 & 18 & 09:50:00 & 15.71 & 17 & 10:26:00 & 16.93 & 13 \\
\hline 09:15:00 & 16.28 & 16 & 09:51:00 & 17.31 & 13 & 10:27:00 & 14.5 & 11 \\
\hline 09:16:00 & 16.87 & 16 & 09:52:00 & 17 & 17 & $10: 28: 00$ & 14.41 & 13 \\
\hline 09:17:00 & 16.9 & 23 & 09:53:00 & 16.59 & 18 & 10:29:00 & 14.28 & 9 \\
\hline 09:18:00 & 17.13 & 18 & 09:54:00 & 13.7 & 13 & 10:30:00 & 14.93 & 14 \\
\hline 09:19:00 & 17.92 & 24 & 09:55:00 & 14.29 & 15 & 10:31:00 & 14.4 & 8 \\
\hline 09:20:00 & 15.5 & 25 & 09:56:00 & 13.66 & 10 & 10:32:00 & 14.99 & 6 \\
\hline 09:21:00 & 14.72 & 24 & 09:57:00 & 14.55 & 9 & 10:33:00 & 14.49 & 7 \\
\hline 09:22:00 & 15.58 & 18 & 09:58:00 & 18.16 & 12 & 10:34:00 & 14.44 & 13 \\
\hline 09:23:00 & 15.84 & 13 & 09:59:00 & 17.02 & 20 & 10:35:00 & 16.14 & 8 \\
\hline 09:24:00 & 14.69 & 16 & 10:00:00 & 16.63 & 15 & 10:36:00 & 15.39 & 10 \\
\hline 09:25:00 & 15.14 & 18 & 10:01:00 & 15.1 & 17 & 10:37:00 & 14.99 & 13 \\
\hline 09:26:00 & 13.84 & 13 & 10:02:00 & 16.1 & 12 & 10:38:00 & 14.97 & 7 \\
\hline 09:27:00 & 13.56 & 13 & 10:03:00 & 15.03 & 13 & 10:39:00 & 14.77 & 7 \\
\hline 09:28:00 & 14.27 & 17 & 10:04:00 & 14.79 & 14 & 10:40:00 & 15.5 & 12 \\
\hline 09:29:00 & 14.04 & 14 & 10:05:00 & 14 & 17 & 10:41:00 & 13.95 & 14 \\
\hline 09:30:00 & 14.29 & 16 & 10:06:00 & 14.02 & 12 & 10:42:00 & 14.06 & 8 \\
\hline 09:31:00 & 14.27 & 15 & 10:07:00 & 13.79 & 12 & 10:43:00 & 13.48 & 9 \\
\hline 09:32:00 & 13.51 & 12 & 10:08:00 & 14.45 & 12 & 10:44:00 & 14.55 & 14 \\
\hline 09:33:00 & 16.66 & 10 & 10:09:00 & 14.69 & 12 & $10: 45: 00$ & 15.86 & 11 \\
\hline 09:34:00 & 15.84 & 17 & 10:10:00 & 16.25 & 14 & $10: 46: 00$ & 15.1 & 12 \\
\hline 09:35:00 & 16.22 & 14 & 10:11:00 & 15.16 & 13 & 10:47:00 & 14.59 & 9 \\
\hline
\end{tabular}


Tabela 28 - Material particulado do dia 25/11/2011 (continuação)

\begin{tabular}{|c|c|c|c|c|c|c|c|c|}
\hline \multirow{2}{*}{ Hora } & \multicolumn{2}{|l|}{ MP } & \multirow{2}{*}{ Hora } & \multicolumn{2}{|l|}{ MP } & \multirow{2}{*}{ Hora } & \multicolumn{2}{|l|}{ MP } \\
\hline & Interno & Externo & & Interno & Externo & & Interno & Externo \\
\hline $10: 48: 00$ & 15.4 & 11 & 11:31:00 & 14.19 & 9 & $12: 14: 00$ & 12.52 & 1 \\
\hline $10: 49: 00$ & 14.96 & 15 & $11: 32: 00$ & 14.3 & 14 & $12: 15: 00$ & 15.65 & 2 \\
\hline 10:50:00 & 16.49 & 10 & $11: 33: 00$ & 13.68 & 4 & $12: 16: 00$ & 14.76 & 3 \\
\hline $10: 51: 00$ & 15.56 & 8 & $11: 34: 00$ & 14.28 & 7 & $12: 17: 00$ & 12.8 & 9 \\
\hline $10: 52: 00$ & 14.88 & 12 & $11: 35: 00$ & 13.39 & 9 & $12: 18: 00$ & 13.04 & 2 \\
\hline $10: 53: 00$ & 14.26 & 5 & $11: 36: 00$ & 13.61 & 8 & $12: 19: 00$ & 14.17 & 7 \\
\hline $10: 54: 00$ & 15.61 & 7 & 11:37:00 & 13.17 & 5 & $12: 20: 00$ & 12.79 & 4 \\
\hline $10: 55: 00$ & 13.68 & 18 & 11:38:00 & 12.91 & 7 & $12: 21: 00$ & 11.6 & 7 \\
\hline $10: 56: 00$ & 14.16 & 12 & 11:39:00 & 12.02 & 4 & $12: 22: 00$ & 12.32 & 7 \\
\hline $10: 57: 00$ & 13.53 & 6 & 11:40:00 & 12.53 & 8 & $12: 23: 00$ & 11.91 & 10 \\
\hline 10:58:00 & 13.96 & 24 & $11: 41: 00$ & 12.69 & 16 & $12: 24: 00$ & 12.49 & 14 \\
\hline 10:59:00 & 14.05 & 7 & 11:42:00 & 11.79 & 6 & $12: 25: 00$ & 12.02 & 4 \\
\hline 11:00:00 & 13.13 & 27 & $11: 43: 00$ & 11.59 & 8 & $12: 26: 00$ & 12.47 & 5 \\
\hline 11:01:00 & 14.88 & 9 & $11: 44: 00$ & 11.9 & 7 & $12: 27: 00$ & 12.55 & 10 \\
\hline 11:02:00 & 12.58 & 6 & $11: 45: 00$ & 11.28 & 7 & $12: 28: 00$ & 11.07 & 11 \\
\hline 11:03:00 & 13.34 & 7 & $11: 46: 00$ & 11.62 & 3 & $12: 29: 00$ & 10 & 11 \\
\hline 11:04:00 & 12.78 & 10 & 11:47:00 & 11.01 & 6 & $12: 30: 00$ & 11.26 & 3 \\
\hline 11:05:00 & 13.07 & 16 & 11:48:00 & 12.02 & 3 & $12: 31: 00$ & 11.87 & 4 \\
\hline 11:06:00 & 12.76 & 8 & $11: 49: 00$ & 10.96 & 3 & $12: 32: 00$ & 10.42 & 2 \\
\hline 11:07:00 & 12.71 & 15 & 11:50:00 & 11.87 & 16 & $12: 33: 00$ & 10.42 & 7 \\
\hline 11:08:00 & 14.09 & 18 & $11: 51: 00$ & 10.91 & 3 & $12: 34: 00$ & 10.39 & 4 \\
\hline 11:09:00 & 13.14 & 17 & 11:52:00 & 12.76 & 5 & $12: 35: 00$ & 11.54 & 1 \\
\hline 11:10:00 & 13.95 & 4 & 11:53:00 & 11.79 & 4 & $12: 36: 00$ & 11.23 & 2 \\
\hline 11:11:00 & 13.99 & 8 & $11: 54: 00$ & 12.09 & 2 & $12: 37: 00$ & 10.01 & 1 \\
\hline $11: 12: 00$ & 13.54 & 10 & $11: 55: 00$ & 11.96 & 3 & $12: 38: 00$ & 11.2 & 4 \\
\hline 11:13:00 & 13.83 & 12 & $11: 56: 00$ & 11.31 & 3 & $12: 39: 00$ & 9.62 & 3 \\
\hline $11: 14: 00$ & 14.42 & 7 & $11: 57: 00$ & 10.86 & 3 & $12: 40: 00$ & 9.73 & 3 \\
\hline $11: 15: 00$ & 14.84 & 13 & 11:58:00 & 10.07 & 2 & $12: 41: 00$ & 9.07 & 22 \\
\hline 11:16:00 & 16.24 & 31 & 11:59:00 & 12.36 & 5 & $12: 42: 00$ & 10.25 & 1 \\
\hline $11: 17: 00$ & 15.1 & 76 & $12: 00: 00$ & 11.21 & 2 & $12: 43: 00$ & 10.85 & 4 \\
\hline 11:18:00 & 15.36 & 14 & $12: 01: 00$ & 12.29 & 5 & $12: 44: 00$ & 10.88 & 6 \\
\hline 11:19:00 & 13.96 & 14 & $12: 02: 00$ & 13.85 & 14 & $12: 45: 00$ & 9.8 & 4 \\
\hline $11: 20: 00$ & 14.4 & 7 & 12:03:00 & 12.03 & 27 & $12: 46: 00$ & 10.68 & 8 \\
\hline $11: 21: 00$ & 14.16 & 43 & 12:04:00 & 12.53 & 13 & $12: 47: 00$ & 9.52 & 4 \\
\hline $11: 22: 00$ & 14.57 & 11 & $12: 05: 00$ & 10.23 & 31 & $12: 48: 00$ & 10.58 & 2 \\
\hline $11: 23: 00$ & 14.08 & 7 & 12:06:00 & 10.4 & 4 & $12: 49: 00$ & 10.7 & 3 \\
\hline $11: 24: 00$ & 13.38 & 39 & 12:07:00 & 10.63 & 11 & $12: 50: 00$ & 12.35 & 2 \\
\hline $11: 25: 00$ & 14.62 & 19 & 12:08:00 & 10.08 & 4 & $12: 51: 00$ & 10.16 & 2 \\
\hline $11: 26: 00$ & 13.65 & 3 & 12:09:00 & 10.71 & 3 & $12: 52: 00$ & 12.01 & 1 \\
\hline $11: 27: 00$ & 14.61 & 3 & $12: 10: 00$ & 13.33 & 1 & $12: 53: 00$ & 10.36 & 5 \\
\hline $11: 28: 00$ & 13.93 & 6 & $12: 11: 00$ & 10.98 & 4 & $12: 54: 00$ & 11.83 & 29 \\
\hline $11: 29: 00$ & 13.61 & 3 & $12: 12: 00$ & 11.08 & 4 & $12: 55: 00$ & 11.47 & 17 \\
\hline 11:30:00 & 13.64 & 7 & $12: 13: 00$ & 11.7 & 3 & $12: 56: 00$ & 12.96 & 1 \\
\hline
\end{tabular}


Tabela 29 - Material particulado do dia 25/11/2011 (continuação)

\begin{tabular}{|c|c|c|c|c|c|c|c|c|}
\hline \multirow{2}{*}{ Hora } & \multicolumn{2}{|c|}{ MP } & \multirow{2}{*}{ Hora } & \multicolumn{2}{|c|}{ MP } & \multirow{2}{*}{ Hora } & \multicolumn{2}{|c|}{ MP } \\
\hline & Interno & Externo & & Interno & Externo & & Interno & Externo \\
\hline $12: 57: 00$ & 11,23 & 4 & $13: 40: 00$ & 10.94 & 3 & $14: 23: 00$ & 13.18 & 6 \\
\hline $12: 58: 00$ & 10.84 & 11 & $13: 41: 00$ & 11.31 & 13 & $14: 24: 00$ & 12.49 & 6 \\
\hline 12:59:00 & 10.52 & 1 & 13:42:00 & 10.71 & 11 & $14: 25: 00$ & 11.88 & 4 \\
\hline 13:00:00 & 11.43 & 1 & $13: 43: 00$ & 11.63 & 0 & $14: 26: 00$ & 13.14 & 0 \\
\hline 13:01:00 & 10.35 & 2 & $13: 44: 00$ & 10.45 & 3 & $14: 27: 00$ & 10.94 & 0 \\
\hline 13:02:00 & 11.38 & 4 & $13: 45: 00$ & 10.61 & 1 & $14: 28: 00$ & 9.77 & 0 \\
\hline 13:03:00 & 11.56 & 9 & $13: 46: 00$ & 11.75 & 3 & $14: 29: 00$ & 9.2 & 4 \\
\hline 13:04:00 & 11.3 & 21 & $13: 47: 00$ & 11.42 & 0 & $14: 30: 00$ & 9.53 & 0 \\
\hline $13: 05: 00$ & 10.3 & 2 & $13: 48: 00$ & 12.02 & 1 & $14: 31: 00$ & 10.78 & 7 \\
\hline 13:06:00 & 9.85 & 3 & $13: 49: 00$ & 12.13 & 5 & $14: 32: 00$ & 8.98 & 2 \\
\hline 13:07:00 & 10.54 & 2 & $13: 50: 00$ & 12.87 & 2 & $14: 33: 00$ & 10.04 & 9 \\
\hline 13:08:00 & 10.38 & 1 & 13:51:00 & 10.89 & 4 & $14: 34: 00$ & 9.36 & 27 \\
\hline 13:09:00 & 10.61 & 1 & $13: 52: 00$ & 11.88 & 3 & $14: 35: 00$ & 10.8 & 15 \\
\hline 13:10:00 & 11.94 & 2 & $13: 53: 00$ & 11.38 & 2 & $14: 36: 00$ & 9.99 & 6 \\
\hline 13:11:00 & 10.76 & 1 & $13: 54: 00$ & 12.65 & 16 & $14: 37: 00$ & 9.8 & 36 \\
\hline $13: 12: 00$ & 13.9 & 2 & $13: 55: 00$ & 12.93 & 2 & $14: 38: 00$ & 9.41 & 2 \\
\hline $13: 13: 00$ & 13.04 & 2 & 13:56:00 & 12.62 & 1 & $14: 39: 00$ & 10.49 & 8 \\
\hline $13: 14: 00$ & 12.12 & 8 & $13: 57: 00$ & 11.29 & 2 & $14: 40: 00$ & 11.43 & 1 \\
\hline $13: 15: 00$ & 11.49 & 4 & $13: 58: 00$ & 12.75 & 3 & $14: 41: 00$ & 10.78 & 4 \\
\hline $13: 16: 00$ & 13.62 & 10 & $13: 59: 00$ & 13.43 & 1 & $14: 42: 00$ & 11.39 & 0 \\
\hline $13: 17: 00$ & 13.84 & 4 & 14:00:00 & 13.14 & 4 & $14: 43: 00$ & 12.35 & 3 \\
\hline $13: 18: 00$ & 11.78 & 1 & 14:01:00 & 13.38 & 28 & $14: 44: 00$ & 12.15 & 25 \\
\hline 13:19:00 & 13.65 & 12 & $14: 02: 00$ & 12.68 & 18 & $14: 45: 00$ & 12.68 & 3 \\
\hline $13: 20: 00$ & 11.9 & 3 & 14:03:00 & 11.17 & 6 & $14: 46: 00$ & 12.54 & 1 \\
\hline $13: 21: 00$ & 11.78 & 6 & $14: 04: 00$ & 11.66 & 5 & $14: 47: 00$ & 12.25 & 2 \\
\hline $13: 22: 00$ & 11.05 & 14 & $14: 05: 00$ & 12.75 & 4 & $14: 48: 00$ & 11.72 & 1 \\
\hline $13: 23: 00$ & 11.01 & 8 & 14:06:00 & 12.23 & 0 & $14: 49: 00$ & 10.89 & 2 \\
\hline $13: 24: 00$ & 11.77 & 1 & 14:07:00 & 10.53 & 19 & $14: 50: 00$ & 10.02 & 2 \\
\hline $13: 25: 00$ & 11.43 & 1 & 14:08:00 & 10.65 & 5 & $14: 51: 00$ & 10.01 & 1 \\
\hline $13: 26: 00$ & 10.91 & 1 & 14:09:00 & 10.5 & 2 & $14: 52: 00$ & 10.99 & 1 \\
\hline $13: 27: 00$ & 10.35 & 0 & 14:10:00 & 10.93 & 6 & $14: 53: 00$ & 11.03 & 6 \\
\hline $13: 28: 00$ & 11.66 & 0 & $14: 11: 00$ & 11.13 & 1 & $14: 54: 00$ & 11.64 & 11 \\
\hline $13: 29: 00$ & 10.7 & 2 & $14: 12: 00$ & 11.89 & 0 & $14: 55: 00$ & 12.35 & 7 \\
\hline $13: 30: 00$ & 11.58 & 4 & $14: 13: 00$ & 11.39 & 2 & $14: 56: 00$ & 12.95 & 4 \\
\hline $13: 31: 00$ & 11.1 & 3 & 14:14:00 & 10.87 & 1 & $14: 57: 00$ & 12.16 & 0 \\
\hline $13: 32: 00$ & 12.2 & 1 & $14: 15: 00$ & 11.81 & 0 & $14: 58: 00$ & 11.24 & 4 \\
\hline $13: 33: 00$ & 10.91 & 0 & $14: 16: 00$ & 11.46 & 9 & 14:59:00 & 11.58 & 2 \\
\hline $13: 34: 00$ & 10.97 & 2 & $14: 17: 00$ & 10.92 & 3 & 15:00:00 & 10.66 & 4 \\
\hline $13: 35: 00$ & 11.62 & 2 & $14: 18: 00$ & 11.86 & 2 & $15: 01: 00$ & 11.21 & 3 \\
\hline $13: 36: 00$ & 12.04 & 13 & 14:19:00 & 11.22 & 3 & $15: 02: 00$ & 17.23 & 3 \\
\hline $13: 37: 00$ & 11.21 & 22 & 14:20:00 & 11.63 & 3 & $15: 03: 00$ & 13.9 & 1 \\
\hline $13: 38: 00$ & 11.67 & 5 & $14: 21: 00$ & 11.92 & 1 & $15: 04: 00$ & 12.93 & 3 \\
\hline $13: 39: 00$ & 11.35 & 13 & $14: 22: 00$ & 11.92 & 4 & $15: 05: 00$ & 14.49 & 4 \\
\hline
\end{tabular}


Tabela 30 - Material particulado do dia 25/11/2011 (continuação)

\begin{tabular}{|c|c|c|c|c|c|c|c|c|}
\hline \multirow{2}{*}{ Hora } & \multicolumn{2}{|c|}{ MP } & \multirow{2}{*}{ Hora } & \multicolumn{2}{|c|}{ MP } & \multirow{2}{*}{ Hora } & \multicolumn{2}{|c|}{ MP } \\
\hline & Interno & Externo & & Interno & Externo & & Interno & Externo \\
\hline $15: 06: 00$ & 12.12 & 5 & $15: 56: 00$ & 10.09 & 5 & $16: 39: 00$ & 10.24 & 3 \\
\hline $15: 07: 00$ & 13.06 & 18 & $15: 57: 00$ & 9.66 & 2 & $16: 40: 00$ & 10.99 & 3 \\
\hline $15: 08: 00$ & 13.49 & 5 & 15:58:00 & 10.46 & 2 & $16: 41: 00$ & 12.56 & 9 \\
\hline 15:09:00 & 12.62 & 4 & $15: 59: 00$ & 9.92 & 2 & $16: 42: 00$ & 12.28 & 12 \\
\hline $15: 10: 00$ & 13.4 & 7 & 16:00:00 & 9.85 & 6 & $16: 43: 00$ & 12.15 & 13.5 \\
\hline $15: 11: 00$ & 11.93 & 9 & 16:01:00 & 10.8 & 10 & $16: 44: 00$ & 11.65 & 15 \\
\hline $15: 18: 00$ & 12.83 & 2 & $16: 02: 00$ & 9.84 & 36 & $16: 45: 00$ & 12.25 & 6 \\
\hline $15: 19: 00$ & 13.98 & 1 & 16:03:00 & 10.76 & 36 & $16: 46: 00$ & 13.25 & 0 \\
\hline $15: 20: 00$ & 13.55 & 3 & 16:04:00 & 10.45 & 36 & $16: 47: 00$ & 11.56 & 5 \\
\hline $15: 21: 00$ & 12.32 & 2 & 16:05:00 & 12.63 & 21 & $16: 48: 00$ & 10.71 & 15 \\
\hline $15: 22: 00$ & 11.04 & 1 & 16:06:00 & 10.61 & 46 & $16: 49: 00$ & 10.91 & 4 \\
\hline $15: 23: 00$ & 11.09 & 1 & 16:07:00 & 10.23 & 21 & $16: 50: 00$ & 11.36 & 3 \\
\hline $15: 24: 00$ & 10.56 & 1 & 16:08:00 & 10.73 & 6 & $16: 51: 00$ & 11.83 & 7 \\
\hline $15: 25: 00$ & 12.79 & 6 & 16:09:00 & 11.34 & 1 & $16: 52: 00$ & 11.28 & 11 \\
\hline $15: 26: 00$ & 11.21 & 3 & 16:10:00 & 11.21 & 10 & $16: 53: 00$ & 10.57 & 2 \\
\hline $15: 27: 00$ & 9.9 & 1 & 16:11:00 & 11.48 & 21 & $16: 54: 00$ & 9.9 & 9 \\
\hline $15: 28: 00$ & 10.06 & 1 & $16: 12: 00$ & 10.86 & 16 & $16: 55: 00$ & 10.83 & 11 \\
\hline $15: 29: 00$ & 10.69 & 3 & $16: 13: 00$ & 11.17 & 4 & $16: 56: 00$ & 10.14 & 3 \\
\hline $15: 12: 00$ & 12.12 & 12 & 16:14:00 & 12.87 & 22 & $16: 57: 00$ & 10.37 & 3 \\
\hline $15: 13: 00$ & 12.88 & 31 & $16: 15: 00$ & 12.24 & 7 & $16: 58: 00$ & & 5 \\
\hline $15: 14: 00$ & 12.56 & 25 & $16: 16: 00$ & 11.27 & 4 & $16: 59: 00$ & & 9 \\
\hline $15: 15: 00$ & 13.22 & 9 & 16:17:00 & 10.54 & 17 & & & \\
\hline $15: 16: 00$ & 13.96 & 4 & 16:18:00 & 10.52 & 14 & & & \\
\hline $15: 17: 00$ & 13.34 & 1 & 16:19:00 & 10.74 & 5 & & & \\
\hline $15: 36: 00$ & 10.72 & 7 & 16:20:00 & 10.51 & 4 & & & \\
\hline $15: 37: 00$ & 11.24 & 4 & $16: 21: 00$ & 11.9 & 12 & & & \\
\hline $15: 38: 00$ & 11.86 & 3 & $16: 22: 00$ & 12.65 & 4 & & & \\
\hline $15: 39: 00$ & 12.58 & 2 & $16: 23: 00$ & 11.18 & 3 & & & \\
\hline $15: 40: 00$ & 12.41 & 6 & $16: 24: 00$ & 10.78 & 14 & & & \\
\hline $15: 41: 00$ & 12.04 & 1 & $16: 25: 00$ & 11.38 & 21.5 & & & \\
\hline $15: 42: 00$ & 12.45 & 5 & $16: 26: 00$ & 11.01 & 29 & & & \\
\hline $15: 43: 00$ & 12.99 & 3 & $16: 27: 00$ & 11.29 & 12 & & & \\
\hline $15: 45: 00$ & 12.31 & 3 & $16: 28: 00$ & 10.57 & 2 & & & \\
\hline $15: 46: 00$ & 12.86 & 13 & $16: 29: 00$ & 11.04 & 6 & & & \\
\hline $15: 47: 00$ & 13.86 & 3 & 16:30:00 & 10.27 & 4 & & & \\
\hline $15: 48: 00$ & 13.89 & 2 & $16: 31: 00$ & 9.67 & 3 & & & \\
\hline $15: 49: 00$ & 11.24 & 17 & $16: 32: 00$ & 10.32 & 1 & & & \\
\hline $15: 50: 00$ & 12.87 & 4 & 16:33:00 & 9.35 & 7 & & & \\
\hline $15: 51: 00$ & 11.4 & 5 & $16: 34: 00$ & 10.06 & 15 & & & \\
\hline $15: 52: 00$ & 11.94 & 7 & $16: 35: 00$ & 12.87 & 2 & & & \\
\hline $15: 53: 00$ & 11.42 & 1 & $16: 36: 00$ & 10.7 & 4 & & & \\
\hline $15: 54: 00$ & 11.68 & 3 & $16: 37: 00$ & 10.85 & 3 & & & \\
\hline $15: 55: 00$ & 10.55 & 2 & $16: 38: 00$ & 10.6 & 17 & & & \\
\hline
\end{tabular}


(ABNT, 2000) (ANVISA, 2003) (OMS, 2006) (AFEEVAS, 2012) 